NAPAP

Biennial

Report to

Congress:

An Integrated

Assessment

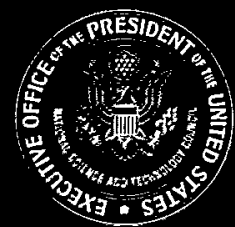

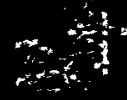
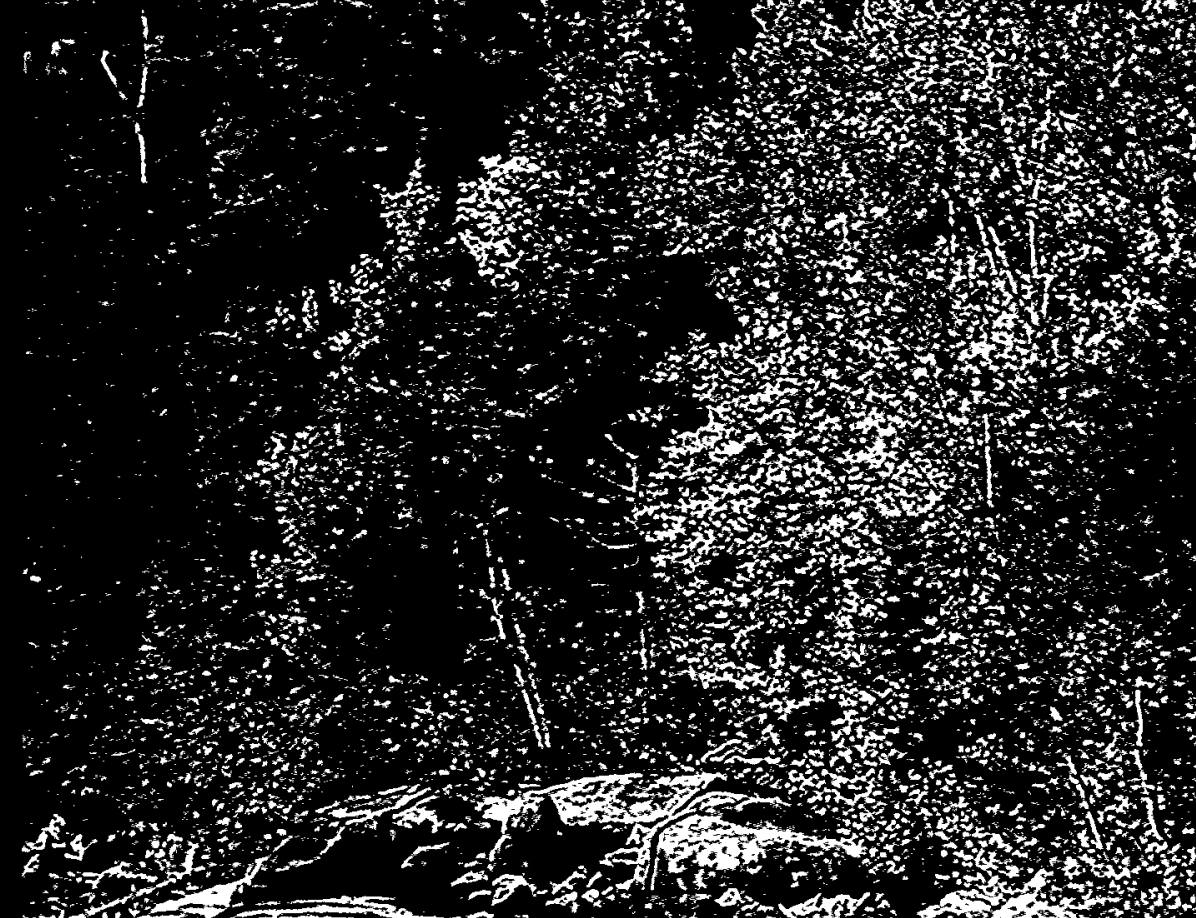

is

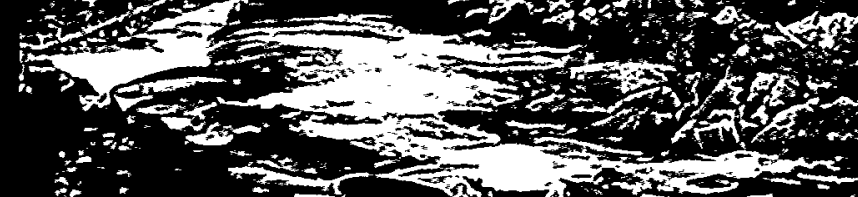

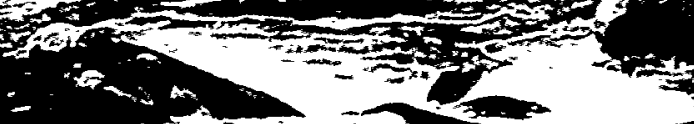

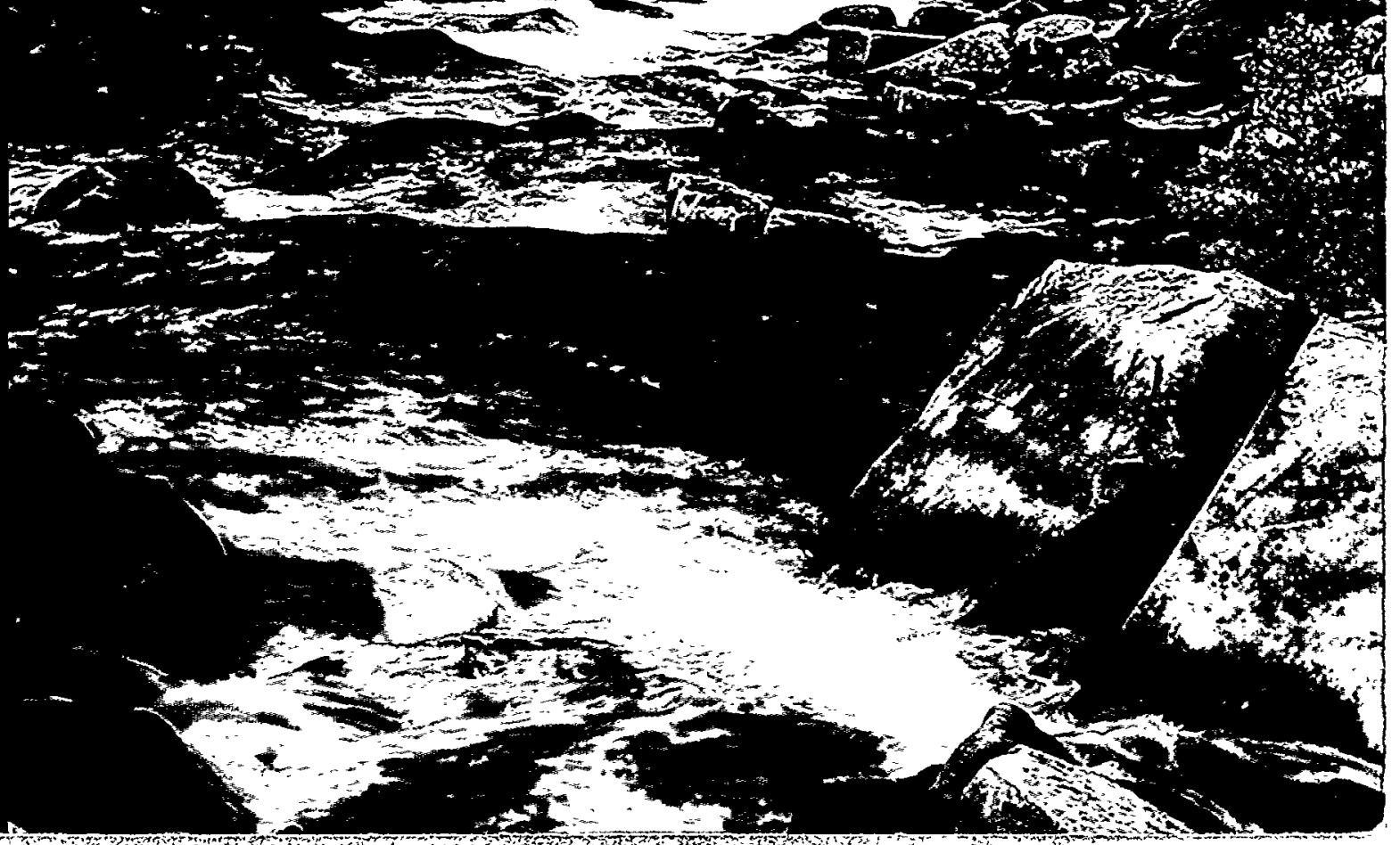




\title{
NAPAP Biennial Report to Congress: An Integrated Assessment
}

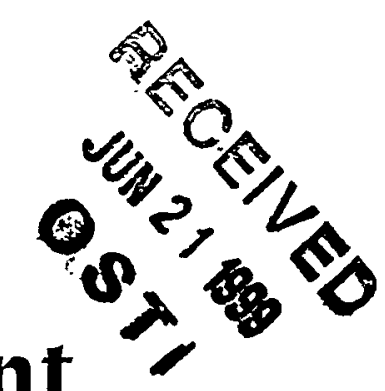

\section{National Acid Precipitation Assessment Program}

\author{
Silver Spring, Maryland \\ May 1998
}




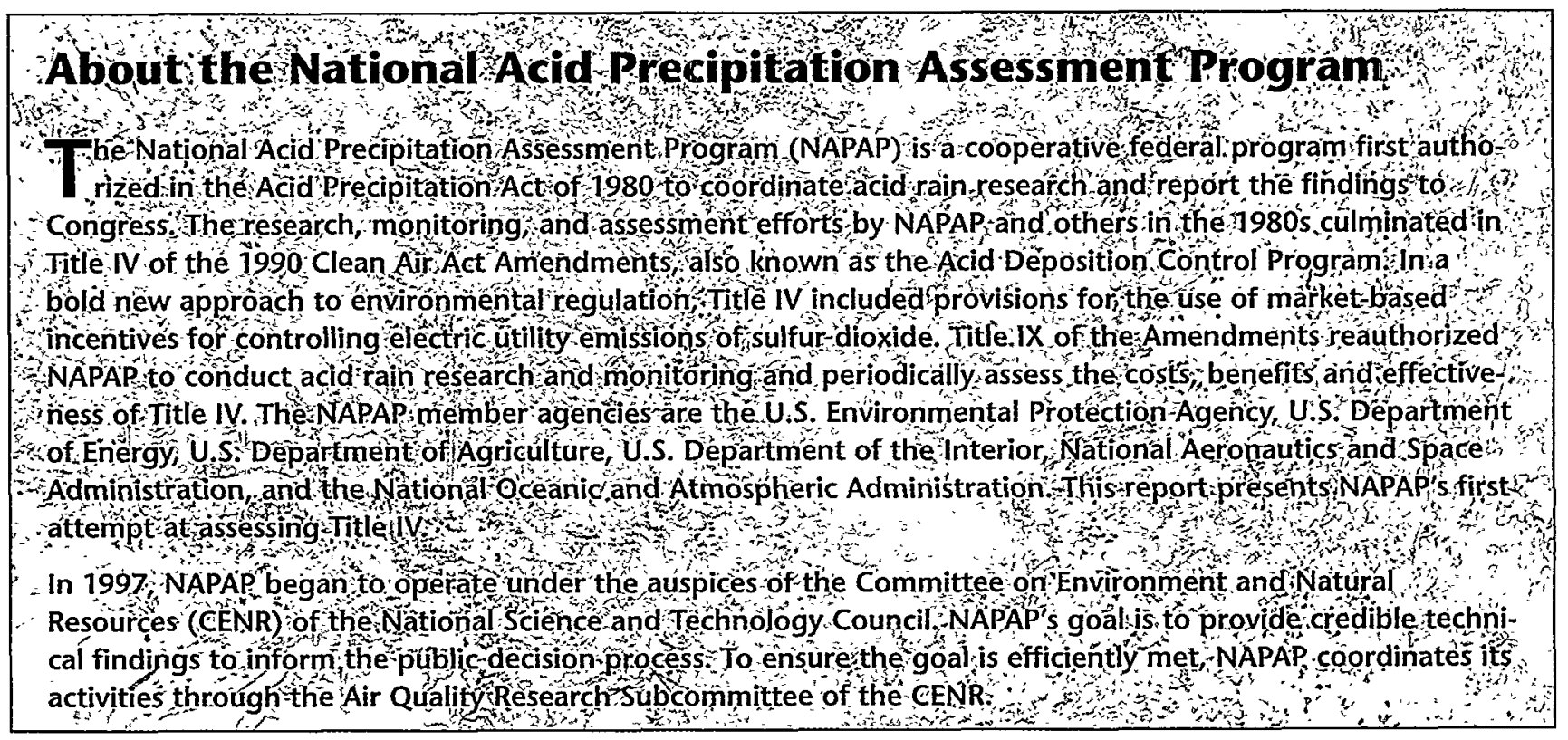




\section{DISCLAIMER}

This report was prepared as an account of work sponsored by an agency of the United States Government. Neither the United States Government nor any agency thereof, nor any of their employees, make any warranty, express or implied, or assumes any legal liability or responsibility for the accuracy, completeness, or usefulness of any information, apparatus, product, or process disclosed, or represents that its use would not infringe privately owned rights. Reference herein to any specific commercial product, process, or service by trade name, trademark, manufacturer, or otherwise does not necessarily constitute or imply its endorsement, recommendation, or favoring by the United States Government or any agency thereof. The views and opinions of authors expressed herein do not necessarily state or reflect those of the United States Government or any agency thereof. 


\section{DISCLAIMER}

Portions of this document may be illegible in electronic image products. Images are produced from the best available original document. 
THE WHITE HOUSE

WASHINGTON

I am pleased to transmit the report, Biennial Report to Congress: An Integrated Assessment, of the National Acid Precipitation Assessment Program (NAPAP). This report presents the results of the first evaluation of the costs, benefits, and effectiveness of the Acid Deposition Control Program. This Program was mandated under Title IV of the 1990 Clean Air Act Amendments and seeks to reduce sulfur and nitrogen emissions from electric utilities through the use of economic incentives. This report fulfills the requirements of Title IX of the 1990 Clean Air Act Amendments.

NAPAP coordinates Federal acid rain research and monitoring under the auspices of the National Science and Technology Council (NSTC) Committee on Environment and Natural Resources (CENR). The assessment was a multi-agency effort that involved individuals from many scientific disciplines. NAPAP sought the input of many stakeholders, including other government and academic scientists, industry and environmental groups, and congressional staffers. The research and monitoring results used in the assessment and the drafts of this report were subjected to extensive peer review.

Biennial Report to Congress: An Integrated Assessment analyzes the results of the first year (1995) that the largest fossil-fueled electric generating units were required to control sulfur dioxide emissions under Title IV. It uses quantitative and qualitative indicators to assess the effectiveness of market-based approaches to reduce emissions and acidic deposition and to keep compliance costs down. It includes analyses of the ecological, human health, materials and cultural resources, and visibility benefits of reduced ambient concentrations of fine particle precursors of acid deposition. The report concludes that the valuation of these benefits could far outweigh the Program's compliance costs. The report also identifies the research, monitoring, modeling, and data access needs for the next comprehensive assessment, to be prepared in 2000 . NAPAP will work closely with its state, academic, industrial, and environmental partners and the CENR to address those needs.

Although preliminary, this assessment should provide valuable insights into the effectiveness of Title IV and its implementation for the congress, especially as it considers market-based solutions to other air pollution problems.

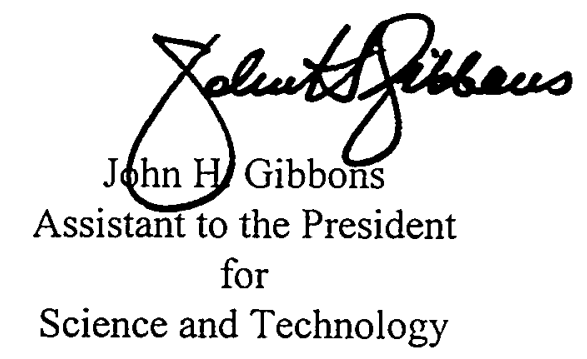


Committee on Environment and Natural Resources

\section{Committee Members}

White House

Rosina Bierbaum, Co-Chair (Acting)

National Oceanic and Atmospheric Administration

D. James Baker, Co-Chair

Smithsonian Institute

Thomas Lovejoy

Environmental Protection Agency

Lawrence Reiter

Department of Energy

Martha Krebs

National Aeronautics and Space

Administration

Ghassem Asrar

National Science Foundation

Joseph Bordogna (Acting)

Department of Agriculture

Eileen Kennedy

Office of Management and Budget

T.J. Glauthier

Department of the Interior

Mark Schaefer
Department of Health and Human Services Kenneth Olden

Department of Transportation

John Lieber

Department of Defense

Sherri Goodman

Department of State

Melinda Kimble (Acting)

Federal Emergency Management Agency

Craig Wingo

Tennessee Valley Authority

Kathryn Jackson

office of the Federal Coordinator

for Meteorology

Samuel Williamson

Central Intelligence Agency

Terrance Flannery

Council on Environmental Quality

Kathleen McGinty

Department of Labor

Roland Droitsch

\section{Subcommittee Members}

Air Quality

Martha Krebs, DOE, Chair

Dan Albritton, NOAA, Vice Chair

Ecological Systems

Mark Schaefer, DOI, Chair

Mary Clutter, NSF, Vice Chair

Donald Scavia, NOAA, Vice Chair

Global Change Research

Robert W. Correll, NSF, Chair

Robert Harriss, NASA, Vice Chair

Mike Dombeck, USDA, Vice Chair

Natural Disaster Reduction

Bill Hooke, NOAA, Chair

John Filson, USGS, Vice Chair

Toxics and Risk

Lynn Goldman, EPA, Chair

Kenneth Olden, NIEHS, Vice Chair

Sherri Goodman, DOD, Vice Chair 
Production of this document was managed by the staff of the NAPAP Office of the Director. Current and former members of the staff who were instrumental in the planning, development, and publication of this report are listed below.

Hundreds of scientists and technical specialists contributed over the years to the extensive knowledge base upon which this integrated assessment depended.

NAPAP's integrated assessment report to Congress was planned, developed, written, edited, and reviewed in a collaborative effort by many scientists, economists, and technical specialists. Their efforts are greatly appreciated. The authors and contributors to the various sections of the report are listed on the following pages.

Special thanks are extended to the extramural peer reviewers, who are identified following the authors. In addition to providing a technical review, they were asked to consider the content of the report as it relates to public policy. Their comments were timely, relevant, and informative.

\section{NAPAP Office of the Director}

Michael Uhart, Director

Noreen Clancy

Karen King

\section{Former Office of the Director}

Derek Winstanley, Director

Judy Hickey

John Barnes

Elizabeth Bennett

\section{Editors}

Michael Uhart

Noreen Clancy

Katie Smythe,

Science \& Policy Associates

\section{Editorial Consultant}

Christopher Bernabo, Science \& Policy Associates

\section{Primary Authors and Contributors}

\section{Integration and Assessment}

Noreen Clancy, NAPAP

Michael Uhart, NAPAP

Katie Smythe,

Science \& Policy Associates

\section{Implementation Status}

Rosemary Wolfe, U.S. Environmental Protection Agency

\section{Emissions and Compliance Costs}

Joe Kruger, U.S. Environmental

Protection Agency

Denny Ellerman, Massachusetts Institute of Technology

Juan Pablo Montero, Massachusetts Institute of Technology

\section{Concentration and Deposition}

Bruce Hicks, National Oceanic and Atmospheric Administration

Mark Nilles, U.S. Geological Survey

Phil Bowman, U.S. Geological Survey

Joseph Sickles, U.S. Environmental

Protection Agency

\section{Aquatic Ecosystems}

Tim Sullivan, E\&S Environmental Chemistry

Kathy Tonnessen, National Park Service Webb Van Winkle, Oak Ridge National Laboratory

Rona Birnbaum, U.S. Environmental Protection Agency 
Forest Ecosystems

Bob Cook, Oak Ridge National Laboratory

John Joslin, Tennessee Valley Authority

Chris Eagar, U.S. Forest Service

Jennifer Knoepp, U.S. Forest Service

Sandy McLaughlin, Oak Ridge National Laboratory

Carl Trettin, U.S. Forest Service

\section{Materials and Cultural Resources}

Victor Mossotti, U.S. Geological Survey

Mary Striegel, National Park Service

\section{Visibility}

Marc Pitchford, National Oceanic and

Atmospheric Administration

\section{Human Health}

Larry Folinsbee, U.S. Environmental Protection Agency

Tom Grahame, U.S. Department of Energy

Ann Watkins, U.S. Environmental Protection Agency

\section{Peer Reviewers}

\section{Integration and Assessment}

Edward Bennett, New York State Department of

Environmental Conservation

James Hammitt, Harvard School of Public Health

Robert Mendelsohn, Yale University School of Forestry and Environmental Studies

\section{Emissions and Compliance Costs}

Stephen Brick, Consultant

Andrew Van Horn, Van Horn Consulting

\section{Concentration and Deposition}

Thomas Butler, Cornell University

Alan Hansen, EPRI

\section{Aquatic Ecosystems}

Nicholas Nikolaidis, University of Connecticut

Kent Thornton, FTN Associates

\section{Forest Ecosystems}

Alan Lucier, National Council of the Paper Industry for Air and Stream Improvement

William Smith, Yale University School of Forestry and Environmental Studies
Adverse Effects

Harry Quarles, Oak Ridge National Laboratory

Response Indicators

Carolyn Hunsaker, Oak Ridge National Laboratory

\section{Benefits Valuation}

Dallas Burtraw, Resources for the Future

Erin Mansur, Resources for the Future

\section{Tracking and Analysis Framework}

Cary Bloyd, Argonne National Laboratory

Max Henrion, Lumina Decision Systems

Rich Sonnenblick, Lumina Decision Systems

\section{Materials and Cultural Resources}

A. Elena Charola, Consultant

John Spence, North Carolina State University

\section{Visibility}

Paulette Middleton, Science and Policy Associates

Pradeep Saxena, EPRI

\section{Human Health}

Petros Koutrakis, Harvard School of Public Health Morton Lippmann, New York University Medical Center

\section{Benefits Valuation}

A. Myrick Freeman, Bowdoin College

Douglas Lipton, University of Maryland 
Executive Summary $\ldots \ldots \ldots \ldots \ldots \ldots \ldots \ldots \ldots \ldots \ldots \ldots \ldots$

Introduction.....................................

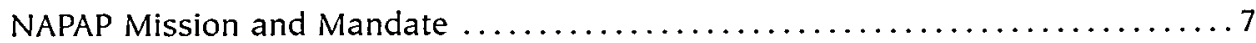

Assessment Process. ................................... 7

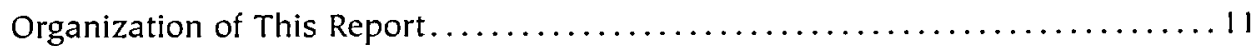

Implementation and Costs of Title IV ................. 12

What is the status of implementation? ............................. 12

How well have utilities complied with the provisions under Title IV? ......... I4

What are the compliance costs of Title IV, and how do they compare to

projections?...................................................

Changes in Emissions, Concentrations, and Deposition ..... 22

What emission reductions have been achieved? ....................... 22

How have air concentrations been affected by these emission reductions? ....28 8

How have deposition rates been affected by the emission reductions? ......... 35

What are current deposition rates, and what is their variability? ............. 38

Benefits of Emission Reductions .....................42

Have changes in effects been observed $(1980-1995) ? \ldots \ldots \ldots \ldots \ldots \ldots \ldots 42$

Aquatic Ecosystems ...................................... 42

Forest Ecosystems........................................ 54

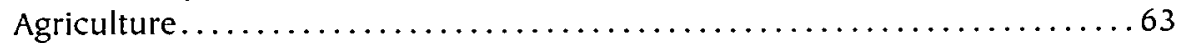

Materials and Cultural Resources ..............................6 63

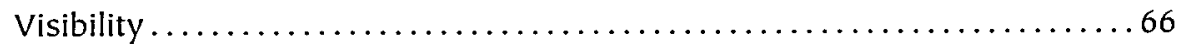

Human Health ......................................... 73

What are the economic benefits related to the effects areas? ...............76

Reductions to Prevent Adverse Ecological Effects ..........88

What are "adverse ecological effects"? ............................ 88

What are the dose-response relationships for sulfur and nitrogen deposition? ..88

How might ecological effects be reduced if deposition were reduced further? . . . 89

Surface Waters.......................................... 89

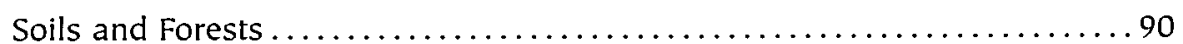

Effectiveness of Title IV: A Market-Based Approach .........92

Did the market-based approach reduce costs? ....................... 92

How did emission and deposition changes compare to projections? .......... 93

Has reduced acid deposition had an effect on sensitive receptors?............94 


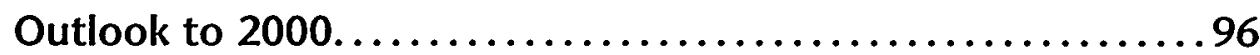

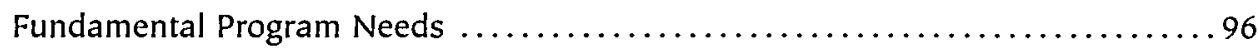

Issue-Specific Needs..................................... 99

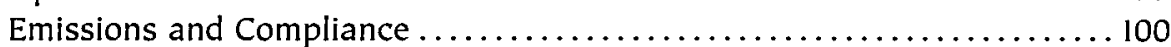

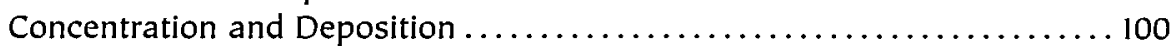

Aquatic Ecosystems . . . . . . . . . . . . . . . . . . . . . . . 100

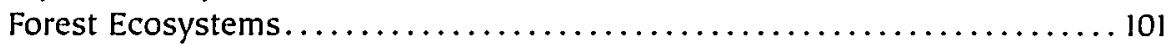

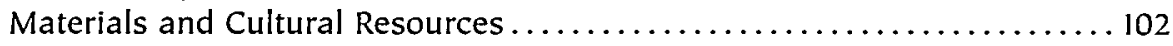

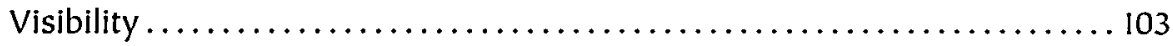

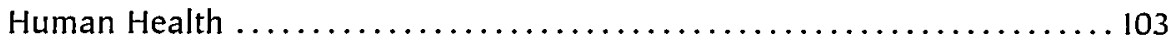

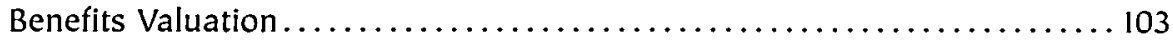

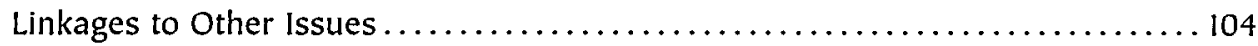

References...................................... 109

Appendix A: Advances in Integrated and Issue-Specific Modeling ........................... A-2

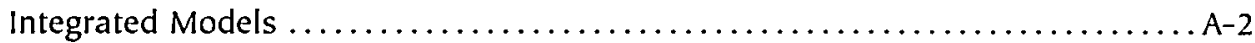

Issue-Specific Models .............................. A 13

\section{Appendix B: Design and Performance of Pollution Trading Programs $\ldots \ldots \ldots \ldots \ldots \ldots \ldots \ldots \ldots \ldots \ldots \ldots \ldots \ldots \ldots$}

Characteristics That Contribute to the Success of Permit Trading Programs ..... B-2

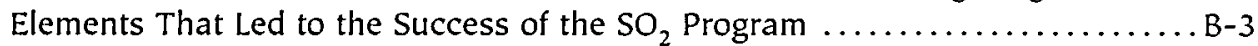

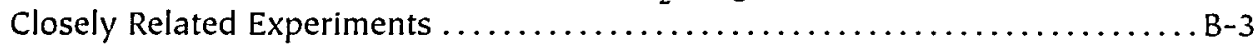

New Applications of Emission Trading Programs. .................

Appendix C: Interpretation of "Adverse" Effects for NAPAP Biennial Reports to Congress ............... C-2 


\section{Figures}

Figure I NAPAP's Conceptual Framework

Figure 2 Electric Utility Units Affected by Phases I and II of Title IV

Figure 3 Allowance Price Trends

Figure 4 National $\mathrm{SO}_{2}$ Emissions (1980-1995)

Figure 5 Annual $\mathrm{SO}_{2}$ Emissions from Phase I Utilities (1980-1995)

Figure 6 Geographic Distribution of Annual $\mathrm{SO}_{2}$ Emissions from Electric Utilities

Figure 7 National $\mathrm{NO}_{\mathrm{X}}$ Emissions from Human Activities (1980-1995)

Figure 8 Processes Involved in Acid Deposition

Figure 9 Ambient Air Concentrations of $\mathrm{SO}_{2}$ (1986-I 995)

Figure 10 Ambient Long-Term Air Concentrations from a Site Near State College, PA (1986-1995)

Figure II Seasonal Trends in Fine-Particle Sulfur

Figure 12 Decreases in Ambient Air Concentrations of Total Sulfur (1989-1995)

Figure 13 NADP/NTN Wet Deposition Monitoring Sites

Figure 14 Differences in Observed and Estimated Concentrations

Figure I5 Annual Deposition of Sulfur and Nitrogen at a Site Near State College, PA

Figure 161995 Geographic Distribution of Acid Precipitation

Figure 17 Relative Response Times to Changes in Emissions

Figure 18 Surface Water Trends at Long-Term Monitoring Sites

Figure 19 Forest Regions Used for This Integrated Assessment

Figure 20 Relationship Between Soil Acidity and Nutrients

Figure 21 Model of Stone Deterioration Processes

Figure 22 Percent Reductions in Particulate Sulfate from Eastern IMPROVE Sites

Figure 23 Regional and Seasonal Percent Reductions in Visibility

\section{Tables}

Table $1 \quad \mathrm{SO}_{2}$ Emission Reduction Methods at Phase I Units in 1995

Table 2 Estimates of Phase I Compliance Costs

Table 3 Scrubber Costs per Ton of $\mathrm{SO}_{2}$ Removed

Table 4 Projected $\mathrm{SO}_{2}$ Emission Reductions Attributable to Title IV

Table 5 Selected Policy-Relevant Developments Since 1990

Table 6 Characteristics for Assessing the Effects of Acid Deposition on Forest Ecosystems

Table 7 Qualitative, Relative Rankings for Benefit Areas Related to Acid Deposition

Table 8 Value of a Statistical Life and Other Health End Points

Table 9 Research and Monitoring Needs for Future NAPAP Assessments 


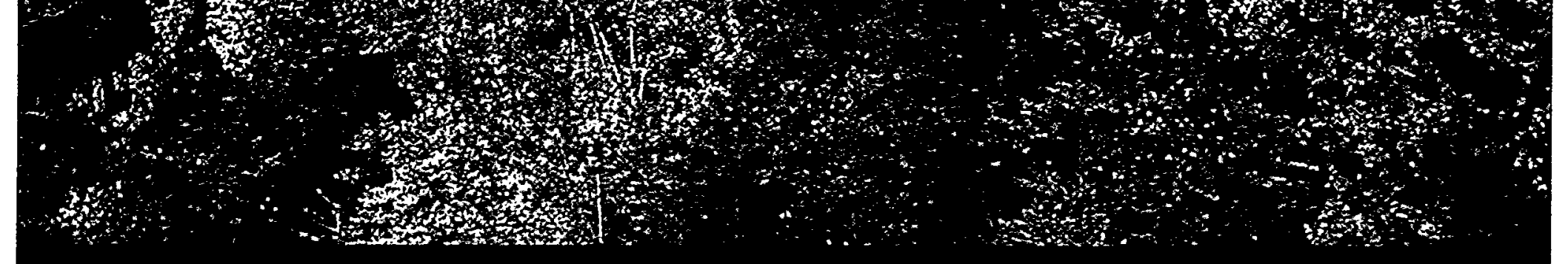

n Title IV of the 1990 Clean Air Act Amendments, Congress set out to decrease the adverse effects of acid deposition through reductions in annual emissions of sulfur dioxide $\left(\mathrm{SO}_{2}\right)$ and nitrogen oxides $\left(\mathrm{NO}_{x}\right)$ from utilities burning fossil fuels. The legislation called for placing a cap on utility emissions to achieve a total reduction of 10 million tons of $\mathrm{SO}_{2}$ emissions below 1980 levels by 2010 . In combination with reductions under Title I (compliance with National Ambient Air Quality Standards) and Title II (mobile sources), Title IV will contribute to the overall 2-million-ton reduction of $\mathrm{NO}_{X}$ emissions from 1980 levels.

In contrast to the typical command-and-control approach to regulation, Congress adopted a market-based control strategy for $\mathrm{SO}_{2}$. Emission reduction goals were established with time allowed to achieve these goals through flexible compliance methods, including an innovative $\mathrm{SO}_{2}$ emission allowance trading and banking program. The $\mathrm{SO}_{2}$ reductions were to be implemented in two phases: Phase I began January I, 1995; and Phase II will begin January I, 2000. Phase I affects the highest-emitting electric generating units and those units choosing to comply early, and Phase II will include the remaining electric generating units.

The Act mandated the interagency National Acid Precipitation Assessment Program (NAPAP) to continue the coordination of federal acid rain research and monitoring. In addition, Congress asked NAPAP to evaluate the costs, benefits, and effectiveness of Title IV and to assess what further reductions in deposition rates are needed to prevent adverse ecological effects. This report to Congress is the first in a series of quadrennial integrated assessments of Title IV. The major goal of NAPAP's integrated assessment is to provide structured, technical information in a format that enables decision makers to evaluate the effectiveness of current public policy and that provides a sound science base for future policy decisions.

The first years that affected utilities were required to comply with the $\mathrm{SO}_{2}$ and $\mathrm{NO}_{x}$ emission reduction programs were 1995 and 1996, respectively. Although utilities have significantly reduced their emissions, observable responses in the environment are not yet expected, mostly due to inherent time lags between changes in emissions and responses by sensitive receptors, especially within ecosystems. Weather variability and its impact on dispersion, transport, and deposition of pollution contribute to the uncertainty in identifying a response of ambient air concentrations and visibility to emission reductions. However, much can be learned from what has occurred in the first two years of implementation of Title IV. The most significant, policy-relevant findings of the assessment follow.

The market-based approach has reduced compliance costs for utilities below those of a command-and-control approach. Costs are below what was expected 


\section{Introduction}

D ecision makers inside and outside of government continue to face important issues relating to the emissions of sulfur and nitrogen; their effects upon ecosystems, visibility, materials, and human health; and, ultimately, the control of these emissions. They need easy access to the latest monitoring and research results and scientific discoveries on topics relevant to acid deposition to evaluate the effectiveness of current public policy and to establish a sound science base for future policy decisions.

The history of air quality management includes many examples of society's responses to pollution. During the Middle Ages in London the ever-present cloud of dust and soot and its effects on human health led to prohibitions on coal burning. During the Industrial Revolution, air pollution was generally considered a municipal problem rather than a public health issue and was managed on a local level, which continued well into the 20th century. The emergence of air pollution in the United States as a public health issue in the 1950s led to the development of federally funded research programs, culminating in the Clean Air Act and establishment of the U.S. Environmental Protection Agency (EPA) in 1970.

Around the world, countries were developing institutional responses to combat the air pollution threat to human health. The effects of air pollution on ecology, however, was not yet considered a serious issue. Having been first documented in England at the end of the 19th century, acid rain and its ecological effects became regional issues in northwestern Europe and in the northeastern United States in the late 1960s. The mounting anecdotal evidence of its harmful effects on aquatic and terrestrial ecosystems launched acid rain as perhaps the first air pollution threat to the environment to receive international attention.

In the late 1970s, the President's Council on Environmental Quality asked scientists to initiate a long-term, interagency research and assessment program to study acid rain. With Administration support and congressional action, the Acid Precipitation Act of 1980 became law. During its first 10 years, the research and periodic assessments conducted by the National Acid Precipitation Assessment Program (NAPAP) furthered understanding of the scientific processes and effects of the larger issue of acid deposition. Peer reviews, workshops, and annual reports throughout the 1980s culminated in the NAPAP State of Science and Technology Reports published in 1991 and the NAPAP 1990 Integrated Assessment Report. ${ }^{2,3}$ The monitoring and research conducted in the 1980 s and the subsequent integrated assessment provided a significant part of the scientific knowledge base for Title IV of the 1990 Clean Air Act Amendments, known as the Acid Deposition Control Program.

The purpose of Title IV is to reduce the adverse effects of acid deposition through reductions in annual emissions of its precursors, sulfur dioxide $\left(\mathrm{SO}_{2}\right)$ and nitrogen oxides $\left(\mathrm{NO}_{\mathrm{X}}\right)$. Recognizing that the principal sources of the acidic compounds and their precursors in the atmosphere are emissions from the combustion of fossil fuels, policymakers initiated control measures to reduce emissions from electric utilities. However, rather than the traditional command-and-control approach to regulation, Title IV provided utilities alternative methods of complying with specific emission limits and deadlines. Alternatives included technological adaptation (e.g., 
scrubbers and higher-efficiency boilers), fuel switching, and an innovative $\mathrm{SO}_{2}$ emission allowance trading and banking program.

Title IV is the first national effort to use market-based incentives to achieve environmental goals. At the time the 1990 Amendments were enacted, it was widely recognized that the allowance trading program was experimental. Due to the innovative nature of using market-based incentives for environmental regulation, and to ease the burden on industry, Congress allowed implementation of the program to be phased in over the following 20 years. Congress built into the same legislation a mechanism for evaluating how well the experiment is working, both during and after its implementation.

\section{NAPAP Mission and Mandate}

Under Title IX of the 1990 Clean Air Act Amendments, Congress reauthorized NAPAP to continue coordinating acid rain research and monitoring, as it had done during the previous decade, and to report the results to Congress biennially, beginning in 1992. In addition, Congress asked NAPAP to assess all available data and information and answer two questions:

1. What are the costs, benefits, and effectiveness of Title IV? This question addresses the costs and economic impacts of complying with the Acid Deposition Control Program as well as benefit analyses associated with the various human health and welfare effects, including reduced visibility, damages to materials and cultural resources, and effects on ecosystems.

2. What reductions in deposition rates are needed to prevent adverse ecological effects? This complex question addresses ecological systems and the deposition levels at which they begin to experience harmful effects.

The results of the assessment of the effects of Title IV and of the relationship between acid deposition rates and ecological effects were to be reported to Congress quadrennially, beginning with this report to Congress. The objective of this report is to address the two main questions posed by Congress and fully communicate the results of the assessment to decision makers. Given the primary audience, it is not written as a technical document, although information supporting the conclusions is provided along with references.

\section{Assessment Process}

The preparation of NAPAP assessments every four years requires the interaction of many disciplines, institutions, and individuals. It is important, therefore, that a framework for the assessments be clear. A framework was presented as a strawman proposal for use in preparing NAPAP assessments at the international workshop on "Developing the Framework for the NAPAP Assessment," held in November 1993. The general consensus of the workshop participants was that the Tracking and Analysis Framework, or TAF (see Appendix A for more details on TAF), or some similar methodology, was a useful and necessary tool to plan, organize, and implement NAPAP assessments. Openness and transparency are cornerstones of the assessment framework and process.

The Tracking and Analysis Framework's detailed structure for NAPAP assessments provides a path to evaluate how acid deposition control decisions, specifically Title IV, can affect emission and deposition rates, health and environmental benefits, monetary and nonmonetary costs and benefits of Title IV, and the reduction in deposition rates needed to prevent adverse ecological effects. This framework serves as an organizing tool to help identify the inputs and outputs between the operational components of the assessment, facilitates communication and information flow, and allows researchers to focus on the connections between, as well as the processes internal to, the individual components.

Policy-relevant assessments bridge the information gap between policy decisions and the social, natural, and physical sciences. An integrated assessment analyzes the linkages among many disciplines and along the full causal chain-from causes to effects to costs and benefits-to provide the information necessary to formulate and evaluate national and international environmental policies and strategies.

Since the passage of the 1990 Amendments and the regulatory decisions described in Title IV, NAPAP has coordinated federal acid rain research and monitoring in fulfillment of its mandate. Emission and deposition monitoring have been continued to characterize human and environmental exposure to acid deposition and its precursors. Human health and environmental monitoring has been extended to perform routine assessments of the effects of acid deposition and its precursors. More resource-intensive levels of data gathering, model construction, and model application 
have been employed to characterize the cause-andeffect relationships more accurately, including the impacts of specific Title IV controls.

The major goal of NAPAP's integrated assessment is to provide structured, technical information in a format that enables decision makers to evaluate the effectiveness of current public policy and provides a sound science base for future policy decisions. It must be credible, open, and communicated fully and responsibly. Secondary goals are to further develop a process for future assessments and to identify the near-term monitoring, research, and modeling needs leading to the 2000 assessment.

The NAPAP assessment process builds upon the experience and lessons of the first 15 years of the program. It uses appropriate data and results from the NAPAP State of Science and Technology Reports, ${ }^{2}$ and 1990 integrated Assessment Report ${ }^{3}$ and subsequent peer-reviewed literature, as well as lessons learned from other assessment activities in the United States and other countries. To enable the assessment to evolve and to be technically sound and policy relevant, the assessment team pursued the following objectives:

I Define the policy-relevant questions.

m Adhere to the scientific method, including peer review.

m Treat assumptions and caveats.

m Synthesize multidisciplinary information at all relevant scales.

- Consider feedback mechanisms.

m Use technically sound extrapolation procedures.

II Set confidence intervals on all conclusions and consider uncertainties.

- Consider how to link outputs from one discipline as inputs to another discipline.

- Use only nonproprietary data and models.

- Encourage open and easy access to data.

m Consider the marginal, cumulative, episodic, and chronic consequences of acid deposition. a Consider integration among affected natural resources and socioeconomic values.

a Include flexible approaches to address changing knowledge, emphases, and policy needs.

a Encourage the use of multiple approaches, models, and valuation schemes.

NAPAP followed four broad steps to conduct this assessment and communicate the results to stakeholders.

1. Define the scope of the assessment.

2. Collect and synthesize issue-specific scientific data and information pertaining to the policyrelevant questions stated in the 1990 Clean Air Act Amendments.

3. Integrate and assess the scientific data and information in a format that facilitates addressing the policy-relevant questions.

4. Communicate the results effectively.

\section{Scope of the Assessment}

In order to match assessment requirements with NAPAP agency resources, organizational roles and responsibilities were established. This was done through a series of workshops and meetings held between 1992 and 1995 to define the scope of the assessment and build the organizational structure needed to conduct the assessment. Beginning with the two main questions posed by Congress in the Amendments, a list of key policy-relevant questions were developed with input from experts within the NAPAP agencies, academia, the private sector, nonprofit organizations, environmental groups, industry groups, and congressional staff. At two workshops held in October 1995, these policy-relevant questions were given realistic bounds within the time frame of the report. The smaller, specific issues were identified along with the end points, sources of information, and tools needed to address them. All of the issues were expressed as questions that several research synthesis teams were charged with answering and that serve as the structure for this report (see NAPAP Assessment Questions text box).

Subsequent to the workshops, the NAPAP Interagency Committee refined the scope of the assessment with guidance from the Air Quality Research Subcommittee 


\section{NAPAP Assessment Questions}

\section{What is the status of implementation, the effectiveness, and the costs and benefits of Title IV of the 1990. Clean Air Act Amendments?}

A: What is the status of implementation (compared to the legislated requirements)?

B. What emission reductions have been achieved?

1. How do the actual reductions (1990-1995) compare with the Title IV benchmark projections (i.e., compared to the expected emissions under Title IV and the projections made in 1990 if Title IV were nót implemented)?

2. What are the reasons for the emission reductions?

C. How have air concentrations and levels of deposition been affected by thesemission reductions and how do the new levels compare to the benchmark projections (i.e, with and without Title IV)?

D. As measured by compliance costs, how effective is the market based approach to emission control compared to a command-añd-control approach (e.g., benchmark projections)?

1. What are the factors affecting participation in the băking and trading program?

2. What market innovations have been achieved?

E. What are the benefits of Title IV within the United States (in the following effects areas)?
1. aquatic ecosystems
3. materiâls and dultúal resources 5 human health

2. forest ecosystems

3. materials

F. Address the following econonmic benefits questions in relation to the effects areas listed under $E$, above:

1. For each of these is there a well-identified end point that affectshuman welfare?

2. If so, for which of these does economics (methodology) contribute to an understanding of the impact? Also, recognize that other criteria exist.

3. For which of these-is there relative confidence within economics (existing datâ)?

4. For each of these, how are the end points linke to Title lv?

G. The following effectiveness questions shoụld be addressed sequentially:

1. What are the current physical, chemical; ior biological characteristics/states of the sensitive receptors?

2. What roles do these receptors play in mäintaining ecosystems?

3. How have these states changed since 1980 and what are the trends in these changes?

4. What is the role of acid deposition controls in these trends?

5. What is the difference between current conditions (i.e. with implementation of Title IV and bench mark scenariós (i.e:, with and without Title IV)?

H. What have been the values of the benefits ofthe emission reductions compared to benchmarkprojections (monetary and nonmonefary)? 14 . What are the consequences of emission allowance trading and banking on the environment?

2. What haye been the monetary and nonmonetary values of the benefits of omplementation compared

to benchmark projections?

1 Where are the significant research gaps in the valuation of benefits costs upstream effects (in the path

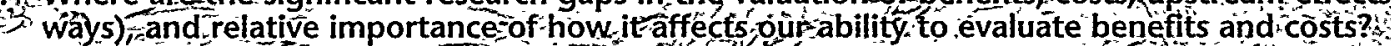

What are the reductions in deposition rates that are needed on order to prevent adverse_ecological effects?

A. What are current deposition rates and what are their variabilities in time?

B. How do we address the issue of "adverse" over time? C. Are there resources whoseresponses are uniquéenough to be identified as specific indicators of changes
in acid deposition?

D. What are the dose-response relationships (observed and modeled forsulfúr and nitrogen deposition the effects areas of interest (see Question $\mathrm{E}$, above)??

1. What is the regional extent and magnitude of these responses?

2. How arêthese key ecological responses generally related to and influenced by other factors (e.g climate change, ozone; land-use changes, and thé carbon cycle)?

E. How mighteffects be reduced if deposition were reduced further?

$F$. What levels of deposition and associated effects (if any) will remain afterimplementation of Title IV? 
of the Committee on Environment and Natural Resources under the President's National Science and Technology Council. The Interagency Committee recommended, for several reasons, an abbreviated report be produced for 1996 and a more comprehensive assessment be conducted in 2000. Since 1995 was the first year of implementation of Title IV, it would be too early to observe the changes in most effects areas resulting from a single year of emission reductions. Weather variability and its impact on dispersion, transport, and deposition of pollution would contribute to the uncertainty in identifying a response of ambient concentrations and visibility to emission reductions over the brief span of time after Title IV took effect. The scope of the issues addressed in this assessment is conceptualized in Figure 1.

As a result, this assessment of the costs, benefits, and effectiveness of Title IV focuses on the observed regional changes in emissions, deposition, and effects for the period 1980-1995. Additional analyses are provided on areas of special interest (e.g., Adirondack Mountains of New York) where information is available. Because of the inherent danger in extrapolation from a one-year period of record, this report contains no projections. Its approach to answering the question about any needed deposition reductions is to describe the ecosystem responses to reductions along a continuum, thereby allowing decision makers to determine the level of acceptable risk.

An abbreviated report was also necessary because of the limited time and resources available. No new research was to be conducted for the assessment; it was to be based on existing peer-reviewed data, information, and published federal agency reports. This revised scope of the assessment was presented at a workshop with the research synthesis teams in September 1996.

\section{Synthesis and Evaluation}

Seven research synthesis teams composed of NAPAP agency scientists and contractors with extensive experience in the acid rain issue were responsible for collecting, synthesizing, and updating the scientific data and information necessary to answer their particular questions. The NAPAP State of Science and Technology Reports and 1990 Integrated Assessment Report were used as a baseline. The data were synthesized and made available to the integration and assessment team in question-and-answer format.

\section{Integration and Review Process}

The integration and assessment team, with the support of the leaders of each of the research synthesis teams, integrated the synthesized data into the report format by addressing the linkages and relationships among the many disciplines.

The independent experts who reviewed this report were made aware of the policy-oriented nature of the work and the need for high-quality science. Most of them were asked to review those portions of the report that pertained to their areas of expertise and the inte-

Figure 1

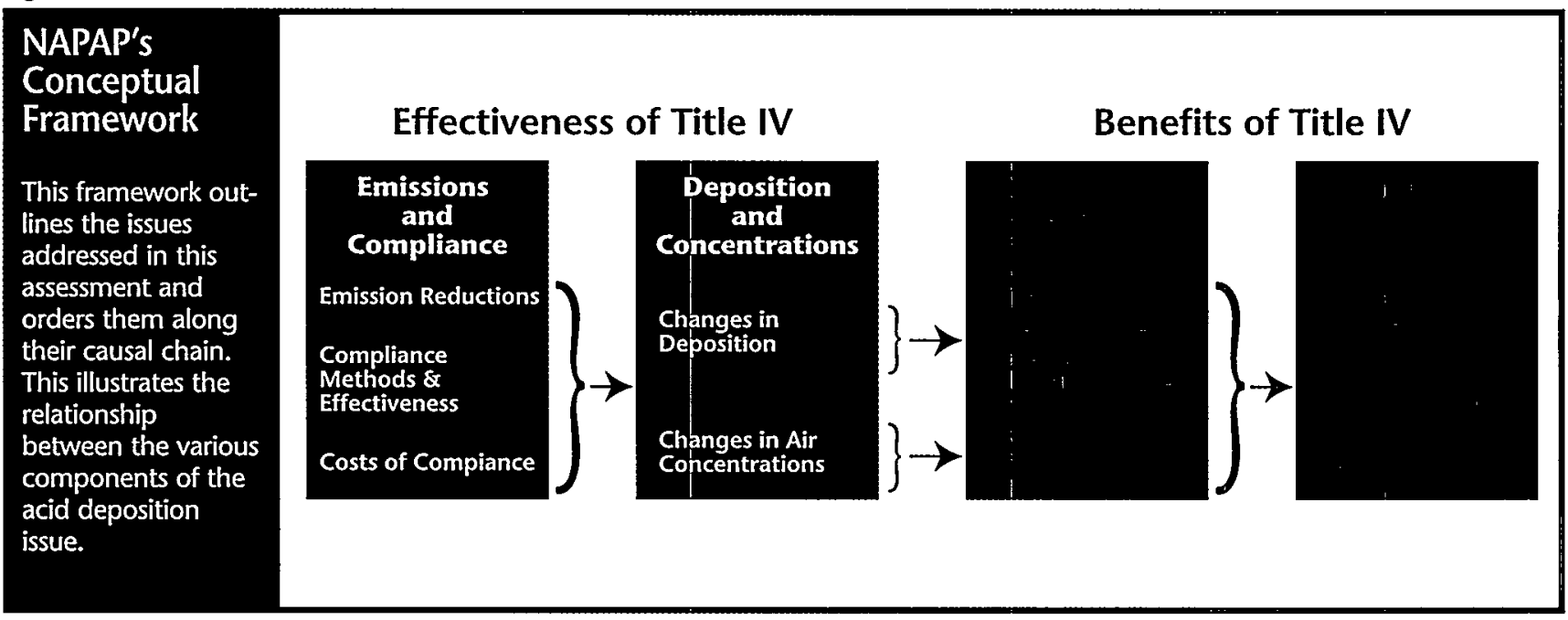


grative aspect of the assessment. Three experts were tasked with evaluating the entire report, from a multidisciplinary, integrated viewpoint. The integration and assessment team incorporated their comments and suggestions into the report for agency review.

\section{Communication of Results}

The primary method of communicating the results of NAPAP assessments is through publishing the reports to Congress. It is the responsibility of NAPAP, through the Office of the Director, to inform stakeholders of the results of assessments and receive feedback. To expand the availability of the report beyond those that will receive the printed version and to improve dialogue with interested parties, NAPAP will place the report on the World Wide Web. In addition, the research synthesis teams have been encouraged to publish their individual synthesis and analyses in the open literature.

\section{Organization of This Report}

This report is directed to Congress but provides valuable economic and scientific information to all public officials who are responsible for setting air quality policy. It attempts to present highly technical information that addresses current public policy issues in a format that can be understood by the nonscientific reader. The report is organized in a series of sections that generally follow the causal chain of events: utility emissions and compliance costs, air concentrations and deposition, effects, and economic valuation of benefits. Where more scientific or economic detail is desired, references are denoted in the text with superscripts and provided at the end of the report.

The status of implementation of Title IV by EPA and the affected utilities and the costs of compliance are presented first, followed by an analysis of the observed changes, both past and present, in emissions of acid rain precursors, air concentrations, and deposition of acidic species. The impact of acid deposition on aquatic and terrestrial ecosystems, visibility, materials and cultural resources, and human health is presented along with the observed and modeled responses by sensitive receptors. The responses are addressed in terms of reductions to physical injury and economic valuation as a result of emission changes. The next section addresses the effectiveness of Title IV, a market-based approach to environmental regulation, relative to the more traditional command-and-control approach to regulation. Finally, an outlook to what can be expected in NAPAP's 2000 assessment is presented, including the monitoring, research, and modeling activities that must be completed for the assessment. 


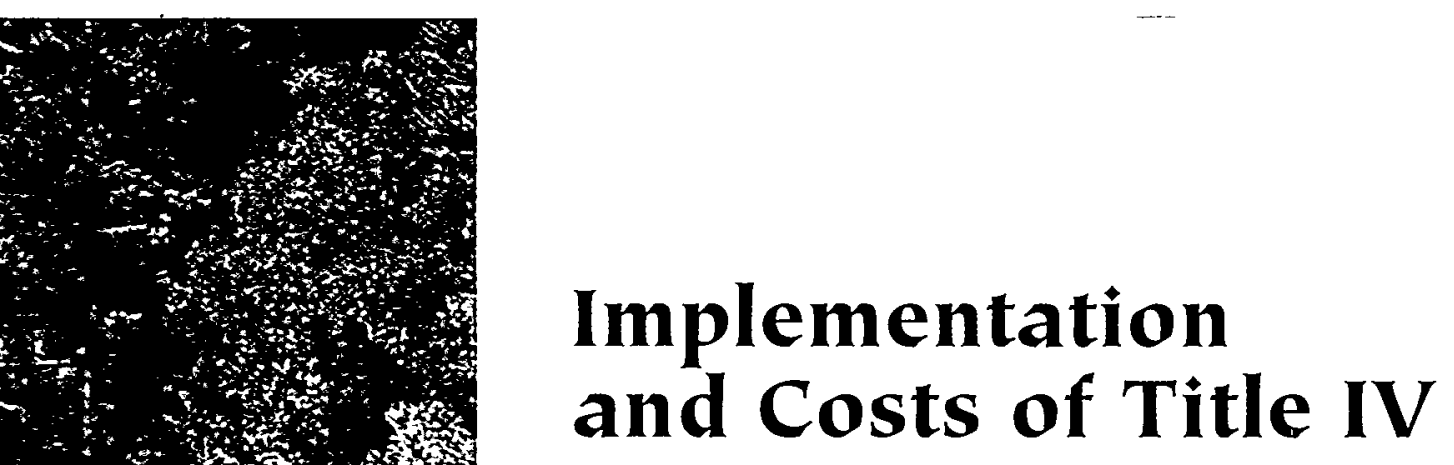

mitle IV of the 1990 Clean Air Act Amendments requires the reduction of acid rain precursors-namely, emissions of sulfur dioxide $\left(\mathrm{SO}_{2}\right)$ and nitrogen oxides $\left(\mathrm{NO}_{\mathrm{x}}\right)$ from electric utilities. This section discusses the status of the Acid Deposition Control Program as required under Title IV of the 1990 Clean Air Act Amendments, as well as the compliance costs associated with Title IV. The results of the emission reduction program are discussed in the next chapter (Changes in Emissions, Concentrations, and Deposition).

The Acid Deposition Control Program is being implemented in two phases (see Figure 2) and has two major goals.

1. Reduction of total $\mathrm{SO}_{2}$ emissions by 10 million tons below 1980 levels by 2010.

2. Reduction of $\mathrm{NO}_{\mathrm{x}}$ emissions from coal-fired boilers that will contribute to the overall target of a 2-million-ton reduction below 1980 levels by 2000 .

Under the $\mathrm{SO}_{2}$ emission reduction program, utility emissions will be capped at 8.95 million tons per year in 2010. Nonutility industrial emissions are capped at $5.6 \mathrm{mil}-$ lion tons per year beginning in 1995 . There is no national cap on $\mathrm{NO}_{\mathrm{X}}$ emissions.

\section{What is the status of implementation?}

\section{$\mathrm{SO}_{2}$ Implementation Program}

M.t. The $\mathrm{SO}_{2}$ emission reduction program started on schedule, which reflects the cooperation by participating electric utilities and the U.S. Environmental Protection Agency (EPA). Phase I was initiated in January 1995; Phase Il begins in 2000.

In 1995, there were a total of 445 electric utility units under Phase 1 of the $\mathrm{SO}_{2}$ implementation program: the original 263 highest emitting utility units in the country, plus 182 substitution and compensating units that voluntarily chose to comply with Phase I requirements early. Phase I utility units reduced $\mathrm{SO}_{2}$ emissions significantly below the allocated allowable levels. $\mathrm{SO}_{2}$ emissions in 1995 were $39 \%$ below the 8.7-million-ton allowable level; in 1996, $\mathrm{SO}_{2}$ emissions were $35 \%$ below the target of 8.3 million tons. ${ }^{4}$

\section{$\mathrm{NO}_{\mathrm{X}}$ Implementation Program}

The first phase of the $\mathrm{NO}_{\mathrm{X}}$ emission reduction program began in January 1996 , one year later than originally scheduled due to a U.S. court action regarding lan- 
guage describing affected sources in the initial EPA rule. Phase II becomes effective in 2000.

The 1990 Clean Air Act Amendments require the 2million-ton reduction in $\mathrm{NO}_{\mathrm{x}}$ emissions to be achieved by a combination of measures from stationary and mobile sources, as specified under Titles I, II, and IV. Title IV, which covers coal-fired electric utility boilers, will contribute a large amount toward the overall emis- sion reduction goal. In 1996, the first year of implementation, Group I units (dry-bottom, wall-fired, and tangentially fired boilers) reduced emissions by $33 \%$ below 1990 levels. $^{4}$

Beginning in the year 2000, $\mathrm{NO}_{\mathrm{x}}$ emissions from Group I boilers are expected to be reduced by approximately 1,170,000 tons annually. Group 2 units (wetbottom boilers, cyclones, cell-burner boilers, and vertically fired boilers) will provide additional $\mathrm{NO}_{\mathrm{x}}$

Figure 2

\section{Electric Utility Units Affected by Phases I and II of Title IV}

The Acid Deposition Control Program is being implemented in two phases under Title IV. Phase I began in 1995 for $\mathrm{SO}_{2}$ and in 1996 for $\mathrm{NO}_{\mathrm{X}}$ and will continue through 1999 . In the first year of the $\mathrm{SO}_{2}$ control program, 445 electric utility units located primarily in the eastern United States were required to reduce their emissions. Phase II, which begins in 2000 and will be completed by 2010 requires reductions in both pollutants from more than 2,000 units across the country.
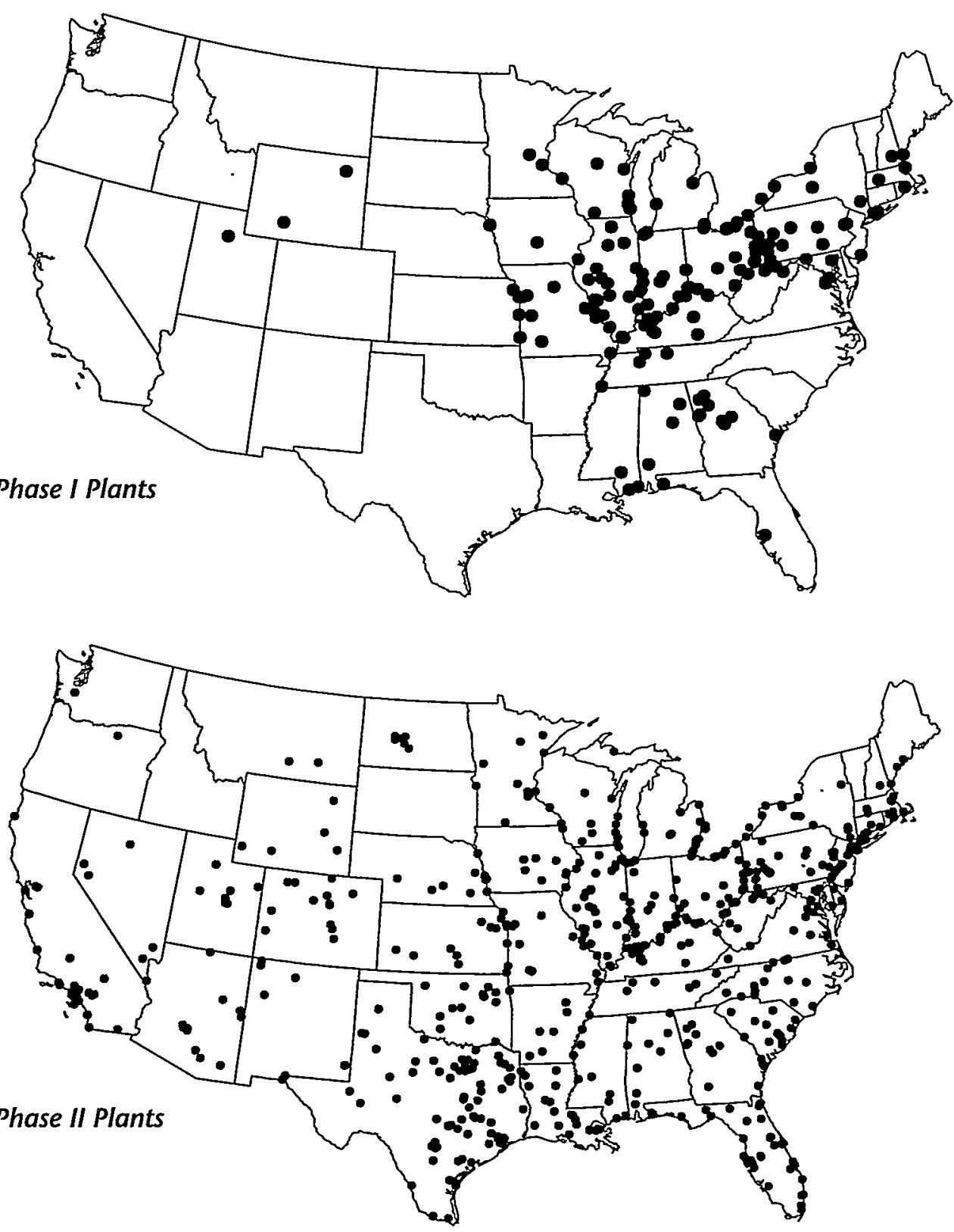
reductions of 890,000 tons per year, thereby decreasing total $\mathrm{NO}_{\mathrm{X}}$ emissions by more than 2 million tons annually.

However, because there is no national cap, $\mathrm{NO}_{\mathrm{x}}$ emissions are expected to rise again after the full-scale reductions take effect in 2000 under Phase II. To meet the expected growth in electricity generation, existing units will be used more, even though their emission rates are limited, and new units, which are not required to offset their emissions, will be built and operated. $\mathrm{NO}_{\mathrm{x}}$ emissions from mobile sources and some industrial sources are also expected to rise within the next 10 years. ${ }^{5}$

\section{How well have utilities complied with the provisions under Title IV?}

田

All Phase I units have met their emission reduction obligations. There has been an unprecedented level of accuracy and compliance by utilities in reporting emissions due to installation of continuous emission monitors on all affected units.

Allowance trading, a unique aspect of Title IV, has significantly increased since the first trades were recorded in March 1994 and serves as a model for other emission reduction programs.

Significant milestones have already been achieved under Title IV. The first year of compliance for Phase I units was marked by a sharp decline in $\mathrm{SO}_{2}$ emissions. In addition, all 445 Phase I units met their compliance obligations. In the first annual reconciliation of allowances and emissions, $\mathrm{SO}_{2}$ allowances matched or exceeded $\mathrm{SO}_{2}$ emissions generated in 1995 at each of the Phase I units. No excess emissions were reported. A total of 3.4 million tons of unused 1995 vintage $\mathrm{SO}_{2}$ allowances were "banked" for future use. (See the Allowance Trading text box for further discussion.)

The volume of allowance transfers has doubled annually since the first transactions were recorded in 1994. By the end of 1996, over 3,100 transactions involving more than 51 million allowances had occurred. Of these 51 million allowances, over 34 million were transferred by private parties; the remainder were transfers from EPA to private parties under various provisions of the Clean Air Act. Approximately $20 \%$ of the allowances transferred by private parties to date have occurred among organizations or companies that have no direct economic link; the number of transfers increased from 1.9 million in 1995 to 4.4 million in 1996. About half of these transfers involved utilities acquiring allowances from brokers, fuel companies, or other electric utilities. More than $25 \%$ of all utilities and $50 \%$ of Phase I affected utilities have engaged in these allowance transfers. Utilities in 33 different states participated in these types of transactions. ${ }^{6}$ The majority of activity in EPA's electronic Allowance Tracking System, however, continues to involve the shifting or redistribution of allowances within one utility's (or group of utilities') holdingsi.e., for the purpose of covering emissions from individual generating units or for allowance accounting purposes.

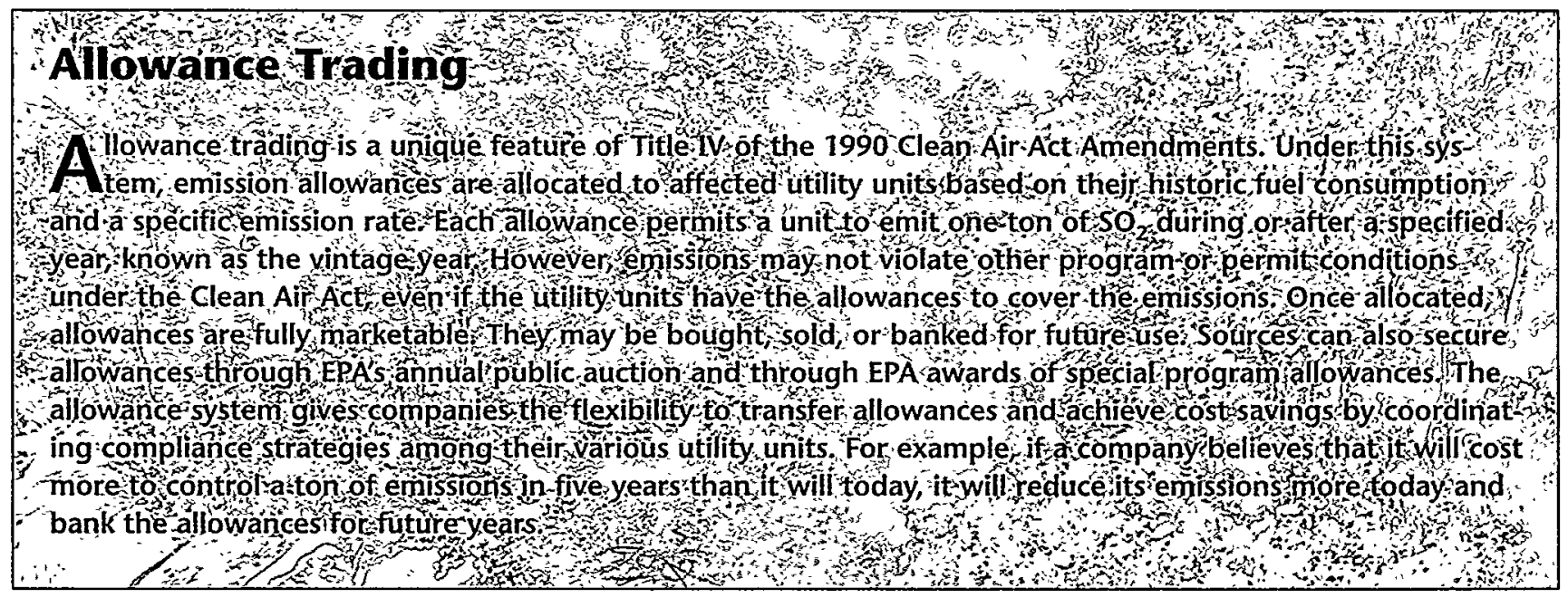


Through 1996, a total of 775,000 allowances were sold at four public auctions. In addition, EPA awarded more than 18,000 allowances from the Conservation and Renewable Energy Reserve to utilities that reduced their emissions through energy-efficiency and renewableenergy projects before the emission reduction deadlines. This growth in awards reflects the increased cumulative number of energy efficiency and renewable-energy measures installed since 1992, the first year for which utilities can take credit for measures that earn bonus allowances based on energy savings or renewable generation. ${ }^{7}$ The 1990 Amendments also established a program to assist small diesel refiners in defraying the capital costs of installing desulfurization equipment at their refineries by providing $\mathrm{SO}_{2}$ allowances based on the amount of diesel fuel produced.

In another program initiative, in 1996 EPA awarded allowances to two industrial sources voluntarily entering the Acid Deposition Control Program. Promulgated in May 1995, the "opt-in" program allows additional combustion sources (e.g., fossil fuel-fired boilers, turbines, or internal combustion engines) not already affected by the program to create allowances through emission reductions. Opting in will be profitable if the revenue from selling allowances exceeds the combined cost of the emission reductions and of participating in the opt-in program.

The effectiveness of the allowance trading program has inspired consideration of its application for other emission reduction programs, such as for controlling greenhouse gases and nitrogen oxides. (See Appendix $B$ for more information on pollution trading programs.)

\section{What are the compliance costs of Title IV, and how do they compare to projections?}

Emission reductions have been achieved at a

lower cost than estimated by many studies.

Estimates of total costs of Title IV continue to be revised downward. Much of the cost savings associated with more recent analyses can be linked to reductions in costs and improved performance of scrubbers. In addition, competition between different compliance options and the integration of the allowance and fuel markets may have a downward impact on compliance costs. ${ }^{8,9}$ Anecdotal evidence suggests that technology innovation is leading to cost savings. ${ }^{10.11}$ Allowance prices are also considerably lower than many experts predicted. ${ }^{12,13}$ These prices have been influenced by developments in the low-sulfur coal market, particularly greater compatibility than expected of western, sub-bituminous coals with eastern boilers designed for bituminous coals, reduced rail rates for delivering western low-sulfur coal to some utilities in the midwestern United States, and lower-than-expected future costs of scrubbers for Phase II of Title IV. ${ }^{11.14}$ Incentive or bonus allowances that encouraged retrofit flue gas desulfurization on Phase I units led to the building of flue gas desulfurization technologies, which has kept the marginal costs of compliance so far in Phase 1, lower than estimated by prior projections. Also, initial over-estimates of costs led to an overestimate in scrubbers and resulted in excess allowances and lower allowance prices.

The significance of these lower costs is twofold. First, they show that it is often difficult to estimate future technological improvements and the more efficient use of existing technologies. For example, significant cost reductions in renewable and energy-efficient end-use technologies are expected in the coming years, but the overall contribution of these technologies to reductions in future environmental compliance costs is difficult to estimate. Economic models that do not estimate these factors may overstate compliance costs for environmental programs. Second, these lower costs again illustrate the benefits of a flexible approach to compliance that allows different technologies and fuels to compete against each other, and rewards firms for finding cost-effective measures that exceed emission reduction targets.

\section{Methods of Compliance}

$\mathrm{SO}_{2}$ emission reductions in 1995 were achieved by an almost equal split between scrubbing and fuel switching.

Table 1 pairs estimated emission reductions at Phase I units with the method of emission control used; where the method was switching, the table lists the source of the lower-sulfur coal. These figures represent the difference between actual 1995 emissions and what the emissions would have been without Title IV (approximately 3.9 million tons). In the aggregate, slightly more than half of the reduction came from switching to lower-sulfur coals, but the contribution from scrubbers 
Table 1

$\mathrm{SO}_{2}$ Emission Reduction Methods at Phase I Units in 1995

\begin{tabular}{lcr} 
Method/Region & $\begin{array}{c}\text { Tons of } \mathrm{SO}_{2} \text { Removed } \\
\text { (in thousands of tons) }\end{array}$ & $\%$ of Total \\
\hline Scrubbing Total & 1,754 & $45.1 \%$ \\
New Title IV Scrubbers & 1,734 & $44.6 \%$ \\
Other Scrubbers & 21 & $0.5 \%$ \\
Switching Total & 2,133 & $54.9 \%$ \\
North Appalachia & 205 & $5.3 \%$ \\
Central Appalachia & 756 & $19.5 \%$ \\
South Appalachia & 60 & $1.5 \%$ \\
Midwestern & 406 & $10.4 \%$ \\
Powder River Basin & 518 & $13.3 \%$ \\
Other Western Coal & 146 & $3.8 \%$ \\
Imported Coal & 22 & $0.6 \%$ \\
Natural Gas & 20 & $0.5 \%$ \\
\hline Total & 3,887 & $100.0 \%$
\end{tabular}

Source: Massachusetts Institute of Technology's

was significant. Twenty-six units installed scrubbers under Phase I; these units accounted for $45 \%$ of the reduction accomplished in 1995,15 and for $62 \%$ of the net surplus of allowances banked in 1995.14

Low-sulfur western coal from the Powder River Basin continued to play an important role in reducing $\mathrm{SO}_{2}$ emissions, but the main contribution to reducing emissions by fuel switching in 1995 came from the bituminous coal-producing regions, mostly in Central Appalachia. Although switching is often seen as changing the source of the coal from a high-sulfur region to a geographically distinct low-sulfur region, much of the reduction occurring in 1995 resulted from fuel switches within a region. This phenomenon was observed in all regions, including the predominantly high-sulfur coalproducing regions of North Appalachia and the Midwest, where the coal was typically mid-sulfur rather than the conventional low-sulfur coal.

\section{Associated Costs of Compliance}

Preliminary results from a retrospective analysis show the total annualized cost of the 3.9-million-ton reduction of $\mathrm{SO}_{2}$ in 1995 was about $\$ 726$ million, ${ }^{15}$ which is at the lower bound of earlier predictions (Table 2). In particular, the observed cost of compliance by scrubbing has been markedly lower than expected. This experience is influencing today's allowance prices, which are more closely related to marginal compliance costs, rather than average costs that include the capital costs of flue gas desulfurization.

Table 3 compares the expected $\mathrm{SO}_{2}$ removal cost for a representative retrofitted unit (as projected by ICF in $1990^{16}$ and EPRI in 1993), with actual $\mathrm{SO}_{2}$ removal costs for the scrubbed units that were fully operational in 1995 (as reported by Ellerman et al. in 1997)..$^{5}$ By 1995. Phase I scrubbers were removing sulfur at an average total cost of $\$ 282$ per ton, or about $40 \%$ less than what had been predicted by earlier estimates of average total overall cost. The cost savings arise from two factors: lower operating and maintenance costs, particularly fixed costs, and more intensive utilization of generating units with scrubbers ( $83 \%$ capacity factor in 1995 versus $65 \%$ as assumed in most earlier studies).

No attempt was made in Table 3 to quantify emissions reduced through demand-side energy-efficiency programs. However, some companies and state public utility commissions have analyzed the impacts of these programs on emissions and compliance strategies, and others have analyzed how the value of $\mathrm{SO}_{2}$ emissions

Table 2

\section{Estimates of Phase I Compliance Costs}

Study

Total Annual Cost (in millions of 1995 dollars)

ICF 1989 (low, constrained) $\$ 871$

ICF 1989 (low, flexible) $\$ 599$

ICF 1990 (low, flexible)

EPRI 1993

$\$ 1,338$

GAO 1994

$\$ 1,163$

EPRI 1995

$\$ 894$

Actual 1995 (Ellerman et al., 1997)

$\$ 726$

Source: Massachusetts Institute of Technology's 
Table 3

\section{Scrubber Costs per Ton of $\mathrm{SO}_{2}$ Removed (in 1994 dollars)}

\begin{tabular}{lccc} 
Types of Costs (per ton $\mathrm{SO}_{2}$ ) & ICF 1990 & EPRI 1993 & Actual 1995 \\
\hline Capital Charge & $\$ 285$ & $\$ 262$ & $\$ 203$ \\
Fixed Operation \& Maintenance & $\$ 66$ & $\$ 83$ & $\$ 14$ \\
Variable Operation \& Maintenance & $\$ 104$ & $\$ 129$ & $\$ 65$ \\
\hline Total Cost & $\$ 455$ & $\$ 474$ & $\$ 282$
\end{tabular}

a The representative retrofitted unit used in EPRI 1993 is a 300-megawatt unit with a retrofit difficulty factor of 1.27. The unit is assumed to remove $90 \%$ of the sulfur from a 3.97-lb coal and to be operating at a $65 \%$ capacity factor and a gross heat rate of 9,722 Btu/kWh.

b Data are from an MIT questionnaire given to affected utilities, as reported in Ellerman et al., 1997. Source: Massachusetts Institute of Technology's

avoided by energy-efficiency and renewable-energy programs improve the cost-effectiveness of these technologies. ${ }^{7,17}$

Lower-than-expected fixed operating costs appear to be a result of reduced personnel costs due to greatly improved instrumentation and controls on new scrubbers. Increased competition in the industry has also added to pressures to reduce these costs. Lower variable costs appear to be due to reduced requirements for power to run scrubbers as a result of better controls. Utilities have also used some innovative sludge disposal techniques to reduce these costs. ${ }^{15}$
Since enactment, the projected cost of compliance with the $\mathrm{SO}_{2}$ emission reductions has declined with each analysis. In 1990, EPA estimated the annualized cost of the $\mathrm{SO}_{2}$ reductions to be $\$ 4$ billion by the year 2010, assuming full inter-utility trading. For its Regulatory Impact Analysis in 1992, EPA estimated the annualized cost in 2010 at $\$ 3.7$ billion. ${ }^{18}$ In 1993, the Electric Power Research Institute estimated Phase II costs with full inter-utility trading to be $\$ 2.2$ billion. In 1994, the General Accounting Office estimated that with full inter-utility trading the annualized cost in 2010 should be less than $\$ 2.0$ billion.

Allowance prices have reflected these declining estimates of control costs. The price of an allowance has dropped from an estimated \$500-600 per ton when the Clean Air Act Amendments were passed to a low of $\$ 68$ per ton at the March 1996 allowance auction; the price at the end of 1996 was about $\$ 90$ per ton (Figure 3). A number of hypotheses have been offered as to why allowance prices are so much lower than expected.

Figure 3
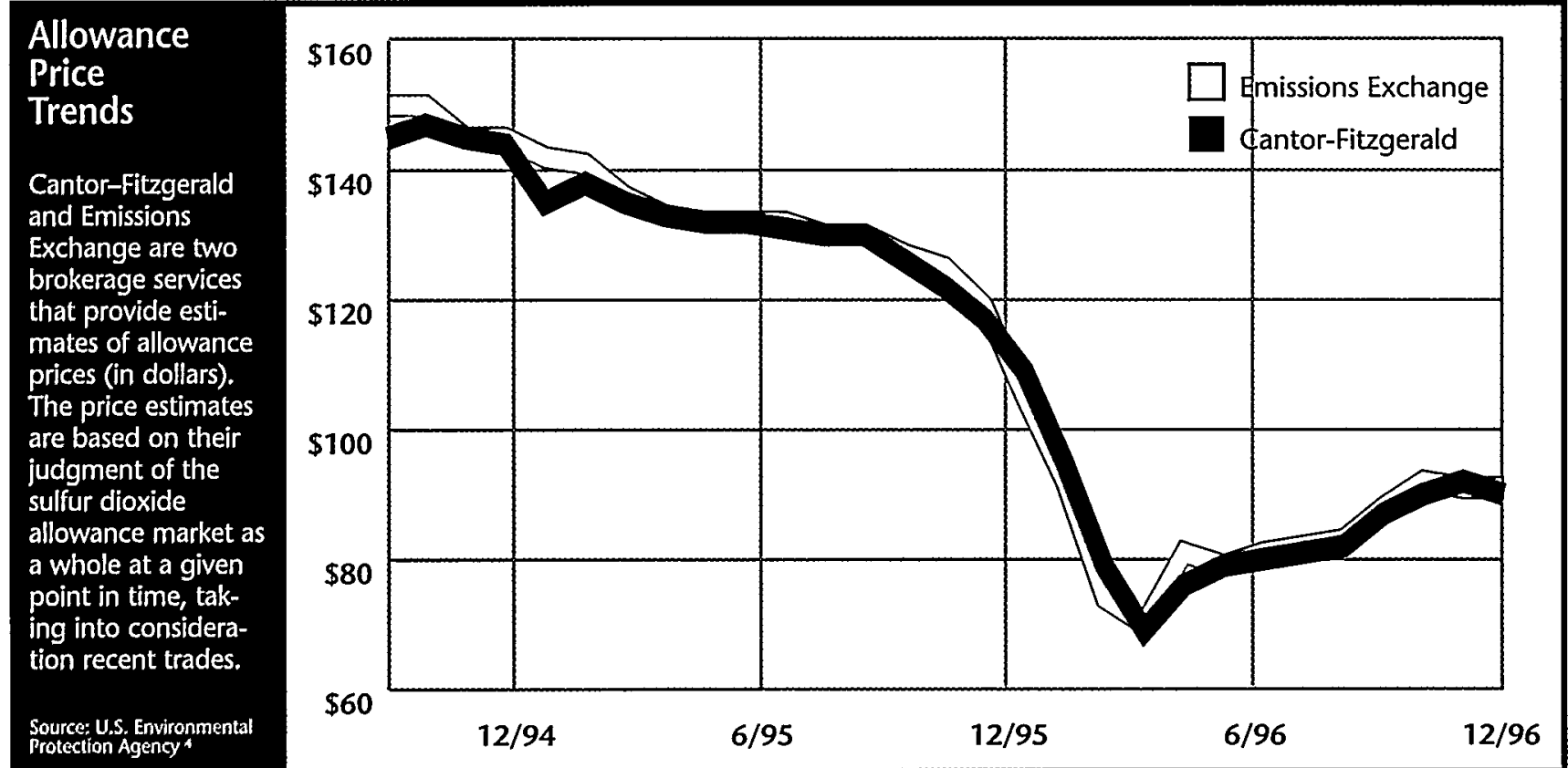
- The low price and widespread availability of low-sulfur fuel reduces allowance prices. Moreover, lower rail costs have made low-cost coal from the Powder River Basin available to midwestern utilities that are "on the margin" in choosing their compliance strategies.

- Scrubber costs, particularly variable costs, are much lower than expected. This has lead utilities to run units with scrubbers at high utilization rates, as long as the value of the extra allowances generated is greater than the variable costs of scrubbing.

a Projected future costs of scrubbing for Phase II could be lower than current costs.

- Costs incurred through fuel switching or scrubbing in Phase II, when the full effect of emission reductions will be realized, should be discounted by the rate of interest for comparison with current period allowance prices.

- The lead time for large capital expenditures on scrubbers required utilities to estimate future compliance costs and allowance prices. However, expectations in the early 1990 s were that the marginal costs of compliance and allowance prices would be considerably higher than their actual levels, leading to overinvestment in scrubbers, overcontrol of emissions, excess allowances, and lower allowance prices.

n Competition between compliance options (e.g., low-sulfur fuels, more intensive utilization of scrubbers, and bundling of higher-sulfur fuels with allowances) has led to lower marginal costs and allowance prices.

- Bonus allowances and regulatory incentives for scrubbing have led to excess allowances and lower allowance prices.

- Substitution and compensating units depress allowance prices because they have lower marginal costs for compliance.

- The Title IV auction design artificially depresses allowance prices.

- Uncertainty about possible future environmental regulations reduces the demand for allowances.
- State public utility commission policies and regulations are a disincentive to allowance trading and depress allowance prices.

These hypotheses are not mutually exclusive. They can be grouped into two categories: (1) hypotheses that assume that low costs are due to underlying market fundamentals (the first five listed), and (2) hypotheses that assume regulatory or other distortions of the market. While most observers agree with at least some of the hypotheses in the first category, there is more debate about hypotheses in the second category. Further discussion about several of these hypotheses appears later in this chapter in the banking and trading section.

\section{Market-Based System}

The market-based approach in Title IV has achieved significant savings when compared to a command-and-control regulatory approach.

A particularly notable feature of Title IV is the cap on utility emissions and the choice of fully tradable emission permits to achieve the environmental objective. The appeal and promise of such market-based instruments is a lower cost of compliance than would be achieved under an equivalent command-and-control instrument. Earlier studies of compliance costs with Title IV have provided estimates of the potential savings, derived by both the differences in predicted costs between scenarios that assumed more and less trading, and variations among these studies in the amount of assumed emissions trading and in the corresponding costs:

D ICF's 1989 analysis predicted the cost savings for limited trading among utilities within the same state to be approximately $\$ 225$ million (in 1988 dollars), about $33 \%$ of the predicted cost of compliance in the "less trading" case. ${ }^{19}$ [ICF's 1990 analysis does not provide a comparable estimate of cost savings from emissions trading because it assumed flexible implementation ("trading to the fullest extent permitted") for both the higher- and lowergrowth scenarios modeled.] In addition, ICF89 estimated that banking provisions might result in an additional annual reduction of emissions in Phase 1 of between 0.8 and 1.2 million tons, resulting in a present-value cost 
savings of $\$ 150$ million-about a third of the predicted cost of avoided Phase II emission reductions.

- EPA's 1992 Regulatory Impact Analysis predicted cost savings of $40 \%$, or $\$ 400$ million (in 1990 dollars), from a "national $\mathrm{SO}_{2}$ trading program" as compared with a "traditional $\mathrm{SO}_{2}$ control program."

- The 1994 GAO report provided an estimate from intra-utility trading only, because very little inter-utility trading was expected: $\$ 230$ million (in 1992 dollars), or $18 \%$ of the predicted cost of compliance under a "traditional command-and-control" approach.

Most recently, MIT has made a preliminary estimate of the cost savings, in 1995 dollars, of $\$ 225-375$ million, or about $25-34 \%$ of the cost of abatement for the same emissions reduction in the absence of trading. ${ }^{15}$

Several studies have estimated the cost savings from the allowance trading program as compared to a command-and-control approach for Phase II of Title IV. One study estimates the annualized cost of compliance with the Phase $1 / \mathrm{SO}_{2}$ emissions cap in 2010 with full inter-utility trading to be less than $\$ 2$ billion, compared to an annualized cost of compliance without trading of $\$ 4.9$ billion. ${ }^{13}$

\section{Technology Innovations}

Increased technology efficiency and innovation have been achieved from the market-based approach.

Recent studies have highlighted the efficiency and innovation in pollution controls that have accompanied implementation of Title IV.10.11 For example, scrubber costs have declined dramatically in the past six years and are now $40 \%$ or more below 1989 levels. At the same time, scrubber sulfur removal efficiencies have improved from $90-92 \%$ in 1988 to $95 \%$ or more in retrofits to utility units affected by Phase I.

There have also been innovations in blending of highand low-sulfur coals. In the past, it was assumed that blending would cause problems for utility boilers, but technical difficulties have been largely worked out through experimentation prompted at least in part by Title IV compliance requirements and flexibility.

\section{Banking and Trading Program}

The $\mathrm{SO}_{2}$ allowance market has become more active and has begun to take on some of the attributes of a more established commodity market. However, there is still debate about the scope and magnitude of opportunities for further trading.

The sulfur dioxide allowance market is becoming an effective private market for trading allowances, and many of the early doubts about the emergence of active allowance trading have not been realized. A wide cross-section of electric utilities has engaged in allowance trading. Nearly half of the 1995 allowance issuance has been traded through time or space, which indicates that electric utilities are availing themselves of the opportunities for cost savings created by the emissions trading provisions of Title IV. On the other hand, there is still some dispute about whether there are barriers preventing even wider development of the market and additional cost savings.

Some analysts contend that state public utility regulations and policies have had an adverse effect on electric utilities' decisions to trade. Advocates of this position note that uncertainty about how commissions will treat the recovery of allowance costs may dissuade utilities from allowance trading. Moreover, where Public Utility Commission policies prevent utilities from keeping the profits from allowance trades, there is a reduced incentive to trade. However, one analysis argues that there is little evidence of such adverse effects. ${ }^{20}$ As of January 1996, only 15 state Public Utility Commissions (out of the 35 states where trading has occurred) had explicitly addressed the subject of allowance trading through the issuance of a formal generic order and/or an informal guideline. Trading does not appear to have been impeded in the 20 states where state commissions have yet to address the ratemaking treatment for allowances.

Another possible barrier to allowance trading is the design of the Title IV auction. Some observers have asserted that the price-discriminating auction design has depressed allowance prices and has thereby discouraged utilities from trading. ${ }^{13,21.22}$ However, a more recent analysis argued that regardless of whether the design of the auction was optimal, there 
is little evidence that it harmed the allowance market. In fact, the early auctions were probably a more accurate reflection of the underlying costs of $\mathrm{SO}_{2}$ control than were the projections of most analysts. ${ }^{23}$

The broader question raised by these debates about market barriers is whether all cost-effective trades are taking place. Some analysts have estimated that the full cost-saving potential of allowance trading is not being reached. ${ }^{10,13}$ Others have argued that the relatively active allowance market provides evidence of cost-effective trades. ${ }^{23}$

The Title IV compliance data for 1995 provide an exact accounting of vintage allowances, and in particular, of how many allowances were traded. The 8.69 million 1995 vintage allowances can be divided into three categories of use: (1) 4.77 million were used to cover emissions by generating units that were issued allowances equal to or greater than this number; (2) 0.53 million were used by almost 100 Phase I affected units (about 20\%) to cover emissions in excess of the allowance issuance to each unit; and (3) 3.39 million allowances were not used in 1995, but were reserved for compliance in future years. The second use category corresponds to the minimum amount of spatial trading, and the third corresponds to inter-temporal trading or "banking." These two uses of vintage 1995 allowances, accounting for a total of $45 \%$, provide the statistics concerning the effectiveness of Title IV's tradable permit program.

Several estimates have been made, based on transactions in EPA's allowance tracking system, of overall allowance trading levels (i.e., not just 1995 allowances used for compliance in 1995). For example, one estimate shows that at least 6.7 million allowances were traded as of March 1996. ${ }^{23}$ Using a slightly different estimation technique, EPA has estimated that at least 7.2 million allowances were traded as of the end of 1996. EPA's estimate includes allowance transfers between utilities, between brokers or traders and utilities, between fuel companies and utilities, between different brokers and traders, and several other types of transfers. ${ }^{24}$ The Electric Power Research Institute has estimated that through 1996.
6.8 million allowances have been traded between different companies in about 960 recorded transactions. ${ }^{14}$ of course, both of these estimates are lower-bound estimates because only those trades entered into EPA's Allowance Tracking System are included. The real level of trading is higher, since many trades are reportedly not entered into the tracking system until they are needed for compliance. ${ }^{4,15}$

\section{Administrative Costs}

Government administrative costs for Title IV implementation have been lower than under more traditional approaches.

The fundamentally different approach to air pollution control embodied by the allowance trading program can minimize many administrative costs associated with command-and-control and previous trading programs. For example, Title IV's performance-based approach eliminates the need to devise source-specific emission limits and to review control technologies and detailed compliance schedules. In addition, eliminating case-bycase review and approval of each trade (including determining the "useful life" of equipment, the intent of the sources regarding future emission and activity levels, and "real" emission reductions achieved), greatly reduces the administrative and transaction costs associated with emissions trading programs. ${ }^{25}$

The program's administrative costs of approximately $\$ 12$ million per year translate into a cost of about $\$ 1.50$ per ton of pollution reduced. Most of these administrative costs are associated with operating the emission monitoring and reporting components of the program. To put these expenditures into context, during the first five years of the program, government spending to set up and operate the $\mathrm{SO}_{2}$ allowance program totaled less than $\$ 60$ million out of a total $\$ 3.5$ billion estimated government expenditure for air pollution control. Thus, the Acid Deposition Control Program is achieving $40 \%$ of the emission reductions under the Clean Air Act with only about $2 \%$ of the staff and other resources. ${ }^{25}$ 


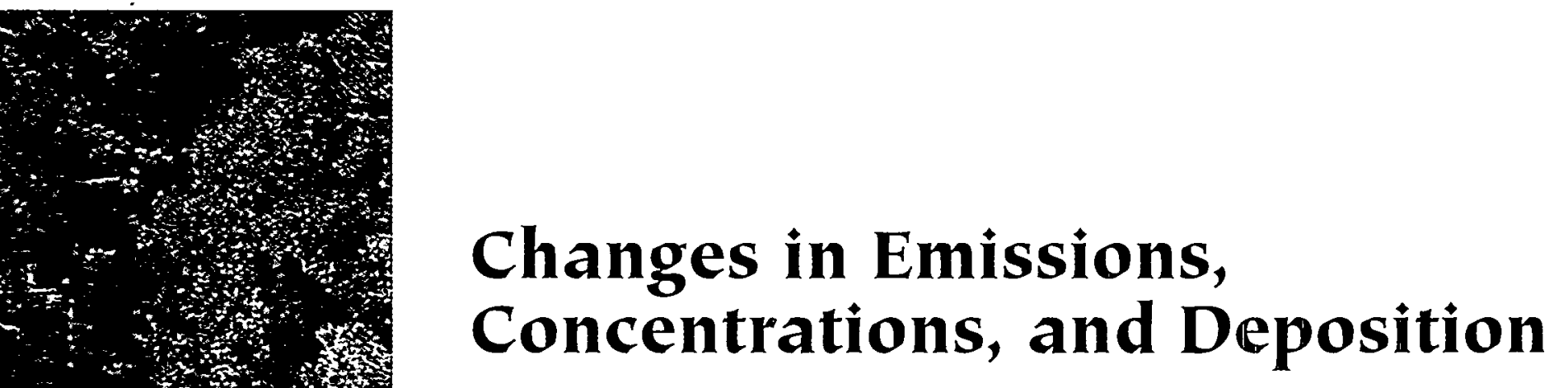

$\mathrm{T}$ here is no universally accepted method for measuring long-term trends in key air pollutants. Intensive ambient air monitoring networks operated by EPA and the states are currently focused on urban and surrounding areas where ambient air concentrations mainly reflect local emissions and where human exposure may be greatest for many air pollutants. Besides representing the inhalation exposure of humans, air concentrations play a significant role in visibility, the reflection of incoming solar radiation (radiative transfer), and the deposition of the pollutants concerned. Air concentrations in rural areas are monitored by agencies, such as the National Oceanic and Atmospheric Administration, EPA, and the National Park Service, and are discussed under the section on air concentrations.

Examination of monitoring sites related to ecosystem effects and regionally representative deposition and visibility data is also included in this assessment. Analysis is based, for the most part, on direct observational evidence. A clear distinction is made between observed emissions data and model calculations (see text box on Emission Monitoring). In addition, a distinction is made between the contribution to total atmospheric emissions of $\mathrm{SO}_{2}$ and $\mathrm{NO}_{\mathrm{X}}$ by utilities, both Phase $\mathrm{l}$ and $\mathrm{Il}$, and by other sources.

This section examines changes in acid deposition patterns and relates them to changes in emissions of precursor pollutants. Current and historical emissions of relevant pollutants are presented along with the resulting air concentrations and deposition at specific receptor locations. Quality-controlled emissions and deposition data through 1995 were available for this assessment. Year-end, qualitycontrolled emissions data for 1996 were not released in time to be incorporated into this assessment, but the data are inserted in footnotes where appropriate.

\section{What emission reductions have been achieved?}

Although $\mathrm{SO}_{2}$ control provisions of Title IV only began in January 1995, dramatic emission reductions that year provide a unique opportunity to place some significance on the analysis of just one year of data. This cannot be said for $\mathrm{NO}_{x}$ provisions, since they were not implemented until January 1996, which was too late for a meaningful analysis of Title IV effectiveness regarding $\mathrm{NO}_{\mathrm{X}}$. Discussion of $\mathrm{SO}_{2}$ and $\mathrm{NO}_{\mathrm{X}}$ emissions in this section is further divided into two categories of sources: electric utilities and all other sources.

\section{$\mathrm{SO}_{2}$ Emissions}

The United States has already achieved a large portion of the $\mathrm{SO}_{2}$ emission reduction goals mandated under Title IV. Significant emission reductions have been achieved by midwestern states and in other areas that have electric utilities with historically high emission rates. 
$\mathrm{SO}_{2}$ emissions have been declining slowly since the early 1970s when the Clean Air Act was first passed. In 1980, the baseline year for Title IV, total emissions from all sources of man-made $\mathrm{SO}_{2}$ were about 26 million tons. By 1995, total $\mathrm{SO}_{2}$ emissions had dropped to 18.3 million tons, with utilities contributing about 12 million tons (Figure 4). There was a dramatic decrease in emissions in 1995, illustrating the first year of compliance under Title IV. The reduction of $\mathrm{SO}_{2}$ emissions from 1994 to 1995 was approximately $19 \%$, all of which can be attributed to reductions from Phase I utilities. In 1995, Phase I units achieved an overall reduction of 5.6 million tons from 1980 levels, which is a $51 \%$ drop in emissions.

There have been major emission reductions in some of the largest, highest-emitting areas of the country. This outcome is important for two reasons. First, underlying Title IV was the understanding that emissions in the Midwest are a significant cause of deposition in the northeastern United States and eastern Canada. The intent of Congress was to reduce these emissions through the 1990 Clean Air Act Amendments, which is now being realized. Second, reductions in these highemitting areas support a fundamental premise of Title IV's market-based approach-that the highest-emitting plants have an incentive to make deep reductions in $\mathrm{SO}_{2}$ emissions because they often face a lower cost per ton of $\mathrm{SO}_{2}$ reduced due to compliance flexibility. So far, concerns expressed at the time Title IV was enacted that the highest emitters of $\mathrm{SO}_{2}$ would simply buy allowances and continue to emit have proven to be unwarranted. Electric utilities have the flexibility to use

\section{Emission Monitoring}

$T^{t}$ he advent of Title IV brought about a change in the method for träking trends in current emissions. To ensure compliance, the statute required each affected combustion unit (boiler or turbine) to install a con tinuous emission monitoring system or for oil and gas units an appioved alternate measurement method to record the concentration and mass of emissions on an hourly basis prior to 19941995 , emissions were estimatedprimarily from emission factors and information filed with the Departwentof 1 nergy's energy. Information Administration.

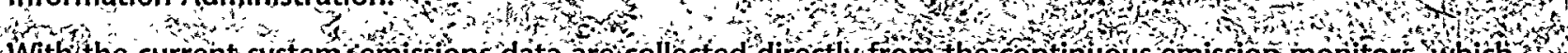
With the current system, emissions data are collected directly from the contínións emission monitors, which w

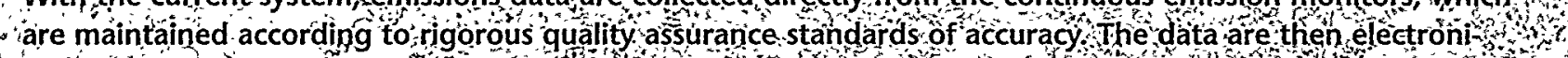
cally' transferred into EPA's Electronic Tracking system, ensuring the quality of the data and eliminating a source of errors pótentially caused by repeated data entry EA A then annually reconciles the datâ with the unit's $\mathrm{SO}_{2}$ allowance holdings to ensure that the $\mathrm{SO}_{2}$ emissons are equal to or lower than the allowances

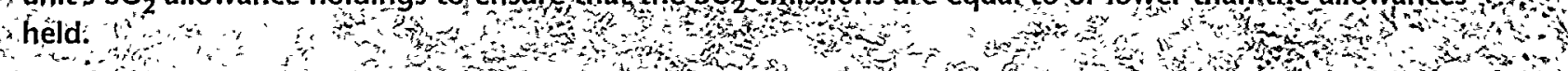
Any change in measurement methodologies will ratse questions about whether obseved differences in emis: sion trends are due to the new metho dor to actual emission reductions How continuous en misson monitor ing compares to the methodology for calculating historical êmissions is still-under investigation to wever for the 263 original Phase 1 units there is continuous emission moñtoring data before Pháséli began (1994) and for the first year of $P$ hase $1(1995)$. Between 1994 and 1995 , these 263 units reduced their so $0_{2}$ emissions by 40\% (almost 3'million tons)

Continuous emission monitors must undergo a relative accuracy test The test en sures that the installed mon itor measures the "true value of the pollutant by comparing the monitor to a refence method used to measure the pollutant in the stack gas concurrently with the monitor Thus far the continuous emis sion monitoring data collected under the Acid Deposition Control Program are remarkably accurate.

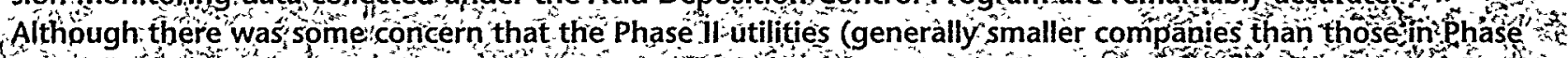
i) might not achieve the same rigotous quâlity ásurance standards as their Phasedcounterparts $98 \%$ of the almost 5,000 monitor tested for the cido position Control Program passed the required $10 \%$ relative

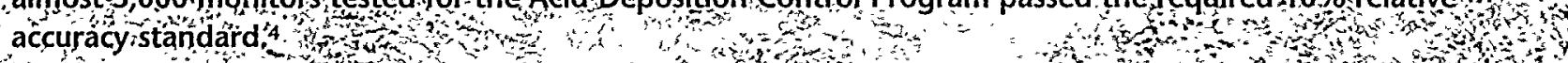

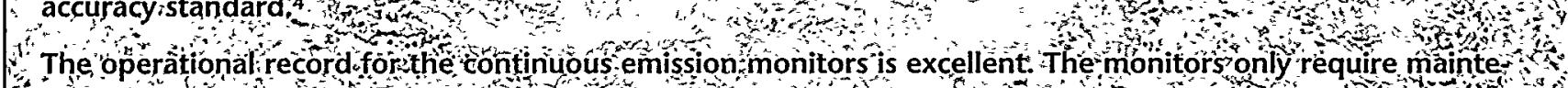
- nance a few day a year over halfotall monitors used to report data forthe Acid Deposition Controp pro - gram were up and running formore then $98 \%$ of the last year and $92 \%$ of all monitors were running fon more than $90 \%$ of the lastear 
Figure 4

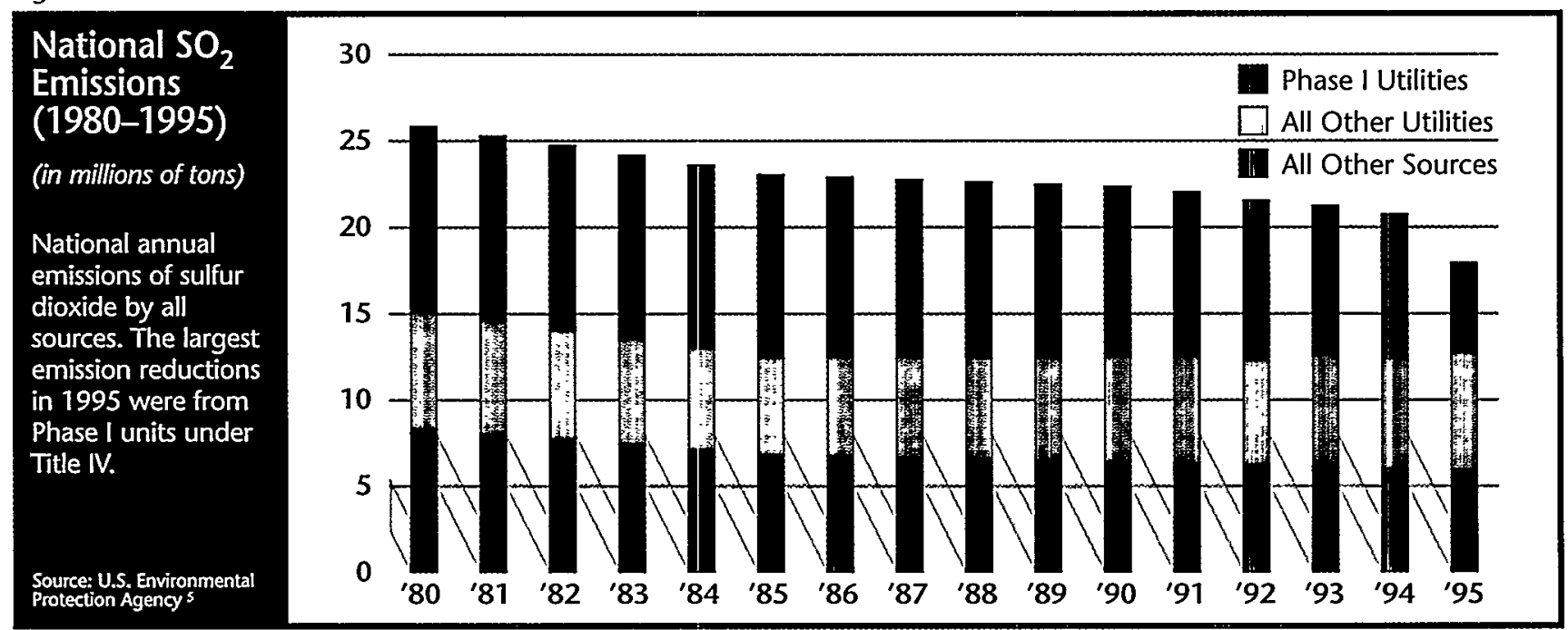

banked allowances, which has spurred early reduction in emissions.

Market-based mechanisms, such as emissions trading, are often thought to be designed entirely for costsaving purposes. However, the banking provision in Title IV illustrates that a properly designed marketbased mechanism may have clear near-term environmental benefits when compared to a more traditional method of regulation.

Of course, the banking provision is also projected to extend the time for achieving the ultimate emission reduction target-the 8.95 -million-ton cap. Most banked allowances are expected to be used between the years 2000 and 2009 , after the more stringent emission limits of Phase II of the Acid Deposition Control Program take effect. Further research is needed to determine whether there is a net environmental or health benefit from the large early emission reductions spurred by the banking provision, compared to a scenario with no early reductions but full achievement of the cap in the year 2000 .

\section{Electric Utilities}

As of 1995, electric utilities reduced their $\mathrm{SO}_{2}$ emissions significantly beyond the level required; total utility $\mathrm{SO}_{2}$ emissions dropped to 11.9 million tons, which was $31 \%$ below 1980 levels and within 3 million tons of the 8.95-million-ton cap.
In 1995, the first year of compliance, the allowable level of $\mathrm{SO}_{2}$ emissions from Phase 1 electric utilities was 8.7 million tons. However, only 5.3 million tons of $\mathrm{SO}_{2}$ were emitted, which was 3.4 million tons (39\%) lower than the level required (Figure 5) (see footnote). These unprecedented early emission reductions are largely believed to be a direct result of two key features of the banking provision in Title IV. First, Title IV provides a performance-based, rather than a technology-based, standard for reducing pollution. It gives each unit a performance target in the form of an emission allowance allocation or budget, but does not require the unit to use a specific technology to reach this target. Second, the banking provision of the allowance trading system gives companies the flexibility to control emissions beyond their performance standards, in effect saving part of their emission budget for future years. Many companies have adopted this strategy of overcontrolling their emissions during Phase I and are banking their extra allowances to meet the more stringent requirements of Phase II. 15

As shown in Figure 6 on pages 26 and $27, \mathrm{SO}_{2}$ emissions have decreased from 1980 levels in most of the 21 states containing Phase I units. ${ }^{26}$ In 1995, Ohio, Missouri, Indiana, Illinois, and Tennessee had the largest overall decline in emissions ( 3.4 million tons) from 1980 levels. $\mathrm{SO}_{2}$ emissions increased in a few states, including Texas, North Dakota, Louisiana, and Oklahoma, which have no Phase I units; these states built new coal-fired power plants that came on-line after 1980. 
Figure 5

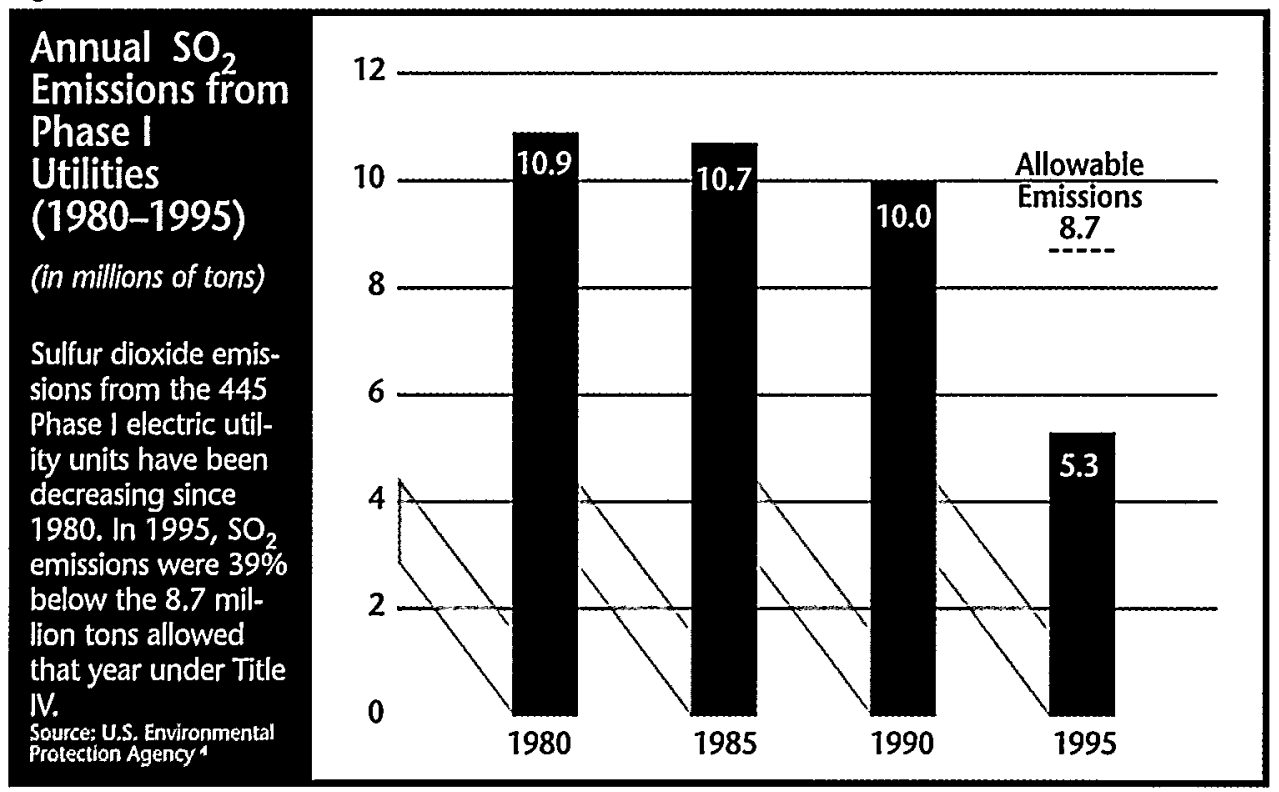

western coals more competitive in midwestern markets on a purely Btu basis (heat content), without regard to the significant difference in sulfur content. As a result, the frontier for western, low-sulfur coal has advanced steadily eastward to the disadvantage of local, highersulfur midwestern coals.

Much of the emission reductions between 1985 and 1993 may have occurred even without Title IV, as declining costs for low-sulfur coal would

There is general consensus that the large reduction of $\mathrm{SO}_{2}$ emissions in 1995 was a direct result of the Clean Air Act Amendments. A more difficult question is what led to reductions of $\mathrm{SO}_{2}$ in the early part of the 1990s. Answering this question requires estimating $\mathrm{SO}_{2}$ emission levels in the absence of Title IV. This estimation is fraught with uncertainty because it requires making difficult assumptions about how coal markets and electric utilities respond to a variety of interdependent economic and regulatory forces, and whether the efforts to pass legislation in the late 1980s had any effect on fuel supplies and purchases. Perhaps a more important aspect of this question is that it indirectly highlights the compliance flexibility inherent in Title IV, allowing electric utilities to take advantage of market forces and the changes in the relative prices of compliance options. ${ }^{10}$ Even if some of Title IV's compliance cost savings had accrued without the 1990 Amendments-because of changes in the railroad industry and low-sulfur coal markets or state acid rain regulations-these hypothetical cost savings might not have materialized under a more traditional regulatory structure (e.g., mandatory scrubbers at all utility units).

Certainly a major impact on Title IV costs and $\mathrm{SO}_{2}$ emissions was the change in the economics of choosing low-sulfur coal. Railroad deregulation during the 1980 s introduced competition into the transportation of low-sulfur coal from the Powder River Basin (Wyoming and parts of Montana) and led to large productivity improvements in rail transportation. The result has been continually lower rail rates that have made distant have made fuel switching attractive to midwestern electric utilities for purely economic reasons. ${ }^{27}$ One study estimates that the economics of coal choice explains a significantly larger share of $\mathrm{SO}_{2}$ reductions during this period than such factors as early compliance by electric utilities or state acid rain programs. ${ }^{27}$

Perhaps anticipation of impending Clean Air Act legislation in the 1980s led western low-sulfur coal producers to invest in new low-sulfur coal properties and expanded existing low-sulfur coal mines." This foresight helped them avoid upward pressure on low-sulfur coal prices in the early 1990s. On the other hand, some of this expansion of low-sulfur coal production in the West could have been spurred by the 1977 amendments to the Clean Air Act.

Anticipation of new legislation may also have spurred experimentation with boiler modification and coal-blending techniques that ultimately allowed electric utilities to burn different types of coal at lower costs than expected. ${ }^{10}$ For Phase I units that used flue gas desulfurization technologies, emissions were reduced by 2.0 million tons below their allowance allocation in 1995, while most of the remainder of the reductions were achieved by coal switching or blending. ${ }^{14}$

Ascertaining how much of an emission reduction would have happened if there had been no Title IV is a necessary step to estimate Title IV's costs and benefits. To the extent that some level of emission reductions may have occurred without the 1990 Clean Air Act 
Figure 6

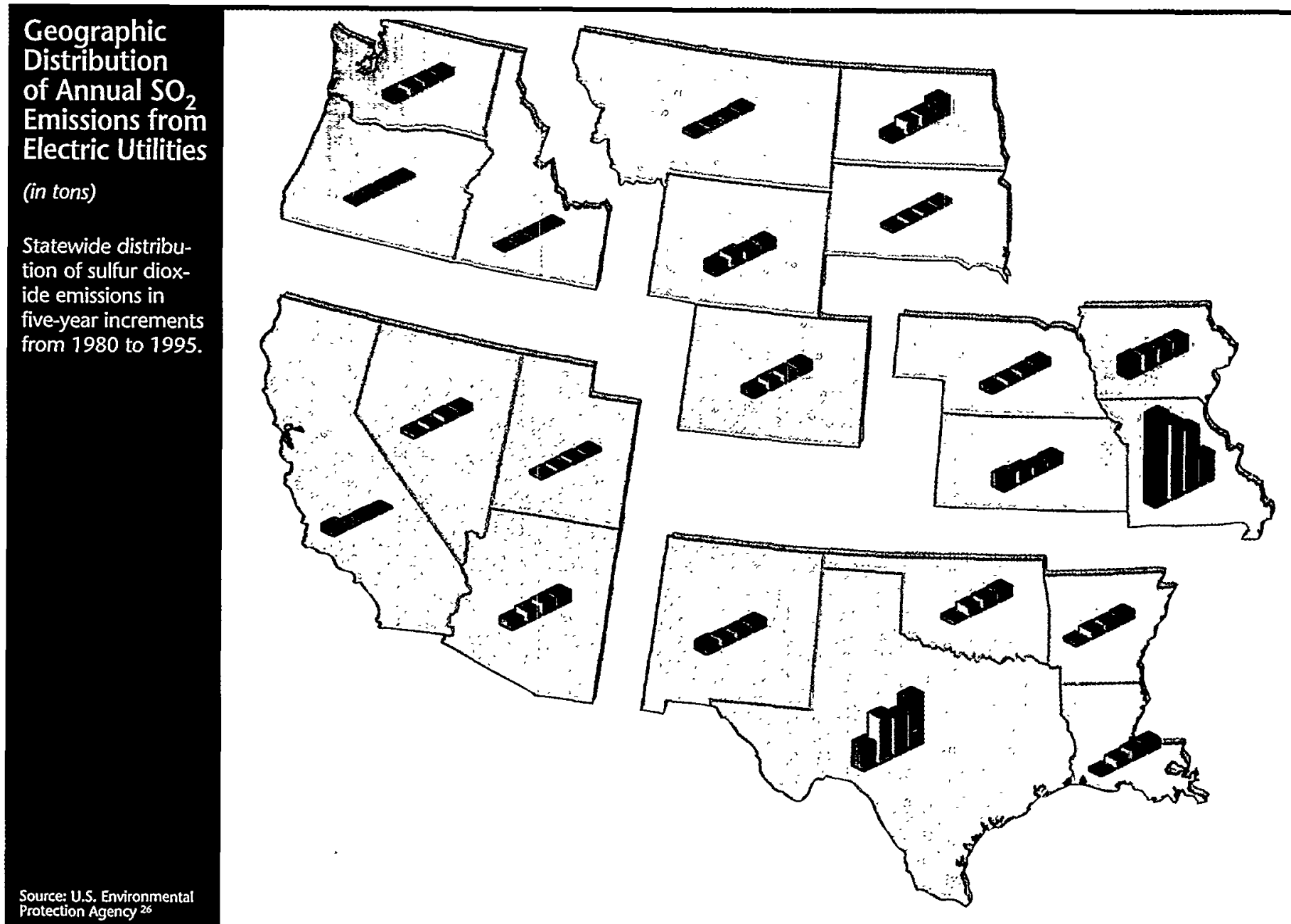

Amendments, cost estimates should be revised downward to reflect "no cost" reductions. Benefits directly attributable to Title IV would also be less.

Table 4 provides estimates from a variety of studies of 1995 Phase I electric utility $\mathrm{SO}_{2}$ emission reductions that are directly attributable to Title IV, as opposed to those that would have occurred even without Title IV. Most of these estimates were developed before the end of 1995, but this table provides a snapshot of the range of projections that were made regarding Title IV's effectiveness in reducing emissions. Actual data are now available for some of the modeling variables-such as actual electricity demand for 1995-

Table 4

\section{Projected $\mathrm{SO}_{2}$ Emission Reductions Attributable to Title IV (in millions of tons)}

\begin{tabular}{lccccccc} 
Title IV Scenarios & $\begin{array}{c}\text { NAPAP } \\
1990\end{array}$ & $\begin{array}{c}\text { ICF 1989 } \\
\text { (constrained) }\end{array}$ & $\begin{array}{c}\text { ICF 1989 } \\
\text { (flexible) }\end{array}$ & $\begin{array}{c}\text { ICF 1990 } \\
\text { (flexible) }\end{array}$ & $\begin{array}{c}\text { EPRI } \\
1993\end{array}$ & $\begin{array}{c}\text { EPRI } \\
1995\end{array}$ & $\begin{array}{c}\text { MIT } \\
1997\end{array}$ \\
\hline Emissions without Title IV & 19.31 & 16.64 & 16.64 & 16.64 & 16.29 & 14.65 & 15.70 \\
Emissions with Title IV & 13.62 & 13.08 & 13.32 & 13.52 & 11.93 & 11.47 & 12.02 \\
\hline Title IV Emission Reductions & 5.69 & 3.56 & 3.32 & 3.12 & 4.36 & 3.18 & 3.68
\end{tabular}




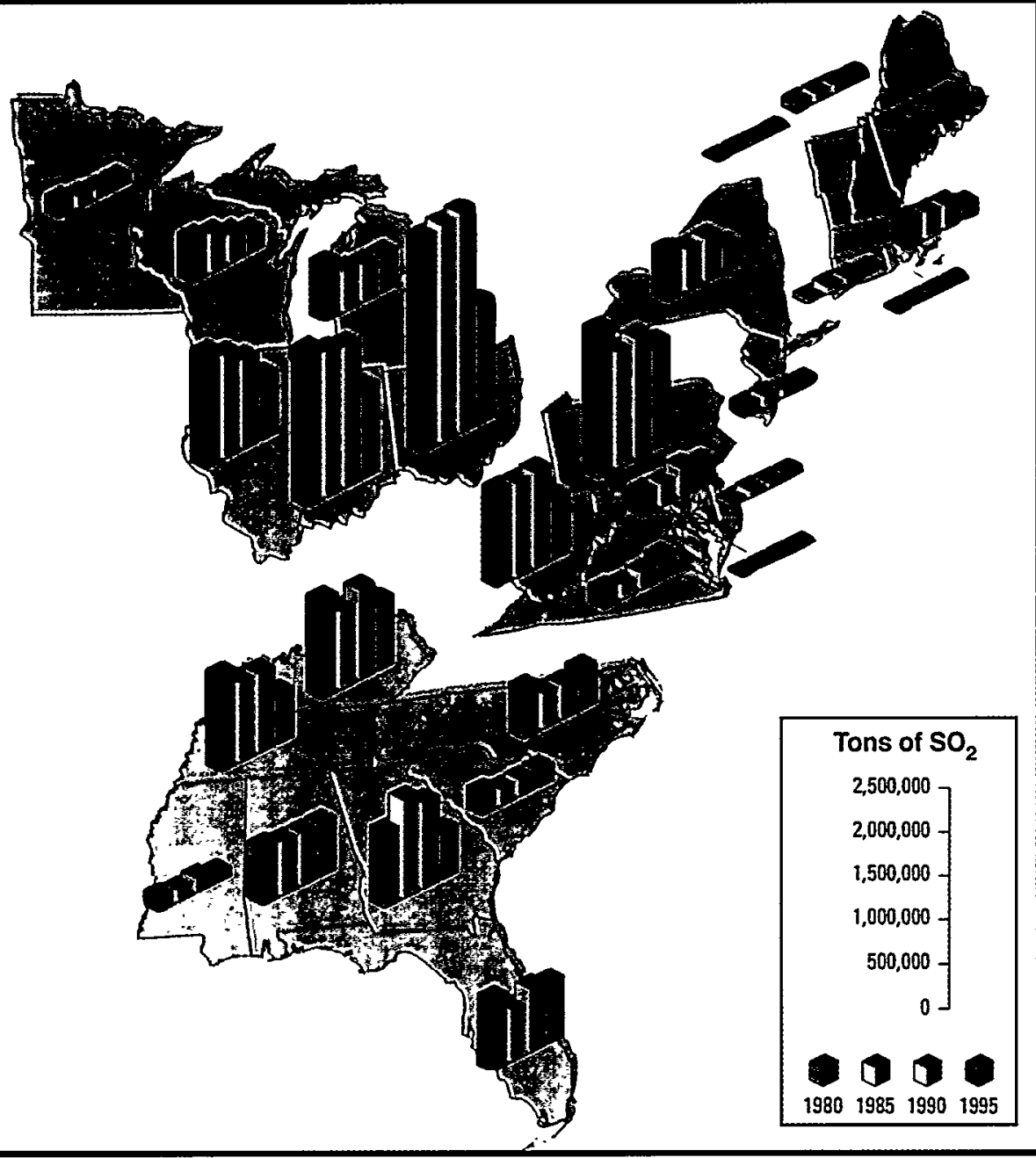

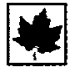

For every predicted scenario,

there were substantial reductions in $\mathrm{SO}_{2}$ between 1990 and 1995, when compared with Title IV benchmark projections.

An estimated 8.4 million tons of $\mathrm{SO}_{2}$ were emitted from all other sourcesindustrial, residential, commercial, and transportation-in 1980. The largest contributors were industrial fuel combustion and metals processing, which contributed about 2.9 and 1.8 million tons of $\mathrm{SO}_{2}$, respectively. NAPAP estimated 1985 emissions from nonutility sources to be $6.1 \mathrm{mil}$ lion tons, with 3.3 million tons from fossil fuel combustion. ${ }^{28}$ Emissions from nonutility sources were estimated to be 5.7 million tons in 1990 , with industrial combustion making up 3.1 million tons and metals processing 663,000 tons. In 1995, emissions from these nonutility source categories were on the order of 6.3 million tons; industrial combustion accounted for 3.0 million tons; and metals processing accounted for 692,000 tons. that were only estimated for most of these studies. Therefore, the emission rates assumed in the "without Title IV" case are now the key variables in estimating the 1995 emission reductions attributable to Title IV. By varying the emission rate, a range of estimates can be developed that differs slightly from those in Table 4 but benefits from our actual knowledge of utilization in 1995. This new range has 3.12 million tons as the lower bound (assumes none of the reduction in emission rates for 1985-1995 is attributable to Title IV) and 5.69 million tons as the upper bound (assumes all of the reduction in emission rates is attributable to Title IV). ${ }^{15}$

\section{Other Sources}

Total $\mathrm{SO}_{2}$ emissions from nonutility sources were 2.1 million tons below 1980 levels, which exceeds the Title IV reduction goal of 1.5 million tons.

\section{$\mathrm{NO}_{\mathrm{X}}$ Emissions}

In 1980, the baseline year for Title IV, total emissions from all sources of man-made $\mathrm{NO}_{\mathrm{x}}$ were about 23.3 million tons. By 1995, total $\mathrm{NO}_{\mathrm{x}}$ emissions amounted to about 21.8 million tons (Figure 7). The 1990 Clean Air Act Amendments require $\mathrm{NO}_{\mathrm{x}}$ emissions from coal-fired boilers to be reduced by 2 million tons below 1980 levels by 2010; there is no national cap for $\mathrm{NO}_{\mathrm{X}}$ emissions.

\section{Electric Utilities}

Annual $\mathrm{NO}_{\mathrm{x}}$ emissions from electric utilities have decreased by 800,000 tons from 1980 levels.

Only a modest decrease in $\mathrm{NO}_{\mathrm{x}}$ emissions from electric utilities has occurred between 1980 and 1995. The Phase I requirements for $\mathrm{NO}_{X}$ reductions became effective after this time period in January $1996 . \mathrm{NO}_{\mathrm{X}}$ emis- 


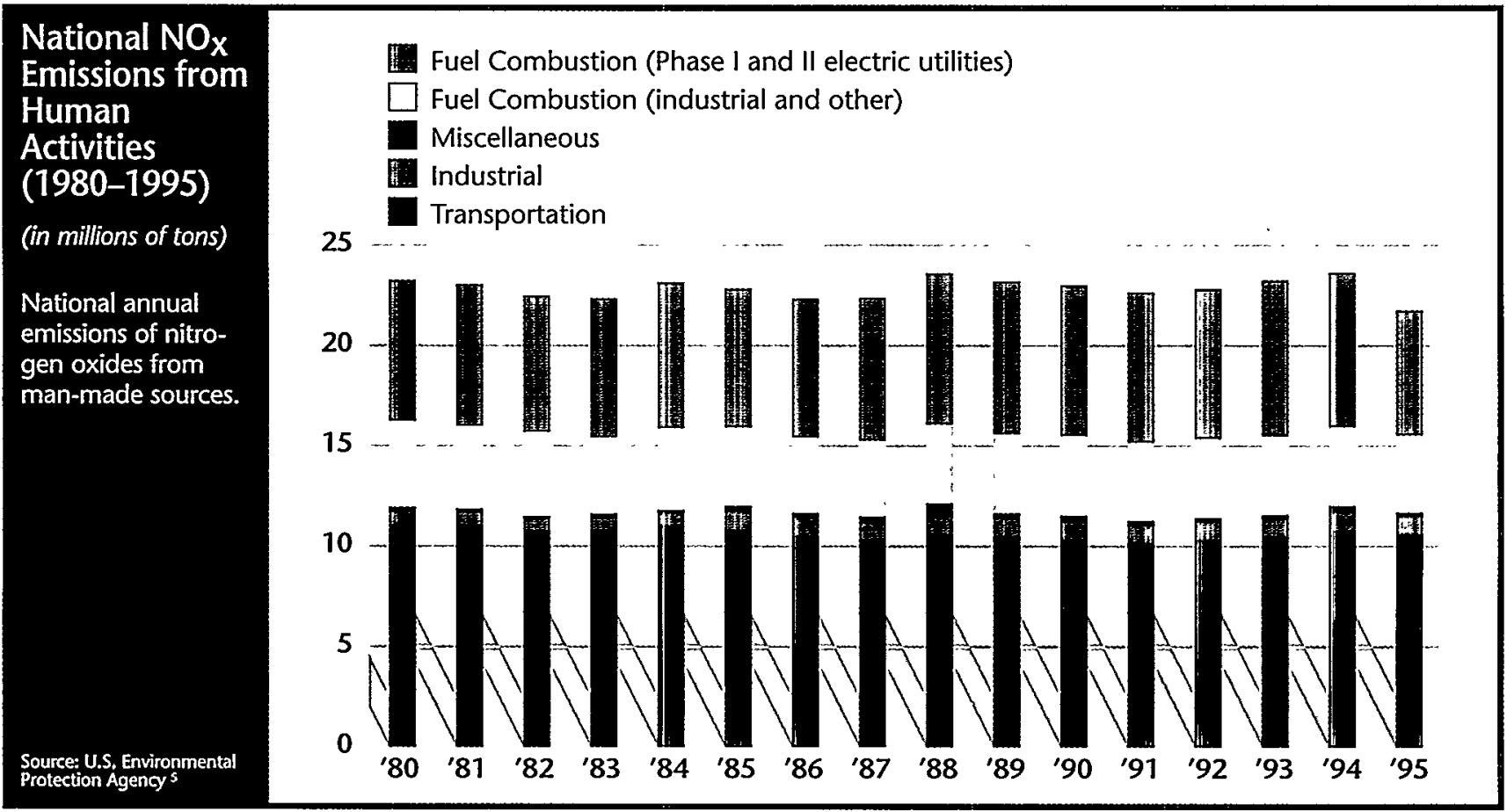

sions from utilities were about 6.2 million tons in 1995 , or approximately $11 \%$ below 1980 levels and 17\% below 1990 levels (see footnote). This recorded decline in emissions is thought to be due to several factors, including early installation of Title IV $\mathrm{NO}_{\mathrm{x}}$ controls at some facilities, installation of $\mathrm{NO}_{x}$ controls in the northeastern United States to meet Reasonably Available Control Technology standards under Title I, and a change in $\mathrm{NO}_{x}$ monitoring and estimation techniques between 1994 and 1995.

\section{Other Sources}

All other sources of $\mathrm{NO}_{\mathrm{x}}$ emissions were estimated to be about 16.3 million tons in 1980 . The largest nonutility contributors were on-road vehicles and industrial fuel combustion, contributing about 8.6 and 3.6 million tons of $\mathrm{NO}_{\mathrm{X}}$, respectively. In 1995, emissions from all nonutility source categories were estimated to be about 15.5 million tons, with 7.6 million tons coming from on-road vehicles and 3.1 million tons from industrial combustion.

\section{How have air concentrations been affected by these emission reductions?}

Given the reduction in emissions discussed above, the question becomes whether there was a sequential reduction in the concentration of the pollutants in the air. This is the next step in the causal chain leading to acid deposition. Figure 8 depicts the processes related to acid deposition and its effects.

\section{Sulfur}

Emission reductions have caused a decrease in air concentrations of $\mathrm{SO}_{2}$. This decrease is most evident in the Northeast where emissions are most concentrated, but apparently extends across the entire region east of the Mississippi River.

Reductions in concentrations of particulate sulfate are also widespread, but are less striking. At a few locations, particulate sulfate concentrations

In 1996, the first year of implementation, Phase I utility units reduced emissions by $33 \%$ (340,000 tons) below 1990 levels. These units demonstrated an average of $18 \%$ overcompliance with required emission rate levels. 
Figure 8

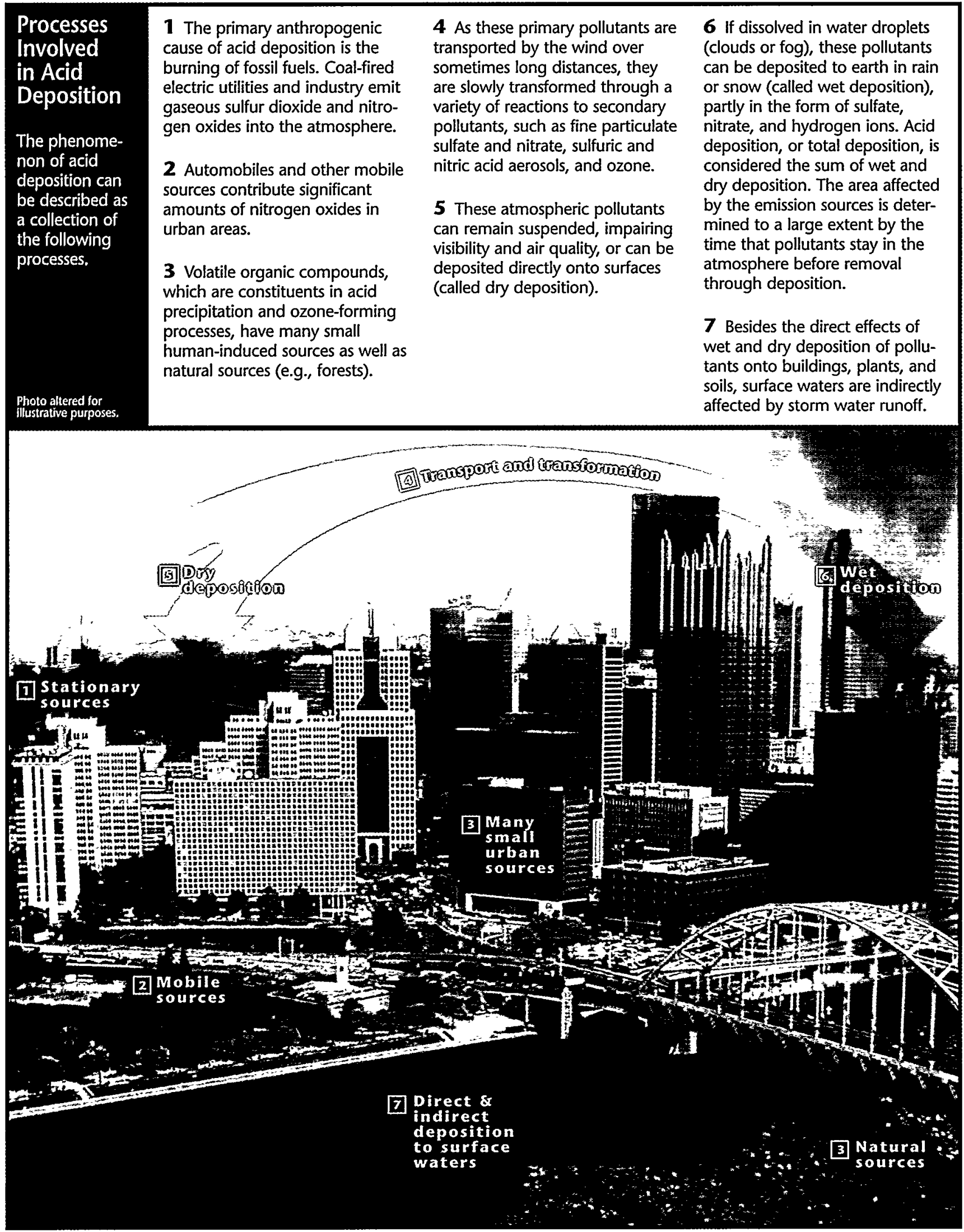




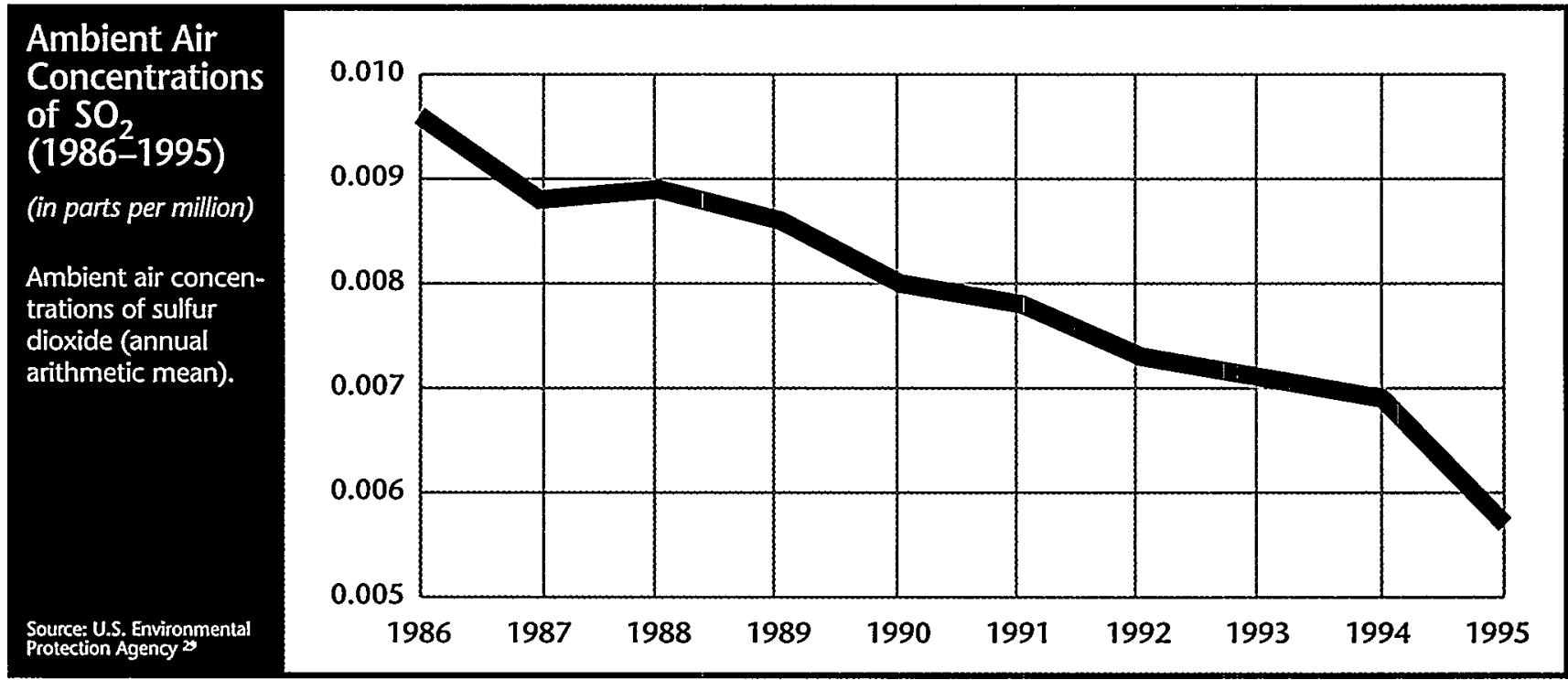

appear to have increased when decreases would have been expected; the reasons remain obscure, and the data record is too short to provide insight to this apparent inconsistency.

Urban monitoring data reveal a steady decrease in ambient air concentrations of $\mathrm{SO}_{2}$ over the approximately 10 years prior to implementation of Phase I and a more pronounced decrease the year following implementation (Figure 9). These data were obtained from observations of air quality at 473 sites across the United States. The sites are generally located in urban areas as part of a regulatory network used to monitor six pollutants (including $\mathrm{SO}_{2}$ and $\mathrm{NO}_{2}$ ) covered by the National Ambient Air Quality Standards under Title I of the Clean Air Act. Between 1986 and 1995, national $\mathrm{SO}_{2}$ concentrations decreased $37 \%$; $\mathrm{SO}_{2}$ emissions decreased $18 \%$. Between 1994 and 1995, national $\mathrm{SO}_{2}$ concentrations decreased $17 \%$, while emissions decreased $13 \% .29$ How these decreases in concentrations are readily associated with emission reductions is not yet known and will require additional years of data to draw a more definitive conclusion.

What is known is that although air pollutant concentrations can only be reduced over time by decreasing pollutant emissions, changes in pollutant concentrations do not always track changes in pollutant emissions resulting from human activities. There are four primary reasons for this observed difference. First, most monitors are in urban areas and track urban emissions, which are mostly from mobile sources, while most stationary sources, such as power plants, are located in rural areas. Second, emissions for some pollutants are calculated or measured in a form (e.g., $\mathrm{NO}_{\mathrm{X}}$ ) different from that of the primary air pollutant (e.g., $\mathrm{NO}_{2}$ ). Third, chemical reactions occur in the atmosphere during the time it takes the pollutants to travel from its source to the monitoring station. Fourth, meteorological conditions often control the formation and buildup of pollutants in the ambient air. ${ }^{29}$

Regional monitoring data provide evidence that emission reductions are having a positive effect on reducing air concentrations. The air concentration records are obtained from sampling stations operated by the two major monitoring networks addressing dry deposition and concentrations in surface air-the EPA Clean Air Status and Trends Network (CASTNet) and the NOAA Atmospheric Integrated Research Monitoring Network (AIRMON). Both of these networks are composed of sites almost entirely in nonurban areas and are not part of the aforementioned regulatory network (see the Monitoring Networks text box on page 35). The reductions are most evident in $\mathrm{SO}_{2}$ concentration data obtained in the region most affected by acid deposition-the corridor downwind of the ohio River Valley and its surrounding area, mainly the northeastern United States where emissions are most concentrated. However, the length of record is currently too short to report with confidence that the effects are as widespread or as large as has been predicted. Data are still being collected and analyzed. The present conclusions represent only a preliminary interpretation of a complicated data record in which year-to-year variability is a strong factor. 
Figure 10 shows long-term records of sulfur dioxide, sulfate, and nitric acid vapor concentrations in surface air derived at the AIRMON-dry site near State College, Pennsylvania. The Pennsylvania record is used here as an example because it appears to be representative of the Northeast region as a whole (for sulfur species but not necessarily for nitrogen, as will be discussed later) and also because there are nearby long-term wet deposition records suitable for comparison against dry deposition data. The strong seasonality of both the $\mathrm{SO}_{2}$ and the sulfate concentrations is clearly evident, though there are significant phase differences in the timing of the annual peaks. $\mathrm{SO}_{2}$ concentrations peak during the winter, while sulfate peaks regularly during the summer.

The time series of Figure 10 shows that 1995 does indicate a downward trend in $\mathrm{SO}_{2}$ concentrations. However, with the year-to-year variation (due to meteorology and other factors) in the annual behavior, a clear statement about how much the emission reductions of 1995 have influenced air concentrations is not easily derived. More data are required before the effects of the year-toyear variability can be taken into account. For the present, the 1989-1995 reduction in the total sulfur present in airborne $\mathrm{SO}_{2}$ and particulate sulfate derived from the data in Figure 10 for the State College site amounts to $23 \%$. An independent examination of CASTNet data ${ }^{30}$ results in much the same conclusion.

A third network, the Interagency Monitoring of Protected Visual Environments (IMPROVE) network, also offers useful data on mountain-top environments where many sensitive ecosystems exist, although the data are not adjusted for meteorology. The three networks (CASTNet, AIRMoN-dry, and IMPROVE) operate with different sampling systems and protocols, reflecting their different purposes and design criteria. An analysis of 1984-1994 data at the two eastern sites in the IMPROVE network is displayed in Figure 11.31,32 This analysis reveals an upward trend in sulfate concentrations in summer at the site in the Shenandoah National Park. The data from the Great Smoky Mountains site do not reveal an increase as great as that from Shenandoah, and there is no trend evident in the winter data.

A spatial picture of the extent of the 1989-1995 reduction in total sulfur concentrations is derived from the CASTNet data set, which did consider meteorological factors in its analysis (Figure 12). Statistical models of the observed concentration data at each site were developed to provide emission-related trend estimates of total ambient sulfur. Nonlinear models were used because of the nonlinear trend in emissions and the nonlinear dependence on meteorological variables that many of the CASTNet variables exhibit. In addition, another statistical approach was applied to the CASTNet data set to identify groupings of sites that display similar temporal behavior and climatology. The extent to which these sites are representative of these broad regional scales remains an open research issue. Algebraic means of the site data were used to calculate the regional estimates. Annual averages were used to provide a measure of percentage change over the entire monitoring period (1989-1995). It is clear that the reduction is a truly regional phenomenon, with annual average decreases in concentrations of more than $30 \%$ at many locations in the eastern United States. It is tempting to point to the emission reductions of the same period and to claim them as the sole reason for the lower concentrations. While it is certain that the emission reductions did improve regional air quality, it is not yet clear how closely the two correspond. It is evident that meteorology-if not regional climatology-needs to be considered before final conclusions are reached about how well air concentrations track emission reductions. Regardless of the year-to-year variability, the CASTNet data indicate that the 1995 reduction in airborne total sulfur (relative to 1989) is truly widespread.

\section{Nitrogen}

There are many nitrogen compounds in air resulting from the initial $\mathrm{NO}_{\mathrm{x}}$ emissions that are susceptible to control. The chemical end products of these emissions are nitric acid vapor and various nitrates. From the perspective of acid deposition, the key chemical species is nitric acid vapor, of which the dry deposition programs now have an extensive record.

For nitric acid vapor in air, regional concentrations show evidence of a similarly widespread reduction as for sulfur species, although of markedly smaller magnitude and with some variation among sites. Control of $\mathrm{NO}_{x}$ emissions under Title IV was not required until 1996.

In general, nitric acid concentrations display a less uniform seasonality than sulfur concentrations, and tend to maximize in the summer when the related chemical reactions are most vigorous. Figure 10 shows that nitric acid concentrations were slowly increasing at the Pennsylvania site until 1993. However, this upward trend is not representative of other stations in 
Figure 10

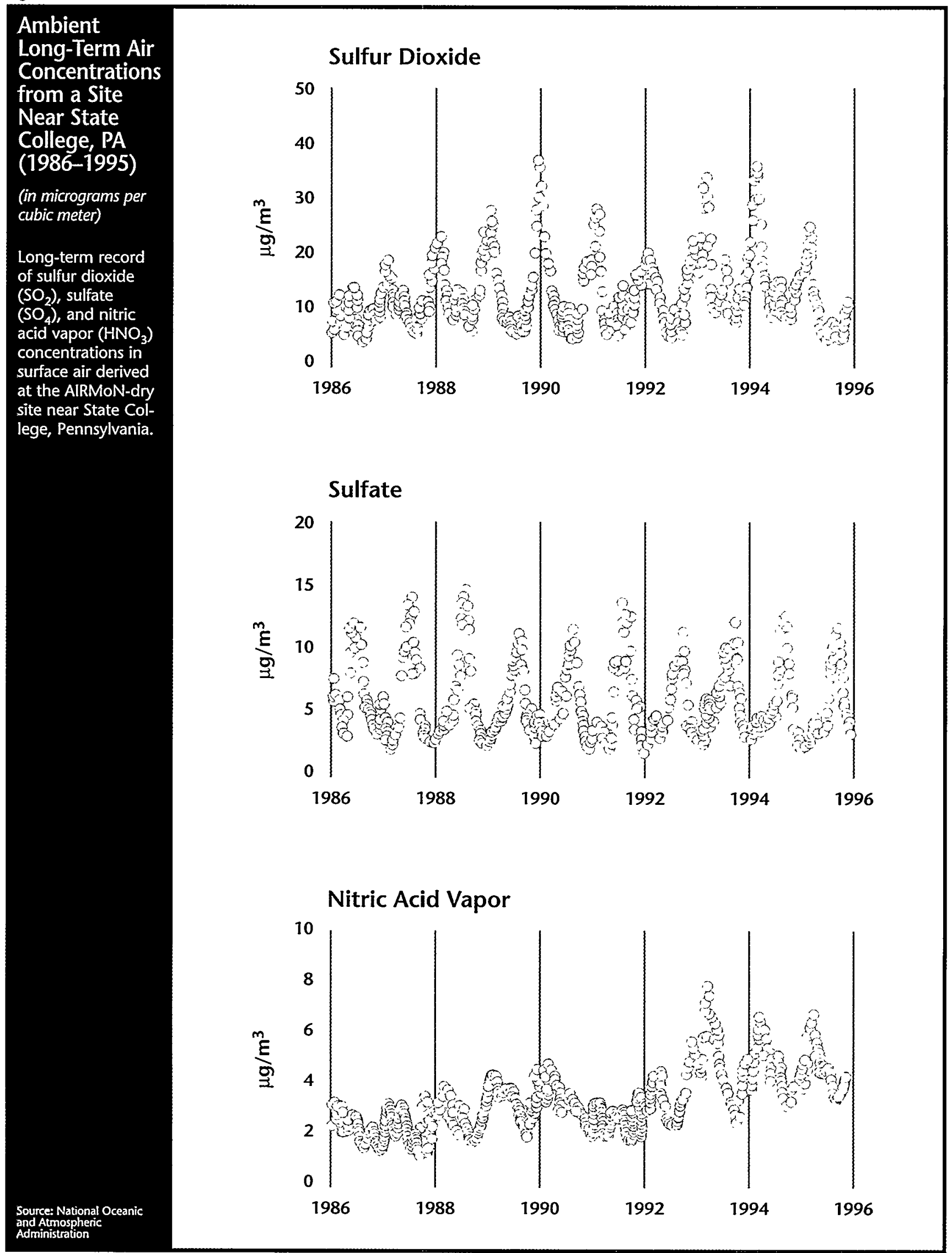


Figure 11

\section{Seasonal}

Trends in

Fine-Particle

Sulfur

(in micrograms per cubic meter)

Mean sulfate con-

centrations

increased in the

summer at the

Shenandoah site, as

well as at the Great

Smoky Mountains

site, although not as

much. The summer

data for a compos-

ite of 10 western

IMPROVE sites

showed no trend.

No trend was

detected in the win-

ter data for any of

the three areas.

the three areas.
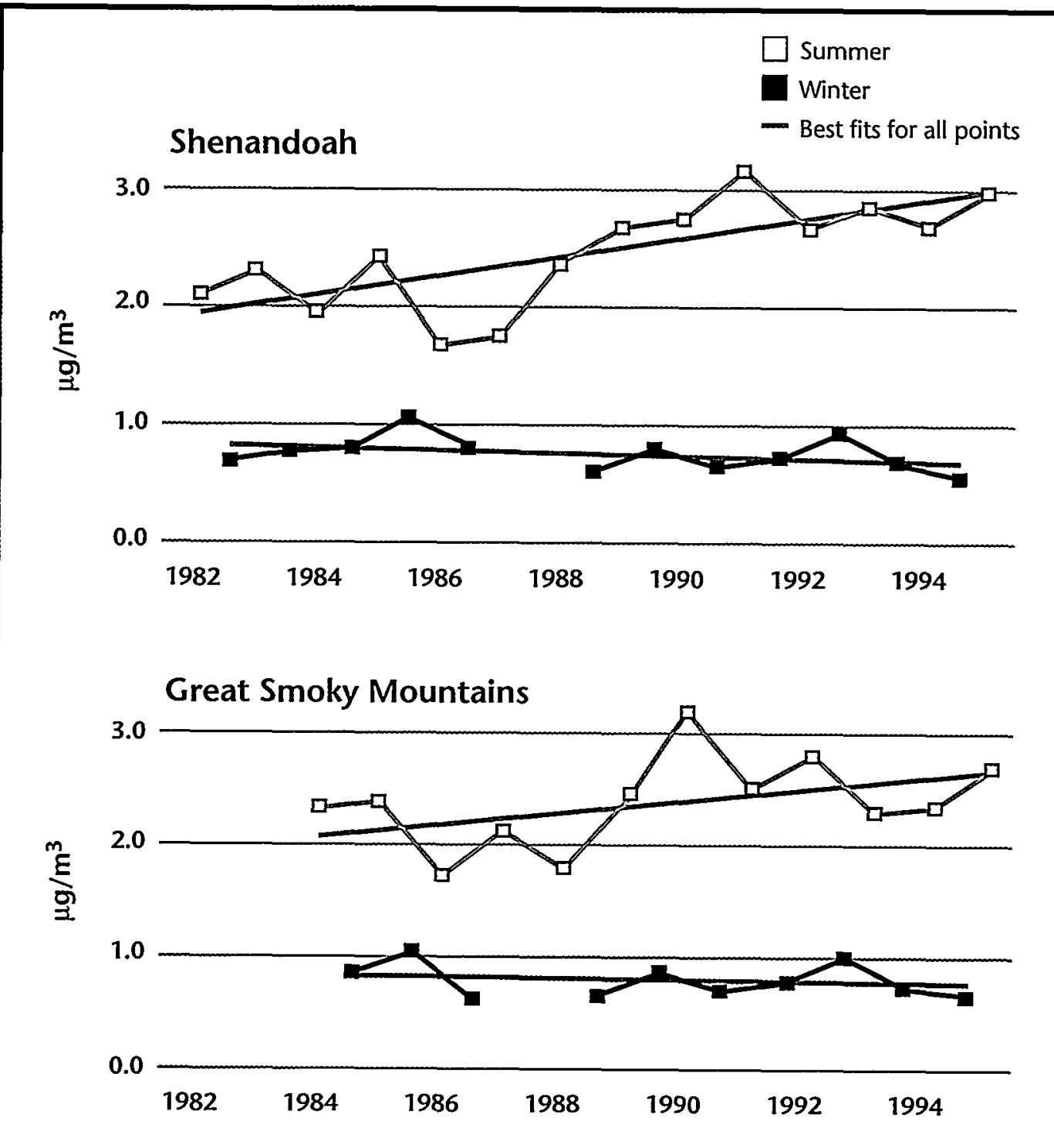

Western Composite

0.4

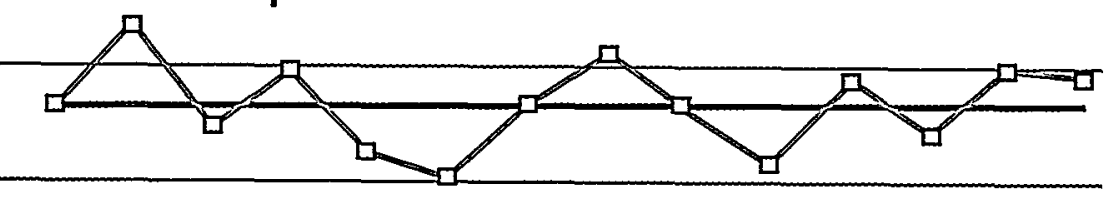

0.3

ํㅗㄹ

0.1

0.0

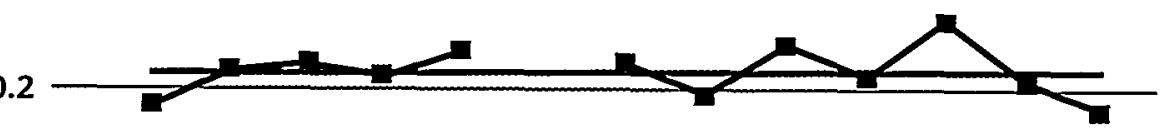

\begin{tabular}{lllllll}
\hline 1982 & 1984 & 1986 & 1988 & 1990 & 1992 & 1994
\end{tabular}




\section{Decreases in Ambient Air \\ Concentrations of Total Sulfur (1989-1995)}

Percent reduction in total sulfur concentrations (derived from CASTNet data) for three regions based on a model that estimates the yearly trend of ambient air concentrations adjusted for the effects of meteorology and seasonal cycles.

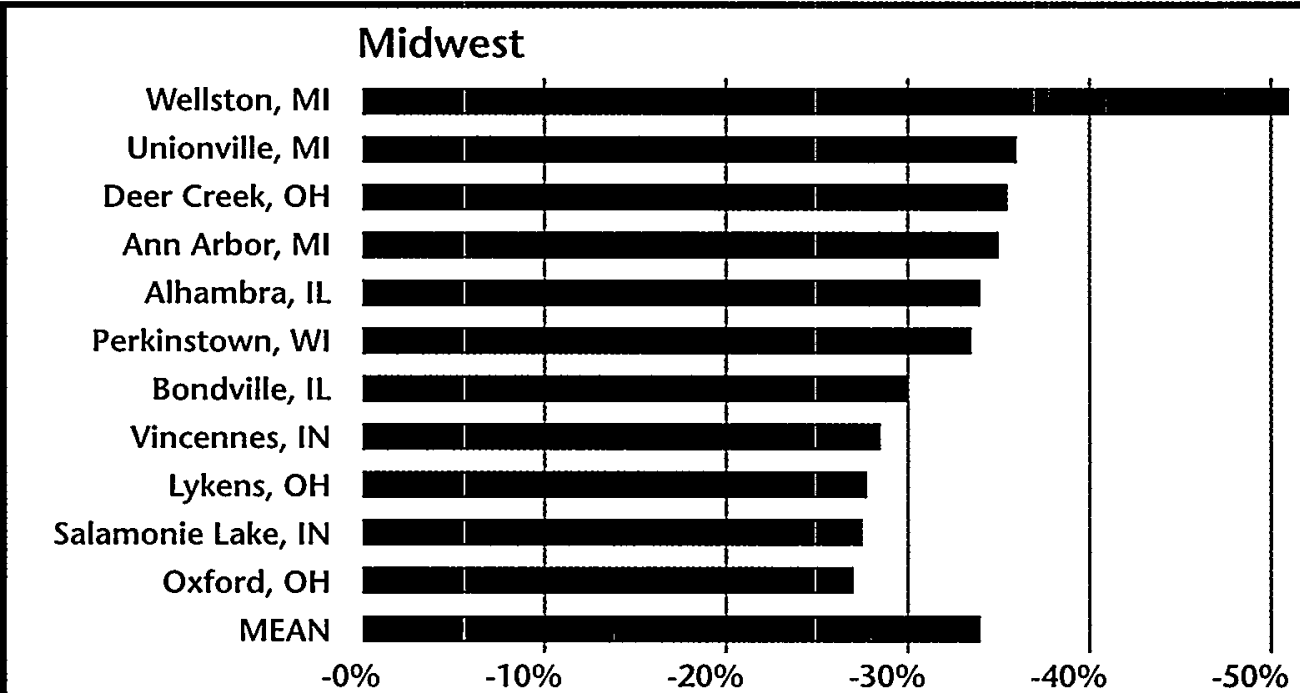

Northeast

Ashland, ME

Woodstock, NH

Laurel Hill, PA

Kane Forest, PA

Conn. Hill, NY

Goddard, PA

Wash. Crossing, NJ

Beltsville, MD

Penn State, PA

Arendtsville, PA

MEAN

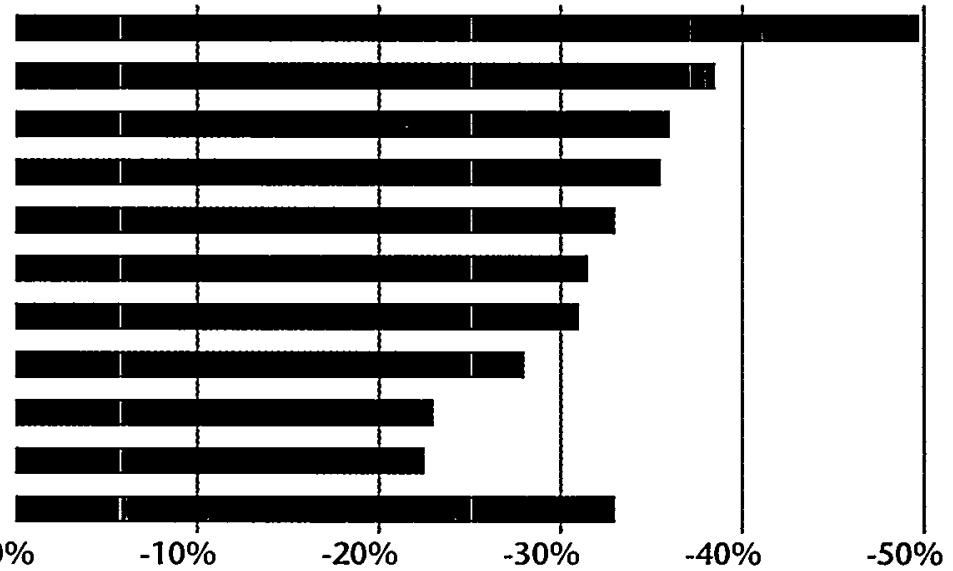

South

Parsons, WV

Caddo Valley, AR

Sand Mtn., AL

Cedar Creek, WV

Sumatra, FL

Coweeta, NC

Prince Edward, VA

Shenandoah, VA

Georgia Sta., GA

Edgar Evins, TN

Coffeeville, MS

Cranberry, NC

Speedwell, TN

Horton Sta., VA

MEAN

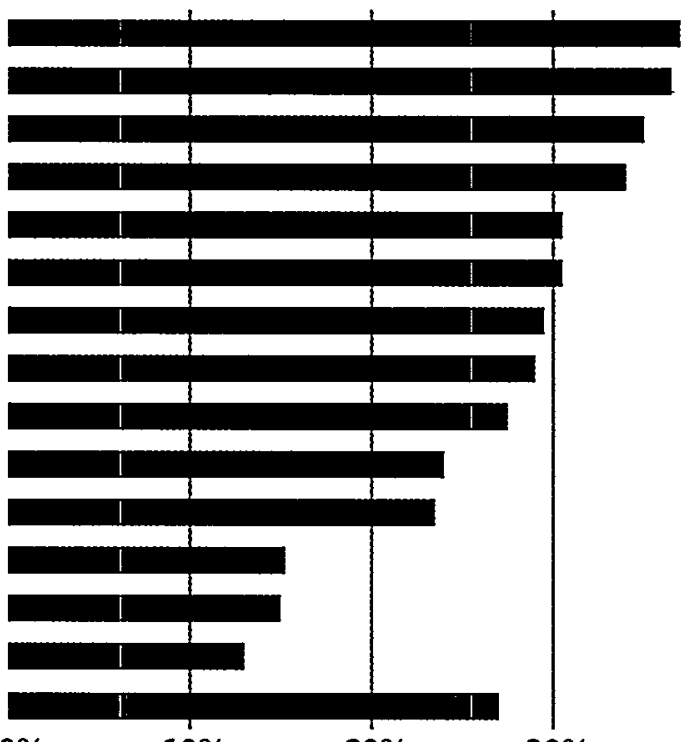


the Northeast, which show slight decreases. Any increase in airborne nitric acid concentrations is of concern because of the corresponding increase in deposition. It is not clear whether the cause is associated with changes in the use of nitrogenous fertilizers in the area, with difficulties in measuring nitric acid vapor, or with some other reason not associated with upwind point-source emissions. As in the case of sulfur, a longer record is needed before it is possible to quantify the changes associated with Title IV of the 1990 Clean Air Act Amendments and its emission reductions.

\section{How have deposition rates been affected by the emission reductions?}

\section{Wet Deposition}

Wet deposition monitoring results clearly and objectively indicate a recent reduction in acid deposition in the eastern United States. In 1995, the concentration of sulfate in precipitation in the East was 10-25\% lower than during 1983-1994. This may have been due wholly or in part to the emission reductions of Phase I.

A critical step in assessing the effectiveness of emission reductions is to evaluate spatial and temporal trends in sulfate, nitrate, and hydrogen ion (acidity) concentrations in precipitation (rain and snow). The repercussions of Phase I emission reductions on precipitation chemistry were explored by determining the significance of the deviations of the 1995 bimonthly observations from estimates of 1995 precipitation chemistry based on more than a decade of pre-1995 observations. A seasonal trend model was developed to explain the historical trend of deposition monitoring data from 1983 through 1994.33 The model was used to extrapolate forward one year to estimate the expected precipitation chemistry in 1995. Allowing for early compliance by some utilities, the 1983-1994 period could be considered prior to Title IV, and 1995

\section{Monitoring Networks}

A

\section{$\because$}

Ambient ấr concentration data are collected both urban and rural settings the intensive ambient air monitoring networks operated by the EPA and states the Nation la Air Monitoring System/state and

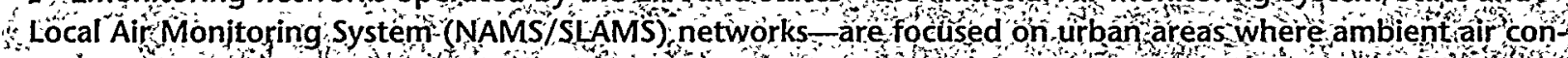
centrations mânly reflect local emissions Ambient air concentrations are also measured in rural areas where

"they are a necessary part of díy deposition networks This network was established to monitor the six pollu-

tants covered by the National Ambient Air Quality Standards.

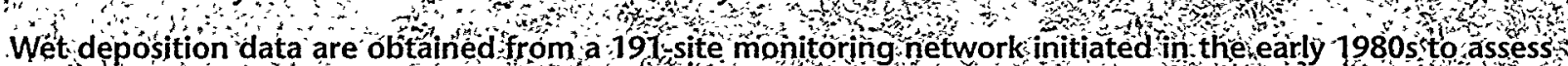
the magnitude of the acid rain problem and to determite spatial and temporal trends in at to spheriechem

istryand deposition. The National Átmospheric Deposition Program/National Trend S Networki (NADP/NTN) is supported by more than 100 organizations inclioding federal, state and local government agencies univer sities; and industry it is the only long-term depostion monitoring program in the united states with natonal coverage (Figure 73 ). NADP/NTN operates with two levels of sampling intensity alarge primary array of of tine weekly sampling, and as smalle subnetwork of more intensive research sites with daily sampling he subnetwork is part of the NOAA Atmospheric lntegrated Research Monitoring Network (AIRMoN wet)

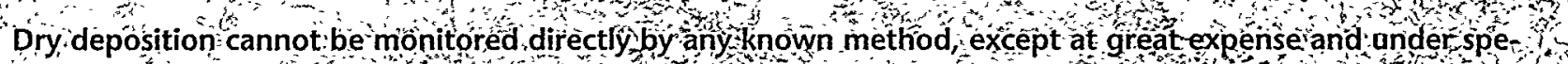
cial circumstances. In existing monitoring operations dry deposition is not directly measured Instead it is inferred úsing directly measured air concentration and model estimates of depositon velocity from which the dry deposition rates are evaluated as the product of deposition velocity and aar concentrations Two net

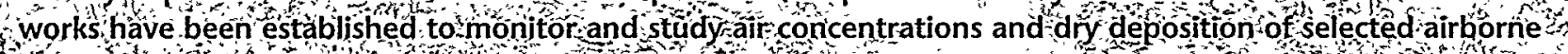
acidifying chemicals and their precursors AIRMON-dry and CASTNet. CASTNethas boad coverag proyiding information across an array of spatially distributed sites it is also used for mode deveilopment and testing.

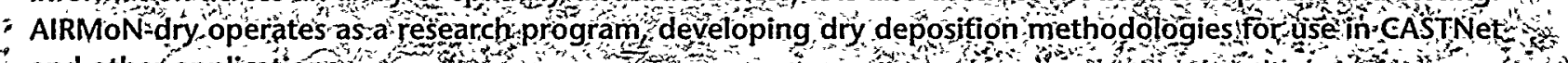
and other applications 
Figure 13

\section{NADP/NTN Wet Deposition Monitoring Sites \\ The National \\ Atmospheric Depo- \\ sition Program/ \\ National Trends \\ Network (NADP/NIN) \\ is the only long- \\ term wet deposition \\ monitoring network \\ in the United States \\ with national cover- \\ age. The network is \\ supported by fed- \\ eral, state, and local \\ agencies; universi- \\ ties; and the private sector. \\ Source: National

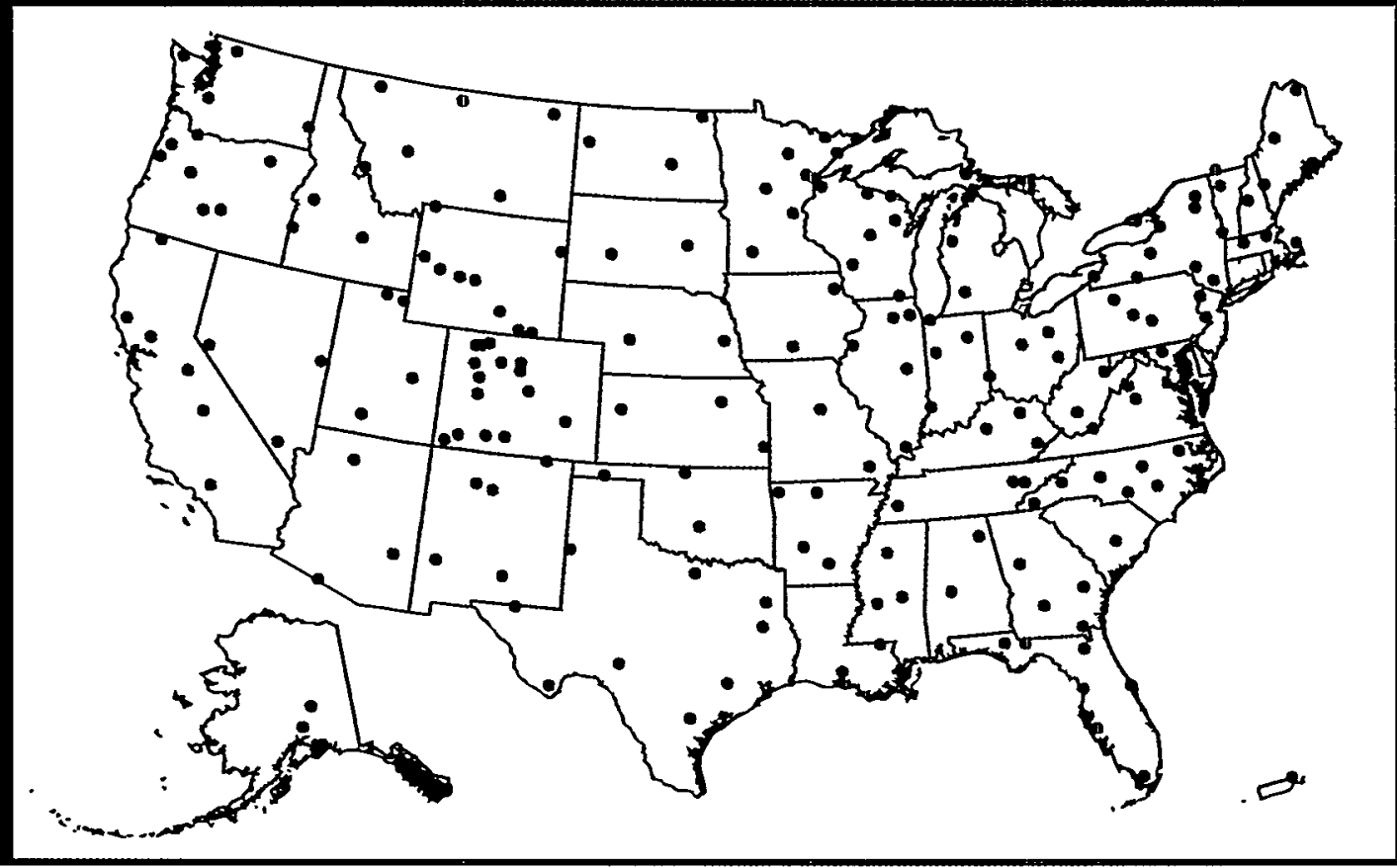

could be considered to be under Title IV. In effect, if all other factors were equal, then the difference between the 1995 observations and the 1995 estimate is the difference in precipitation chemistry between Title IV and no Title IV, respectively. Results indicated that the observed 1995 chemistry data were different from the estimated chemistry at deposition monitoring sites located in the eastern United States.

Analysis of the 1995 wet deposition monitoring data demonstrates that the 1995 reduction in $\mathrm{SO}_{2}$ emissions in the midwestern and northeastern United States resulted in a substantial reduction of the acidity (as represented by hydrogen ion concentration) and sulfate concentration of precipitation in those regions (see text box on Monitoring Networks). Figure 14 displays changes in precipitation chemistry over the eastern United States for $1995 .{ }^{34}$ The maps illustrate the departures of observed sulfate, nitrate, and hydrogen ion concentrations (in percent) from the estimated seasonal trends for 1995. This type of analysis is used to assess the changes in wet deposition that occurred in 1995 due to emissions changes in 1995. Reductions occurred in the Ohio River Valley region where many of the Title IV Phase I units are located, as well as to the east of this region-across the Mid-Atlantic region and north through Maine. The spatial pattern of hydrogen ion decreases in the East correlated well with the pattern of sulfate decreases, although the magnitude of the hydrogen ion concen- tration and percentage decreases was even larger than the sulfate decreases.

Observed sulfate and hydrogen ion concentrations in 1995 were $89 \%$ and $79 \%$ of the estimated concentrations for northeastern and southeastern sites, respectively. Overall, measured sulfate concentrations in the eastern states were about $10 \%$ less than estimates and as much as $25 \%$ less in areas in the Upper Northeast, Mid-Atlantic, and Ohio Valley. In contrast, at sites west of the Mississippi River, 1995 sulfate concentrations averaged higher than the estimates. These sites are upwind of virtually all of the Phase 1 units and therefore did not benefit from those units' emission reductions.

Unlike sulfate and hydrogen ion concentrations, nitrate concentrations in 1995 were greater than estimated concentrations at most of the sites in the eastern and western regions of the country. This is not unexpected, since implementation of Title IV $\mathrm{NO}_{\mathrm{x}}$ reductions only began in January 1996. Approximately $61 \%$ of the eastern sites and $57 \%$ of the western sites recorded higher nitrate concentrations in 1995 than estimated. Nitrate concentrations in 1995 were about $5 \%$ greater than the estimates in the eastern part of the country (Figure 14), and about $4 \%$ greater in the western part. Unlike sulfate concentrations, there was no evidence of sharp decreases in nitrate concentrations recorded in the Northeast. 


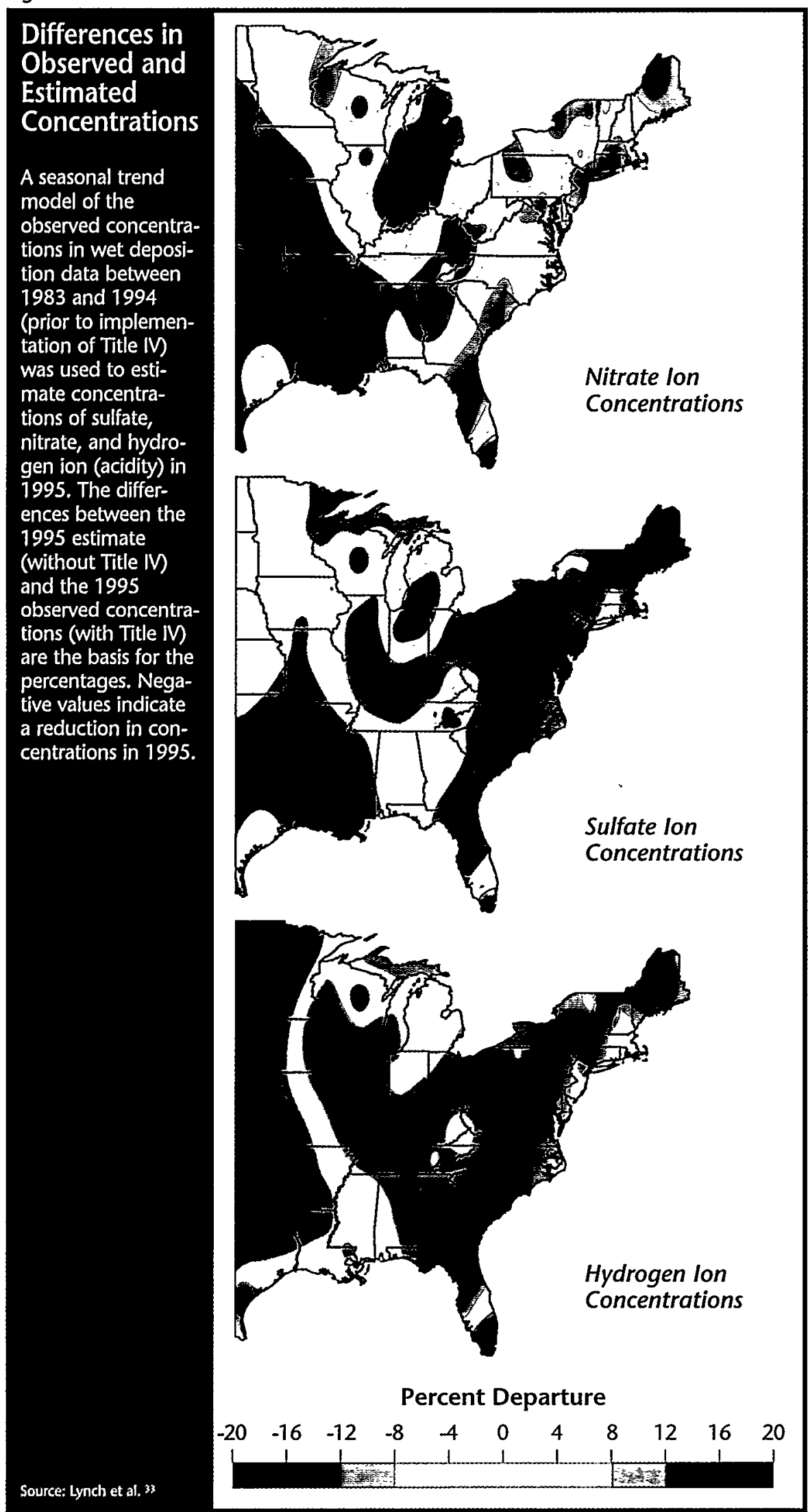

Departures from the longterm average precipitation amount (1983-1994) cannot by themselves explain the observed decreases in sulfate and hydrogen ion concentrations in precipitation chemistry in 1995. Reductions for sulfate and hydrogen ion do not correspond to natural variability driven by precipitation patterns. Smaller precipitation volumes are typically associated with higher concentrations, and most of the eastern states had belowaverage precipitation in 1995. In fact, in 1995, the smaller precipitation volumes resulted in greater concentrations for virtually all ions except sulfate and hydrogen. The notable exceptions are the lower Mississippi River basin, including east Texas, and an area from Illinois to lower Michigan. In these areas, the increases in both sulfate and nitrate ion concentrations are primarily the result of below-average precipitation volumes. The increases in concentrations at a site in central Wisconsin and another in south Florida cannot be explained by departures of precipitation from the mean. Local sources may be responsible, but detailed emissions data were not available for analysis. The conclusion is that sulfate and hydrogen ion concentrations decreased independently of precipitation volume in the Ohio River Valley and the states located immediately downwind of this region in the northern part of the MidAtlantic, indicating a reduction in acid precipitation in 1995. 


\section{Dry Deposition}

In 1995, dry deposition rates of sulfur at State College, Pennsylvania, decreased to their lowest level since 1986. Deposition rates of nitrogen compounds have slowly increased.

Current capabilities for understanding the processes controlling dry deposition are still exploratory. Clear answers cannot be given for the general areawide deposition rates that affect sensitive ecosystems. With this limitation, scientists have focused on some specific areas, where the chances of success are greatest and where relevant information is most desired.

Work conducted in the United States ${ }^{35}$ on the deposition of $\mathrm{SO}_{2}$ also indicates that the historic evaluations of dry deposition of gaseous sulfur may underestimate actual rates, perhaps by as much as 15-20\%, depending on the site. The reason is complex, but involves the development of a better understanding of the processes controlling dry deposition and their representation in analysis routines. Since any underestimates apply universally across the entire data record, they should not affect the trends in deposition.

\section{Total Deposition: A Relevant Example}

In 1995, total deposition rates of sulfur at State College, Pennsylvania, decreased to their lowest level yet recorded. Deposition rates of nitrogen compounds remained near their historic level.

Data gathered at the research area near State College, Pennsylvania, have been identified as a good example of the sort of understanding that could be made available for the region as a whole, provided the scientific research is appropriately targeted. Total deposition of sulfur is the sum of measured wet deposition of sulfate and estimated (through calculations) dry deposition of sulfur dioxide and particulate sulfate. The data indicate that annual dry deposition rates of sulfur are typically about the same as for wet deposition, with dry exceeding wet for drought years (Figure 15). Average total deposition rates of sulfur have been about 13-16 $\mathrm{kg} / \mathrm{ha} / \mathrm{yr}$ (an average of the last 10 years), with 1995 being somewhat lower (about $11 \mathrm{~kg} / \mathrm{ha} / \mathrm{yr}$ ). It is not clear how much of this drop in 1995 is properly attributable to emission reductions. All estimates of total deposition are site specific.
For deposition of nitrogen compounds, the data indicate a trend in the ratio of dry-to-wet deposition, from about 0.2 in the mid-1980s to about 1.0 in 1995. The reason is not clear, but several potential explanations are currently being explored-all related to the fact that dry deposition of nitric acid vapor is a more local phenomenon than wet deposition of nitrogen as nitrate and ammonium. First, local farmers could have increased their use of nitrogenous fertilizers, which would affect regional air quality. Second, regional decreases in $\mathrm{NO}_{\mathrm{X}}$ emissions could decrease the amount of wet deposition.

As expected, total nitrogen deposition data do not indicate a sharp decline in 1995. The values appear to be maintaining a total deposition rate of about 8 $\mathrm{kg} / \mathrm{ha} / \mathrm{yr}$ of nitrogen at State College. Again, this is likely to be an underestimate due to current omission of organic nitrogen contributions and of dry nitrogen species other than nitric acid vapor. It is also possible, however, that some of these causes for underestimation may be offset by the likely presence of ammonium nitrate particles in the air. Ammonium nitrate is not measured well by the apparatus used in the AIRMoN-dry program. A possible explanation for the time trends evident at State College is that local use of nitrogenous fertilizers has increased, in which case ammonium nitrate is quite likely to have been present. If so, then the methodologies reported here would have overestimated nitrate deposition. Clarifying this situation is not within existing capabilities. More studies are needed if the related questions are to be answered.

\section{What are current deposition rates, and what is their variability?}

Precipitation data show that widespread declines in sulfate concentrations and acidity (hydrogen ion) accompanied by decreases in such cations as calcium, magnesium, potassium, and sodium have occurred since about 1980. The most significant declines in sulfates and hydrogen ion occurred in 1995. Nitrate and ammonium concentrations showed considerable variability.

The acidity (as measured by hydrogen ion) of precipitation may not have declined as much during 1983-1994 due to the simultaneous 
Figure 15

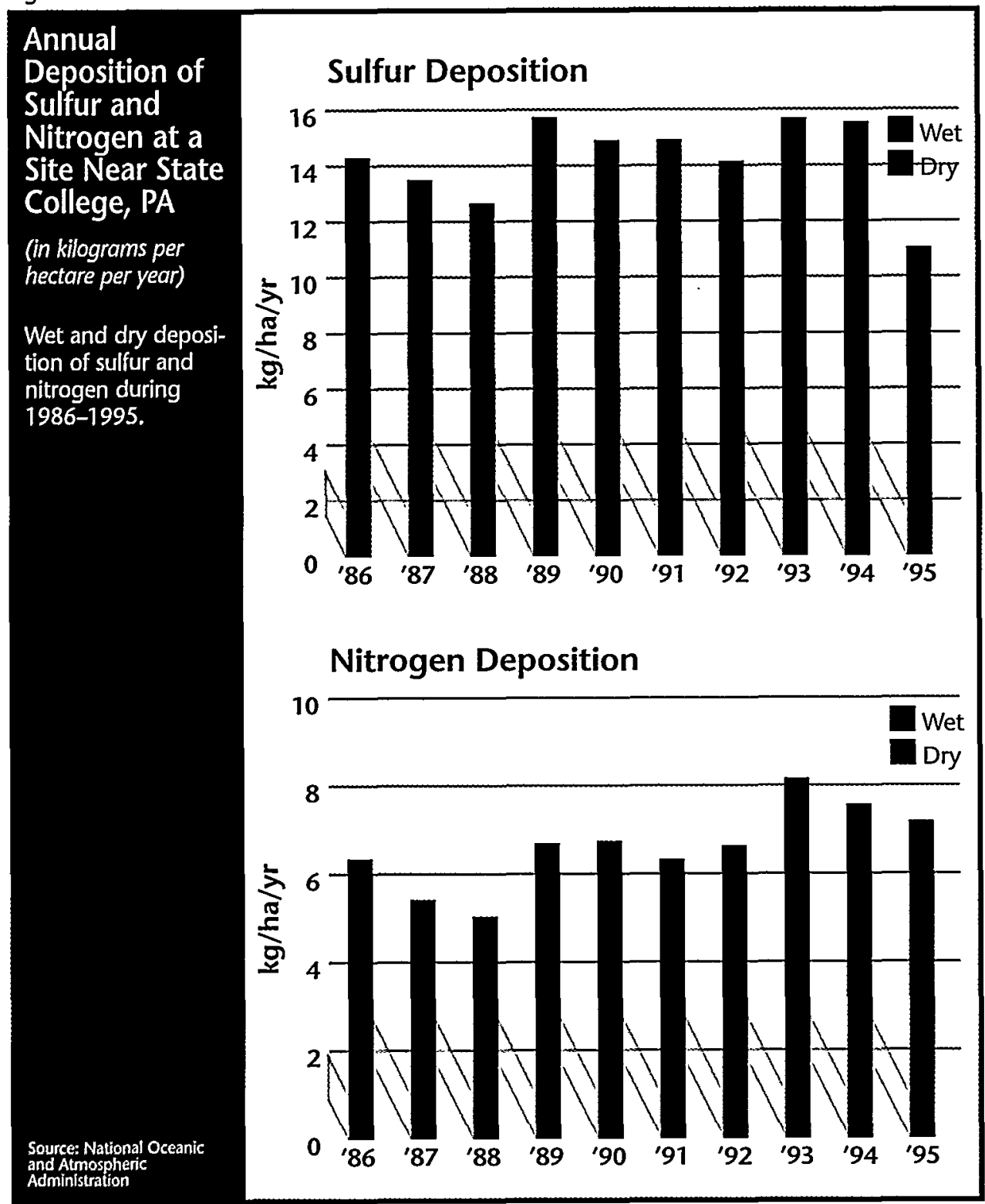

Based on NADP/NTN data, nitrate concentrations in precipitation did not exhibit a consistent spatial or temporal pattern between 1983 and 1994, although the number of sites measuring increases in nitrate exceeded the number where decreases occurred. ${ }^{33}$ The largest increases in nitrate concentration occurred in the western United States. Ammonium concentrations increased at $80 \%$ of the deposition monitoring sites during 1983-1994, for a total increase of $28 \%$. Hydrogen ion concentrations (acidity) declined during the same period, although a lack of consistency between the magnitude of sulfate reductions and reduction in free acidity suggests that the decline in acid-neutralizing cations may have offset some of the expected decline in the acidity of precipitation.

Widespread declines in sulfate concentrations accompanied by decreases in base cations

decline in base cations in precipitation, which act to buffer the acidity, and also to an increase in nitrate. However, 1995 wet deposition data show a substantial drop in acidity (hydrogen ion) and an increase in $\mathrm{pH}$ commensurate with the sulfur concentration reductions.

Deposition of ammonium, which along with nitrate is a significant contributor to nitrogen enrichment to ecosystems via atmospheric deposition, generally increased throughout the United States. have been measured since the late 1970s. The largest declines occurred from 1979 to 1982 , with continued declines throughout the 1980s. ${ }^{36}$ Consistent with these findings, an analysis of precipitation data ${ }^{33}$ found concentrations decreased more rapidly during the early 1980 s and less rapidly thereafter until 1995, when significant reductions were measured. Nitrate and ammonium concentrations showed considerable variability. The large decreases in the early 1980s were similar to changes in $\mathrm{SO}_{2}$ emissions, which also decreased rapidly between 1980 and 1983 , then remained nearly constant in many states during the remainder of the decade. Figure 16 shows the 1995 weighted mean $\mathrm{pH}$ of precipitation and the 1995 wet deposition rates for 
Figure 16

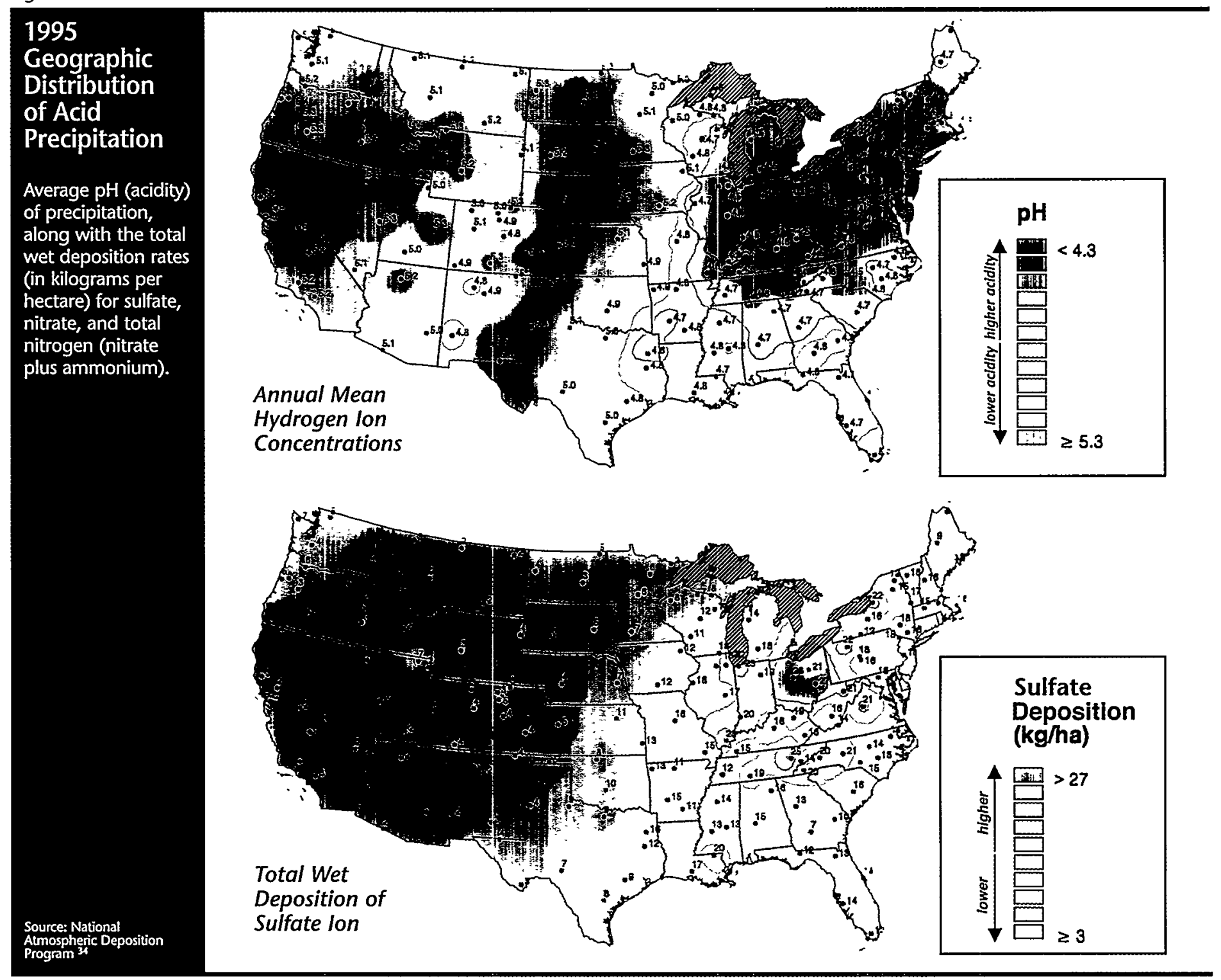

sulfate, nitrate, and total nitrogen (nitrate plus ammonium, expressed as nitrogen).

A major factor influencing the statistical depiction of atmospheric deposition is the areal variability of the signal. Wet deposition is largely a "spatially ergodic" process - that is, a sample obtained at a selected location is likely to be representative of the area as a whole. Dry deposition is substantially different, because it is driven by surface properties that are site 

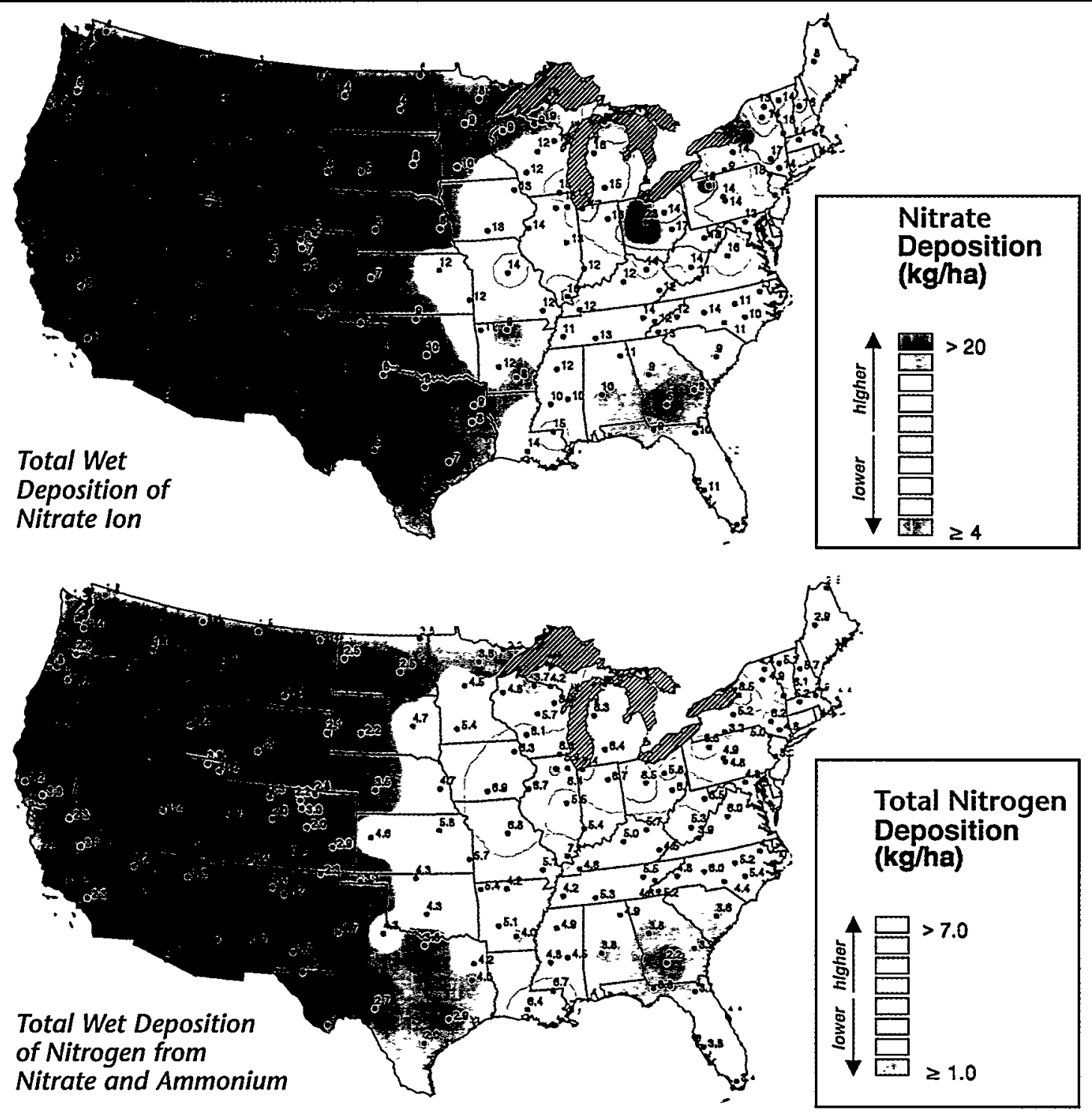

specific. Deriving a spatial average rate of dry deposition from single-location information presents a challenge that is currently daunting. The capability to measure dry deposition rates across selected areas (using highly advanced instrumentation on aircraft) has been developed only very recently. In the mean- time, the best contemporary numerical models use grid cells that contain many land-use types. Comparing model outputs for a selected grid cell against dry deposition data obtained for a particular land-use type within the same grid cell remains a difficult problem. ${ }^{37}$ 


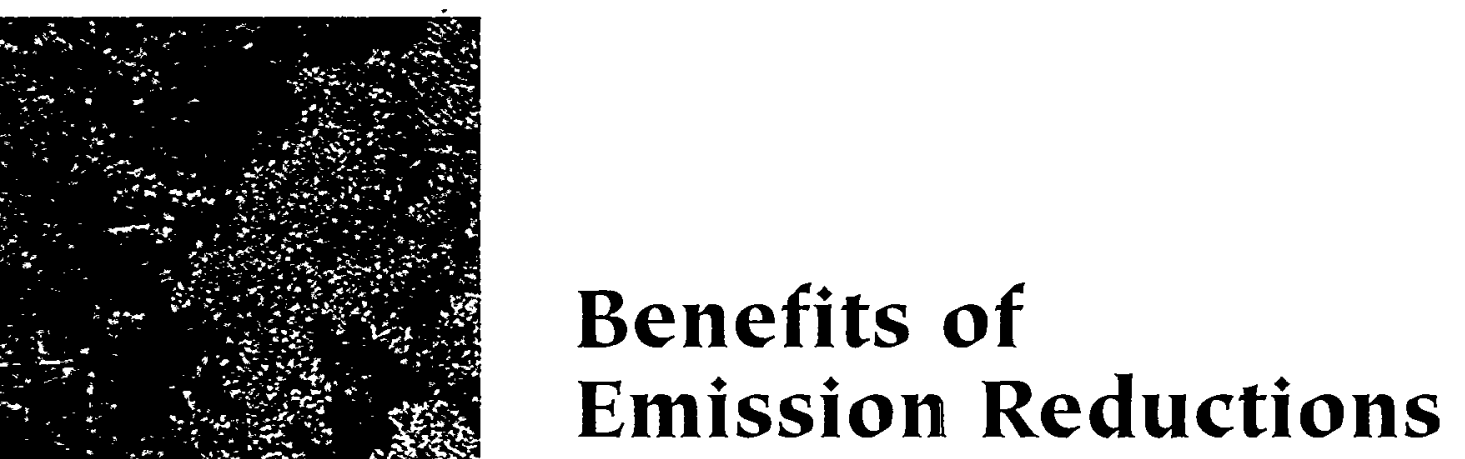

\begin{abstract}
A $s$ the amount of sulfur and nitrogen oxides emitted into the atmosphere is reduced, concentrations of pollutants in the air and deposition of acidic compounds to the Earth's surface should be reduced. Reducing the amount of acid deposition is also expected to decrease the damage to ecosystems, materials, visibility, and human health. The emission reductions under Title IV only began in January 1995, and the time frame of responses to those reductions varies (Figure 17). Concentrations of pollutants in the air respond to these reductions within hours, and these compounds are deposited to the earth's surface usually within days to weeks (e.g., during a rain event). Thus, receptors affected by air concentrations, such as human health and visibility, will respond quickly (from hours to days).
\end{abstract}

The effects of deposition on sensitive receptors can range from days to centuries. Ecosystems are complex systems that are simultaneously responding to a variety of inputs, such as climate, land-use patterns, and other pollutants besides sulfur and nitrogen oxides. These multiple stressors can result in chemical changes within the ecosystem, which can exhibit long lag times before manifesting a response. Therefore, in many effects areas, responses to the Title IV emission reductions will not be expected for many years. Monitoring the changes in the effects areas over time will be necessary to determine whether the expected benefits are realized.

\title{
Have changes in effects been observed (1980-1995)?
}

NAPAP has focused on five effects areas for this assessment: aquatic ecosystems, forest ecosystems, materials and cultural resources, visibility, and human health. The following issues are addressed in each effects area:

n effects of acid deposition on sensitive receptors over the period 1980-1995,

- significant developments since the NAPAP 1990 Integrated Assessment Report, and

- dose-response relationships.

Highlights of the policy-relevant developments since 1990 are presented in Table 5.

\section{Aquatic Ecosystems \\ Observed Effects}

Although it is too early to detect specific changes in aquatic systems from emission reductions under Title IV, significant progress has been made since the 1990 Integrated Assessment Report ${ }^{3}$ in refining understanding of acidification processes and quantifying dose-response relationships. This information improves model forecasts of anticipated change in aquatic systems due to reduced emissions. Particular areas include naturally occurring organic acidity, the depletion of base cation reserves from soils, nitrogen dynamics in forested and alpine ecosystems, interac- 
Figure 17

\section{Relative \\ Response \\ Times to \\ Changes in \\ Emissions \\ The span between \\ the time emissions \\ of $\mathrm{SO}_{2}$ and $\mathrm{NO}_{x}$ \\ from electric utility \\ units increase or \\ decrease and the \\ time when changes \\ in sensitive recep- \\ tors are detectable \\ can range from \\ hours to centuries. \\ In many effects \\ areas, detectable \\ responses to Title IV \\ emission reductions \\ are not expected for \\ many years.}

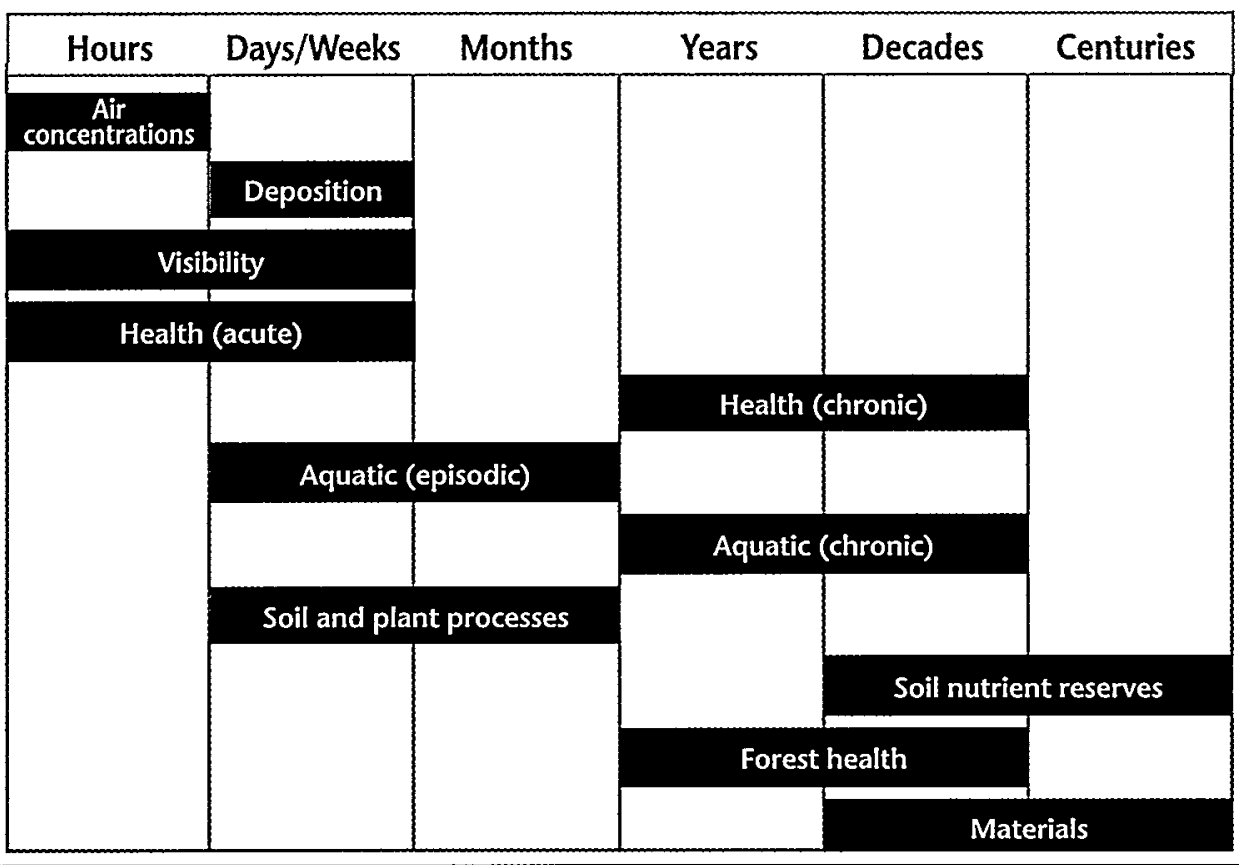

tions between acid deposition and land use, and the role of aluminum in fisheries response. These advancements and observed trends in aquatic effects are discussed below.

\section{Sulfate and Nitrate Concentrations}

Lakes and streams in some areas of the United States have experienced substantial decreases in sulfate and base cation concentrations in response to reduced levels of atmospheric sulfur deposition. However, acid neutralizing capacity and $\mathrm{pH}$, which can affect aquatic biota, show little consistent change, particularly in the most sensitive ecosystems.

Monitoring data have been available since the early 1980s for many lakes and streams in acid-sensitive areas of the United States. The concentration of sulfate in surface waters has decreased in many of these lakes and streams over the past $10-20$ years. This decrease has been caused by reductions in emissions and subsequent decreases in atmospheric deposition of sulfur on a regional basis throughout many parts of the United States during that period. To some extent, these changes may be partly related to implementation of Title IV, but changes were also already occurring without Title IV, most likely as a result of pollution controls, including those in response to the 1970 Clean Air Act and its 1977 Amendments.

In parts of the northeastern United States, approximate reductions of $15 \%$ in sulfate concentrations of lakes and streams have been measured in recent years, and additional decreases undoubtedly occurred prior to implementation of long-term monitoring programs. Sulfate concentrations are expected to continue to decline in the Northeast and many other areas. Exactly how that will affect surface water acidity and biological recovery is uncertain and will require continued monitoring. On the other hand, lakes in New England do appear to show statistically significant recoveries in acid neutralizing capacity as a result of sulfate reductions. ${ }^{38}$ This is based on analyses of long-term monitoring data and is discussed in more detail under Sensitive Receptors, following this Observed Effects section. Future data analyses should focus on the years following Title IV implementation to provide a period of record long enough to determine trends. A recent assessment of surface waters in the southern Appalachians reports that the few long-term monitoring sites in the region have been experiencing sulfate concentration increases over the last $10-20$ years, as has been predicted by acidification models. ${ }^{39}$

Concurrent changes in the concentrations of other chemical parameters have been generally less clear 


\begin{tabular}{|c|c|c|}
\hline $\begin{array}{l}\text { This information } \\
\text { represents the signi- } \\
\text { ficant developments } \\
\text { since the NAPAP } \\
1990 \text { Integrated } \\
\text { Assessment Report. }\end{array}$ & $\begin{array}{l}\text { WHAT'S NEW SINCE } 1990 \\
\text { Sulfur Concentra }\end{array}$ & $\begin{array}{l}\text { SIGNIFICANCE } \\
\text { ion in Precipitation }\end{array}$ \\
\hline \multirow[t]{12}{*}{$\begin{array}{l}\text { This information } \\
\text { represents the signi- } \\
\text { ficant developments } \\
\text { since the NAPAP } \\
1990 \text { Integrated } \\
\text { Assessment Report. }\end{array}$} & $\begin{array}{l}\text { Sulfur concentration levels in wet deposition } \\
\text { decreased 10-25\% over large areas of the } \\
\text { eastern United States in } 1995 \text {, with the largest } \\
\text { decreases in and downwind of the Ohio River } \\
\text { Valley. Similar decreases were found in sulfur } \\
\text { concentrations in dry deposition. } \\
\text { Aquatic Effect }\end{array}$ & $\begin{array}{l}\text { The significant drop in acid deposition (and } \\
\text { emissions) in } 1995 \text { provides a unique scien- } \\
\text { tific (and economic) opportunity to validate } \\
\text { atmospheric deposition models and dose- } \\
\text { response relationships. }\end{array}$ \\
\hline & $\begin{array}{l}\text { Nitrogen is now recognized as playing a } \\
\text { greater role in watershed acidification. }\end{array}$ & $\begin{array}{l}\text { There may be limited recovery in some sen- } \\
\text { sitive systems because NO } \mathrm{O}_{x} \text { reductions } \\
\text { under Title IV may not be sufficient enough } \\
\text { to result in measurable improvements in } \\
\text { chemical or biological changes. }\end{array}$ \\
\hline & \multicolumn{2}{|c|}{ Surface Water Trends } \\
\hline & $\begin{array}{l}\text { Concentrations of sulfate in lake and stream } \\
\text { waters have decreased in many areas, with } \\
\text { evidence of recovery from acidification in } \\
\text { New England. However, the majority of } \\
\text { Adirondack lakes have remained fairly con- } \\
\text { stant, while the sensitive Adirondack lakes } \\
\text { continue to acidify. }\end{array}$ & $\begin{array}{l}\text { Reductions in sulfur deposition to date may } \\
\text { be insufficient in some areas to improve the } \\
\text { acid-base status of acidified surface waters. }\end{array}$ \\
\hline & \multicolumn{2}{|c|}{ High-Elevation Spruce-Fir Dieback } \\
\hline & $\begin{array}{l}\text { Strong linkage was confirmed between acid } \\
\text { deposition and damage to high-elevation } \\
\text { spruce-fir forest ecosystems. }\end{array}$ & $\begin{array}{l}\text { There is a higher likelihood of some short- } \\
\text { term benefits from controls of acid deposi- } \\
\text { tion precursors. }\end{array}$ \\
\hline & \multicolumn{2}{|c|}{ Cultural Resources } \\
\hline & $\begin{array}{l}\text { Dry deposition of } \mathrm{SO}_{2} \text { and aerosols is now } \\
\text { thought to be more damaging to stone } \\
\text { than wet deposition. }\end{array}$ & $\begin{array}{l}\text { The role of dry deposition and its relative } \\
\text { impact on benefits to cultural resources } \\
\text { must be reviewed. }\end{array}$ \\
\hline & \multicolumn{2}{|c|}{ Fine Particle Impacts on Health } \\
\hline & $\begin{array}{l}\text { New studies associate fine-particle }\left(\mathrm{PM}_{2.5}\right) \\
\text { exposure with premature mortality and } \\
\text { other health impacts. }\end{array}$ & $\begin{array}{l}\text { Title IV controls on emissions of precursors } \\
\text { of fine sulfate and nitrate particles will } \\
\text { reduce ambient } \mathrm{PM}_{2.5} \text { concentrations. }\end{array}$ \\
\hline & \multicolumn{2}{|c|}{ Valuation of Economic Benefits } \\
\hline & $\begin{array}{l}\text { Expected benefits are greater than previ- } \\
\text { ously thought, especially in the areas of } \\
\text { human health and visibility. }\end{array}$ & $\begin{array}{l}\text { The magnitude of valued benefits in these } \\
\text { areas exceeds the costs of Title IV, indepen- } \\
\text { dent of benefit estimates for other areas. }\end{array}$ \\
\hline
\end{tabular}

and less consistent than for sulfate and base cations. These other parameters are more strongly influenced by factors other than atmospheric deposition. Another consistent response of surface water chemistry to the recent observed decrease in sulfate concentration in lakes and streams has been a decrease of approximately the same magnitude in the concentration of calcium and other base cations (see text box on Water Chemistry). In most cases, pH, aluminum, and acid neutralizing capacity have not responded in a large or systematic fashion to changes in sulfate concentrations. Examples of monitoring data from two sites are shown in Figure 18. Seasonal and annual variability tend to be large in relation to the overall trend. 
Figure 18

Surface Water

Trends at

Long-Term

Monitoring

Sites

Monitoring data

from a stream site

and a lake site in

the eastern United

States show a de-

crease (measured as

micro-equivalents

per liter) in sulfate

concentration, but a

corresponding

change in pH (acid-

ity) and acid neu-

tralizing capacity

has not been

detected; the con-

centration of base

cations at these two

sites has decreased

slightly. The figure

also illustrates the

large seasonal and

annual variability

relative to the over-

all trend.
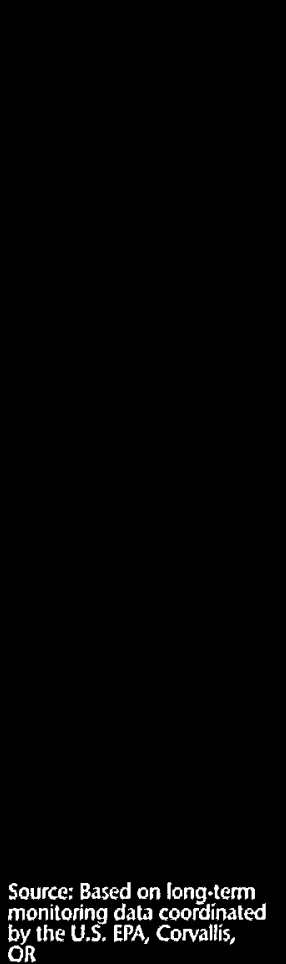

Biscuit Brook, PA

Sulfate $(\mu \mathrm{eq} / \mathrm{L})$
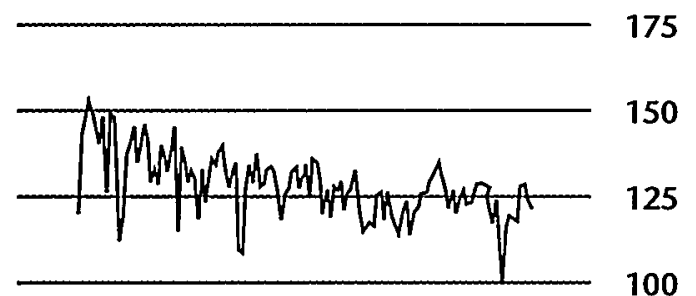

Lake Rondaxe, NY

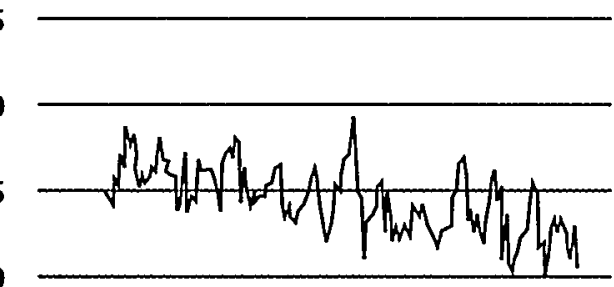

$19 \overline{81}$

1986

1991

$1996^{75} 19 \overline{81}$

1986

1991

1996

Base Cations ( $\mu$ eq/L)

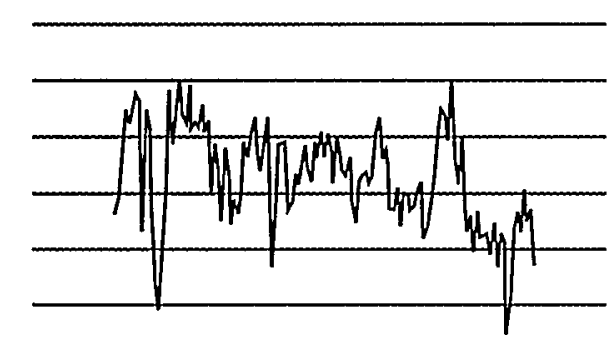

275
250
225
200
175
150
125

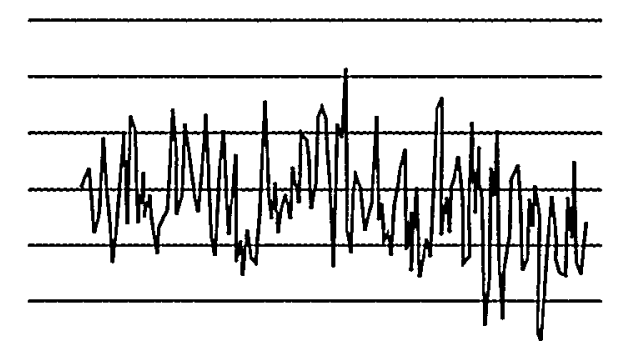

$19 \overline{81}$

1986

1991

$1996^{125} 19 \overline{81}$

1986

1996

pH (acidity)
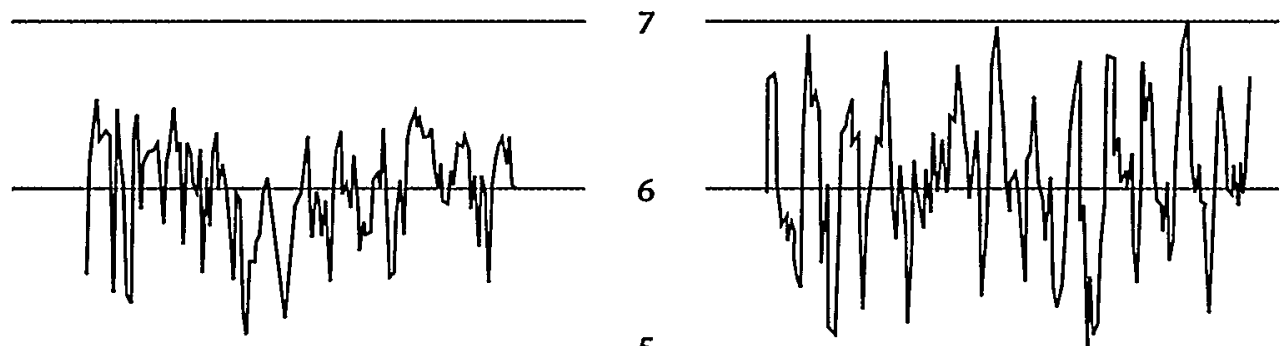

1981

1986

1991

$1996^{5} 19 \overline{81}$

1986

1991

1996

Acid Neutralizing Capacity ( $\mu \mathrm{eq} / \mathrm{L}$ )
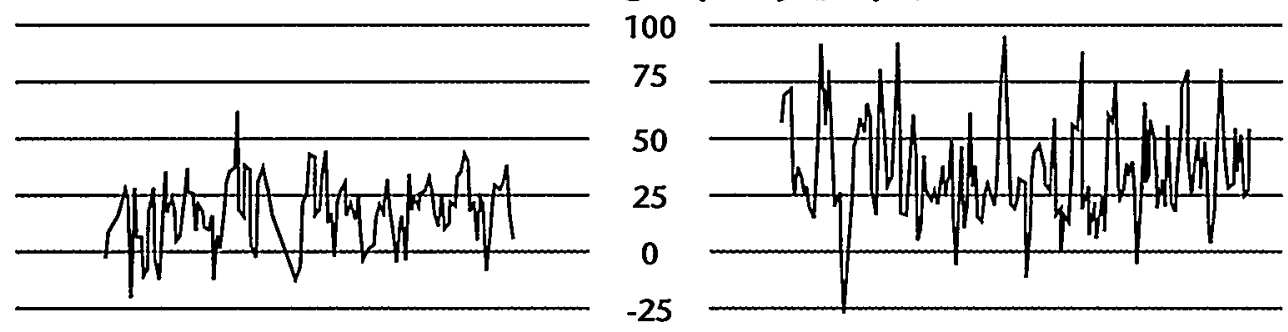

$19 \overline{81}$

1986

1991

$1996^{-50} 19 \overline{81}$

1986

1991

1996 


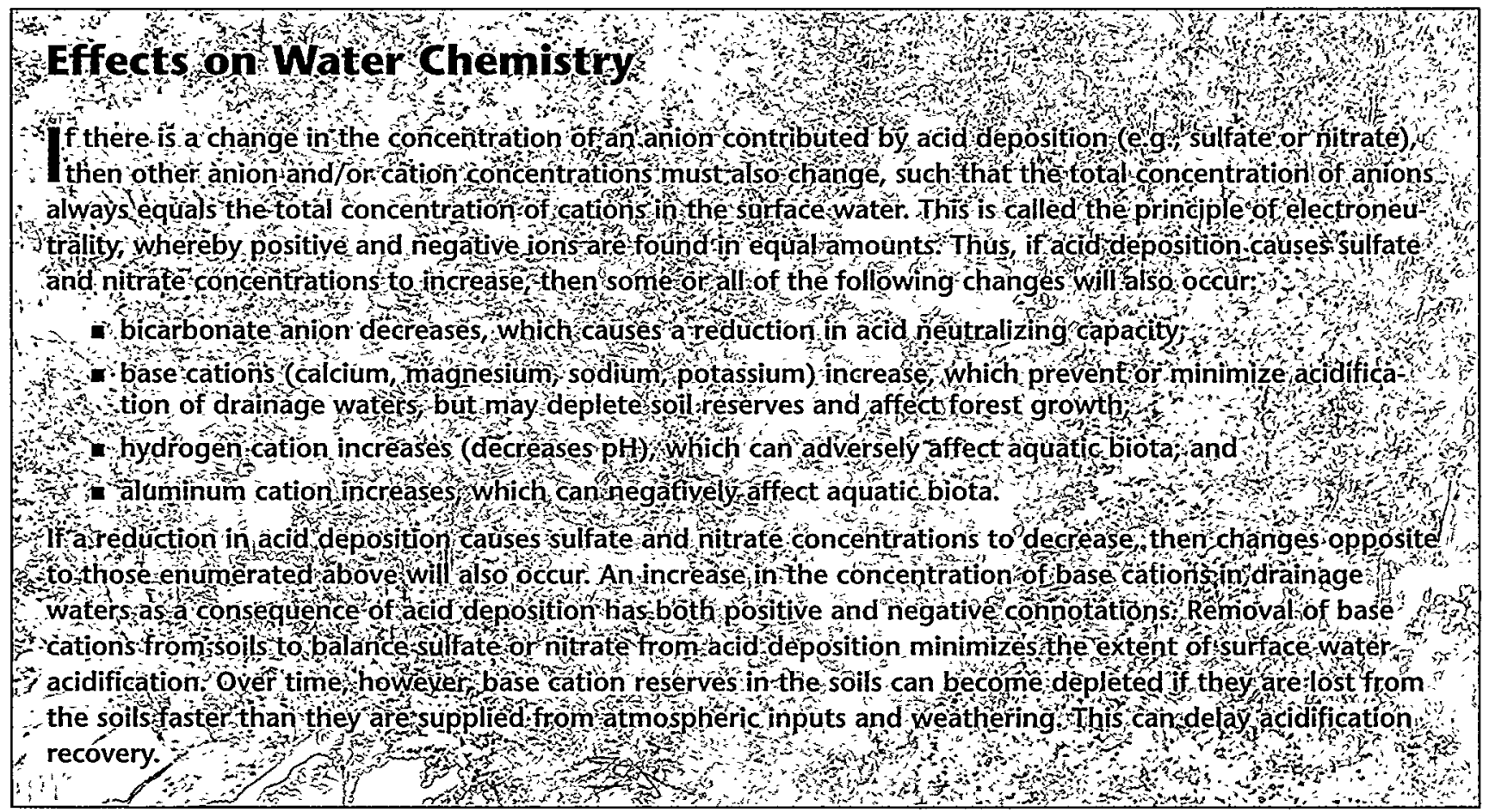

Concentrations of key chemical parameters often vary per season by more than can be accounted for (or attributed to) acid deposition. For example, a decrease in sulfate concentration in a lake or stream may not be solely attributable to a decrease in acid deposition, but may also be attributable to normal seasonal variability of sulfate concentration in that lake or stream. Such variability makes it difficult to quantify acidification and recovery responses, and also complicates attempts to evaluate sensitivity to acidification based solely on "index" chemistry (i.e., samples taken during broad-scale synoptic surveys at a time when water chemistry is expected to be relatively stable). Seasonal variability is particularly problematic in determining long-term trends. Continued monthly monitoring of different types of lakes and streams located in sensitive regions will provide much needed data on seasonal variability. This will be especially important for evaluating the possible need to reduce nitrogen deposition in some regions during the winter/spring period prior to snowmelt, in view of the apparent seasonal nature of nitrogen impacts on water quality.

The observed changes in the concentration of nitrate in some surface waters have most likely been due to a variety of factors, including nitrogen deposition and climate. In many areas of the northeastern United States, nitrate concentrations in lakes and streams increased during the latter part of the 1980s. This trend was reversed in about 1990, however, despite relatively constant levels of nitrogen deposition during the past 10 years. ${ }^{40}$ This is because the amount of nitrate that leaches through soils to drainage waters is the result of a complex set of biological and hydrological processes that include: nitrogen uptake by plants and soil microbial communities, microbial transformations between different forms of inorganic and organic nitrogen, rates of organic matter decomposition, the amount of rain and snow received, and the amount (and form) of nitrogen that enters the ecosystem as atmospheric deposition. Most of these important processes are strongly influenced by climatic factors, such as temperature, moisture, and snowpack development. The end result is that nitrate concentrations in surface waters, although clearly influenced by atmospheric nitrogen deposition, respond to many factors and can be difficult to predict. ${ }^{41}$

\section{Episodic Acidification}

Nitrogen is quantitatively as-or, in some cases, more-important than sulfur as a cause of both chronic and especially episodic acidification than was understood in 1990.

Biological effects on fish during acidic episodes are largely attributable to increased concentra- 
tions of dissolved aluminum in stream water. This aluminum is transported from soils to streams by short-term increases in acidity, which are largely associated with nitrogen-specifically, nitrate leaching.

Episodic acidification is the process by which lakes and streams experience short-term (hours to weeks) decreases in acid neutralizing capacity and $\mathrm{pH}$. Generally, these episodes occur during periods of high water flow, such as storms or snowmelt, and often occurs at the most biologically sensitive time of the year-spring spawning. Typically, several chemical changes accompany the decrease in acid neutralizing capacity that occurs during episodes. In regions with the most severe episodes, $\mathrm{pH}$ and calcium often decrease and dissolved aluminum increases, creating more adverse conditions for aquatic life. ${ }^{42}$

A review of episodic acidification of surface waters in portions of the eastern United States ${ }^{43}$ clearly demonstrated that (1) episodic events are a natural facet of watershed processes, (2) nitrate attributable to atmospheric deposition plays an important role in the episodic acidification of some surface waters, and (3) increased aluminum concentration has the greatest impact on biota. EPA's Episodic Response Project documented the occurrence of acidic episodes with a minimum $\mathrm{pH}$ of less than 5 and a high aluminum concentration in the northern Appalachian region of Pennsylvania and the Catskill and Adirondack Mountains of New York. ${ }^{44} \mathrm{~A}$ regional assessment of the acidbase status of native brook trout streams in the mountains of Virginia included examination of the relationship between the median acid neutralizing capacity observed during spring and the minimum acid neutralizing capacity observed during episodic acidification. The results indicated that the extreme episodic acid neutralizing capacity values were about $20 \%$ lower than the median values. 45

Episodic acidification has been found to be nearly ubiquitous in drainage waters. Nearly all lakes and streams that have been studied throughout the United States, Canada, and Europe experience loss of acid neutralizing capacity during hydrologic events. Chemical changes during episodes are controlled by a number of natural processes, including dilution of base cation concentrations, nitrification, flushing of organic acids from terrestrial to aquatic systems, and the neutral salt effect. Acid deposition contributes to episodic acidification, particularly via enhanced nitrate leaching. Under some conditions, episodes can be partly caused by increased sulfate concentrations. There is also the likelihood that chronic acidification by acid deposition can precondition a watershed, thereby increasing the severity of episodic acidification.

Nitrate is the principal acid anion in snowmelt in many areas of the United States. Nitrate in snowmelt runoff has been recognized for some time as an important component of biological damage resulting from atmospheric deposition. A number of factors can be involved in controlling the loss of nitrogen from forested and alpine watersheds, including atmospheric inputs, forest stand age and condition, land use, soil nitrogen and carbon pools, and flow paths of percolation and melt water within the watershed. Except in cases of excessive nitrogen saturation, the effects of nitrogen deposition on surface waters are expected to be primarily episodic. However, data required to make regional assessments of episodic effects are generally not available.

\section{Organic Acidity}

Naturally occurring organic acids are more important components of surface water acid-base chemistry $(\mathrm{pH})$ and have more significant influences on the sensitivity of model projections of acidification than was widely believed in 1990 . Predictions of the $\mathrm{pH}$ of sensitive lakes in the Adirondacks have been revised accordingly.

Organic acids commonly exert a major influence on surface water acid-base chemistry, particularly in dilute waters having moderate-to-high concentrations of dissolved organic carbon. Some lakes and streams are naturally acidic as a consequence of organic acids in solution. Even naturally acidic surface waters can be at risk of becoming further acidified, particularly on an episodic basis. The presence of organic acids also provides buffering to minimize $\mathrm{pH}$ changes in response to changes in the amount of mineral acid anions (e.g., sulfate and nitrate) in solution. Organic acids will most likely become more important components of acid-base chemistry as acid deposition continues to decline.

Recently revised model simulations that included organic acids ${ }^{46,47}$ showed improvements in the agreement between modeled and historic acidity inferred from diatoms of up to one full $\mathrm{pH}$ unit for individual lakes. The revised Model of Acidification of Ground- 
water in Catchments (MAGIC) predicts less $\mathrm{pH}$ recovery of Adirondack lakes by 2034 in response to decreased sulfur deposition than the earlier version of the model used as the basis for NAPAP's 1990 Integrated Assessment Report. ${ }^{3}$ Other surface water chemistry indicators, such as acid neutralizing capacity, are not affected to the same extent by organic acids. (See Appendix A for further discussion of MAGIC model improvements.)

\section{Base Cation Depletion}

Sensitive watersheds in the Adirondack Mountains have responded to atmospheric sulfur inputs primarily by enhanced base cation leaching, especially calcium and magnesium. This means that drainage waters have been less acidified than was earlier reported by NAPAP in 1991. Such a response has also raised concerns about longterm depletion of base cation reserves from forest soils, which could decrease future forest productivity and the rate of watershed recovery in response to lower levels of sulfur deposition.

Base cation depletion has been recognized as an important effect of acid deposition on soils for many years. However, scientific appreciation of the importance of this response has increased with the realization that many watersheds previously acidified by acid deposition are not exhibiting acid neutralizing capacity and $\mathrm{pH}$ recovery in response to recent decreases in sulfur deposition. As sulfate concentrations in lakes and streams have declined, so too have the concentrations of calcium and other base cations for several reasons. First, decreased movement of sulfate through watershed soils reduces leaching of base cations from soil surfaces. Second, the atmospheric deposition of base cations has decreased in recent decades, ${ }^{48}$ probably due to a combination of air pollution controls that targeted large particles, changes in agricultural practices, and the paving of roads. The latter two of these factors generate dust that is rich in base cations. ${ }^{36}$ Most of these reductions of dust occurred in the 1960s and 1970s; dust has remained fairly stable for the past 20 years. Third, soils in some sensitive areas have experienced prolonged base cation leaching to such an extent that their base cation reserves have been depleted. Such depletion prolongs the acidification recovery time of watersheds and may adversely impact forest productivity. ${ }^{49.50}$ (See the Forest Ecosystems section for further discussion.)

\section{Nitrogen Cycling}

Significant progress has been made in understanding nitrogen cycling in forested and alpine ecosystems, and the effects of nitrogen deposition on nitrate leaching and consequent acidification of surface waters. The ability to model nitrogen dynamics effectively on a regional basis is on the immediate horizon.

Increased atmospheric deposition of nitrogen does not necessarily cause adverse environmental impacts. In some cases, nitrogen acts as a fertilizer and is taken up by terrestrial biota increasing forest productivity. ${ }^{51}$ However, in some areas, especially at high elevations, terrestrial ecosystems have become nitrogen saturated, and high levels of deposition have raised the levels of nitrate in drainage waters. ${ }^{52.53}$ This enhanced leaching of nitrate depletes calcium and other base cations from forest soils and can cause acidification of drainage waters in base-poor soils. Nitrogen saturation means that the input of nitrogen (e.g., nitrate, ammonium) to the ecosystem exceeds the requirements of terrestrial biota (that is, more nitrogen comes in than can be taken up by plants and microorganisms), and a substantial fraction of the incoming nitrogen leaches out of the ecosystem and into ground water and surface water. (Further discussion about nitrogen effects is presented in the section on Forest Ecosystems.)

Prior to the mid-1980s, research on the effects of atmospheric deposition focused almost exclusively on sulfur. During the last 10 years, the research focus has shifted more to nitrogen. Although some high-quality research has been conducted in the United States on the environmental effects of atmospheric nitrogen deposition since 1990, such work has been conducted to a far greater extent in Europe.

In Europe, direct ecosystem-level data have been obtained on nitrogen saturation from atmospheric deposition and subsequent ecosystem recovery. Results from experimental manipulations and other studies have shown that nitrogen generally leaches into drainage waters in European forests only where atmospheric deposition of nitrogen is greater than about 10 kilograms per hectare per year (kg/ha/yr). Other important factors controlling nitrogen leaching include the ratio of carbon to nitrogen in the forest floor and soils, the age of the forest, and past forest management practices and disturbances. 
Chronically high nitrate concentrations in lake or stream water, indicative of ecosystem nitrogen saturation, have been found in recent years at a variety of locations in the western and eastern United States, including the San Bernardino and San Gabriel Mountains within the Los Angeles air basin, ${ }^{54}$ the Front Range of Colorado, 55,56 the Allegheny Mountains of West Virginia, 57 the Catskill Mountains of New York, ${ }^{53,58}$ and the Great Smoky Mountains in Tennessee. ${ }^{59}$ Nitrogen saturation is occurring throughout high-elevation watersheds of the Colorado Front Range. ${ }^{56}$

Total nitrogen deposition in high-elevation watersheds of the Colorado Front Range is about $4 \mathrm{~kg} / \mathrm{ha} / \mathrm{yr}$, which is about double that in most other mountainous areas of the West and approaching the deposition levels found in some parts of the East. It is much lower, however, than the $10 \mathrm{~kg} / \mathrm{ha} / \mathrm{yr}$ threshold value for nitrogen leaching found in Europe. The observed high concentrations of nitrate in lakes and streams of the Front Range are likely due to leaching from tundra, exposed bedrock, and talus areas at high elevations. In the alpine areas of Colorado, about $50 \%$ of the nitrogen is deposited in the snowpack and released with the spring thaw. This large release of nitrogen moves through the watershed, removing base cations and reducing the acid neutralizing capacity of lakes and streams. ${ }^{56}$

A comparison was recently made for 37 watersheds in the United States and Canada to examine the relationship between atmospheric nitrogen deposition inputs and nitrogen outputs in drainage waters. Over onethird of the watersheds that receive nitrogen deposition higher than about $6 \mathrm{~kg} / \mathrm{ha} / \mathrm{yr}$ are leaching appreciable amounts of nitrogen (more than about $2 \mathrm{~kg} / \mathrm{ha} / \mathrm{yr}$ ). ${ }^{60}$ The highest inputs and outputs of nitrogen were found at the Fernow Experimental Forest in West Virginia.

Results from an experimental manipulation site in Maine illustrate the rapidity with which some forested watersheds in the northeastern United States may move toward nitrogen saturation in response to increased nitrogen loadings. The forest ecosystem continued to accumulate nitrogen, but the rate of accumulation decreased steadily with the experimental treatment. ${ }^{61}$

\section{Land Use}

Human land-use activities, especially disturbance of soils and forest management, have important effects on the responses of terrestrial and aquatic ecosystems to the atmospheric inputs of sulfur and, especially, nitrogen.
In the northeastern United States, land-use practices and resulting vegetation patterns have changed some areas from forests to agriculture and back to forests more or less continuously for about the past 250 years. These changes in human activity, and consequent changes in forest structure and dynamics, can influence the response of forested ecosystems to external stressors, such as atmospheric deposition of sulfur or nitrogen, exposure to ozone, natural disturbance factors (e.g., wind and fire), and climatic changes. Some landscape processes contribute to the acidification of soil and surface waters or reduce the base cation saturation of the soils, thereby increasing their sensitivity to acid deposition. Acid deposition is only one of many factors that affects acidity status, although in acid-sensitive regions it remains one of the primary factors influencing the health of ecosystems.

Disturbances such as logging, blowdown, and fire affect surface water $\mathrm{pH}$ and acid neutralizing capacity. When they occur within a watershed, these disturbances disiupt the normal flow of water. In some cases, they cause increased contact between runoff water and soil surfaces, and often lead to increased base cation concentration and acid neutralizing capacity in surface waters. In most cases, recovery from disturbance will lead to a decrease in $\mathrm{pH}$ and acid neutralizing capacity, as the system returns to predisturbance conditions. Such acidification can be erroneously attributed to acid deposition.

The removal or cutting of forests has immediate effects on the chemistry of drainage water. Dry deposition of sulfur and nitrogen to the site is reduced. Leaching of nitrate increases and, in some cases, causes a pulse of surface water acidification, and base cations are lost from the soils.

The subsequent regrowth of the forest following deforestation also affects drainage water chemistry. Young, fast-growing forests are considerably more acidifying to the soil than older forests because young trees take up more of the base cations from the soil, leaving less to neutralize any acidic inputs. In contrast, old-growth forests need less nitrogen to sustain growth and, therefore, may be more susceptible to nitrate leaching into nearby surface waters.

Lake water acidification in the Adirondacks has been correlated with widespread changes in landscape cover that occurred in response to massive logging operations and fires around the turn of the 20th century and unprecedented forest blowdown during a large wind storm in 1950.62 Although such changes- 
particularly forest regrowth-have not been shown on their own to cause lakes to become acidic, they can cause decreases in the base saturation of soils, thereby predisposing sensitive watersheds to subsequent acidification from acid deposition. The importance of these landscape changes has not been widely recognized.

Modeling studies and calculations performed for selected watersheds in Europe have suggested that acid deposition and landscape processes are of approximately equal importance as regulators of surface water acid-base chemistry within the watersheds investigated. ${ }^{63,64}$ In the United States, however, the importance of landscape processes in influencing surface water acid-base chemistry and the response of surface waters to atmospheric deposition of sulfur and nitrogen have not been well studied. For simplicity, early modeling investigations ${ }^{3}$ of the response of acid-sensitive watersheds in the United States did not consider landscape processes. Such omission may have biased model projections toward less acidification and/or quicker recovery of surface waters in response to changing levels of sulfur deposition. It may be responsible-at least in part-for the observed tendency for MAGIC model hindcasts of historical acidification to exceed diatom-inferences of acidification of some Adirondack Mountain lakes. The need to include land use in modeling efforts will most likely increase as efforts shift more to modelbased assessments of nitrogen effects. This is because nitrate leaching from forested watersheds is largely controlled by age-dependent forest nitrogen uptake processes as well as atmospheric deposition of nitrogen.

Future studies to address the quantitative response of surface water $\mathrm{pH}$ and acid neutralizing capacity to changing levels of sulfur or nitrogen inputs should include the influence of landscape changes on key watershed processes. This will require the collection of detailed, watershed-specific information on past, current, and future forest management and the occurrence of major landscape disturbances. In addition, research is needed on watersheds that contain multiple land uses-e.g., forests, agriculture, and urban areas. Consideration of the cumulative impact of all major processes that influence the acid-base chemistry of drainage waters will be required to improve model projections of future dose-response relationships.

\section{Biological Response to Deacidification}

Biological recovery of previously acidified lakes can be a slower process than chemical recovery.
Studies in both the United States and Canada have provided new understanding of the feasibility and complexity of biological recovery in response to chronic deacidification. The rate of biological recovery can be slower because of several factors: (1) other environmental stresses, such as metal contamination (e.g., as in Sudbury, Ontario);65-70 (2) barriers imposed by water drainage patterns between lakes, hindering recolonization by some fish species; ${ }^{67}$ (3) the influence of predation by fish species that are not identified as acid-sensitive on the recovery of zooplankton and macroinvertebrate communities; 68 and (4) predation on tributary-spawned young trout when they move downstream into lakes inhabited by predatory fish and birds. ${ }^{71}$

Results from a liming study in the Adirondacks indicated that reestablishment of tributary-spawning populations of brook trout may be possible with future reductions in acid deposition. However, restoration of tributary-spawning habitat may not be sufficient to produce self-sustaining populations because of high rates of predation on young trout after they move downstream into lakes. ${ }^{71}$ Woods Lake continues to be examined as part of the Adirondack Long-Term Monitoring Project to evaluate the effectiveness of liming to provide a self-sustaining brook trout population.

\section{Sensitive Receptors}

Several types of aquatic systems and/or regions are particularly sensitive to acid deposition. The focus of this report is on four sensitive receptors: Adirondack and New England lakes, high-elevation western lakes, aquatic biota, and estuaries and near-coastal waters.

Overall, lakes and streams in areas of the United States that have experienced significant recent decreases in sulfur deposition have shown decreases in sulfate and base cation concentrations of approximately similar magnitudes. Other ions have been less affected by the changes in deposition.

\section{Adirondack Mountains and New England}

In the Adirondack Mountains, where acid deposition has recently been considerable, the acid neutralizing capacity of the majority of lakes has remained fairly constant, but has continued to decline in the sensitive 
Aquatic Ecosystems

lakes (i.e., acidification has increased) despite relatively large decreases in sulfate concentrations in lake water. As a result, the recovery anticipated in 1990 has not been realized. ${ }^{3}$

In contrast, lakes in New England, especially those considered highly sensitive to acid deposition, have shown statistically significant recoveries in acid neutralizing capacity, based on analyses of long-term monitoring data. ${ }^{38}$ Although the precise reasons for these differences are not known, it is believed that the extent to which base cation reserves in the soil have been depleted by acid deposition is an important factor. Monitoring of acid-sensitive waters should continue in order to identify the processes of recovery and to improve the models used to predict recovery times.

\section{High-Elevation Western Lakes}

Episodic acidification associated with nitrogen deposition may be occurring to a significant degree in the watersheds of many high-elevation western lakes. These systems may be predisposed to episodic events.

Based on existing data, many high-elevation lakes in the West are currently experiencing nitrogen deposition sufficiently high to cause chronic nitrate leaching (i.e., nitrate concentrations in lakes and streams remain high, greater than $10 \mu \mathrm{eq} / \mathrm{L}$, throughout the year), and associated chronic and episodic acidification, albeit small in magnitude.

A number of factors predispose western systems to potential episodic effects, including:

- The abundance of dilute to ultra-dilute lakes, exhibiting very low concentrations of base cations and, therefore, acid neutralizing capacity, throughout the year.

- Large snowpack accumulations at high elevations, causing substantial episodic acidification via the natural process of base cation dilution.

- Short retention times for many of the high-elevation drainage lakes, enabling snowmelt to rapidly flush lake basins with highly dilute melt water.

Lakes and streams in the Sierra Nevada, Cascade, and Rocky Mountains are highly sensitive to the potential effects of acid deposition because of the predominance of granitic bedrock, thin acidic soils, large amounts of precipitation, coniferous vegetation, and extremely dilute waters. Although, there are no data to suggest that lakes in these areas have experienced chronic acidification to any significant degree, episodic effects could be occurring under current deposition regimes, and nitrate concentrations could be causing a small loss of acid neutralizing capacity on a chronic basis at some high-elevation sites. Unfortunately, the data that would be needed for such determinations have not been collected to a sufficient degree in acid-sensitive areas of the West to permit any regional assessment of either episodic or chronic nitrogen-driven acidification.

\section{Aquatic Biota}

Acid deposition can cause long-term adverse effects on fish populations and other aquatic organisms in both lakes and streams. The migration of fish downstream to less acidic water may reduce some effects, but not long-term impacts on species composition.

New information is available on adverse effects on fish populations and communities in chronically acidified streams in Shenandoah National Park (Virginia). Fish species richness, population density, condition factor, age distribution, size, and bioassay survival were all reduced in streams with low acid neutralizing capacity, as compared to those with intermediate and high acid neutralizing capacities. ${ }^{72-74}$

A study of 13 streams in the Adirondack and Catskill Mountains in New York and the northern Appalachian Plateau in Pennsylvania showed longterm adverse episodic effects on fish populations. Streams with suitable chemistry during low flow, but low $\mathrm{pH}$ and high aluminum levels during high flow, had substantially lower numbers and biomass (weight) of brook trout than were found in nonacidic streams. Streams having acidic episodes showed significant fish mortality. Some brook trout avoided exposure to stressful chemical conditions during episodes by moving downstream or into areas with higher $\mathrm{pH}$ and lower aluminum. This migration of brook trout only partly mitigated the adverse effects of episodic acidification, however, and was not sufficient to sustain fish biomass or species composition at levels that would be expected in the absence of acidic episodes. 
These findings indicate that stream assessments based solely on chemical measurements during low-flow conditions will not accurately predict the status of fish populations and communities in small mountain streams. ${ }^{44.75 .76}$ A study of coastal plain streams indicated that larval mortality of river herring due to episodic acidification may be substantial during wet years, which exhibit more frequent and more severe episodes. ${ }^{77}$ Based on lake chemistry from the Adirondack Long-Term Monitoring Project, episodic acidification may also be biologically relevant to certain kinds of lakes, depending on the magnitude and duration of the spring snowmelt period. In 1993, 1994, and 1996, approximately $50 \%$ of the highly and moderately sensitive lake classes in this study became acidic during the snowmelt period. Additional research is needed to determine the impacts on the populations of sensitive fish species that inhabit these waters.

Rainbow trout are sensitive to acidification not because of acidity itself, but because of elevated aluminum concentrations due to low $\mathrm{pH}$ levels (lower than 5.0). Aluminum accumulates on gills and disrupts gill ion transport and respiratory function. ${ }^{78}$

Some organisms can serve as specific indicators of changes in acid deposition. In aquatic ecosystems, loons are effective "bioindicators," linking recovery from lake acidification to higher trophic levels (fish). If loons nest on acidic lakes, their reproductive success is lower, in part due to the reduced survival of their young. This reduced survival is presumably linked to reduced fish biomass. ${ }^{79}$ Thus, loons are less likely to nest on acidic lakes.

\section{Estuaries and Near-Coastal Waters}

Changes in atmospheric deposition of nitrogen can have significant impacts on the biology and chemistry of estuaries and near-coastal waters.

Through a combination of monitoring, experimental research, and modeling, scientists better understand how atmospheric deposition of nitrogen-in the form of nitrate and ammonium - to both water surfaces and watersheds is affecting the biological and chemical status of estuaries and near-coastal waters. Nitrogen is the limiting nutrient for the growth of algae in many estuaries and near-coastal systems, rather than phosphorus, which typically limits algal growth in freshwater systems.
Defined as one of the United States' "Great Waters," Chesapeake Bay is the nation's largest estuarine system with a watershed of almost 64,000 square miles encompassing one-sixth of the Eastern Seaboard. The Bay has an important fish and shellfish industry and serves as a nursery for marine commercial and sport fish. There has been considerable research and monitoring on the effects of nitrogen and phosphorus loading to Chesapeake Bay. Changes in atmospheric nitrogen deposition can have significant impacts on aquatic biology. Excess nitrogen entering the Bay produces algal blooms that block sunlight needed for submerged aquatic grasses, and the decomposition of excess algae depletes life-sustaining oxygen needed by invertebrates inhabiting bottom waters. The best estimates of atmospheric nitrogen loads to Chesapeake Bay and other estuaries along the Atlantic and Gulf Coasts range from $10 \%$ to $45 \%$ of the total nitrogen inputs from all sources. Additional research is needed to quantify the current effects and the expected benefits from reducing nitrogen deposition on estuary systems.

\section{Dose-Response Relationships}

Chemical effects in surface waters due to changes in atmospheric deposition can exhibit lag times of one to many years. Lags in measurable effects on aquatic biota can be even longer. Continued monitoring of surface water chemistry into the future will be required to assess potential improvements that may occur as a consequence of emission reductions already realized.

Researchers must be cautious in interpreting the observed surface water chemistry as a direct response to estimated changes in sulfur and/or nitrogen deposition. Some effects of changing deposition can take years before the ecosystem comes into balance with the changed or cumulative amount of sulfur and nitrogen inputs. For example, certain watershed soils-e.g., those that are sulfur saturated-may continue to release sulfur at a higher rate for an extended period of time subsequent to a decrease in atmospheric sulfur loading. Thus, sulfate concentrations in surface waters may continue to decrease in the future as a consequence of deposition changes that have already occurred. Also, if the soil's acid neutralizing base cation reserves continue to be depleted by long-term sulfur deposition, base cation concentrations in some 
surface waters could continue to decrease, causing additional acidification, irrespective of any further changes in sulfate concentrations.

Quantitative dose-response relationships for sulfur have been determined, using a variety of approaches in a number of regions in North America and Europe. Such studies have included, for example, measured changes in water chemistry during periods when sulfur deposition changed appreciably, regional paleolimnological investigations (e.g., diatom-inferred change in $\mathrm{pH}$ and acid neutralizing capacity), watershed manipulation studies, and intensive process modeling.

Measured changes in surface water chemistry in areas that have experienced short-term (less than 20 years) changes in chemical constituents in response to changes in mineral acid inputs are available from a number of sources. Proportional changes in acid neutralizing capacity, base cations, and inorganic aluminum relative to changes in sulfate or sulfate plus nitrate concentrations have been documented for several lakes and streams, ${ }^{80}$ including lakes in the Sudbury region of Ontario; the Galloway Lakes area of Scotland; a stream site at Hubbard Brook, New Hampshire; and catchment manipulation experiments in Norway and Wisconsin. Most of the observed changes are coincident with decreased acid deposition, but it is unclear whether acidification and recovery are symmetrical.

In most cases, the largest response to the change in dose (sulfate plus nitrate concentration) has been a concomitant change in base cation concentrations. The measured base cation response has typically been in the range of $50-90 \%$, although values as low as $35 \%$ have been found for highly sensitive watersheds made up largely of exposed bedrock. The acid neutralizing capacity response is usually smaller $(10-50 \%)$, as is the aluminum response $(0-15 \%)$.

Considerable experimental research has been conducted over the past several years to quantify the environmental effects of atmospheric deposition, especially of nitrogen. This research has been initiated almost exclusively in Europe; little comparable work has been conducted in the United States. The experimental approach has shifted heavily into the area of broad, whole-ecosystem manipulations across gradients of atmospheric deposition, climate, and other environmental factors. This holistic approach is used to evaluate key processes in the broader context of ecosystem structure and function, rather than as isolated process studies. The research needs to be sustained over an extended time to understand the long-term impacts of atmospheric pollutants and other factors.

The whole-ecosystem manipulation experiments in Europe have been augmented by a number of detailed, process-level studies at the various manipulation sites. Key aspects include stable isotope tracer studies to quantify the partitioning of nitrogen into various ecosystem pools (e.g., soil, litter, trees, ground vegetation) and to measure changes in the quantities of stored nitrogen in these pools. Other studies focus on quantifying the rates of important ecosystem processes, including the nitrogen conversion processes, nitrification, and mineralization.

Results of both the broad-scale and detailed studies are being used to build and test mathematical models that simulate nitrogen processing, nutrient cycling, and water regulation in coniferous forest ecosystems under varying depositional and climatic regimes. Ultimately, these models will be used to predict nitrogen saturation, estimate the critical loads of nitrogen for forests, and specify emission controls needed to protect forests from the detrimental effects of excess nitrogen deposition.

The effects of other ecosystem stressors must also be considered in quantifying ecosystem effects attributable to acid deposition. Climatic fluctuations, especially precipitation input and its effects on water availability, act synergistically with a variety of indirect effects of acid deposition. The effects of climatic variability make it particularly difficult to predict acidification or deacidification responses. The obvious linkages between short-term climatic fluctuation and anthropogenic sources of nitrogen and sulfur are incorporated into the experimental approach followed by the European EXMAN program. ${ }^{81}$ Both drought and nitrogen-plus-sulfur inputs are evaluated alone and in combination under a variety of conditions. The linkage with climatic change is taken further still in the European CLIMEX project, which entails simultaneous whole-ecosystem manipulation of temperature, atmospheric carbon dioxide, and acid deposition. ${ }^{82}$ Long-term climatic trends will also affect ecosystem responses to acid deposition, and atmospheric concentrations of sulfur oxides have been linked with regional or global impacts on temperature. 


\section{Forest Ecosystems}

At present, the mortality and decline of red spruce at high elevations in the Northeast and observed reductions in red spruce growth rates in the southern Appalachians are the only cases of significant forest damage in the United States for which there is strong scientific evidence that acid deposition is a primary cause.

The interaction of acid deposition with natural stress factors has adverse effects on certain forest ecosystems. These effects include:

- Increased mortality of red spruce in the mountains of the Northeast. This mortality is due in part to exposure to acid cloud water, which has reduced the cold tolerance of these red spruce, resulting in frequent winter injury and loss of foliage.

- Reduced growth and/or vitality of red spruce across the high-elevation portion of its range.

- Decreased supplies of certain nutrients in soils to levels at or below those required for healthy growth.

Although forest ecosystems other than high-elevation spruce-fir are not currently manifesting damages directly attributable to acid deposition, less sensitive forests throughout much of the United. States are experiencing gradual losses of base cation nutrients due to acid deposition, which in many cases will reduce the quality of forest nutrition over the long term (decades).

Nitrogen deposition is now recognized with sulfur as an important contributor to effects on forests in some ecosystems, which occurs through direct impacts via increased foliar susceptibility to winter damage, foliar leaching, leaching of soil nutrients, elevation of soil aluminum levels, and/or creation of nutrient imbalances. An excessive amount of nitrogen causes negative impacts on soil chemistry similar to those caused by sulfur deposition in certain sensitive high-elevation ecosystems, and is a potential contributor to these impacts in some low-elevation forests.
Responses of forest ecosystems to emission reductions will depend on the relationship between the location of the reductions in $\mathrm{SO}_{2}$ and $\mathrm{NO}_{\mathrm{X}}$ and the location of sensitive receptors (soils and forests types) and other factors, such as elevation. Some of the most sensitive soils and vegetation are at high-elevation sites in the eastern United States, where regional emissions are already high and have been so for decades. The frequent occurrence of acidic cloud water approximately doubles the exposures at these sites, compared to exposure levels typically encountered at lower elevations. In these sensitive high-elevation ecosystems, nitrogen deposition can be of equal or greater importance than sulfur deposition in causing adverse effects. In contrast, in many forests throughout the United States, where nitrogen is deficient, nitrogen deposition may actually be beneficial.

Because sensitive forest receptors exhibit both a shortterm and a long-term response to changes in deposition, the timing of those changes needs to be estimated. But during the 1990s, there has been no systematic attempt to monitor the changes in forest condition or in the chemistry of forest soils in response to changes in acid deposition, although such monitoring at a few individual locations has occurred. The scarce data that are available from specific sites are not regionally representative and do not cover the 1990-1996 period.

\section{Observed Effects}

Geographic regions of the United States-and the forest ecosystems within those regions-vary in their current status and their sensitivity to effects from the deposition of nitrogen and sulfur. Variations in potential future forest response and/or sensitivity result in part from differences in (1) deposition of sulfur and nitrogen, (2) sensitivities of ecosystems to sulfur and nitrogen, and (3) responses of soils to inputs of sulfur and nitrogen.

The response of ecosystems to sulfur and nitrogen deposition is frequently an indirect response in which soil chemistry plays a potential role. Research results on soil and plant responses to sulfur and nitrogen additions in greenhouse, laboratory, controlled-exposure, and field studies indicate that negative responses will occur in nutrient-depleted soils. These negative responses include: (1) plant nutrient deficiencies, particularly of base cation nutrients like calcium, magne- 
sium, and potassium; (2) elevated levels of aluminum and calcium/aluminum ratios in soil water that interfere with plant uptake of these nutrients; and (3) elevated levels of aluminum that are directly toxic to plant roots. The last is the least common of the three because it requires particularly high levels of aluminum for most forest species.

Soil sensitivity to deposition varies based on differential ability of soils to retain the deposited sulfur and nitrogen. Soils with a low sensitivity have high capacity to adsorb sulfur and have plants and microbes that are low in nitrogen and readily take up and use deposited nitrogen. The sensitivity of soils is also determined by the size of their stores of base cation nutrients. Sensitive soils, which cannot retain much additional sulfur and/or nitrogen (i.e., are saturated) lose these base cation nutrients as sulfur and nitrogen in soil water pass through the forest and into streams. When soil base cation stores become low, naturally occurring but potentially toxic soil aluminum begins to replace the cations in soil water. Differences in ecosystem sensitivity are also tied to a number of plant characteristics, including the sensitivity of individual species to direct effects of deposition, and the nutrient requirements and growth rates of those species. The latter affect a plant's ability to use deposited nitrogen or to respond to nutrient losses.
In addition to the broad geographic patterns of deposition, increases in elevation can cause large increases in both sulfur and nitrogen deposition. Not only do rainfall and wind speed increase, and temperature and other natural stresses change with elevation, but both cloud water and dry deposition also increase dramatically. On average, concentrations of sulfur, nitrogen, and acidity in cloud water are two to five times higher than in rainfall. Acidic cloud water, plus high winds on mountaintops and the efficient collection of cloud water by tree needles, make deposition to high-elevation sites several-fold higher than nearby low-elevation sites.

\section{Sensitive Receptors}

For purposes of discussion of forest ecosystem effects in this assessment, the United States has been divided into four very broad regions based on their differential sensitivities in general and the differential amounts of deposition received (Figure 19 and Table 6). In addition, these regions have differing aesthetic, recreational, and economic characteristics that need to be considered when evaluating impacts from acid deposition. Three regions are east of the Great Plains: high-elevation spruce-fir forests; southern pine and pine-hardwood forests; and hardwood (deciduous) forests of the Midwest and the Northeast, which

Figure 19

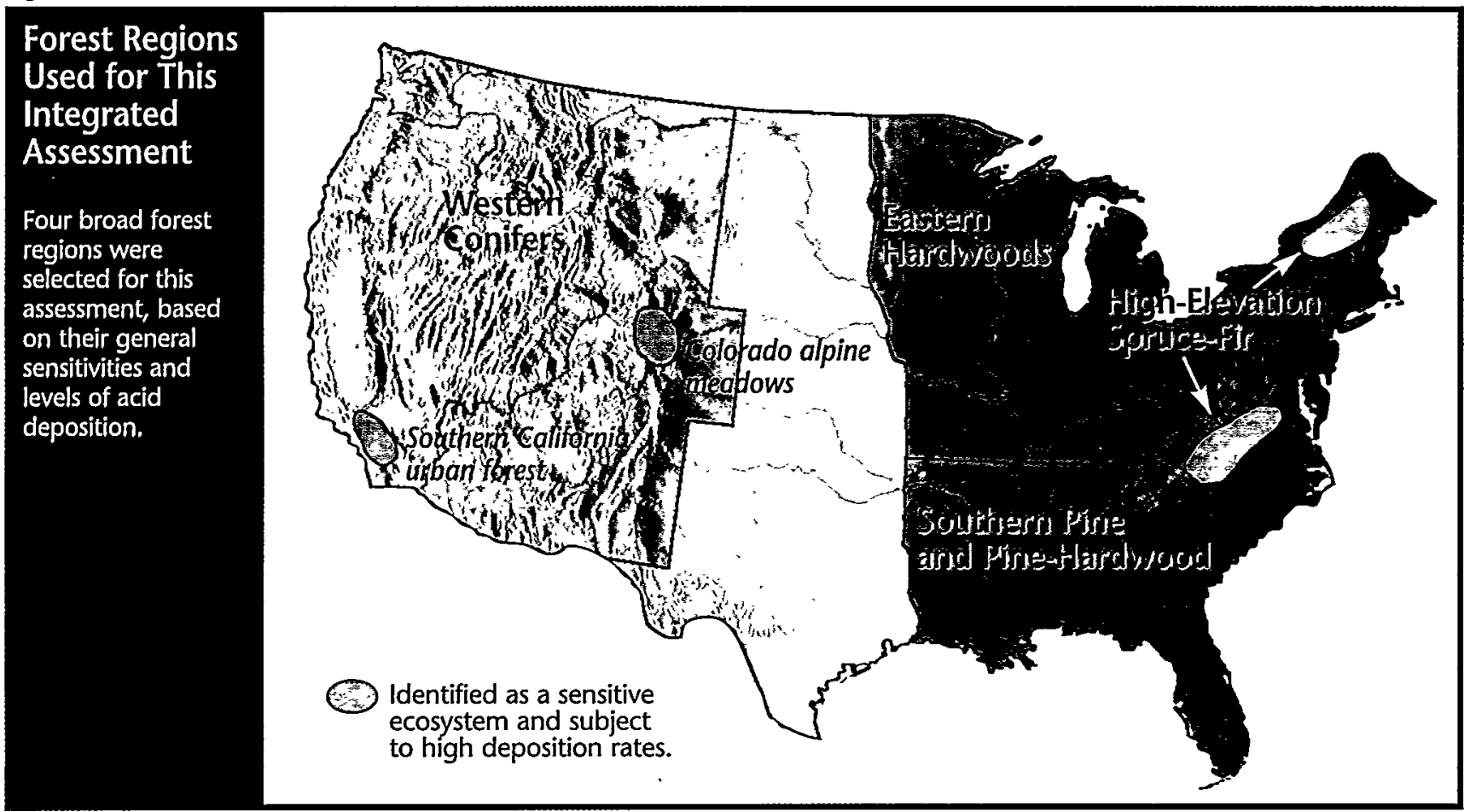


include areas of low-elevation conifer forests, especially in the northernmost portions of the eastern United States. The fourth broad region, which includes all the ecosystems west of the Great Plains, encompasses a wide variety of plant communities; however, the significant impacts of acid deposition have only been detected on a limited area. Most of these western ecosystems are relatively unaffected either because they receive limited amounts of sulfur and nitrogen, or because they are relatively well buffered against their effects, or both. A summary of the observed effects on each of these four types of forest ecosystems follows.

\section{High-Elevation Spruce-Fir Forests}

High-elevation spruce-fir ecosystems in the eastern United States epitomize sensitive soil systems. Base cation stores are generally very low, and soils are near or past their capacity to retain more sulfur or nitrogen. Deposited sulfur and nitrogen, therefore, pass directly into soil water, which leaches soil aluminum and minimal amounts of calcium, magnesium, and other base cations out of the root zone. The low availability of these base cation nutrients, coupled with the high levels of aluminum that interfere with roots taking up these nutrients, can result in plants not having sufficient nutrients to maintain good growth and health.

Exposure to acidic clouds and acid deposition has reduced the cold tolerance of red spruce in the Northeast, ${ }^{89-91}$ resulting in frequent winter injury of currentyear foliage during the period 1960-1985. Repeated loss of foliage due to winter injury caused crown deterioration and contributed to high levels of red spruce mortality in the Adirondack Mountains of New York, the Green Mountains of Vermont, and the White Mountains of New Hampshire. 92.93 However, there is uncertainty about the relative importance of sulfur, nitrogen, and acidity in causing this decline in cold tolerance.

Acid deposition has contributed to a regional decline in the availability of soil calcium and other base cations in high-elevation and mid-elevation spruce-fir forests of New York and New England and the southern Appalachians through two mechanisms: leaching of base cations from foliage and from the primary rooting zone, and the mobilization of labile aluminum. ${ }^{93.94}$ The role of nitrogen deposition in this deterioration of soil base cation availability is greater than previously realized.

Changes in soil chemistry and red spruce nutrition over the past few decades may have contributed to both growth declines and deterioration of crown condition in the Northeast and at the higher elevations of the southern Appalachians, based on physiology changes induced by acid deposition in field and laboratory studies. ${ }^{94}$ While red spruce in the southern Appalachians has not shown areawide increased mortality in recent decades, ${ }^{95}$ approximately a two- to threefold increase in significant crown deterioration at upper elevations was observed between 1985 and 1989. The relative roles of acid deposition and severe winter weather on red spruce crown deterioration in

Table 6

Characteristics for Assessing the Effects of Acid Deposition on Forest Ecosystems

Characteristics were used to select forest ecosystems for assessing the regional effects of acid deposition. Predominant characteristics appear in most forests of that ecosystem type. Variable characteristics appear in some forests of that ecosystem type, but not in others.

\section{TYPE OF FOREST ECOSYSTEM}

\begin{tabular}{|c|c|c|c|c|}
\hline CHARACTERISTICS & $\begin{array}{l}\text { High-Elevation } \\
\text { Spruce-Fir }\end{array}$ & $\begin{array}{l}\text { Southern Pine/ } \\
\text { Pine Hardwood }\end{array}$ & $\begin{array}{c}\text { Eastern } \\
\text { Hardwood }\end{array}$ & $\begin{array}{l}\text { Western } \\
\text { Conifers }\end{array}$ \\
\hline Sensitive Ecosystem & Predominant & & & Variable \\
\hline Sensitive Soils & Predominant & Predominant & Variable & \\
\hline High Regional Deposition & Predominant & Variable & & \\
\hline High Local Deposition & Predominant & & Variable & Predominant \\
\hline $\begin{array}{l}\text { Aesthetic or Recreational Value } \\
\text { Economic Value }\end{array}$ & Predominant & $\begin{array}{c}\text { Variable } \\
\text { Predominant }\end{array}$ & $\begin{array}{l}\text { Predominant } \\
\text { Predominant }\end{array}$ & $\begin{array}{c}\text { Predominant } \\
\text { Variable }\end{array}$ \\
\hline
\end{tabular}


the southern Appalachians are unclear. ${ }^{95}$ While ice damage has been associated with loss of canopy integrity in the Black Mountains, ${ }^{96}$ it should be noted that significant loss of canopy integrity also occurred in the Smoky Mountains, where significant ice damage was not observed. ${ }^{97}$ Foliar calcium levels and soil and root calcium/aluminum ratios are considered low to deficient over most of the southern spruce-fir region and portions of the northern region. 83.98 Changes in soil chemistry, trends in wood chemistry, and changes in lake water chemistry suggest that a significant loss of calcium has occurred during recent decades from the organic soil layers, which is the primary rooting zone for red spruce. 99,100 Both tree uptake and storage of calcium and acid leaching losses are responsible for these losses from the soil.98 Fertilization experiments in the southern Appalachians show positive growth responses and positive leaf physiological responses to additions of calcium. ${ }^{94.101}$ Stress in red spruce in the Northeast is indicated by an increase in the biochemical stress marker putrescine in red spruce needles from areas of high acid deposition and low soil calcium/aluminum ratios. ${ }^{102,100}$ Negative physiological responses have also been observed at highly polluted sites in the South ${ }^{103}$ and in the North. ${ }^{104}$

Recent evidence indicates that most southern Appalachian spruce-fir ecosystems are near or at nitrogen saturation. Nitrogen saturation is often defined as a condition of the terrestrial ecosystem where outputs from the system equal or exceed inputs, resulting in elevated levels of nitrogen in soil solutions, ground water, and streams draining the terrestrial system (see the Aquatics section, under the Nitrogen Cycling subheading). For these saturated systems, high nitrogen deposition is transmitted through the ecosystem and results in base cation and aluminum leaching from soils, elevated aluminum in soil water, which reduces base cation nutrient uptake, and elevated nitrate and aluminum levels in streams. ${ }^{98,105}$

\section{Southern Pines and Pine-Hardwood Forests}

Significant impacts of acid deposition on forest health have not been detected in the southern pine and pinehardwood region. However, acid deposition is a major contributor to the depletion of base cations in many poorly buffered soils supporting southern pines and will most likely, over the long term (decades), impede productivity. Short-term positive effects on growth are expected for some nitrogen-deficient soils, while neg- ative effects are expected to be limited to the most acidic, base-depleted soils.

A synthesis of studies that originated as a part of NAPAP to evaluate the sensitivity of southern pines to acid deposition and ozone has now been completed. 106 In chamber studies, saplings of the three principal commercial pine species (loblolly, shortleaf, and slash pine) were exposed to simulated acid rainfall and ozone. Maximum annual growth reductions in saplings due to ambient ozone were quite small ( $2-5 \%)$, but the yield could be significantly reduced over longer time frames. ${ }^{107}$ Growth rates of saplings typically responded positively to ambient levels of acid rainfall. However, longer-term exposures are expected to have cumulative negative effects on soil nutrition. Currently, an estimated $59 \%$ of the pine forests of the Southeast have soils that are low enough in base cations to be susceptible to acidification by cation leaching due to acid deposition, and $10 \%$ of the soils are considered extremely acidic. ${ }^{88,108}$ An estimated $10-15 \%$ of the commercial pine forests in the South may be limited by availability of these nutrients. ${ }^{109}$ Thus, additional leaching may further limit pine growth on these soils. While these impacts will most likely have negative long-term consequences, the inputs of atmospheric sources of nitrogen to many soils with low nitrogen reserves, which currently support southern pine forests, should have small cumulative positive effects on productivity for as long as decades. ${ }^{109-111}$

\section{Eastern Hardwood Forests}

Studies have shown that acid deposition has caused increased cation leaching from some hardwood ecosystems, and this leaching may affect the health of those systems. ${ }^{57,112-117}$ Although sulfate is the primary anion causing base cation leaching, nitrate is a significant contributor in watersheds that are nearly nitrogensaturated as a result of acid deposition, ${ }^{60}$ and studies indicate that some hardwood ecosystems are close to nitrogen saturation."18 Nevertheless, in general, the health of eastern hardwood forests has not been shown to be adversely affected by acid deposition. However, broad-scale monitoring has not been conducted to confirm this finding.

The compositional properties of foliage may also be altered by acid deposition, resulting in changes in organic matter turnover and nutrient cycling." sensitivity of hardwood soils to acid deposition is largely controlled by inherent properties, climate, and 
land use."13 However, tools to assess present conditions or susceptibility to nutrient depletion are not readily available or widely applicable. ${ }^{120}$

\section{Western Forests}

While most of the forest ecosystems in the western United States do not show significant impacts from acid deposition, certain areas appear to be affected negatively, especially by high rates of nitrogen deposition. Forested sites near urban areas in southern California and alpine meadows of the Front Range in Colorado have been exposed to high levels of nitrogen and sulfur deposition for the last 40 years. ${ }^{21.122}$ Many of these sites are showing signs of nitrogen saturation, which include elevated levels of nitrogen in streams (see the previous section on Aquatics) and changes in the cycling of nitrogen and carbon. Continued nitrogen deposition may also lead to shifts in species composition and biodiversity.

In southern California, ozone exposure and nitrogen and sulfur deposition occur coincidentally. Ozone exposure and acid deposition are greatest near Los Angeles, and decrease along a gradient running to the east/northeast toward the San Bernardino and San Gabriel Mountains. ${ }^{123}$ The greatest exposure to all pollutants occurs in the summer, when these forests are also subject to drought stress. ${ }^{124}$ These multiple stressors weaken trees, making them vulnerable to bark beetle attack, which ultimately causes mortality. ${ }^{125}$ In addition, ozone causes premature leaf abscission, and nitrogen deposition has a major impact on soil and forest floor processes. These factors combined can lead to changes in patterns of nitrogen and carbon cycling. ${ }^{26}$

In the alpine areas of Colorado, nitrogen deposition occurs during summer and winter. ${ }^{127}$ Nitrogen additions to alpine meadows also change the cycling of nitrogen and carbon. Nitrous oxide emissions from soil increase and rates of methane oxidation decrease. ${ }^{128}$ Methane is a greenhouse gas, and its removal from the atmosphere by oxidation is an important function of natural systems. ${ }^{128}$ In addition, sites with high nitrogen deposition have decreased surface water quality due to elevated nitrate levels.

\section{Regional Dose-Response Relationships}

Models predict that recent reductions in sulfur deposition will rapidly improve some aspects of soil chemistry related to intensity factors (see text box on Sensitive Forest Components) in sensitive forests (i.e., immediate but brief increases in the concentrations of base cations in solution and/or reductions in aluminum concentrations), but full recovery of these soils and forests from previous impacts will be quite slow (decades to centuries). Full recovery would require: (1) regrowth of dead stands, (2) return to historical growth rates for species like red spruce, and (3) replenishment of lost cation nutrient stores.

Nitrogen deposition is of approximately equal importance to sulfur deposition in causing changes to occur in sensitive forest ecosystems. Such systems should rapidly show partial recovery in response to significant reductions in nitrogen deposition.

When evaluating how forests respond to changes in the levels of acid deposition, it is important to take into account specific soil and forest responses (see the Soiland Forest-Related Effects text box). Following are descriptions of the different responses of various regions.

\section{High-Elevation Spruce-Fir Forests}

Reductions in ambient concentrations of acid deposition and cloud water should rapidly reduce the susceptibility of red spruce to winter injury. However, data are not available to provide the specific reduction levels of various compounds (sulfate, nitrate, or acidity) that are required to fully protect foliage from past increases in susceptibility to freezing injury. A linear dose-response relationship exists between the acid dose from cloud water and the freezing injury $130-132$ both in the Northeast ${ }^{89}$ and in the southern Appalachians. ${ }^{133-135}$ While increased frequency of damage to red spruce foliage has been notable at high elevations in the North, only a very mild form of winter damage has been observed in the South, ${ }^{136}$ probably because extremely low temperatures occur less frequently at southern high elevations.

While high-elevation spruce-fir forests should experience some immediate improvements in health with reductions in sulfur and/or nitrogen deposition, their growth and vitality will probably be limited by the availability of certain nutrients for decades. Results of modeling efforts using a nutrient cycling model 


\section{Sensitive. Forest Components}

Predicting changes in the health or function of forest ecosystems in response to changes in the levels of acid deposition requires identifying ecosystem components that are afféctéd by acid deposition and that also affect the function of forest ecosystems. One forest component that ha's become more prominently recognized as a valuable indicator of ecosystem change is fóliar nutrient concentration ${ }^{83}$

\section{Foliar Nutrient Concentratión}

Both the store of nutrients in the foliage and the immediately available store of nutrients in the soils can be quite small and potentially susceptible to large depletion caused by acid deposition there is increasing evidence that reduced availability of câlcium, both from short-term increased foliar leáching ${ }^{84}$ and long term. reduced soil supply, may alter photosynthesis to respiration ratios and cause reductions in carbon fixation rates and whole-plant growth rates in red spruce.85

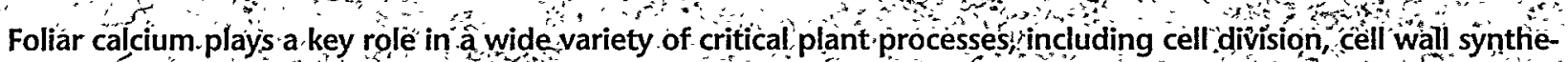
sis, diseáse resistançé, cold acclimatization, and plant senescence. Chánges in calcium contént in the soil caused

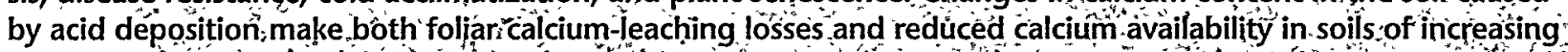
jnterest in understanding the ability of forest ecosystems to respond to other environmental stresses.

\section{Forest Soils} sit.
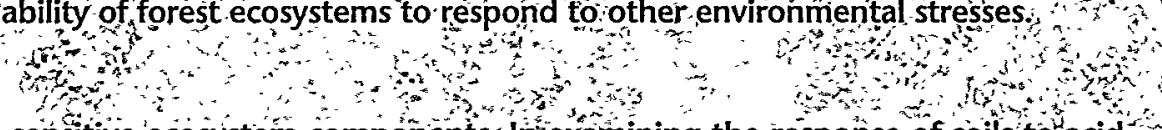

the response of soils toacid a compon deposition, it is important to make aldistinction between short-term response (from changes in intensity fáctors) and longer -term response (from changes in capacity fáctors) ${ }^{6} 6$ intensity factors refer to the concentra tion of a chemical in soil water, wheneas capacity factors refer to the total content of bases, aluminum, and iron stored in the soil itself. Ihe soil represents a large chemical pool compare to the chemicals in soil water Changes in intensity factors result from significant and rapid shifts in certain small chemical pools in the soil and vegetation. Because the chemical pool size of capacity factors is large relative to changes caused by acid deposition or other natural processes, changes in capacity factors in the short term are typically small s Changes in intensity factors, can have apid impact on the chemistry of soil solutions. Increases in amounts of sulfur or nitrogen in acid deposition can cause immediate increases in acidity and mobilization of aluminum in soil solutions. Increased concentrations of aluminum and an increase in the ratio of calcium-to-alựis: minum in soil solution have been linked to significantly reduced plant availability of essential base cations, increased plant respiration, and increased biochemical stress indicators:

Changes in capacity factors are the result of many processes acting over long time periods. For example the base cation icontent of soils is the resultiof inputs of base cations (calcium, magnesium, sodium, potassium), from, atmospheric deposition, vegetative decomposition, geologic wéthering, and losses due to plant uptake and leaching : Increased leaching of base cátions caused by acid deposition may result in nutrient deficienciés in soils if other inputs of basế cations (e,got atmospheric deposition, geologic weathering) cannot resupply these losses at the same rate. This appears to be the case in many sensitive forest ecosystems in the United

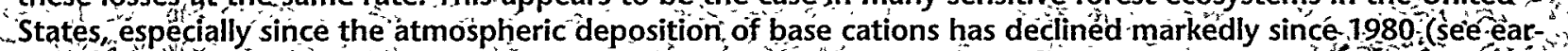
lier section on Emissions, Concentrations, and Deposition) and geologic weathering rates are very slow in many ecosystems. The situation is also complicated by the removal of base cations from forest soils by tree uptake and incorporation in plant material 87 Subsequent harvest removal of base cations is generally of the "same magnitưde as leảching dûe to aćid deposition.

Even though acid depostion causes cation nutrient depletion in sols, the nitrogen in acid depositiom may a stimulate tree growth in certain areas. In many forest ecosystems, nitrogen is the primary nutrient that limits? - growtho 8 Thứs pósitive impacts (nitrogen fèrtilization) and negativề impacts (cation leaching from soils) may be operating at the same time in the same system. The relative importance of these two impacts must be assessed to to derstand the leyel and timing of responses of forest ecosystems to émission reductions The intensty and capacity characteristicsof forest ecosystems are significant because they highlight the importance of interactions between deposition of strong anions (sulfate and nitrate) and natural factors that

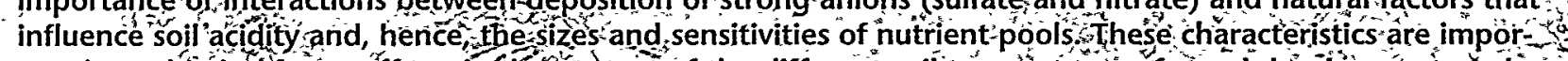
tant in evalưting forest effects in the context of the different soil types; stages of stand development, and forest manágenent practices, relation to acid deposition levels r o 


\section{Soil- and Forest-Related Effects of Acid Deposition}

\section{Soil-Related Effects}

In sẹnsitive soils - ones where-base cation stores are very low and the ability of the ecosystems to retain sulfur or nitrogen is minimal-the response to changes in sulfur or nitrogen dosès can be quite ràpid. As levels of sulfur and nitrogen compounds in soil water decline, both aluminum and base, cation levels decline as well, but aluminum levels decline silightly more rapidly. The opposite occurs as concentrations of sulfur and nitrogen compounds increase; aluminum increases more rapidly than base cations Response both ûpand down are particularlys sensitive to changes in nitrogen inputs becaús in nitrónen-saturated ecosystems nitrate passes quickly înto soll water and on to streams. Sulfư compounds sare more likely to be retained by yarious reactions in the soil: While some rapid changes in soll water chemistry will oc cur full replenishment of base cation stores will be áslow process. The response of less sensitive ecosystems is considerably slower These systems either still have adequate

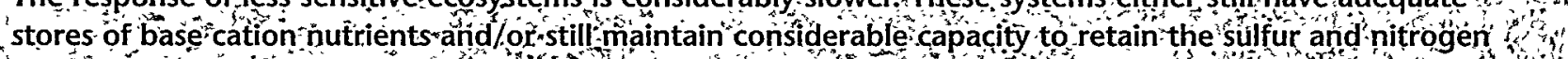

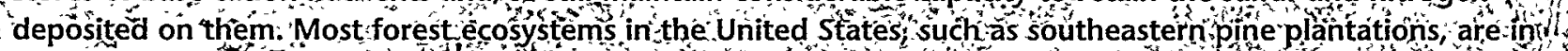

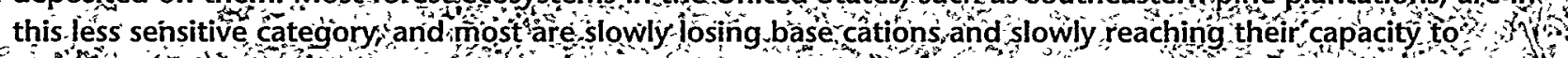

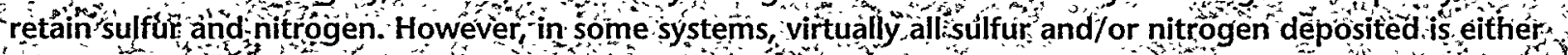
adsorbed on the soil or used by growing vegetation of microbes Much of this sulfur and especially nitrogen

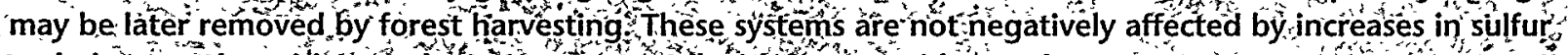
and nitrogen deposition, and even may respond with pore rapid growth,

\section{Forest-Rélated Effects}
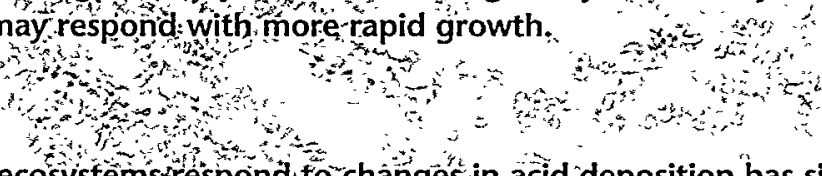

Understanding how sensitive forestecosystems tespond to changes in acid deposition has significantly

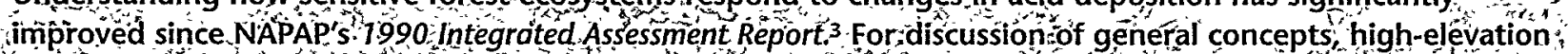
spruce-fir forests are used as a model $1 \mathrm{n}$ geñeral, other forest ecosystems in the United States are not currently experiencing the same effects in mortality and growth as the spruce-fir ecosystem However the process of base cation leaching and a trend toward more acidic, aluminum-dominated soils is occurring slowly in many of these forested ecosystems figure-20 illustrates the generalose-response relationship for nutrient limitations associated with increasing soil and deposition acidity $\rightarrow+x^{2}+\infty$ Théavaliability of calcium is inceasingly recognized as important to forest health 94 , In studies of spruce fir. forests, calcium deficiency symptoms increased in red spruce saplings at high-élevation sites with increased exposure to acid deposition. Low calcium availability was well correlated with high levels of soil aluminum.

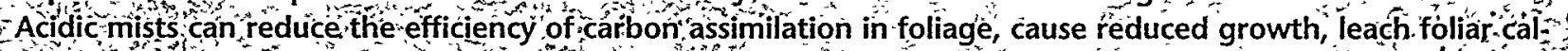
cum, and alter patterns of root growth. Fertilize, experiments in the field have now substantiated that foliar calcium levels at high elevation sites are low enough to reduce growth of both rèd spruce saplings 129 and mature trees.

\%hanges in foliar nutrient content, sol nutrient content and the availability of calcium are involved in the

observed responses of red spruce to acid deposition, While some rapid reduction in basection leathing can

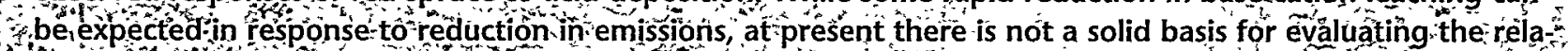

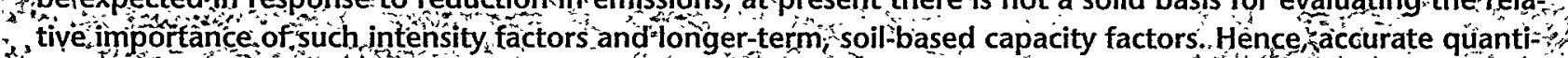
4 tative pojections of response rates to emission reductions are not possible.

(NuCM) for a highly acidic spruce-fir forest in the southern Appalachians predicts that significant reductions in sulfur or nitrogen deposition would result in some rapid improvement in the amount of calcium available for uptake ${ }^{137}$ and small improvements in the calcium/aluminum ratio. While this model predicts significant improvements in the short-term supplies of calcium and other base cations, the recovery of longterm storage capacity will be limited because (1) existing high levels of aluminum saturation reduce the ability to store calcium introduced by atmospheric deposition, weathering, or decomposition of litter;99,138 
Forest Ecosystems

Figure 20

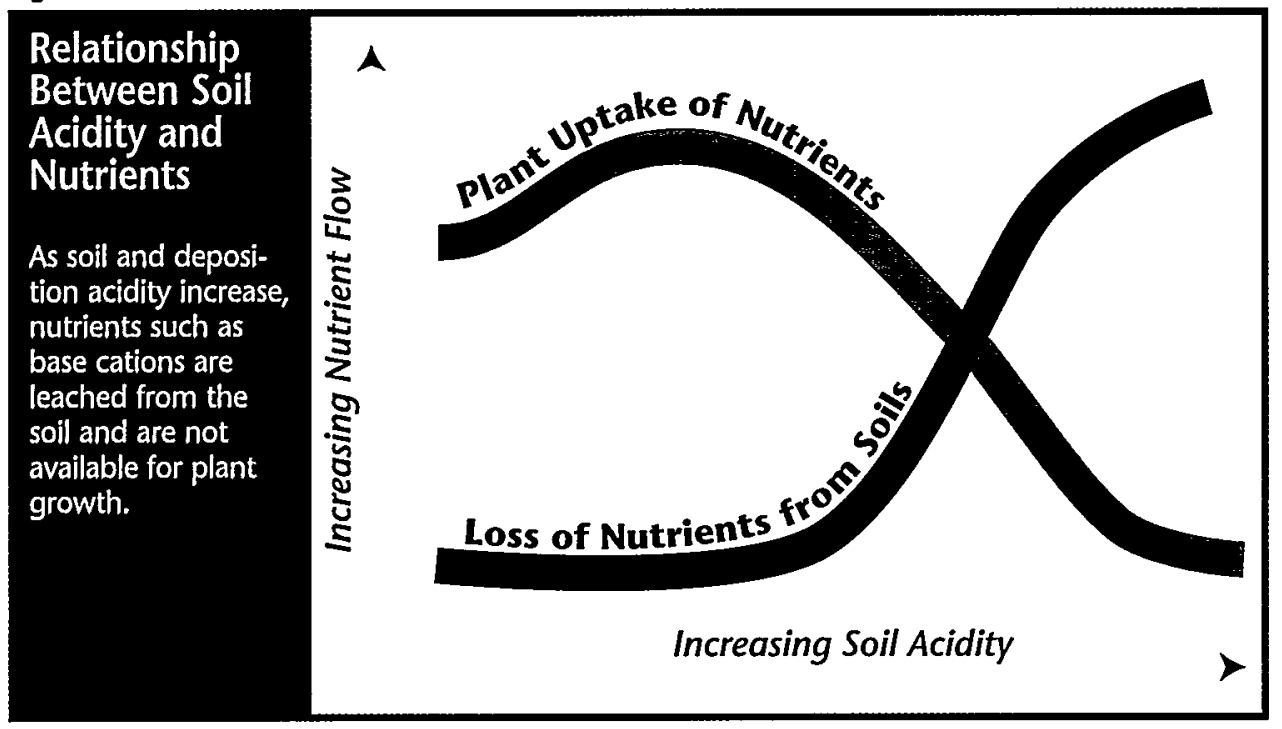

release of stored nitrogen as a result of warming. These soils typically have very large stores of nitrogen in their organic matter. ${ }^{98,141,142}$ Rates of nitrogen mineralization, nitrate release, nitrate leaching, and nitrogen in streams are already very high in these ecosystems. ${ }^{98,143}$ Increases in nitrate resulting from soil warming have been observed in field studies. ${ }^{118,144}$ Warmer temperatures will increase foliar respiration, an

and (2) decreased atmospheric deposition of base cations will limit inputs." 2 (See The Calcium/Aluminum Ratio as a Forest Ecosystem Indicator text box.)

The future health of spruce-fir ecosystems may also be quite sensitive to increased temperatures due to global warming. ${ }^{139,140}$ High-elevation spruce-fir soils are particularly vulnerable to increased acidification by their effect that has also been stimulated by calcium deficiency and increasing exposure of red spruce to acid deposition in the southern Appalachians. ${ }^{103}$ Analyses of tree-ring data from mature high-elevation red spruce trees in the southern Appalachians show that growth effects associated with warmer temperatures and higher rainfall have become increasingly negative during the past three decades. 1 to

\section{The Calcium/Aluminum Ratio as a rorest Ecosystem lndicator}

T 4 a

in he health of forests can be assessed by monitoring such indicators of stress as crown condition growth

mortality, and basal area The calcium/âluminum ratio of the soil solution is a possible écological indicator

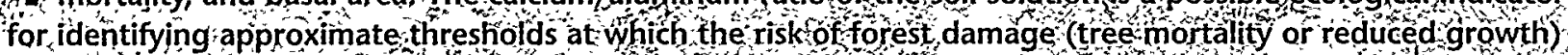

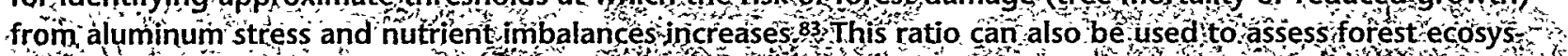
tem changes over time in response to acid deposition as well as to forest havesting and other processes con

tribuiting to acid soil infertility J jis ratio may no be reliable indicator of stres in $(j$ areas with both high atmospheric deposition of ammonium and magnesium deficiency via antagonism ino

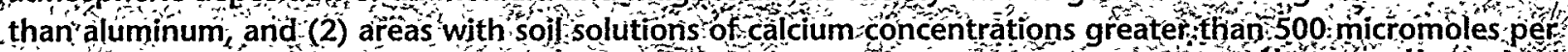

liter

If the calcium/aluminum ratio js 1.0 , then forests have a $50 \%$ risk of adverse impacts

If the ratio is 0.5 , then the risk is $75 \%$

af the ratio is 0.2 then the risk is nearly $100 \% 0 \%$ os

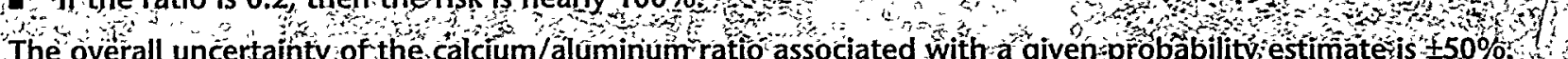

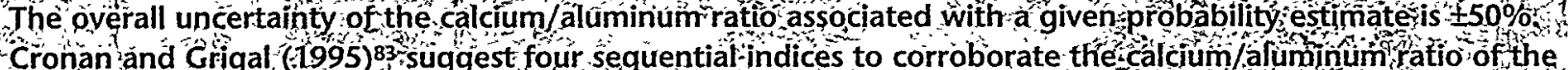

Soil sôlution

W

- Soj base saturation less than $15 \%$ of effective cation ex change capacity

Soj-solution calcum/aluminum molar ratio less than 0 for $50 \%$ risk

- Fine root tissue calcium/aluminum molay a to than 0.2 for $50 \%$ risk

Foliar tissué calcium/aluminum molar rafo Tess than 12.5 for $50 \%$ s. 


\section{Southern Pines and Pine-Hardwood Forests}

The productivity of southern pines is expected to be more limited by ambient ozone levels than by ambient levels of acid deposition. Short-term (one- to threeyear) experiments to evaluate the interactive effects of acid deposition and ozone on seedlings and saplings have indicated that ambient levels of acid deposition have not exacerbated the negative effects of ozone on growth. ${ }^{145}$ Studies on older trees in acid soils are needed to evaluate the long-term impacts.

Adverse effects of ozone on growth have typically been associated with reduced carbon gain in photosynthesis and premature loss of foliage. Estimated annual effects of ozone on seedlings under ambient exposures are typically small $(2-5 \%)$ and difficult to detect statistically, but are a basis of concern for longer-term, cumulative effects on growth. ${ }^{107}$ In addition, studies with mature loblolly pine trees have demonstrated short-term reductions in stem growth at ambient ozone levels that were amplified by both moisture stress and high air temperatures. ${ }^{146,147}$ The latter study suggests that future ozone effects may be amplified if global change produces a warmer, drier climate.

In some cation-deficient soils, potentially positive short-term growth responses to deposited nitrogen may be followed by longer-term negative influences of acid deposition due to continued leaching of base cations. ${ }^{88.145 .148}$ Predictions of growth responses across the region are not available yet, however, because the effects have not been quantified.

Reducing the levels of acid deposition will reduce the rate of cation depletion of southern pine forests. However, recovery of soil cations by natural processes is expected to be slow because both mineral weathering and cation recycling are very low. 88 Since neither growth losses from past acid deposition levels nor growth enhancement from nitrogen fertilization have been quantified to date, it is not possible to estimate either the direction or the rate of change in these forests in response to emission reductions.

\section{Eastern Hardwood Forests}

Hardwood soils are known to be sensitive to acid deposition, but the dose-response relationships have not been determined. The sensitivity is expressed in terms of low buffering capacity (i.e., low resistance), but low levels of acidic input can cause nitrogen saturation and base cation depletion. Changes in atmos- pheric deposition may cause rapid changes (months to years) in the chemical properties of soils in hardwood forests. Models may be useful in assessing doseresponse relationships, but they must be tested and validated.

Lack of specific dose-response relationships or modeling tools to assess sensitivities or thresholds precludes large-scale assessments of hardwood forest responses to altered levels of acid deposition. Watersheds exposed to chronic, low-level acidic inputs have shown symptoms of nitrogen saturation and base cation depletion, and experimental additions of nitrogen and sulfur have shown that nitrogen saturation can be induced in a short period (i.e., three years). ${ }^{115}$ Assessment of ecosystem responses to dosed additions of nitrogen and sulfur is further complicated by the exposure history of the site or watershed, land-use history, natural disturbance regime, and climate. Models have been useful in evaluating acidification processes and cation leaching; 137 however, further model development and validation are needed.

\section{Western Forests}

Several sensitive areas in the western forests are becoming nitrogen saturated due to chronic nitrogen deposition. Pine forests in the San Bernardino Mountains of southern California receiving high levels of nitrogen deposition $(\sim 25 \mathrm{~kg} / \mathrm{ha} / \mathrm{yr})$ are already nitrogen saturated, while those receiving moderate levels $(6-16 \mathrm{~kg} / \mathrm{ha} / \mathrm{yr})$ show evidence of approaching saturation. ${ }^{121}$ Exposure to high levels of sulfur, nitrogen, and ozone, along with drought stress, weakens the trees and leads to premature mortality.

Alpine meadows along the Colorado Front Range are also showing signs of nitrogen saturation, but at lower levels of nitrogen input $(3-5 \mathrm{~kg} / \mathrm{ha} / \mathrm{yr})$ than those in southern California. ${ }^{127}$ The increase in nitrogen deposition at sites in Colorado has coincided with climatic changes, including decreased mean annual temperature, increased annual precipitation, and decreased daily solar radiation. The increase in precipitation accounts for about $50 \%$ of the increase in nitrogen deposition. These changes in climate are driven by local conditions and may not be related to regional and global climate trends. ${ }^{122}$ In the alpine areas of Colorado, about half of the nitrogen is deposited in snowpack and then is released with the spring thaw. This large release of nitrogen leaches through the soil, removes base cations from the soil, and degrades the quality of streams and lakes. 149 


\section{Agriculture}

Based on crop-effects research conducted by NAPAP and other research programs in the 1980s, acid deposition at ambient levels in the United States was not found to be responsible for regional crop yield reduction. In fact, sulfur and nitrogen deposition in precipitation can provide a portion of the crop requirement for these elements essential for plant growth. ${ }^{152}$ Ozone, on the other hand, represents a significant stress factor in agricultural production in the United States. $\mathrm{NO}_{\mathrm{X}}$ reductions under Title IV should decrease the creation of ozone and its subsequent damage to agriculture. However, data on changes in ozone resulting from Title IV are not currently available.

\section{Materials and Cultural Resources}

Approximately 900,000 properties of aesthetic and historic value in the United States are potentially at risk for damage by air pollution, including sulfates, other particulate matter, and ozone. This figure does not include the 10-30 million tombstones and grave site memorials. The value at risk of such cultural assets (e.g., statues, monuments) is greater than that for purely operational resources (e.g., buildings, fences, bridges) because the value of cultural resources is mainly in their appearance, which is particularly vulnerable, and because of the emotional capital attached to such properties by an extended population.

Structures made of limestone and marble are particularly sensitive to acid deposition. The salts produced on stone surfaces as the result of acid deposition are now considered to be potentially more damaging than are the dissolution effects of the actual acid delivered to the stone. While the incremental erosion of calcareous stone due to acid rain is generally a small fraction of the background erosion by clean rain (clean rain effect), the soiling effects and the loss of structural integrity of the stone associated with salt deposition generally represent the most deleterious effects.

\section{Observed Effects}

Acid deposition, particularly dry deposition of finesulfate aerosols ${ }^{153}$ and fine particulate matter, dam- ages materials used both for operational assets and for cultural resources, potentially affecting their structural and aesthetic values. While the reduction of sulfur dioxide emissions associated with Title IV is expected to decrease the rate of deterioration of materials, the effects of such a reduction may not be currently visible because latent incremental effects often require decades to appear above the natural soiling and weathering effects.

An implicit assumption by NAPAP of materials effects research is that the benefits of Title IV's pollution reduction for cultural materials greatly exceed those for purely operational assets. The value at risk is greater for cultural resources because such resources are mainly valued for their unique character and historic significance. These attributes are normally associated with the surface appearance and morphology of the construction materials, rather than with their bulk properties. In contrast, the preservation value of purely operational assets is not significantly affected by pollution because their utility is normally associated with the bulk properties of the materials used for their construction (shelter, strength, etc.). It follows that pollution compromises the general utility of cultural resources in less time than it diminishes the utility of purely operational assets. However, there is no program for systematically monitoring the condition of cultural properties for potential damage from air pollution. Moreover, while the impact on cultural resources is not generally reversible, any negative impact of pollution on operational assets (e.g., paint on a bridge) can be reversed because replacement is a viable option.

Most benefit-assessment research has focused on the materials that are predominately used for cultural resources. Such materials include granite, calcitic sandstone (i.e., sandstone cemented with calcite rather than silicate minerals), bronze, mortar, limestone, and many types of marble. Calcareous stone, which is the stone type used for many cultural resources, has received precedence in materials effects research and, thus, is the focus of discussion in this report.

Studies of marble tombstone weathering in North America demonstrate that air pollution (probably sulfur dioxide) has been responsible for more deterioration of carbonate building stone and statuary than other weathering processes. ${ }^{154}$ Indeed, most studies have focused more on the effects of sulfates than on the effects of nitrates because the products of nitrate deposition have not been found to be as pervasive as 
sulfates in stone deterioration processes and the relationship between $\mathrm{NO}_{\mathrm{x}}$ emissions and ozone-damaged materials is not well understood.

The interactions between pollutants and calcareous stone are complex and involve multiple processes that are highly interdependent. Laboratory and field studies of the degradation mechanisms have demonstrated that salts resulting from the wet and dry deposition of acids and the deposition of particulate matter are more damaging to calcareous stone than the dissolution effects of the actual acids delivered to the stone. Because the dissolution due to acid is generally insignificant relative to the dissolution effect of clean rain, the focus of research on stone deterioration has shifted to an understanding of alteration effects that degrade the aesthetic and structural qualities of the resource. Geographic location and the natural environment of the resource also affect the extent and magnitude of damage. For example, stone degradation rates are negligible in dry areas, such as the southwestern United States. Degradation processes for wet and dry deposition are discussed in the accompanying text box.
In a recent reinterpretation of the NAPAP-sponsored laboratory and field observations of materials effects, the most conspicuous dynamics of stone decay were codified. 156 An elementary System-wide Unified Reduced Form (SURF) model was developed to show the dominant processes of stone erosion and soiling (Figure 21). The SURF model is not intended to represent a conclusive understanding of stone decay, but rather to serve as an operational framework that provides perspective on the impact of environmental stresses on exposed materials. Under actual field conditions, stone weathering involves interactions between ever-changing meteorological variablessuch as rain, wind, temperature, humidity, and other factors-and continually changing complex stone surfaces.

Some interactions occur at the microscale, while others are affected by the macro properties of the stone's surface. These interactions are not independent. When they positively reinforce each other, the system can be driven to failure. For example, the way water flows over a carved stone surface (a macroscale variable) influences the mobilization of salts and particulate materi-

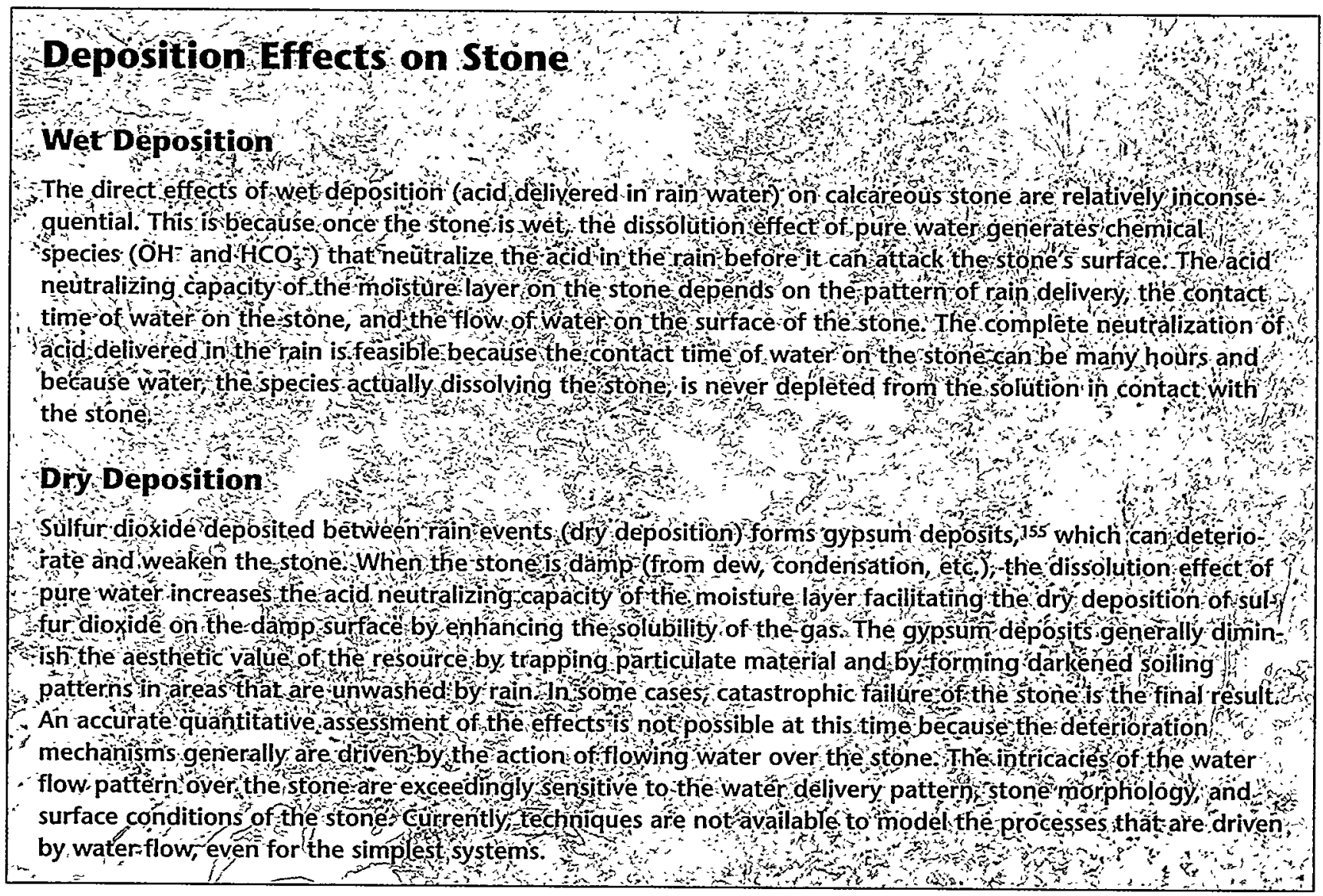


als on the surface and can change the stone's chemistry and porosity (microscale variables). A slight change in the overall shape of the surface, either due to weathering or by design, may change the way water flows over the surface and could radically influence the erosion and soiling patterns.

\section{Sensitive Receptors}

Both cultural materials and operational materials are sensitive receptors at risk to damage by acid deposition. Cultural properties are considered to be the most at risk to damage from acid deposition because of the

Figure 21

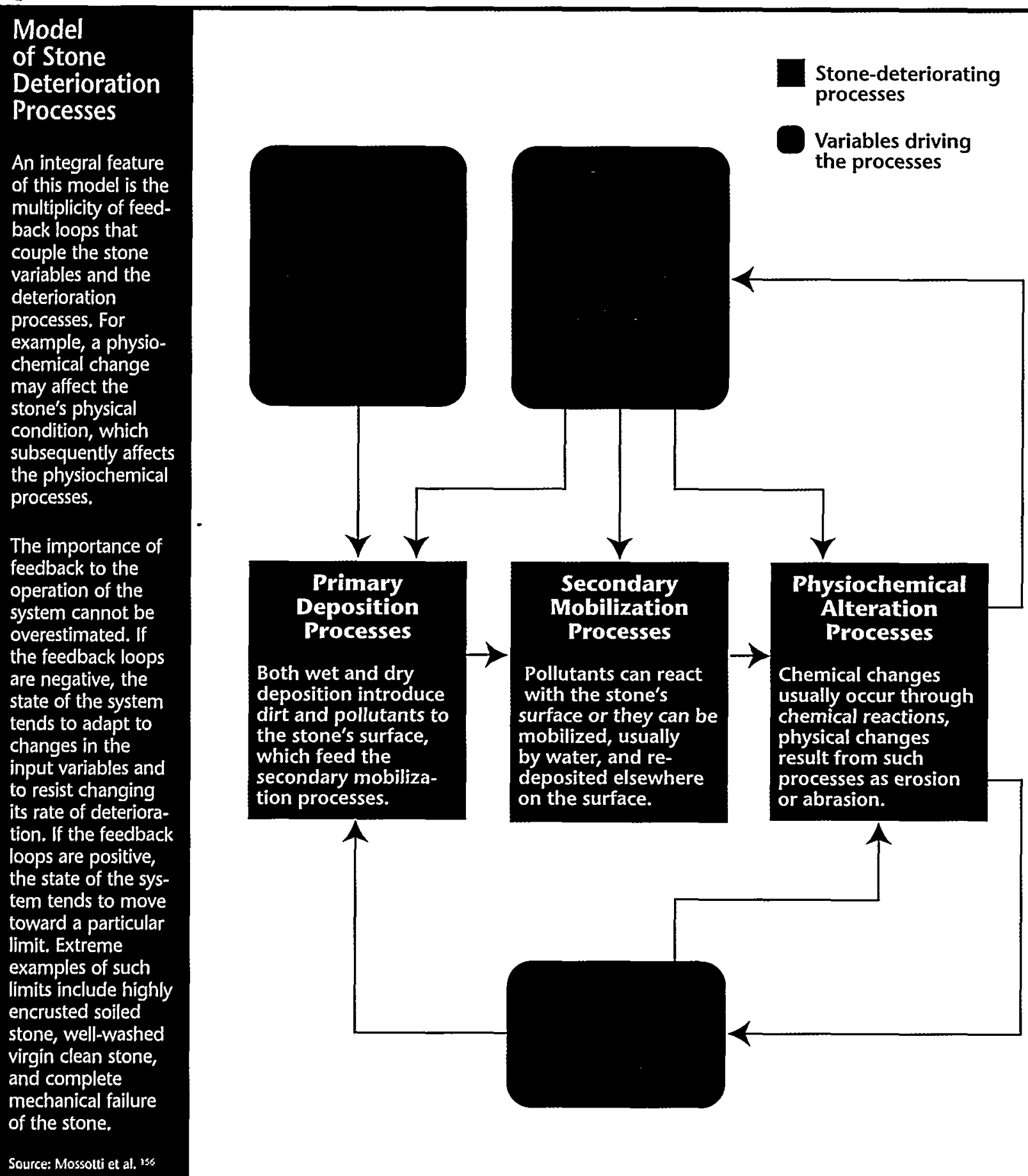


greater value placed on the potential loss of these resources, as was previously discussed. Some of the specific materials used for cultural properties include granite, calcitic sandstone, bronze, mortar, limestone, and many types of marble. As previously stated, the focus of most of the research has been on calcareous stone (limestone and marble).

\section{Dose-Response Relationships}

A dose-response relationship has been used to partition the effects of natural and anthropogenic acidity on galvanized steel. ${ }^{157.158}$ The model has been used to predict regional corrosion rates of fencing, wire, and flat plates in eastern North America. Field studies on well-characterized calcareous stone have been used to develop preliminary dose-response relationships. ${ }^{159-161}$ Laboratory studies in controlled environments have provided quantitative measurements of sulfur dioxide deposition to calcareous stone. ${ }^{162.163}$ Although these basic field and laboratory data on materials effects have been systematically collected over the past 15 years, there have been many difficulties with reconciling observations from poorly controlled field experiments with results from highly sanitized laboratory experiments.

A preliminary damage function for marble has been developed based on studies of the effects of air pollution on gravestones in North America. ${ }^{154}$ However, this linear damage function does not take geographic location into consideration. The slope of the damage function will differ for those areas with less pollution and more rain. Weathering rates for heavily polluted urban areas may be greater than measured because many badly weathered gravestones may have been broken or removed. Other improvements to the damage function may arise from better modeling of historic sulfur dioxide concentrations at more locations throughout the United States.

\section{Visibility}

Particulate sulfate formed in the atmosphere by the conversion of $\mathrm{SO}_{2}$ is responsible for $40-65 \%$ of the haze in the eastern United States, based on a combination of measurements and calculations. Reduced $\mathrm{SO}_{2}$ emissions under Title IV are expected to decrease sulfate concentrations and their contribution to haze.

In 1995, sulfate concentrations were $15 \%$ lower than previous years at sites in the eastern United
States. Although this decrease was predicted to improve visibility by $8 \%$, there was no measurable difference at the seven eastern sites that directly measure visibility. The relative influences of emission reductions, meteorological variations, and changes in nonsulfate particulate concentrations in the observed visibility are currently not well understood.

$\mathrm{SO}_{2}$ emissions have an indirect effect on visibility (see the Visibility Impairment text box on page 69). Some of the $\mathrm{SO}_{2}$ emitted is converted in the atmosphere to sulfate aerosol, which is responsible for a large share of the haze in the eastern United States. Visibility levels can be directly measured at sites where optical instruments are used. At other locations, where only aerosol composition data are available, calculations can be made of visibility levels and the contribution of the five major aerosol species (sulfates, nitrates, organic carbon, elemental carbon, and crustal elements) to reduced visibility.

\section{Observed Effects}

The Interagency Monitoring of Protected Visual Environments (IMPROVE) network is the principal source of aerosol and visibility information. ${ }^{31}$ Thirteen of the IMPROVE sites, are located in the East, where emission changes under Title IV are expected to be the greatest (Figure 22). Twelve of those sites are in rural areas. At least three of the 13 eastern sites have been operational continuously since 1988: Acadia National Park, Maine; Shenandoah National Park, Virginia; and Great Smoky Mountains National Park, Tennessee. The Shenandoah and Great Smoky sites actually have data beginning in 1983, prior to the establishment of the IMPROVE network. Ten additional aerosol monitoring sites were initiated during 1992 and 1993. All 13 sites collect samples that allow for the analysis of the five major aerosol species for the fine-particle fraction (diameter of less than $2.5 \mu \mathrm{m}$ ) and the mass concentration of the coarse-particle fraction (diameter of $2.5-10.0 \mu \mathrm{m}$ ). Seven of the sites also directly measure visibility.

Figure 23 shows the seasonal and annual fractional contributions of sulfates and nitrates to the lightextinction coefficient averaged over three years of the IMPROVE monitoring program, March 1992 through February $1995 .{ }^{164}$ On an annual basis, sulfate aerosols contribute from just over $45 \%$ to nearly $70 \%$ of the haze seen in the East. Sulfate contributions are highest in the summer (up to $75 \%$ ) and lowest in the winter 


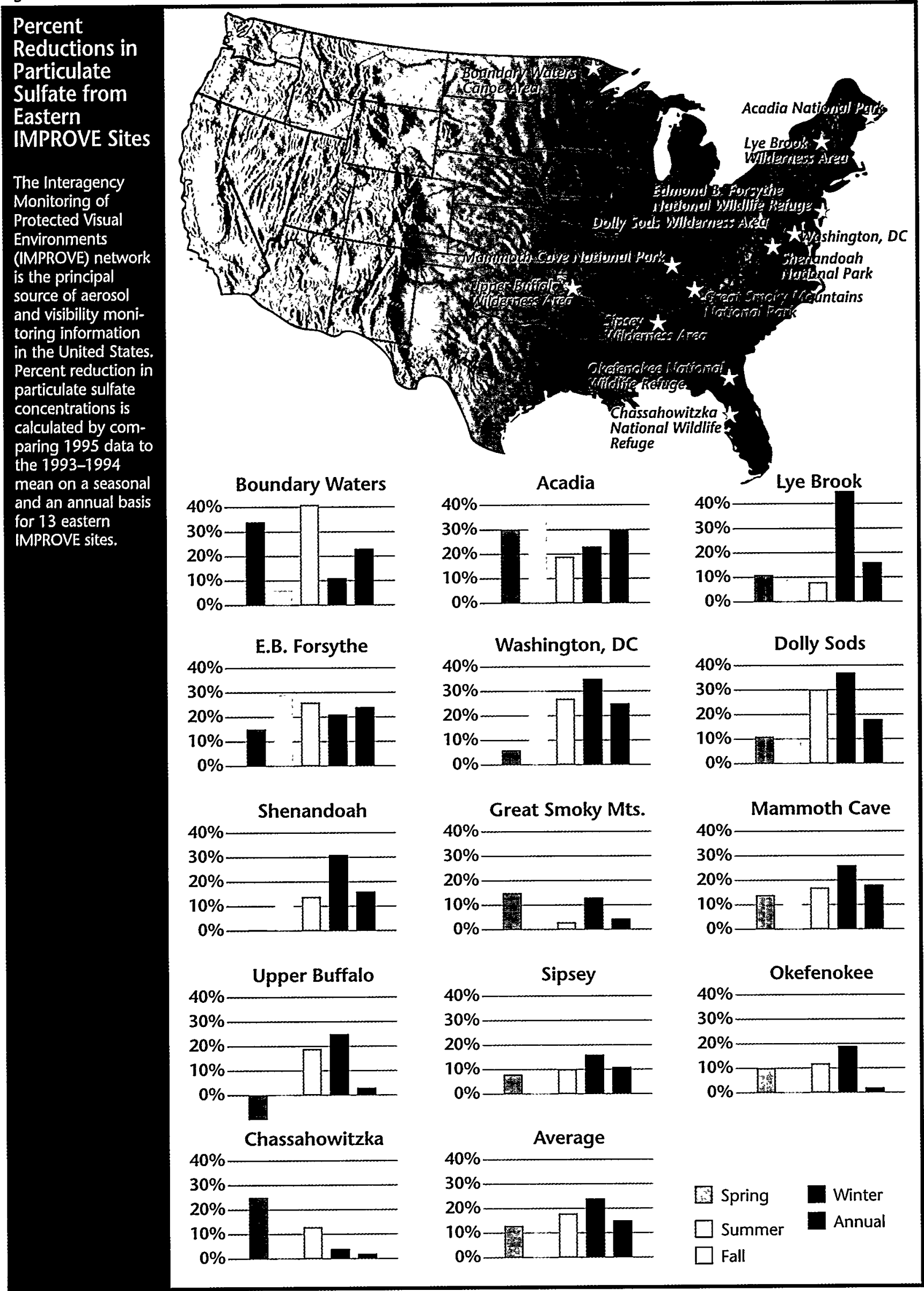


Figure 23

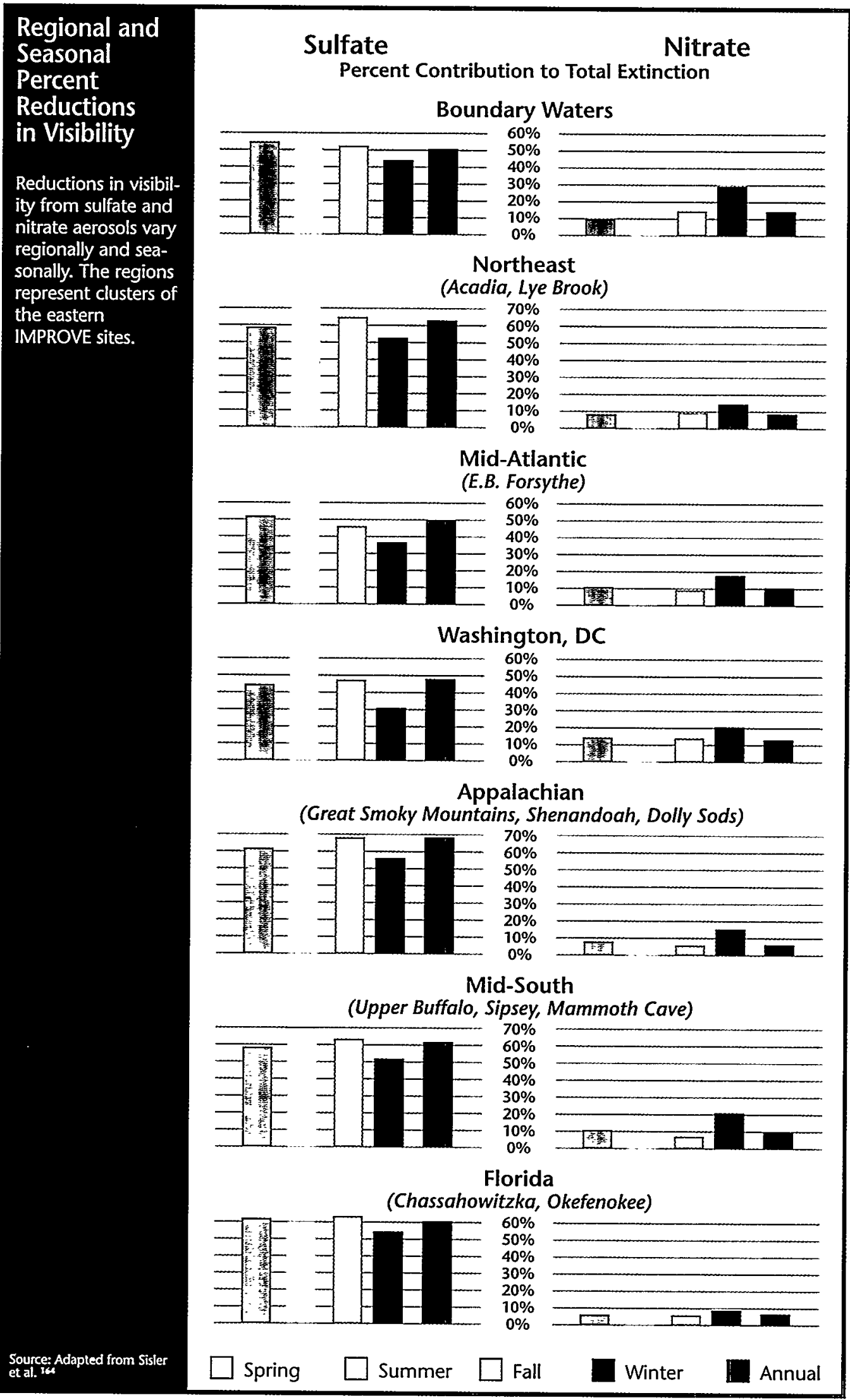

(as low as 30\%). Nitrates contribute $6-14 \%$ of the haze on an annual average basis, with much lower contributions in summer (less than 5\%) than in winter (almost $30 \%$ ). Nitrate concentrations in urban areas are generally higher than in surrounding rural areas as a result of the influence of urban transportation sources. It is important to note that a seasonal change in visibility is likely to include days with no change and other days with significant change. The same can be true for spatially averaged visibility. Within a region, the overall change in visibility may appear small but may actually include certain areas that experience very noticeable changes in haze levels (e.g., near sources that have reduced emissions).

NAPAP's 1990 Integrated Assessment Report ${ }^{3}$ predicted that a $10-$ million-ton reduction in $\mathrm{SO}_{2}$ emissions would result in a $37 \%$ average reduction in sulfate concentrations and, therefore, a $37 \%$ reduction in the sulfate contribution to light extinction. It also indicated that sulfate was responsible for about $57 \%$ of the total light extinction on average, so that a 
$21 \%$ change in total light extinction ( $57 \%$ of $37 \%$ ) would result from the 10 -million-ton $\mathrm{SO}_{2}$ reduction. Annual average sulfate reductions were predicted to vary spatially from more than $44 \%$ in the upper Ohio River Valley to about $30 \%$ across much of the East moving away from the Ohio River. This is due to having significantly greater $\mathrm{SO}_{2}$ emissions in the Ohio River Valley than in other parts of the eastern United States. Summer (April to September) was predicted to have somewhat greater reductions in the sulfate concentrations $(40 \%)$ than in the winter season $(37 \%)$.

Spatial and seasonal patterns of sulfate change using the IMPROVE monitoring data were examined to compare with predictions in the 1990 Integrated Assessment Report. ${ }^{3}$ The $1995 \mathrm{SO}_{2}$ emission levels were about five million tons lower than those of the previous few years as a result of Title IV emission controls within the electric utility industry (see Figure 4). Assuming that the nonutility $\mathrm{SO}_{2}$ emissions were unchanged, about a
$20 \%$ reduction would occur in the annual average sulfate contribution to light extinction, which would correspond to about a $10 \%$ reduction in total light extinction. Because most of the emission reductions occurred near the beginning of 1995, the three-year data record at the 13 eastern IMPROVE sites is useful in short-term trends analysis. The two sites with the longer monitoring records can be used to examine long-term trends and to investigate variability during periods of relatively small annual $\mathrm{SO}_{2}$ emission changes.

Interannual variations in meteorology confounds any attempt to make simple comparisons between predicted and measured changes in sulfate concentrations. Measured sulfate concentrations are influenced by both emission changes and meteorology. Even years that may seem to be "typical" can have meteorological differences that would have significant effects on the sulfate concentrations, independent of $\mathrm{SO}_{2}$

\section{Visibility Impairment}

B ynterfering with the transmission of light, pollutants associated with acid deposition reduce the clarity of the atmosphere. Much of the concernabout visibility is related to the aesthetic damage from air polliation the inability to see the formi textare; and color of scenic features (1) Unlike certain acid /deposition effects thát involve air/land/waterinteractions that build up over time or that are delayed, a timospheric optical effects are instantaneous properties of air quality The fundamental physics

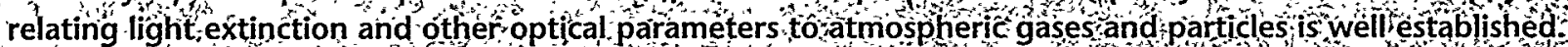
to Under a yariety of viewing conditions, visibility reduction or haziness a approximately proportional to a parameter called atmosphericlight extinction light extinction refers to the fraction of light that is attenü ated per unit distance by the atmosphere tight extinction is a simple linear sum of four components inght scattering and light absorptión by both gases and particles in a homogenous atmosphere visual range is inversely proportional to light extinction, However, neither visuă range nor light extinction necessarily

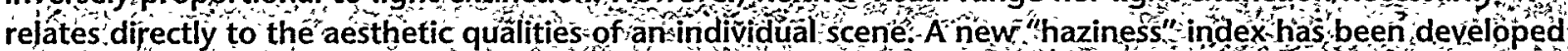
for this. ${ }^{165}$ Measured in deciview units, this index was designed to be more linear with respect perceived visual change over jts entire range, analogoús to the decibel scale for sound A one deciview change répesents a small change in scenic quality that would be noticed by most people regardies of the initial visibility condition. Pollution-free air corresponds to 0 deciviews, with higher values indicating greáter visibility inpair ment Partiç (aerósols composed of sulfate and nitrate as well sas other chemicals) tend tơ dominate light extinc

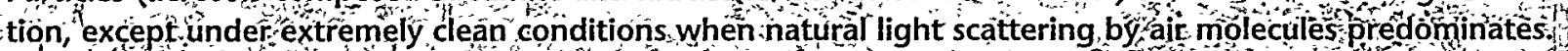
Fine particles (diameter less than $250 \mathrm{~m}$ ) must be distinguished from coarse particles (diameter greater than

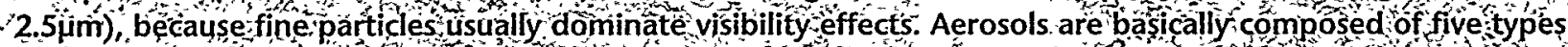
of chemical species sulfates ónganic elemental carbon ammonium nitrate and soil dust it is impontant to note that hygroscopic particles (those thátabsorb water, such as sulfates, ammonium nitrate and some

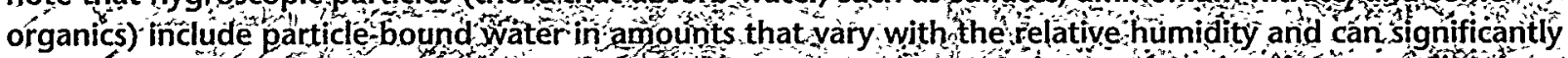
add to the impaiment of visibility under humid conditions (relative humidity greater than $80 \%$ o

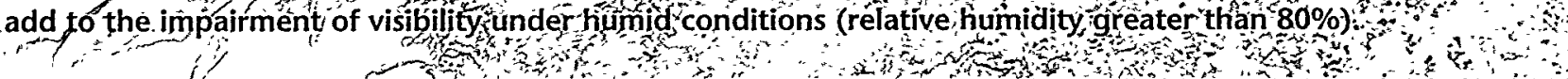


emission rates. A common approach to handle these meteorological variations is to average $10-20$ years of data. Obviously, this is not possible when looking for the effects of emission changes over the previous five years or less. A more sophisticated approach (not used here) would be to use deterministic or statistical models to try to account for the influence of meteorological variations.

\section{Trend Analysis}

Trends analysis has been conducted at the two IMPROVE monitoring locations with relatively longterm sulfate aerosol concentration data: the Shenandoah and Great Smoky Mountains National Parks. Also, all 13 sites with three years or more of data were examined to assess short-term changes in concentrations that may be caused in part by emission changes. Spatial variations in short-term changes in sulfate concentrations were examined, but could not be interpreted without corresponding spatially resolved total $\mathrm{SO}_{2}$ emissions data (including both utility and nonutility), which were not readily available. Seasonal sulfate and sulfur aerosol concentration values were used to identify seasonal patterns. Corresponding seasonal total $\mathrm{SO}_{2}$ emission values (current and historical) are needed to better interpret these patterns, but such data were not available in time for this report.

\section{Long-Term Trends}

An examination was conducted on nearly 10 years of fine particulate sulfur concentration data (1983-1992) from 12 IMPROVE sites, two of which were in the East. 166 One of the more surprising results of this analysis was an average annual increase in concentrations of $4 \%$ at the Shenandoah and Great Smoky Mountains sites. Both of these sites had small decreasing trends during the winter and moderate increasing trends during the spring and fall. The overall annual fine-particulate sulfate concentration increased by an average of $2-3 \%$ at the two eastern sites. What makes these trends unusual is the decreasing $\mathrm{SO}_{2}$ emissions in the eastern United States during this same period. Trends at sites in other U.S. regions seemed better correlated with $\mathrm{SO}_{2}$ emission change expectations. These included sites in the southwestern United States with decreasing fine-particle sulfur changes in areas where copper smelter and coal-fired utility emissions were reduced. The researchers did not discuss why fine-particulate sulfur was increasing at the two eastern sites.
In a more recent paper, a longer period of record was examined (1983 to summer 1995), and focused on possible explanations of the fine-particulate sulfur trends in the eastern United States, especially at the Great Smoky Mountains monitoring site. ${ }^{32}$ The possible effects of the changes in sampling protocols between two monitoring programs were discussed, as well as the occasionally large unexplained discrepancies between paired sulfate ion and elemental sulfur measurements that occur in the summer under very humid conditions. The discrepancies were highest in the summers of 1993 and 1994, with mean sulfate concentrations that were $21 \%$ and $31 \%$ higher than the mean sulfur concentrations at the Great Smoky Mountains site. The discrepancy did not appear in the summer of 1995 and remains a subject of further investigation. The authors make the case that these issues do not significantly affect their sulfur trend conclusions.

The effect of including an additional 2.5 years of data was to reduce the magnitude and uncertainty of the summer and winter trends, especially at the Great Smoky Mountain site. At that site the three additional summers $(1993,1994$, and 1995) lowered the summer trend from $+3.9 \%( \pm 2.4 \%)$ per year to $+2.1 \%$ $( \pm 1.3 \%)$ per year, and the two additional winters ( 1993 and 1994) changed the winter trend from $-2.6 \%$ $( \pm 3.1 \%)$ per year to $-0.9 \%( \pm 1.7 \%)$ per year. By calculating summer trends separately for the earlier half of the data record (1984-1990) and the later half (1990-1995), the authors showed that the 12-year trend of increasing fine-particulate sulfate resulted from large increases in the first half of the period followed by either flat trends (Shenandoah $-0.1 \%( \pm 1.7 \%)$ per year) or improving trends (Great Smoky Mountains $-3.8 \%( \pm 2.8 \%)$ per year) during the second half.

Figure 11 on page 33 shows the winter- and summeraveraged fine-particulate sulfur concentrations for the Shenandoah and Great Smoky Mountains, and a composite of the 10 western IMPROVE sites. Much of the year-to-year variations in the seasonal averages is thought to result from interannual meteorological effects on production, dispersion, and deposition of particulate sulfate from gaseous $\mathrm{SO}_{2}$ and sulfate concentrations, since the emissions are thought to be less variable. The changes in seasonal averages were caused principally by changes in the highest concentration days since the low- and mid-level sulfate concentrations were nearly the same year to year.

The researchers suggest a few reasons for the apparent inconsistency between increasing fine-particulate 
sulfur and decreasing national annual average $\mathrm{SO}_{2}$ emissions of about I \% from 1985 to $1994 .{ }^{32}$ One plausible explanation is the increasing use of electricity for air conditioning. $\mathrm{SO}_{2}$ emissions may be increasing over the years during the hottest days, and yet may not affect the overall reductions in the annual average $\mathrm{SO}_{2}$ emissions. Hot days are thought to be associated with more rapid production of fine-particulate sulfate from $\mathrm{SO}_{2}$ and with greater pollution buildup caused by stagnant air motion compared to colder days. Therefore, any increment of additional $\mathrm{SO}_{2}$ emissions on hot days may produce much more fine-particulate sulfate than the same increment on other days. This explanation is consistent with the seasonal trends information developed by the authors, but should be tested further with temporally resolved $\mathrm{SO}_{2}$ emissions; such data were not readily available for this report.

A second possible explanation given by the researchers involves the spatial distribution and influence range of $\mathrm{SO}_{2}$ emissions. The trends in the 11 -year annual fine-sulfur concentrations at the Great Smoky Mountains monitoring site were comparable to the annual $\mathrm{SO}_{2}$ emission rates for the Tennessee Valley Authority power plants that dominate $\mathrm{SO}_{2}$ emissions in the near-upwind region of that site. During the important high sulfur concentration periods, it is reasonable to expect stagnant air conditions and a greater-thannormal influence by nearby sources compared to other periods. This explanation also requires further testing with spatially and temporally resolved $\mathrm{SO}_{2}$ emissions data when they are available.

\section{Short-Term Trends}

Additional analysis using the IMPROVE aerosol data was conducted as a case study specifically for this report. The analysis involved calculating the ratio of the average seasonal sulfate concentrations in 1995 to the average seasonal sulfate concentrations for 1993 and 1994 combined. Restricting the analysis to these three years enabled the inclusion of data from all 13 eastern IMPROVE monitoring sites. This improved spatial resolution will ultimately allow comparisons to local $\mathrm{SO}_{2}$ emission levels so that analysis can be conducted similar to those stated above for the Great Smoky Mountains site. ${ }^{32}$ (Seasonal emissions data were not available prior to preparation of this report.)

A serious shortcoming of this analysis is that interannual variations in meteorology can easily overwhelm the effects caused by minor changes in emissions. Figure 11 illustrates that substantial year-to-year variations are common. Ultimately, this difficulty may be mitigated to some extent if $\mathrm{SO}_{2}$ emissions near some of the monitoring sites are substantially changed and if the speculation by the researchers for the Great Smoky Mountain site is correct that seasonal trends are dominated by the activity of nearby $\mathrm{SO}_{2}$ emission sources. ${ }^{32}$ No attempt is made in this analysis to sort out the confounding effects of interannual meteorological variations.

Annual averaged $\mathrm{SO}_{2}$ emissions for the eastern United States were considerably reduced between 1993 and 1995 (see Figure 4). The use of sulfate aerosol data from the 13 monitoring sites provide much better spatial coverage than the three sites with longer periods of record. Sulfate ion data were used for this analysis instead of elemental sulfur data, as was used in the long-term trend analyses. Though not yet completely resolved, current thinking by those responsible for the IMPROVE aerosol monitoring program is that the sulfate ion values are likely to be more correct for those very humid periods in summer when there is a discrepancy between measured sulfate and sulfur.

The more northerly sites showed a greater reduction in fine-particulate sulfate concentrations in 1995 (compared to the two previous years) than the more southerly sites. This pattern is not as clear in the seasonal patterns (Figure 22). An average of the ratios across sites indicates a network reduction of fineparticulate sulfate in 1995 compared to the previous two years of about $24 \%$ in winter, $13 \%$ in spring, $10 \%$ in summer, and $18 \%$ in fall.

The overall conclusion that fine-particulate sulfate concentrations at the eastern IMPROVE sites were about $15 \%$ lower in 1995 compared to the previous two years is sensitive to having selected the sulfate ion instead of elemental sulfur. Had elemental sulfur been selected, the 1995 concentrations would have been only $5 \%$ lower than the previous years.

A $15 \%$ decrease in one year could have been caused solely by interannual variations in meteorology. For instance, between 1989 and 1990, annual sulfate at the Great Smoky Mountains site increased by about $25 \%$, while emissions near that site increased by less than about $12 \%$, and overall $\mathrm{SO}_{2}$ emissions in the East were slowly decreasing. ${ }^{32}$ It seems less likely that such a large change would occur at a 13-site average across the East. Seasonal averaged data predating 1993 indicate that 1995 is consistently one of the lowest sulfate concentration years on record. Given consistency across space ( 13 sites in the East) and time, it is 
reasonable to hypothesize that a reduction in sulfate concentrations is beginning to emerge as a result of Title IV $\mathrm{SO}_{2}$ reductions. However, a longer data record is needed to quantify the magnitude of this signal.

The selection of 1995 as the year to compare with previous years was due to 1995 being the first year of implementation of Title IV, with accompanying significant decreases in $\mathrm{SO}_{2}$ emissions from the previous years. However, this is a poor approach for examining the effects of emission changes on visibility. The timing and location of emission rate changes were not available when this analysis was conducted. When these data are fully aggregated, a more appropriate method would be to identify reasonable source influence regions for each of the monitoring sites by season and to examine relationships between emissions within those regions and sulfate concentrations. Another important approach to understanding the relationship between emissions and local visibility is to examine the extent to which emissions are attributed to local air pollution emissions or from regional transport of air pollutants.

The visibility change that would be predicted to result from an annual eastern sulfate reduction of $15 \%$ is about $8 \%$ change in light extinction, which corresponds to a change of about 0.8 deciview. This magnitude of improvement in visibility would probably not be perceptible to the casual observer. However, this change on average, involves some time periods and locations with much less change and others with much greater change. From this perspective, it is likely that the contribution of sulfates to haziness was noticeably lower in 1995.

Visibility was directly measured at seven of the 13 eastern IMPROVE sites. Comparisons of the 1995 annual averages to the previous two years-in a manner similar to that described above for sulfate concentrationsresulted in no overall change (less than a $1 \%$ decrease or improvement). The results ranged from $15 \%$ improved visibility ( 1.4 deciview change) at Great Smoky Mountains to $9 \%$ decreased visibility $(0.9$ deciview (hange) at Mammoth Cave, Kentucky. A lack of correspondence between these visibility changes and the changes in sulfate contributions to light extinction is not surprising, given that more than $40 \%$ of the contributions to light extinction are related to nonsulfate parameters, which were primarily unchanged.

The nitrate contribution to visibility levels is relatively small, except during the winter (Figure 23). Using the same technique as described above for sulfate, analysis of short-term trends in nitrate concentrations resulted in no significant change (less than $1 \%$ ) in the 13-site annual or winter seasonal-averaged nitrates for 1995 compared to the previous two years. Annual nitrate trends at individual sites varied from an increase of $18 \%$ to a decrease of $22 \%$, with no apparent geographic pattern. Site-to-site variations of the nitrate trends were even greater during the winter, ranging from a $47 \%$ increase to a $33 \%$ decrease. These variations are likely to result principally from interannual meteorological variations, including temperature, which is critical to determining the nitrate partitioning between particle and gas phases in the atmosphere.

\section{Dose-Response Relationships}

There are two approaches to determining visibility dose-response relationships. One is a technically rigorous but complex situation-specific method, while the other is a simplified approach using broad assumptions that can be more generally applied.

In the more rigorous approach, aerosol water growth relationships and Mie theory are applied to determine the optical characteristics of aerosol from information on the composition, shape, and number of particles as a function of the particle size and the relative humidity of the atmosphere. Sophisticated radiative transfer models using the aerosol optical characteristics, the lighting and scene characteristics, and the spatial distribution of the pollutants are used to calculate the path and wavelength of image-forming and nonimageforming light that reaches a specific observer at a specific time and date from all points in the scene being viewed. Computer image-processing methodology can show the visual effects of any modeled pollution situation on a clear-condition photograph of the scene of interest. This technique was used in NAPAP's 1990 Integrated Assessment Report ${ }^{3}$ and State of the Science and Technology Report 24.167 While this sort of analysis is useful for assessing specific cases, it is impractical to address regional haze issues, where visibility is experienced in a nearly infinite variety of situations and where the detailed characteristics of the pollution, lighting, and scene conditions are rarely known.

The simplified approach uses aerosol species-specific extinction efficiencies with water growth functions to determine the light-extinction coefficient of the aerosol from its composition and the relative humidity of the 
situation of interest. Extinction efficiencies and the relative humidity dependence of the aerosol are based upon typical results using the more sophisticated methods indicated above. Light-extinction coefficients determined by this approach are easily converted to the deciview scale of the haziness index. This index was specifically designed so that anywhere along its scale, haziness changes that are about equally perceptible correspond to the same deciview difference (see the Visibility Impairment text box on page 69 for discussion of deciview units). For example, a 3-deciview difference caused by changed air quality should result in about the same perceived change in haziness, whether under pristine or highly polluted conditions. This characteristic of the deciview scale requires that the scene being viewed have a sufficient number of sensitive scenic features for the baseline haze level. No one scene is likely to have such scenic features for all conceivable haze levels. However, the nearly infinite variety of scenes available where regional hazes are concerned ensures that many will have the desired characteristic for any haze level.

Based upon viewing scenic photographs with computergenerated hazes, changes as small as about 0.5 deciview can be visually detected if a sensitive scenic feature is prominent in the scene. A I-deciview change is more often detected because the requirement for a sensitive scenic feature is less restrictive; however, such a change is subtle. One must bear in mind when considering how much of a change is perceptible that visibility is an effect that is instantaneously manifested, while assessment results generally are in terms of temporal averages. It is important to note again that a seasonal change of 1 deciview is likely to include days with no change and other days with prominent changes. A similar argument can be made for spatial averaging. Predicted regional averaged visibility changes may seem small, while areas within the region and near sources with changed emissions can experience much more noticeable changes in haze levels.

\section{Human Health}

The Clean Air Act establishes the mechanism for National Ambient Air Quality Standards for particulate matter with the goal of protecting public health. EPA is required to periodically review and revise this standard, as appropriate, to primarily protect against adverse health effects, and secondarily to protect against welfare effects (e.g., impacts on vegetation, crops, ecosystems, visibility, materials). EPA recently completed a comprehensive review of the significant new body of epidemiological evidence, which can be found in the Air Quality Criteria for Particulate Matter. ${ }^{168}$ This review forms the primary references for this summary of health benefits.

At the end of the 1980s, NAPAP reported that the human health benefits resulting from reductions of atmospherically formed particles and ozone that accompany the control of $\mathrm{SO}_{2}$ and $\mathrm{NO}_{\mathrm{x}}$ emissions were considered to be potentially significant, but very uncertain. Current scientific knowledge about the health effects of particulate matter indicates that the extent of such benefits may be substantial.

Sulfate and nitrate particles constitute a portion of particulate matter that varies geographically and that consists primarily of fine particles. Although no consensus exists on the causal relationship between sulfates and nitrates and adverse human health effects, many epidemiological studies suggest a statistical association between various pollutants and demand for hospital services, and mortality and morbidity rates.

Epidemiological studies evaluate the association between air pollution and adverse human health effects, typically in an urban setting. In these studies, statistical techniques (usually a type of regression analysis) are used to estimate dose-response relationships between pollution levels and health effects. These types of studies are useful in that they allow the estimation of the incidence of health effects related to varying levels of air pollution. However, epidemiological studies alone have significant limitations when trying to prove the existence of a cause-and-effect relationship between pollutant dose and a health response.

Reductions in levels of fine particulate matter represent a potential source of major health benefits as a result of Title IV's reductions in $\mathrm{SO}_{2}$ and $\mathrm{NO}_{\mathrm{X}}$ emissions. $\mathrm{SO}_{2}$ and $\mathrm{NO}_{\mathrm{x}}$ emissions interact with other chemical species in the atmosphere to form secondary sulfates and nitrates, which comprise a significant portion of atmospheric fine particulate matter. In the eastern United States, which is largely urban and where the impact of Title IV emission reductions will be greatest, sulfate aerosols represent $30-40 \%$ of average ambient levels of fine particulates. In the West, sulfate constitutes only $10 \%$ of fine particulate matter, whereas nitrate reportedly constitutes $15-20 \% .^{168}$ (However, because of inaccuracies in measurement techniques, nitrate levels may be significantly underestimated.) 
Determining the specific effect of sulfate aerosols on human health is difficult because epidemiological studies are limited in their ability to separate the effects of sulfates from the effects of other components of fine particulate matter. ${ }^{169}$ Many studies of human health benefits from emission reductions are based upon epidemiological findings that are focused on health effects from exposure to particulate matter or fine particulate matter. However, a growing number of studies are focusing on the health effects of exposure to sulfates specifically. ${ }^{169}$

The epidemiological studies indicate that some or all of the constituents of fine particulate matter (including sulfates and nitrates) are harmful to human health. Laboratory studies suggest that some types of sulfates, especially sulfuric acid aerosols, are harmful to the respiratory system when subjects are exposed to sulfates alone. This evidence suggests that sulfates may be contributing, at least in part, to the health effects observed in association with fine particulate matter. ${ }^{169}$

Some of the epidemiological studies of the health effects of sulfates specifically, and particulate matter in general, have examined the extent to which other factors-such as temperature, humidity, ambient levels of other pollutants, smoking, and time spent indoors-may confound the suggestion that the observed health effects are associated with Title IV pollutants. Some analyses of particle epidemiology, including the previously referenced EPA Criteria Document, concluded that many of these studies correctly controlled for confounding factors, which supports the reported statistical association between levels of fine particulate matter and health effects.168.170 These analyses also note that uncertainties remain, particularly with respect to the exact quantitative relationship between ambient air concentrations and human health responses, and with the potential biological mechanisms that would account for the observed epidemiological results. A recent critical review of relevant epidemiological studies proposed that a case can still be made that some uncontrolled factor may be acting as a confounding factor and may thereby provide a plausible explanation for the apparent particlerelated health effects. ${ }^{171}$

Based on its review of the scientific criteria and standards, 168 EPA recently revised the primary (healthbased) and secondary (welfare-based) National Ambient Air Quality Standards for particulate matter, retaining the previous standards for particles 10 microns or less in size $\left(\mathrm{PM}_{10}\right)$ with some revisions to the form of the 24-hour standard, and adding new daily and annual standards for fine particles (particles 2.5 microns or less in size $-\mathrm{PM}_{2.5}$ ). EPA estimates that the impact of the new standards could range from minimal in areas that already meet them to a substantial $(45-50 \%)$ reduction in particulate matter associated morbidity and mortality in areas with high levels of particulate matter. ${ }^{172}$

Members of the Clean Air Scientific Advisory Committee, an independent scientific review panel, reached a consensus that a new National Ambient Air Quality Standard should be established for fine particles. However, there was no consensus on the level, averaging time, or form of a fine particulate standard. The panel members' diversity of opinion reflects the many unanswered questions and uncertainties associated with establishing a cause-and-effect relationship between fine particulate matter and premature mortality. ${ }^{173}$ There is also a lack of consensus on the existence of a level below which there will be no adverse health effects. However, there is a general consensus that a reduction in fine particles as a result of the Clean Air Act Amendments of 1990 will have a positive impact on public health.

\section{Observed Effects}

Based on epidemiological studies, reductions in fine particulate matter (which include sulfates and nitrates) as a result of the 1990 Clean Air Act Amendments are likely to improve public health.

Epidemiological studies indicate that potential health benefits from decreased $\mathrm{SO}_{2}$ and $\mathrm{NO}_{\mathrm{x}}$ emissions-and thereby decreased levels of fine particulate matter (assuming other fine particulate matter constituents do not increase in concentration)-include reductions in: premature mortality from cardiorespiratory disease, particularly in the elderly; 168,172 hospital admissions for respiratory and cardiovascular causes, 168.174 asthma attacks, and medication use; respiratory symptoms; and school-loss and work-loss days. Whether such reductions will have a significant impact on the rate of occurrence of chronic obstructive pulmonary disease, which includes chronic bronchitis and emphysema, is less clear. Air pollution has a limited role, if any, as a cause of asthma, but it clearly aggravates existing asthma. The association of respiratory emergency visits with air pollutants-specifically sulfates (winter), ozone (summer), and particulate matter 
(year-round)-even at very low levels, suggests that further reductions in these pollutants will lead to fewer asthma exacerbations. ${ }^{175}$

Indications from epidemiological studies of a statistical association between ambient particles and human health end points suggest that Title IV's decreased emissions could lead to a reduction in premature mortality and morbidity from cardiovascular and respiratory causes. Using available epidemiological evidence, an EPA study estimated the annual number of cases in 1997 of sulfate-related health effects that would be prevented under Title IV. ${ }^{69}$ The study assumes that sulfates play a causative role in producing adverse health effects and estimates the following cases could be prevented (20th to 80 th percentile range): 400 to 5,700 cases of premature mortality, 1,600 to 6,600 new cases of chronic bronchitis, 500 to 870 cardiac hospital admissions, and 800,000 to $2,370,000$ asthma symptom days. EPA is currently conducting a costbenefit analysis of all the 1990 Clean Air Act Amendments (not just Title IV), which will also include benefit projections for additional pollutants controlled by the Amendments.

Human health benefits are also associated with decreased concentrations of gaseous $\mathrm{SO}_{2}$, gaseous $\mathrm{NO}_{2}$ (including the associated changes in ozone levels), and air toxics (reductions of these are associated with reduced $\mathrm{SO}_{2}$ and $\mathrm{NO}_{\mathrm{x}}$ emissions). While the potential health benefits of reductions in air toxics are not well understood and the effects of $\mathrm{NO}_{2}$ may be minimal, the effects of $\mathrm{SO}_{2}$ and ozone (ozone levels are related to $\mathrm{NO}_{\mathrm{X}}$ emissions) have been studied extensively. Increased ozone levels are associated with increased hospital admissions for asthma, increased asthma attacks, and increased medication use. ${ }^{176}$ Asthma attacks are more likely to occur near point sources of gaseous ambient $\mathrm{SO}_{2}$. Every year, $1-3 \%$ of asthmatics living near a pollution source will experience respiratory symptoms and changes in lung function as a result of $\mathrm{SO}_{2}$ exposure. 177

\section{Sensitive Populations}

For this assessment, the sensitive populations are children, especially those with asthma, and the elderly, especially those with cardiorespiratory disease who may be more likely to die prematurely during episodic pollution events.
Individuals most at risk to the acute effects of sulfates and other fine particles are typically those with preexisting conditions (as a result of current or previous illness), genetics (inherited characteristics), age, or exposure. To be at risk, an individual must be exposed to particulates including sulfates and nitrates. Exposure to ambient airborne pollutants is generally increased by being active and being outdoors where concentrations are typically higher (increased breathing rates and increased exposure). Fine particles outdoors efficiently penetrate indoors where they contribute to human health effects. This makes indoor exposures important because of the large percentage of time spent indoors, despite the somewhat lower activity levels.

Among the diseases that are exacerbated by particulate air pollution are chronic obstructive pulmonary disease (mainly chronic bronchitis and emphysema), asthma, heart disease, and respiratory infections (acute bronchitis, pneumonia). Children and elderly adults may also be at increased risk for these diseases-children, because of their greater outdoor activity levels, and the elderly, because of their relatively poorer average health status. Effects may not be limited to these groups; new and ongoing studies indicate an association between exposure of healthy people to fine particulates and potential shortening of their lives. ${ }^{178}$

\section{Concentration-Response Relationships}

Concentration-response information is available for numerous health end points, including premature mortality, hospitalization for respiratory causes, and respiratory symptoms.

Concentration-response functions have been adapted from the epidemiological literature, 169 although it is still not known whether a threshold value for particulate matter exists. Changes in the number of incidences of health effects predicted as a result of reductions in particulate matter reductions can be estimated using these functions. Recent studies have identified concentration-response functions for sulfates, for all particulate matter, and for fine particulate matter. ${ }^{168,172}$ Due to limited scientific literature addressing the health impacts of nitrates, exposure currently is analyzed as exposure to fine particulate matter. Many epidemiological studies suggest an association between both mortality and morbidity and exposure to 
ambient fine particulate matter, but specific biological mechanisms have not yet been identified. Studies in laboratory animals are beginning to provide preliminary evidence of plausible biological mechanisms. ${ }^{179}$ Definitive results, however, are not expected for several years.

\section{What are the economic benefits related to the effects areas?}

Economic methods for valuing the effects of pollution on marketed goods and services have been available for many years. The ability to estimate benefits for these effects is limited by the availability of economic and scientific data.

In contrast, methods for estimating nonmarket values and passive-use values have only recently become widely used and accepted. The reliability of economic estimates for specific environmental effects from Title IV is greatest for the health benefits, although significant uncertainties characterize the estimates. Estimation of recreational damages is less reliable because the economic studies are lacking, there are gaps in the science, and there is a lack of baseline recreation participation information specific to reference environments of interest.

The 1990 Clean Air Act Amendments direct NAPAP to coordinate federal agencies' efforts to analyze the costs and benefits of Title IV controls. Although NAPAP's 1990 integrated Assessment Report ${ }^{3}$ identified a large number of potential economic benefits, three obstacles limited a quantitative assessment: (1) linkage to end points that directly affect welfare from an individual's perspective-that is, a determination of the quantitative effect of emission reductions on an item that is valued by individuals-was often poorly established; (2) inconsistent levels of rigor and reliability characterized the economic methods that were available for valuation; and (3) even where end points and methods for valuation were well developed, poor scientific or economic data often undermined the ability to estimate potential benefits. Since 1990, there have been advances in science and economics that make estimates of economic benefits more feasible. In some cases, even though estimates remain uncertain, more is known about the range of potential benefits and about the contribution that additional research could make to reducing uncertainty.

This assessment of economic benefits addresses the following areas: human mortality, human morbidity, visibility, materials and cultural resources, ecosystem health (nonuse values), aquatics (recreation), forests (recreation), agriculture and commercial forestry, and radiative forcing. For this assessment, NAPAP asked the following questions about each of the areas.

1. Does science provide the information needed for economic analysis? Are benefit end points well established?

2. Are economic methods adequately developed?

3. Are data available from science and economics for an assessment of benefits?

4. Are the expected benefits large?

5. With the goal of improving benefit estimates, what is the relative short-term return on investment for research?

A matrix was developed to display a qualitative, relative ranking for each benefit area with respect to these questions (Table 7). The major conclusions of this benefits assessment are summarized in the text below and are followed by a discussion of the rankings assigned each area.

\section{Benefits Estimation: Approaches and Conclusions}

Benefits estimation provides a means to assess the values people place on the expected effects of Title IV. From an economic perspective, values are defined in relative terms and are measured by how much of one asset or service people are willing to sacrifice to obtain or preserve another. Economists refer to this as an opportunity cost approach to valuation.

Values are expressed in monetary terms, although in principle they can be expressed in other metrics. The methodologies used to obtain a monetary measure of value depend on the type of information available. For example, market goods have observable market prices and quantities from which estimates of value can be obtained. However, nonmarket goods and services and nonuse values must employ alternative techniques. 
Table 7 displays a qualitative, relative ranking for each benefit area with respect to the primary assessment questions of interest to NAPAP. The qualitative rankings are ordinal; for instance, the highest ranking is better than the second highest, but should not be interpreted as twice as high. The rankings are primarily of interest relative to each other. They should be viewed both as rankings among benefit areas for a given question (within a column), and among questions for a given benefit area (within a row). Even in cases where the highest ranking is indicated, there still remains considerable room for improvement.

\section{Market Goods and Services}

\section{Agriculture and Commercial Forestry}

The value or opportunity cost of goods and services that are readily traded in markets is reflected in their prices. Benefits from emission reductions to agriculture and commercial forestry fall in this category. However, the benefit in these areas is not simply the change in crop yield multiplied by crop price. Rather, it is the value of the change in yield compared with the next best use of the resources used to produce the crop. The opportunity to substitute among crops if the yield of one crop falls substantially provides a bound on the magnitude of the economic impact on agriculture. Also, if effects are widespread, product prices will change as will consumer demand, which also must be taken into account.

\section{Materials}

The effect on materials is another benefit area that includes marketed goods and services. Again, the benefit in this area is not, for example, the fractional change in the physical lifetime of a material multiplied by its original cost. Rather, it is the lost economic use of the asset. Material assets often have shorter economic lives than physical lives, as is evident when a structure is torn down while it is still fully functional in order to construct a new one. The economic depreciation of material assets tends to lower the estimate of benefits to material resources from that which would occur if those resources were valued at their original cost less their physical depreciation. In other cases, the useful service life of an asset, such as an automobile, may be affected only slightly by damage to paint finish, but its economic value at each age may be greatly affected. The economic methods for valuing the effects of Title IV on marketed goods and services have been available for many years. The ability to estimate benefits is limited by the availability of economic and scientific data.

\section{Nonmarket Goods and Services}

The valuation of goods and services not traded in markets can be sensitive to the geographic location of impacts and cannot be observed directly from prices. Because the effects of Title IV are so widespread, it is prohibitively expensive to measure values with individual studies targeted at all the specific locations and effects. One approach to comprehensively measuring value in these situations is termed benefit transfer. Information from studies that value changes at specific geographic locations is "transferred" to estimate benefits at other locations.

The rigor and validity of benefit transfer vary with the types of benefits under consideration. They are central features in the assessment of the reliability of benefit estimates. A simplistic approach is the use of a uniform value for a day of recreational activity (unit-day value) calculated at a specific site and applied at various other sites with a wide range of characteristics. But estimates are unreliable because sites vary greatly, and uniform values for a day of recreational activity cannot be used to value a change in the quality of a recreational experience. A more sophisticated and preferable approach would be to identify the attributes of the sites that have been studied previously and to estimate the individuals' willingness to pay for these attributes at these and other locations.

Of the various effects of Title IV, impacts on aquatic and forest recreation are the most problematic with regard to transferring benefit estimates. The value of environmental assets has generally been calculated with unit-day values, but numerous values exist for all types of uses and environments. 180 Accounting for regional factors (such as the range and quality of substitute sites) and site-specific factors (such as congestion) is difficult, and there are no acceptable procedures for determining the spatial extent of the market. The methods for determining the size of the population that would be or is affected by a change in recreational quality or quantity are still being debated.

\section{Aquatic Recreation}

The most reliable valuation of environmental assets affected by Title IV is for aquatic recreation in the geo- 
graphically specific but important Adirondack Park (New York). The seminal paper in this area'sl contains estimates for the value changes in the catch rate for trout and other fish species, given their relative sensitivity to lake acidity. The study also addresses the availability of substitute sites for aquatic recreation and an individual's willingness to pay to avoid degradation at sites affected by Title IV. However, the literature in general is weak on the issue of participation rates, assuming effectively that the number of anglers as a percentage of the population remains constant. Further, the valuation of benefits to lakes outside the northeastern region will require sophisticated benefit transfer.

\section{Forest Recreation}

Valuation of the benefits of Title IV for forest recreation poses the same potential problems as valuation of benefits for aquatic recreation. Forest recreation depends on the availability of substitute recreational activities, which has not been successfully modeled previously. Furthermore, there is no individual setting where credible estimates have been developed.

\section{Human Morbidity}

The area that affords the most credible benefit transfers is human morbidity. Once atmospheric or other natural processes are taken into account (e.g., in estimating the effect of reduced emissions on ambient air quality), the health effects and the values people place on avoiding them are assumed to be reasonably similar across locations in the United States, especially if the transfer occurs between populations with similar health status and life styles. Applying unit values for health effects at all sites affected by Title IV is less problematic than applying unit-day values to specific environmental changes, because of the presumption that willingness to pay to avoid health effects is less influenced by region and site variables than willingness to pay for recreation. This is one reason why relatively good progress has been made in health benefits analysis.

\section{Human Mortality}

The valuation of risks of human mortality depends on estimates of the willingness to pay of individuals for small changes in the risk of premature death. Most original studies in this area address accidental deaths in prime-age adults-a setting inappropriate for most types of environmental mortality risks, except perhaps accidental toxic waste releases and similar catastrophes. Hence, they are not appropriate to transfer to the valuation of health benefits from environmental changes. One study ${ }^{182}$ addresses the latency issue that is important for valuing deaths due to cancer, but it does not consider the effect of prior health status and age on valuation, which influences rates of environment-related deaths, such as those from heart disease and respiratory failure. Few reliable, peer-reviewed studies are available to value life-years saved, and none do so for individuals with impaired health, even though this health end point can be estimated by health scientists. Nonetheless, the weight of evidence is so great regarding the presence of mortality effects that in sensitivity analysis using a wide range of parameters for the value of a statistical life, relatively large benefit estimates are consistently obtained.

\section{Visibility}

Benefit transfer for valuing visibility presents formidable challenges because of the sensitivity of values to regional, site, and personal characteristics. While visual range can be characterized in a relatively straightforward way, the vista being affected is difficult to characterize in generic or transferable terms beyond such labels as "urban," "rural," and "recreational area," which are not likely to be sufficient. Despite these challenges, the literature on visibility benefits is fairly conducive to benefit transfer. Several studies of visibility values in multiple cities ${ }^{183-185}$ permit examination of city-specific factors affecting values and derivation of functional relationships to predict willingness to pay, given the baseline visual range and the size of the change. ${ }^{186}$ There is a somewhat thinner base upon which to construct estimates of benefits for changes in visibility at recreational sites. ${ }^{187.188} \mathrm{~A}$ recent study estimates a significant annual value of total benefits of Title IV in 2010 for both (1) residents of the eastern United States and (2) national parks. ${ }^{189}$

The major problem with calculating benefits for visibility is not the reliability of transferring estimates from original studies to other study sites. Rather, it is the reliability of the original studies. Often the valuation of visibility has relied on stated preference methods, or contingent valuation, specifically. Contingent valuation techniques rely on information revealed through choices made by individuals in a hypothetical setting, rather than information revealed through actions in a real economic setting. Significant debates surround protocols for eliciting values in contingent valuation studies. For example, the size of photographs shown to 
respondents appears to influence willingness to pay. There are also concerns about joint valuation of visibility and health (i.e., that reported values for visibility improvements are confounded by concerns about health effects) and embedding (i.e., identification of the proper geographic scope for valuation).

Research on recreational values has concentrated on national parks in the Southwest. This focus has the advantage that health and visibility may not be confounded, but provides little information about changes in visibility at eastern national parks affected by Title IV. Nonetheless, these existing studies indicate that benefits from improvements in visibility at recreational sites can be substantial. In addition, previous studies indicate the valuation of visibility effects in residential areas is likely to be as important as changes in visibility at national parks because these are use values centered where people spend their daily lives.

\section{Nonuse Values}

Up to this point, commodity values have been used to describe the valuation of benefits to marketed goods and services, and use values have described the value of nonmarketed goods and services that individuals use or enjoy directly. Another potentially important category of values is designated nonuse values. This value stems from an individual's willingness to pay to avoid damages to environmental assets, even if the individual has no expectation of directly enjoying or using that asset. Nonuse values are now widely accepted as a legitimate category of benefits estimation, but estimating such values is highly controversial.

\section{Ecosystem Health}

The most important area of potential benefits that would be characterized by nonuse values is ecosystem health. By its nature, this area describes effects that occur over long time frames and broad geographic areas, and that are the product of interactions between the effects of Title IV and other impacts on the environment. People may hold significant nonuse values for the stability of ecological systems, in addition to the use values for aquatic and forest recreation in these systems. Some progress has been made in the last few years, in particular, in the valuation of estuaries. These studies indicate economically significant nonuse values for environmental assets, but a range of potential benefits from Title IV cannot yet be determined. Clearly, the literature on nonuse values for environ- mental assets cannot yet support benefit transfers, because most of the studies concern nonmarginal changes in unique environments (e.g., species extinction, loss of an ecosystem).

\section{Cultural Resources}

Another area that would be characterized in large part by nonuse values is the potential benefits of Title IV emission reductions to cultural resources, including historic monuments and buildings, gravestones, and statues. Various studies in Europe have found very high estimates in this benefit area. A recent study indicates that important economic benefits measured by willingness to pay may result from the impacts of Title IV on national monuments. ${ }^{190}$ However, the available scientific and economic data are insufficient even to place bounds on these potential benefits. Valuation of cultural materials typically involves summing estimates of an individual's willingness to pay to preserve the attribute of the cultural resource (e.g., a monument) that is being degraded by emissions. This will include the values of those that actually visit the cultural resource as well as the value that nonusers (those that may never visit the monument) may place on preserving the resource (existence value).

\section{Reliability of Economic Estimates}

In summary, the reliability of economic estimates for specific environmental effects from Title IV is greatest for the human health benefits, although significant uncertainties characterize the estimates. Recreation damage estimation is less reliable because the economic studies are lacking, there are gaps in the science, and there is a lack of baseline recreation participation information specific to reference environments of interest. The valuation of aquatic effects for one important region, Adirondack Park, is fairly reliable. However, estimation of aquatic benefits in other regions will be difficult because of differences in water temperature, chemistry, availability of substitute sites, and the mix of species at other locations. Estimates of visibility damages are weak, partly because of weak methodology (e.g., some are limited to annual averages only) and partly because data on changes in visual range for the majority of affected recreational and residential vistas are of low quality. Methods for valuation of agricultural and commercial forestry and materials are well understood, but the availability of estimates is limited by scientific and economic data. Nonuse value estimation studies for ecological systems and cultural resources suggest the value of 
changes in these assets may be relatively large, but there are almost no studies of marginal changes in the quality or quantity of these assets, such as what may likely result from Title IV.

\section{Expected Benefits and Associated Uncertainties}

In general, quantifiable benefits are relatively large in the areas of health and visibility-areas where relatively large benefits may not have been anticipated, or that were not the primary motivation for Title IV originally. The magnitude of benefits in these areas compares favorably with the costs of Title IV, independent of benefit estimates for other areas.

While estimates of health and visibility benefits remain uncertain, the cost of reducing this uncertainty appears to be relatively less than reducing uncertainty for many other areas. Benefits to materials and cultural resources may also be sizable; an incremental research effort could provide substantial information about the likely extent of these benefits.

To evaluate Title IV on the basis of a comparison of benefits and costs, it may be sufficient to focus efforts on assessing benefits from health and visibility, because these benefits alone appear to outweigh the costs. Environmental areas, such as aquatics and forests, will also benefit, although quantification of ecosystem benefits is somewhat more uncertain. If future research reveals this to be an erroneous conclusion, then NAPAP would be justified in looking further into potential benefit areas where results may be more elusive. However, if NAPAP research is to be used to determine whether further controls on $\mathrm{SO}_{2}$ emissions are warranted, then a comparison involving the additional benefits from all benefit categories and the additional costs would be necessary.

A somewhat different perspective would be suggested if NAPAP were to consider a longer time frame and a more sustained research effort, with attention focused on possible amendments or extensions to the goals set forth in Title IV. In this case, the assessment of nonuse values for ecosystem health should be afforded higher priority. However, a research emphasis in this area would require sustained levels of funding over several years to yield results that would be reliable. Also, agriculture and commercial forestry would receive a somewhat higher ranking were a sustained level of funding to be committed. One reason is that agriculture is undergoing structural change, due to 1996 congressional reforms, which may not be fully attained until the next decade. In addition, the cost of research in this area stems from the need for modeling of changes in ozone,

\footnotetext{
Relative Magnitude of Expected Benefits

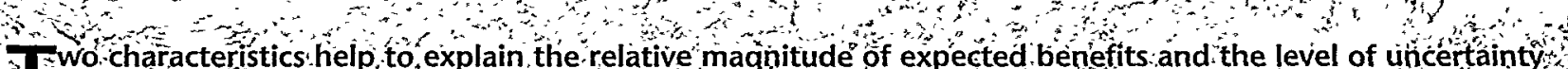

3. in these estimates as illustrated under Questions 4 and 5 in table 7

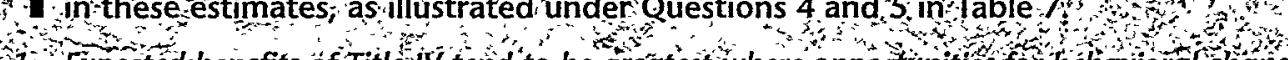

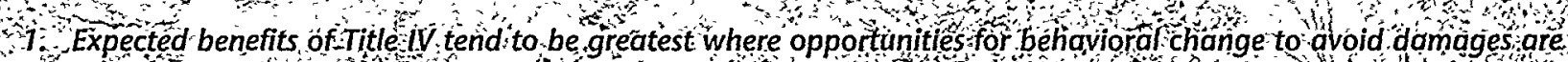

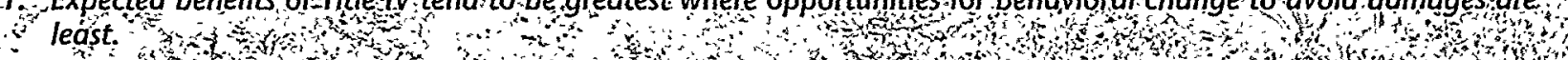
Human health and isibility share the characteristic that indivduals have few options to avoid detrimental

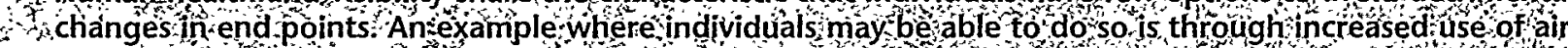
conditioning to avoid poor air quality such opportunities a a wuch more evident in the recreational th

- choices people make for example, angling actiy ity at one lake may beaffected by diminished câtch per

unit of effot, but anglers are ilikely to respond by moving to other lakes The willingness to pay is the

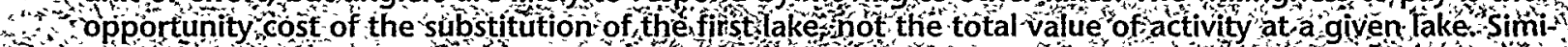

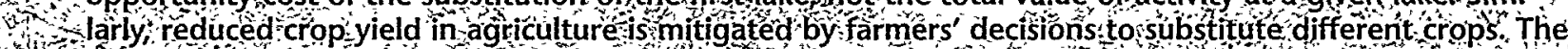

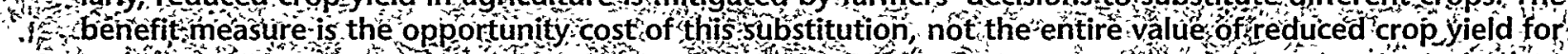

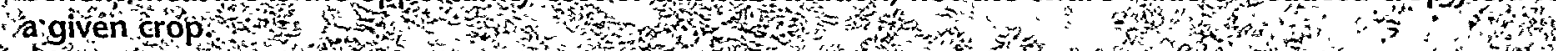

2 Links between scince and economics are strongest where changes in atmospheric concentrations directiy affect end points relévant to individuals they are wedest where ecological systems play a more important role

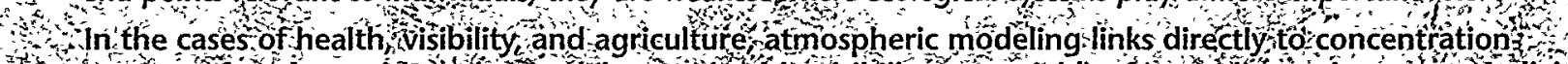

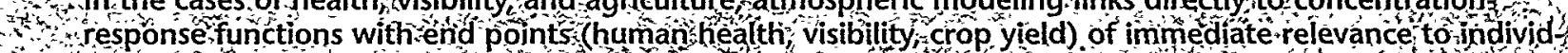

40 uals In other benefitareas the science is more complicated because ecological systems intervene between

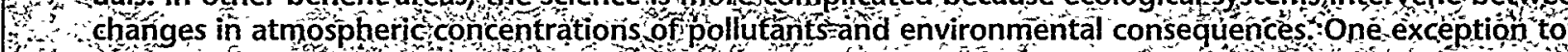

w this general rule is matenals where the linkage is weak due to a relative lack of oresearch data

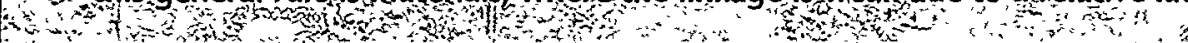

sing 


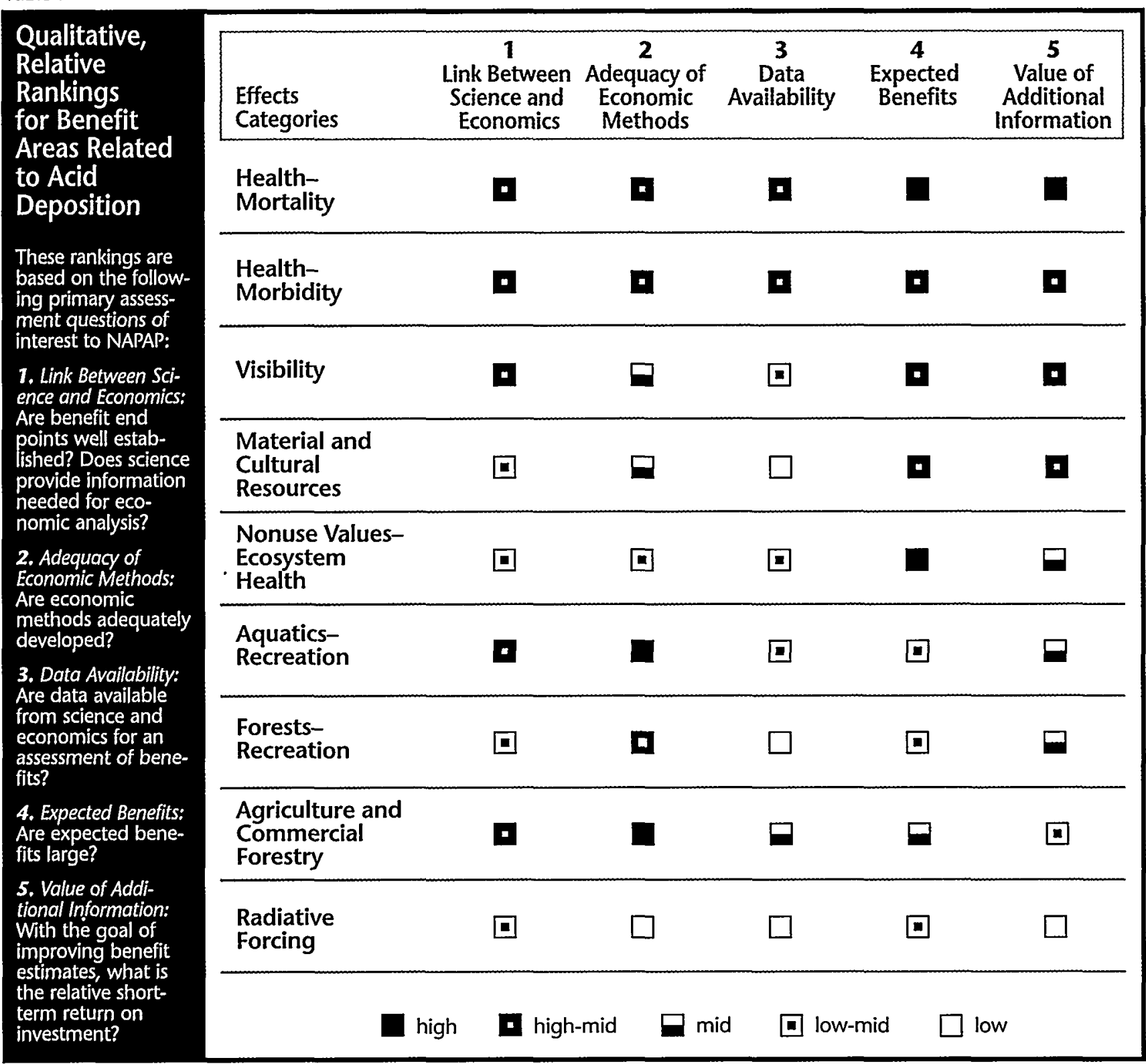

which may be costly and time consuming, though such modeling would also contribute to an understanding of human health benefits and forest recreation.

\section{Qualitative Ranking Summary}

Assessment of economic benefits has significant room for improvement in each benefit area. The most pressing needs within each area are identified for the purpose of reducing uncertainty in benefit estimates. Brief explanations are provided for the qualitative rankings given for the first three questions in Table 7. The rankings illustrate the relative strength at each step along the pathway linking environmental impacts and economic benefits. These rankings, coupled with a sense of the relative cost of improving information at each step (which is not considered formally in this document), provide evidence for prioritizing incremental research to narrow the uncertainty associated with an overall assessment of benefits (Question 5). The relative magnitude of expected benefits is also discussed in the accompanying text box.

\section{Human Mortality}

Evidence of mortality effects from exposure to air pollutants is convincing, and their magnitude may be 
large, but major uncertainties remain about the particle sizes and composition affecting death risks. In addition, the traditional approach to estimating such risks and valuing them is problematic. Because health benefits will largely accrue to the older population, economists increasingly recognize that statistical years of life gained is the critical end point, rather than a "body count" of statistical lives lost. However, estimates of changes in life years have not been in standard use in their valuation of health effects (Question 3).

From an economic standpoint, health research is providing adequate concentration-response functions (Question 1), particularly from prospective studies linking cumulative exposures of health populations to premature mortality-through the increased probability of developing and exacerbating chronic illness and the vulnerability of old age. The added role of acute exposures, if any, is less clear. Just as important, the valuation of a statistical life for environmental risks draws on inappropriate estimates from accidental death and occupational risks (Question 2). The methods to calculate more appropriate measures of the willingness to pay for increased life expectancy are being developed, but only one study has been conducted. ${ }^{191}$ Such an approach is called a "life years lost" approach and is likely to yield lower benefits than the conventional approach of "value of a statistical life" (this difference is discussed in greater detail in the next section on valuation).

The highest priority for reducing uncertainty in benefit estimates should be placed on human mortality. An improved basis is needed for the valuation of small risks to mortality due to environmental changes. Also, economists need to develop estimates for willingness to pay to avoid these risks that depend on the age and health status of the affected individual. Better estimates of the concentration-response functions and life years saved conditional on the age and health status of individuals are required from the health science and epidemiology disciplines.

\section{Human Morbidity}

There is strong evidence of health morbidity effects from exposure to air pollutants (Question 1). From an economic perspective, the health science provides adequate concentration-response functions linking air concentrations to acute health effects, in the sense they are consistent and biologically plausible. Good functional relationships are available for medical and other indicators of distress, such as hospitalization and work-loss days for acute illness, and there are reliable, though partial, measures of willingness to pay to avoid these effects (Question 3). Also, literature exists that employs averting-behavior studies to value health morbidity, but they are less convincing (Question 2). The uncertainties in this area could be reduced substantially through additional research. Although contingent valuation approaches for valuing acute health effects are reasonably well established, there are no recent studies in this area using such approaches. The literature is more ambiguous on the possible link between exposure and some chronic respiratory diseases and heart disease. Also, the willingness-to-pay estimates for chronic illness are less developed.

\section{Visibility}

A comprehensive analysis of visibility benefits requires better monitoring data and atmospheric modeling. Monitoring data are important because visibility effects are nonlinear (Question 3). The economic methods for valuation include hedonic property valuation and stated preference for residential visibility, and travel cost and stated preference for recreational visibility. However, the economic research has failed to identify end points with adequate precision (Question 2). There is evidence that people care about characteristics of the distribution of visibility effects over seasons, weather conditions, and time of day, but valuation other than mean values has not been explored. Similarly, the atmospheric modeling has not addressed important distributions in time and space (Question 1), and the level of importance of this detail should be determined before additional resources are spent on monitoring and modeling. For moderate resources, additional valuation studies could be implemented to enhance the precision of the end points that are important for assessing benefits. Particular attention should be paid to the nature of preferences for changes in visibility. This information would provide guidance for modeling of changes in visibility at a more decentralized level in more areas of the country.

\section{Materials and Cultural Resources}

The main problem in both materials and cultural resource valuation is the lack of a complete inventory of affected assets (Question 3). A second problem is the lack of data about the economic lives of the assets. Further, information on behavioral responses is inadequate (e.g., changes in maintenance or replacement in response to physical deterioration). From an economic 
perspective, the methods for estimating general materials damage are more straightforward than those for estimating damage to cultural resources (Question 2). The latter requires stated preference methods, which have only recently been applied to cultural resources. Some dose-response functions of the effect of pollution on materials exist for cultural (e.g., monuments), commercial (e.g., buildings, clothes, rubber, automobile paint), and public (e.g., bridges, fences) assets, but there is uncertainty about how well these data describe the exposure and effects outside an experimental setting and how Title IV's controls contribute to reduced damages (Question 1).

\section{Ecosystem Health (Nonuse Values)}

Ecosystem changes associated with Title IV cannot yet be determined (Question I). Almost as significant is the lack of a valuation framework for assessing benefits from improvements in ecological indicators, especially given the temporal aspects of ecological dynamics (Question 2). Hence, there are only illustrative studies to serve as an indication of potential benefits (Question 3). Valuation studies should identify the attributes of ecosystems that affect willingness to pay most significantly. This information should then become the focus of ecosystem modeling.

\section{Aquatics (Recreation)}

With respect to angler activities, the linkage between water chemistry and survival of fish fry is well understood in a laboratory setting, using dose-response methodology (Question 1). Translation of these results to wild populations may be imperfect because mortality as well as reproductive rates may be affected. Other possible contributing factors are not controlled for in laboratory tests. Results-expressed in terms of "acid stress indices"-are species-specific but may not have been carried out for all recreationally targeted species.

Three issues affect angler activities: effects of acid stress indices on angler catch per unit of effort; angler valuation for changes in catch per unit of effort; and effect of catch per unit of effort on angler participation rates. Only the first factor is relatively straightforward. The link between science and economics (acid stress indices to catch per unit of effort) is tenuous and limited to a few species (fewer than the number for which there are acid stress indices data). Links between acid stress indices and catch per unit of effort have been estimated only for Adirondack Park. Catch per unit of effort is valued using travel cost data and either of two competing methods: hedonics or random utility. Neither currently accounts for effects of changing fishing conditions on individual decisions to fish, which should be estimated jointly with valuation of catch per unit of effort and site choice. Such models have not yet been applied to freshwater fishing (Question 2). Nonetheless, among areas with nonmarket benefits, the techniques that have been developed in aquatic recreation are the most sophisticated.

With respect to boating and swimming, scientific models of eutrophication with predictions of turbidity (especially related to nitrogen) are being developed. Acidification may improve clarity of the water, thereby benefiting swimming and boating; however, nitrogen deposition may contribute to eutrophication, thereby worsening conditions for swimming and boating. Economic models of the benefits of boating and swimming involve valuation and participation rates. The methods share common characteristics with angler activities. As with angling, there are significant data on swimming and boating behavior, but little data on recruitment (Question 3). The science-to-economics links for affected regions outside the Northeast should be developed more fully. Within economics, a model of participation decisions is needed, to be estimated jointly with angler valuation.

\section{Forests (Recreation)}

There is ample evidence of the effects of sulfur, nitrogen, and ozone on forests. A key concern is the decline of forest resources, particularly high-elevation trees. However, the link between primary pollutants and effects that people may care most about, such as foliage intensity and range, is not established (Question 1). A variety of confounding factors, such as drought and introduced pests, has made it difficult for forest researchers to quantify the relationship between air pollution levels and forest decline.

Economic methods for valuation of forest recreation draw essentially on the same techniques used in aquatics recreation (Question 2). However, the forest recreation literature is focused too narrowly to be of immediate value, does not provide evidence on the effect of Title IV's controls on forests, and typically has not incorporated substitution opportunities. Science has not established robust links to valuation end points, so data on changes do not exist (Question 3). Valuation data are also not available. Priority should be given to developing a regional model of forest recreation, to account for the range of recreation opportu- 
nities, and to develop estimates of willingness to pay to avoid damage to individual, or classes of recreationally related, forest resources. This economic research would help to focus the contribution of additional work in natural science and, especially, to identify end points that would help link science and economics.

\section{Agriculture and Commercial Forestry}

Of all air pollutants, ambient ozone is likely to cause the most significant crop damage. Dose-response functions for ozone are available for most major agronomic crops and some specialty crops (Question 1). A number of studies have used ozone dose-response functions and standard economic data and models to estimate the monetary losses. However, most studies have failed to adequately account for behavioral responses, such as adaptation of crop varieties or adjustment of input mixes (e.g., using more fertilizer), although economic methods for doing so exist (Question 2). Moreover, data on changes in ozone resulting from Title IV are not currently available (Question 3). $\mathrm{NO}_{X}$ reductions under Title IV are believed to decrease the creation of ozone and damage to agriculture. Regional models of ozone are needed to predict its effects on agriculture and commercial forestry. (These models would also improve health benefit estimates for Title IV.) In addition, industry-level models are needed to predict changes in cropping patterns in response to changes in crop yields, which would mitigate the economic cost of reduced yields.

\section{Radiative Forcing}

Atmospheric models predict changes in particulates and their effect on radiative forcing (Question 1). Predictions of local changes in temperature are also available. However, changes in variability and the effect on general circulation in the atmosphere are not known. Economic methods for modeling damages of climate change are very uncertain, so measuring the benefits of avoided change are also uncertain (Question 2). Data for valuation of local effects are not available.

\section{Valuation of Emission Reduction Benefits}

The largest potential benefits stem from human health and visibility, and possibly from ecosystem health. Significant potential benefits also arise from materials, agriculture (through the $\mathrm{NO}_{\mathrm{x}}$ /ozone link), and commercial forestry.

\section{Human Health}

EPA has estimated the benefits from reduced risk of human mortality resulting from $\mathrm{SO}_{2}$ emission reductions under Title IV to be approximately $\$ 1,800$ per ton of $\mathrm{SO}_{2}$ reduced in 1997 to $\$ 3,400$ per ton reduced in 2010 (in 1990 dollars). 169 The difference reflects, in part, population growth and a shift in emission reductions to areas upwind of larger population centers. (Pennsylvania and the Carolinas have larger shares of the emission reductions in 2010 than in 1997, while Ohio and Missouri have smaller shares.) These estimates are based on an assumption that sulfates play a causative role in producing mortality (although no consensus exists about such causality) and apply a value to a "body count" of statistical lives lost rather than valuing statistical years of life gained, even though many of the deaths may be premature by only days or weeks. This issue was explored in the sensitivity analysis of the EPA estimate conducted for NAPAP by Resources for the Future (RFF) 192 using the recently peer-reviewed Tracking and Analysis Framework (TAF) modeling system, which was developed to support NAPAP assessments.

One estimate that was varied in the RFF analysis was EPA's willingness-to-pay estimates of the expected "value of a statistical life" of $\$ 3.2$ million per statistical life with a range of \$1.7-7.9 million (1990 dollars). This is an age-weighted distribution, placing greater weight on values relevant to the cohort over 65 years of age than for the general population. The willingness-to-pay approach may overstate the value of excess premature mortality or the death of an extremely ill individual who is expected to die within days or weeks. It may also overstate benefits in contrast to a "life years lost" approach, which more explicitly accounts for the age distribution of the affected population and, in principle, better reflects decisions and trade-offs that would be made by individuals of comparable age in assigning values to health effects.

In the RFF case, the mean of $\$ 3.1$ million per statistical life (in 1990 dollars) was used, along with a 90 percent confidence interval of \$1.6-6.0 million. This distribution generally accords with the valuation literature, but is somewhat on the conservative side because less weight was given to the labor market studies relative to the contingent valuation studies, the latter being marginally more appropriate for valuing mortality risks in the environmental health context and also captures age effects (as does the EPA value), based on lones-Lee et al. (1985).193 Based on the 
Table 8

Value of a Statistical Life and Other Health End Points (in 1990 dollars per case)

\begin{tabular}{|c|c|c|c|}
\hline Health Effect & Section 812 Study ${ }^{a}$ & Health Benefits Report ${ }^{b}$ & RFFc \\
\hline Mortality & $\$ 4,800,000^{\star}$ & $\$ 3,200,000$ & $\$ 3,100,000$ \\
\hline Chronic Bronchitis & $\$ 260,000$ & $\$ 211,490$ & $\$ 223,300$ \\
\hline Respiratory Hospital Admission & $\$ 6,100$ & $\$ 12,340$ & $\$ 6,650$ \\
\hline Cardiac Hospital Admission & $\$ 8,300$ & $\$ 12,340$ & $\$ 12,350$ \\
\hline Work-Loss Day & $\$ 83$ & $\$ 53$ & $\begin{array}{l}\text { other measures of } \\
\text { reduced-activity days used }\end{array}$ \\
\hline Asthma Attack & $\$ 32$ & $\$ 36$ & $\$ 31$ \\
\hline \multicolumn{4}{|c|}{$\begin{array}{l}\text { * Or } \$ 293,000 \text { per life year lost. Note the Health Benefits Report (U.S. EPA, 1995) and RFF (1997) studies use an age-weighted expected value } \\
\text { of statistical life, while the Section } 812 \text { study (U.S. EPA, 1997) is a best estimate not explicitly considering age. }\end{array}$} \\
\hline \multicolumn{4}{|l|}{ a Source: U.S. EPA, 1997, Table 1-2 196} \\
\hline \multicolumn{4}{|l|}{ b Source: U.S. EPA, 1995, pp. 5-24169 } \\
\hline c Source: RFF, 1997192 & & & \\
\hline
\end{tabular}

Jones-Lee study findings, EPA assumed that the value of a statistical life for those 65 years old and older is about $75 \%$ of that for adults under age 65 . Even using the conservative $\$ 3.1$ million estimate, the EPA numbers appear to be quite robust. Examples of the value of a statistical life and the value of other health end points in these two studies are reported in Table 8 (also see footnote). Ozone-related benefits due to Title IV's $\mathrm{NO}_{X}$ controls would be in addition to those health benefits of Title IV's $\mathrm{SO}_{2}$ controls.

The EPA Health Benefits Report ${ }^{169}$ and the RFF analysis 192 estimate the benefits from reduced risk of human health effects resulting from $\mathrm{SO}_{2}$ emission reductions under Title IV, assuming that sulfates play a causative role in producing mortality. The 1990 Clean Air Act Amendments also require EPA to estimate the total benefits, including human health, achieved as part of the entire Clean Air Act (1970-1990, with a separate ongoing effort to estimate benefits achieved from 1990 to 2010). The valuation estimates of these health benefits are also listed in Table 8 under the Section 812 Study column. ${ }^{194}$ This analysis includes the benefits of reducing many pollutants, in addition to $\mathrm{SO}_{2}$ emissions.

Using the TAF modeling system with various assumptions, RFF developed median estimates of health mor- tality benefits that range from $\$ 2,800$ to $\$ 3,800$ per ton of $\mathrm{SO}_{2}$ emission reduction in 2010.192 The lower estimate stems from the use of the Regional Acid Deposition Model to model atmospheric transport and pollutant concentrations in EPA's 1995 Health Benefits Report, coupled with health epidemiology and valuation coefficients from the EPA's 1996 Regulatory Impact Analysis ${ }^{196}$ for the new particulate matter standard, which were equivalent to those used in the Section 812 Study. The higher estimate is based on the use of the Advanced Statistical Trajectory Regional Air Pollution model for atmospheric modeling and the health epidemiology and valuation coefficients cited above. The Regional Acid Deposition Model yields smaller health effects than the Advanced Statistical Trajectory Regional Air Pollution model; this is partly offset by the Regulatory Impact Analysis valuation numbers, which yield higher values than those used by RFF. Means are above the medians in all cases.

TAF incorporates sophisticated analysis of uncertainty by propagating the measures of uncertainty in demographic, climatological, dose-response, and valuation parameters and functions for all the modeled benefit pathways, resulting in a wide range of possible benefit estimates around the medians that are reported. The $90 \%$ confidence interval around TAF's reference case

In the final draft of EPA's 1996 Regulatory Impact Analysis, 195 which was released after the data for this assessment were compiled, a "life years lost" approach was used to calculate a lower bound for the value of mortality benefits. As discussed in the text, this approach is significantly different from the "value of a statistical IIfe" approach used to calculate an upper bound in that study, and which has been the mainstream approach used in most previous EPA analyses. Using this promising new approach of "life years lost," which continues to evolve, would importantly lower the results of the mortality benefits reported in Table 8. 
estimate for mortality benefits ranges from $\$ 1,075$ to $\$ 15,020$ per ton. This reflects the tremendous uncertainty in this estimate. However, the main result from this comparison is to confirm the probable magnitude of benefits relative to cost estimates reported elsewhere in this study. The median value of benefits from reduced risk of human morbidity effects estimated by TAF for 2010 is an additional $\$ 475$ per ton of $\mathrm{SO}_{2}$ emission reduction.

The median estimates of benefits resulting from changes in $\mathrm{NO}_{\mathrm{X}}$ emissions in 2010 are predicted by the TAF model to be $\$ 476$ per ton for reduced risk of human mortality and $\$ 259$ per ton for human morbidity. These estimates include effects from reduced secondary particulate formation, assuming nitrates are as potent as the average particle of particulate matter in affecting human health, but do not include the health effects from changes in ozone concentrations.

\section{Visibility and Materials}

As a result of emission reductions, potentially significant benefits may be achieved in the areas of visibility and materials. As preliminary evidence discussed earlier indicates, reasonable estimates of benefits to materials and cultural resources are not available. With regard to visibility, in one study standard visual range with and without Title IV was compared to assess the economic benefits of improvements in visibility. Drawing on several previous survey studies to value changes in visibility, substantial monetary benefits were obtained for residential areas in 31 eastern states and for national parks in the southeastern United States. Benefits to this region were estimated to be $\$ 3.4$ billion ( 1994 dollars) in 2010 , or about $\$ 377$ per ton of $\mathrm{SO}_{2}$ emission reduction. ${ }^{189}$ The sensitivity of this estimate has been explored using TAF, which predicts median estimates of visibility benefits for improvements at recreational sites that range from \$11 8 to $\$ 224$ per ton of $\mathrm{SO}_{2}$ reduction under alternative scenarios. In part, the range reflects uncertainty about the baseline against which emission changes under Title IV should be measured. Visibility changes vary in a nonlinear fashion with emission changes, resulting in the variation in benefits per ton. Benefits at residential sites were found to be of substantial magnitude.

\section{Ecosystem Health}

Reasonable estimates of potential ecosystem (nonuse) benefits are not attainable at this time. Ecosystem health benefits are expected to be large in part because they encompass broad changes that affect many environmental end points, perhaps to a small degree, but that taken together could alter large-scale systems. Aquatic and terrestrial effects are likely to have significant benefits through nonuse values, but uncertainties around these values remain among the largest. The link between changes in emissions and changes in ecosystems is even more tenuous than is the valuation based on these changes. Nonetheless, the evidence based on a small number of relatively narrow studies suggests these values may be significant.

\section{Aquatics, Forests, and Agriculture}

Expected benefits (for use values) were found to be low in areas that were the primary focus of benefits assessment in the 1980s-namely, ecological effects (aquatics, forests, and agriculture).

Public attention in the 1980 s to air pollution from $\mathrm{SO}_{2}$ and $\mathrm{NO}_{\mathrm{X}}$ emissions largely centered on the problem of acidification ("acid rain"), with particular concern for effects on water and soil chemistry and ultimately ecological systems. Given that, some find it surprising that relatively low benefit values have been estimated for effects on aquatics, forests, and agriculture. These low values stem from an assessment of use values, or commodity values in the case of agriculture. Agricultural benefits result in large part from changes in ozone concentrations, but modeling of ozone changes resulting from Title IV is not complete. Also, these low values result from the availability of substitutes that ameliorate the economic losses from emissions. The lack of substitutes for increased life or health makes morbidity and mortality a more important contributor to the benefits of emission reductions. 


\section{How might ecological effects be reduced if deposition were reduced further?}

Answering this question depends on dose-response functions used in a predictive mode. Such models were used extensively to answer a similar question posed by Congress to EPA under Title IV (Appendix B, Section 404 of the 1990 Clean Air Act Amendments). EPA's report' focused on surface waters in a few specific regions; the findings are reviewed in this report. There has been no parallel review of soils and forest effects, but this report attempts to at least qualitatively address them.

\section{Surface Waters}

The feasibility and effectiveness of an acid deposition standard to protect sensitive aquatic and terrestrial resources were examined in the Acid Deposition Standard Feasibility Study-Report to Congress.' In the study, EPA projects the impacts of implementation of the Clean Air Act Amendments on surface waters for three case study regions and projects a range of responses if deposition were reduced further.

Both nitrogen and sulfur deposition are important contributors to chronic and episodic acidification of surface waters. Further reductions in nitrogen as well as sulfur deposition may be necessary to fully protect targeted sensitive systems.

The feasibility study concluded that establishing standards for sulfur and nitrogen deposition in the United States is technically feasible, but that two critical areas of uncertainty advised against taking such action at that time. First, policy decisions regarding appropriate or desired goals for protecting sensitive systems were needed, especially with respect to the level of protection desired and the costs and benefits of such protection. Second, key scientific unknowns, particularly regarding watershed processes that govern nitrogen dynamics, limited EPA's ability to recommend specific deposition standards at that time.

The Nitrogen Bounding Study 197 was developed as a primary component of the Acid Deposition Standard Feasibility Study. This study illustrates the modeled results of scenarios of potential future nitrogen and sulfur deposition rates and different watershed nitrogenretention conditions and their combined effects on surface water chemistry at regional scales. The study evaluated target populations of surface waters in three regions: lakes in the Adirondack region of New York, and stream reaches in the mid-Appalachian and southern Blue Ridge Mountains.

The Nitrogen Bounding Study illustrates that, for the near term, sulfur deposition is likely to remain the primary acidification problem in the most sensitive areas of eastern North America. Model projections indicate that at certain times and under deposition scenarios tested, sulfur and nitrogen are projected to have approximately equal roles in surface water acidification. The modeling shows that nitrogen deposition effects in the mid-Appalachians and southern Blue Ridge might more closely approximate sulfur deposition effects (i.e., than in the Adirondacks). For most areas where current or near-term needs for additional controls are projected, and where watershed nitrogen saturation is not likely imminent, the greatest potential benefits will come primarily from control of sulfur emissions and deposition. In regions where nitrogen deposition is now or would likely become a more direct cause of chronically acidic conditions in sensitive waters, with potential effects of sulfur and nitrogen deposition becoming approximately equal and directly additive, further limits on nitrogen deposition could produce a twofold impact by both reducing acid deposition rates and lengthening average times to watershed nitrogen saturation.

The Acid Deposition Standard Feasibility Study concluded that scientific uncertainties regarding varying regional rates and differences in processes affecting watershed assimilation of acid-forming sulfur and nitrogen compounds preclude quantifying the reduction in deposition of either chemical below which there would be no significant adverse impact. Available information indicates that additional decreases in deposition would reduce regional proportions of chronically acidic surface waters or proportions of surface waters most sensitive to episodic effects. The magnitude of these potential benefits to each group of surface waters varies considerably by region. The study projections indicate for some surface waters in the Adirondacks, mid-Appalachians, and southern Blue Ridge that potential benefits may amount to a shift of a few percentage points in proportions of acidic or sensitive surface waters. For other groupings in other regions, deposition reductions could benefit $20 \%$ or more of 
the acidic or sensitive waters. However, even a few percentage points may mean that many lakes or miles of stream reaches are benefiting.

\section{Soils and Forests}

Decreasing deposition of sulfur and nitrogen will lead to decreasing concentrations of sulfate, nitrate, and cations in soil water and in surface water draining forest soils. Some change will occur rapidly in soils that have lost their ability to retain nitrogen-such as nitrogen saturated, highelevation, spruce-fir forests-or in soils that do not have appreciable sulfate sorbed to soils.

Water in soils with low supplies of base cations will most likely remain acidic and will contain aluminum, while water in soils with moderate to high supplies of base cations will most likely experience an increase in pH (lower acidity).

Reduced nitrogen and sulfur deposition will decrease leaching of base cations from forest soils. The time to replenish base cation supplies in soils will be decades to centuries, depending on rates of weathering and cation cycling, which are typically slow. Consequently, an important portion of the effects on forests of low levels of base cations (in particular calcium) will remain until base cation supplies can be replenished.

The acid-base chemistry of the soils and the water draining forest soils will depend on the characteristics and sensitivity of the soils. In general, decreasing the input of sulfur and nitrogen from deposition will decrease sulfate and nitrate levels in soils and soil water. The timing of this decrease in soil and soil water sulfate depends on the amount of sulfur stored. Soils high in sulfur will most likely experience a slower decrease in soil water sulfate, as the soil slowly releases stored sulfur. For nitrogen, the timing of the decrease will depend on the amount of nitrogen stored and the growth needs of the forest. A forest that has high demand for nitrogen, relative to nitrogen storage and throughput, will experience smaller decreases in nitrogen in soil water in response to decreased nitrogen deposition compared to a forest that has a low demand for nitrogen. A forest's need for nitrogen is strongly dependent upon the age of the forest. Thus, young, actively growing forests are far less likely to experience nitrogen saturation than older stands that have reached steady-state conditions. 


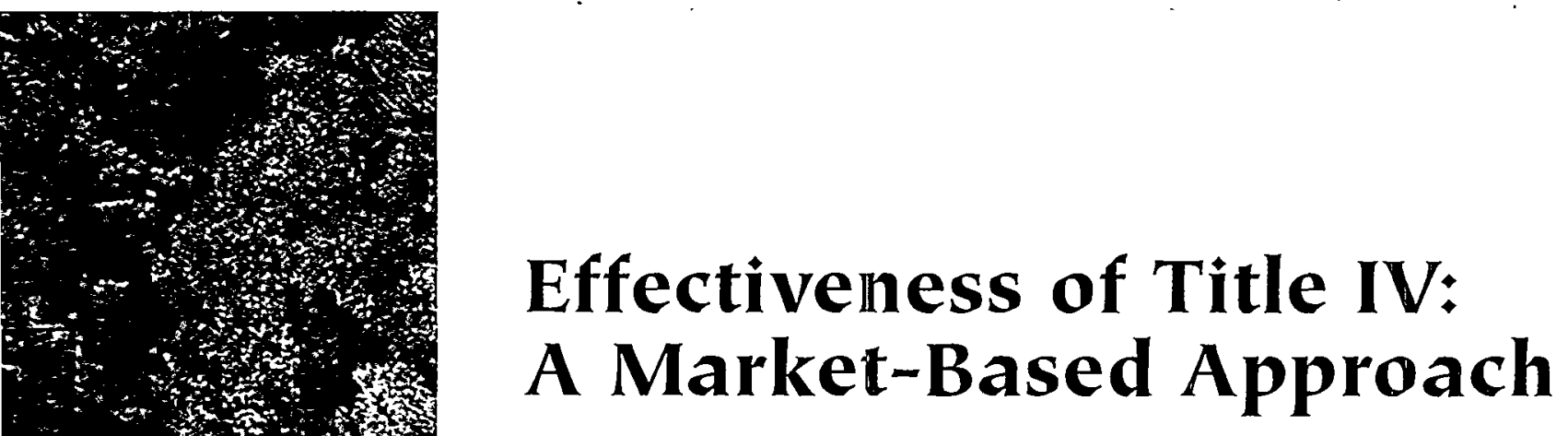

\begin{abstract}
A $s$ part of the iterative process of establishing and refining air quality management choices, it is essential to evaluate their effectiveness in achieving the Idesired results. In the case of Title IV, the desired result was to reduce the adverse effects of acid deposition by reducing emissions at a cost lower than could be achieved under traditional methods of regulatory control by using market-based incentives.
\end{abstract}

Looking across the causal chain from emissions to effects, there are several points at which one can evaluate the effectiveness of reducing emissions. This section will review some of those measures, such as the costs of compliance for utilities, the administrative costs for the government, the reduction in emissions and acid deposition, and its subsequent minimizing effects on human health, ecosystems, visibility, and materials and cultural resources.

\title{
Did the market-based
approach reduce costs?
}

There are three aspects to the evaluation of the cost-effectiveness of Title IV. First, did simply the choice of a market-based approach to control over the traditional command-and-control approach reduce compliance costs by utilities? This is a basic economic question that, when answered, may have a significant influence on the development of future pollution control options. Second, is the management of the control program by the government cost-effective? Third, given that the marketbased approach was selected as the management strategy for Title IV, were the initial projections of compliance costs accurate, and are we getting better at making these economic projections? It is necessary that uncertainties in projections be reduced to the point that they can be confidently used in developing policy. These three aspects are discussed below.

The market-based approach in Title IV has achieved significant savings when compared to a command-and-control regulatory approach.

As was predicted at the time of enactment of the 1990 Amendments, the competition between different compliance options and the integration of the allowance and fuel markets have reduced compliance costs. Several recent analyses have estimated that the cost savings from the market-based approach of Title IV amount to $50 \%$ or more of the predicted cost of compliance. Several studies have been conducted since 1990 of the cost savings in 1995 from emissions trading. Although these studies used different assumptions, the projected cost savings from trading alone have ranged from $\$ 230$ million in 1992 dollars, ${ }^{13}$ to $\$ 400-600$ million in 1990 dollars'18 to about $\$ 225-375$ million in 1994 dollars. ${ }^{15}$ In 1994, the General Accounting Office estimated the annualized cost in 2010 to be less than $\$ 2$ billion with full inter-utility trading, compared to $\$ 4.9$ billion without trading. ${ }^{13}$

The costs for the government to administer Title IV are less than the administrative costs associated with more traditional approaches to regulation. Title IV's per- 
formance-based approach eliminates the need to devise source-specific emission limits and to review control technologies and detailed compliance schedules. In addition, eliminating case-by-case review and approval of each trade greatly reduces the administrative and transaction costs associated with emission trading programs. ${ }^{25}$ The program's administrative costs of roughly $\$ 12$ million per year translate into a cost of about $\$ 1.50$ per ton of pollution reduced. 198

Emission reductions have been achieved at a lower cost than previously estimated for Title IV.

Since 1990, estimates of total costs of Title IV continue to be revised downward. Most recently, a retrospective analysis shows compliance costs in 1995 to be $\$ 726$ million. Projections for annualized costs of $\mathrm{SO}_{2}$ reduction by the year 2010 have declined from $\$ 3.7$ billion's to $\$ 2$ billion. ${ }^{13}$ Lower costs have been linked to costreduction efforts and improved performance of scrubbers and changes in fuel markets. Some of these revisions can be attributed to the difficulty in estimating future technological improvements, the more efficient use of existing technologies, and future economic conditions. These technologies are being developed in a competitive environment. Anecdotal evidence indicates that technological innovation is leading to cost savings. However, without a flexible approach to compliance that allows different technologies and fuels to compete against each other, firms would not have any incentive to find and develop cost-effective measures that exceed emission-reduction targets.

The flexibility of the Title IV program has continued to apply downward pressure on compliance costs by allowing electric utilities to take advantage of market forces and the changes in the relative prices of compliance options. Allowance prices are much lower than experts had predicted and are an indicator of the success of the control program by reacting to the developments in the low-sulfur coal market, reduced rail rates for delivering western low-sulfur coal to some midwestern utilities, lower-than-expected future costs of scrubbers for Phase II of Title IV, and new efficiencies in the operation of existing scrubbers that reduce emissions at lower costs. The price of allowances has reflected the declines in control costs, dropping from an estimated $\$ 500-600$ per ton when the 1990 Amendments were passed to about $\$ 90$ per ton at the end of 1996.

\section{How did emission and deposition changes compare to projections?}

In 1995, the first year of compliance with the provisions of Title IV, electric utility emissions of $\mathrm{SO}_{2}$ were below the projected levels.

In 1995, total electric utility emissions of $\mathrm{SO}_{2}$ were 12 million tons. Actual 1995 utility emissions were less than the projections available in 1990 (see Table 4 for the various projections). Only Phase 1 with its prescribed emission limits was in effect in 1995.

Utilities participating in Phase I were about 39\% (3.4 million tons) below their 1995 allowable emission level of 8.7 million tons. This overcompliance was beyond any projections or expectations. There is a general consensus that these reductions were a direct result of the market-based mechanism of Title IV. Of significance is the fact that most of the emission reductions were in the Midwest, the highest-emitting area of the country. This is consistent with the fundamental premise of Title IV's market-based approach, that the highest-emitting plants have an incentive to make deep reductions in $\mathrm{SO}_{2}$ emissions because they usually face a lower cost per ton of $\mathrm{SO}_{2}$ reduced.

By the only emission goal available at this time-the allowable level for Phase I units in 1995-Title IV has been effective in reducing emissions of $\mathrm{SO}_{2}$. The market-based approach contributed to a significant overcompliance in 1995. Care should be taken in extrapolating this performance into the future. It is too early to quantify the effectiveness of Title IV in reducing $\mathrm{NO}_{\mathrm{X}}$ emissions.

The Phase 1 requirements for $\mathrm{NO}_{\mathrm{x}}$ reductions under Title IV only took effect in January 1996. Even so, there has been a steady decline in $\mathrm{NO}_{\mathrm{x}}$ emissions from utilities between 1980 and 1995. The largest year-to-year decline occurred between 1994 and 1995 (1.3 million tons, or $19 \%$ ). Reductions in $\mathrm{NO}_{\mathrm{X}}$ emissions are also required under Title I and Title II.

Emission reductions imposed by Title IV have decreased acid deposition in the eastern United States. 
Analysis of the 1995 deposition monitoring data support the hypothesis that the 1995 reduction in $\mathrm{SO}_{2}$ emissions in the eastern United States substantially decreased the acidity and sulfate concentration in precipitation. The largest reductions occurred in the Midwest and Northeast. These deposition reductions were geographically and climatologically consistent with the large emission reductions in the Midwest. Sulfur concentration levels at dry deposition monitoring sites are also in accord with these reductions.

On the other hand, nitrate concentrations in 1995 were about $5 \%$ greater than predicted in the eastern part of the country. Unlike sulfate concentrations, higher nitrate concentrations were recorded at only $61 \%$ of the monitoring sites. Even though utility emissions of $\mathrm{NO}_{\mathrm{X}}$ declined in 1995, they account for only $29 \%$ of all $\mathrm{NO}_{\mathrm{x}}$ emissions (vehicles contribute the largest fraction). Combined with the annual variability in meteorology, the record is too short to be able to attribute changes in nitrate concentrations in precipitation to $\mathrm{NO}_{\mathrm{x}}$ reductions by utilities.

Qualitatively, Title IV has been effective in reducing acid deposition. However, the geographic distribution and the quantitative measure of the changes in total deposition resulting from emission reductions require a longer monitoring record and further analysis.

\section{Has reduced acid deposition had an effect on sensitive receptors?}

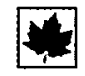

It is still too early to make a definitive statement on the impacts of deposition changes on sensitive receptors.

The magnitude, spatial distribution, and timing of changes in sulfur and nitrogen emissions and deposition-before and after implementation of Title IV-need to be more fully established. The location of changes in emissions and deposition is important because the distribution of sensitive receptors is not uniform, and responses depend on specific exposure factors. While some effects have already been observed-e.g., substantial decreases in surface water sulfate concentrations in some areas-other impact trends that can be directly attributable to Title IV have not yet been observed. Some systems, particularly aquatics, forests, and materials, can take many years to respond to chemical changes as a result of reductions in atmospheric deposition. Two years since initiation of emission reductions under Title IV is too short of a time period to detect changes. In addition, for many effects areas, long-term monitoring data for sensitive receptors during this time period are not available. 


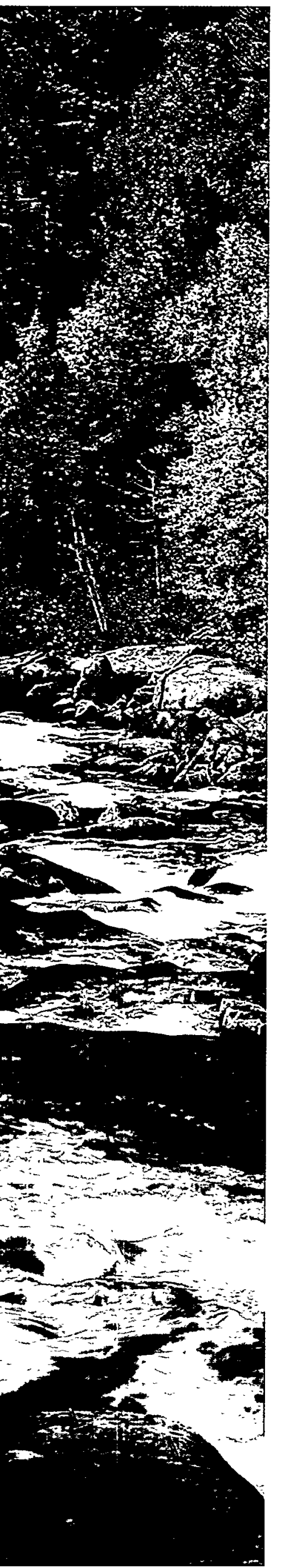

\section{Outlook to 2000}

$\mathrm{N}$ APAP recognized with the passage of the 1990 Clean Air Act Amendments that a complete assessment of Title IV in 1996 would be premature because emission reductions would not begin until 1995. Furthermore, due to scientific uncertainties, weather variability, and the inherently slow response times of many ecosystems, a quantification of human and ecosystem responses to any changes in emissions could not be made with reasonable confidence in 1996. Hence, a limited assessment was planned for 1996, with the goal of a more comprehensive assessment in 2000 .

The goals of the assessment were to (1) provide information about acid deposition in a format that facilitates communication with policymakers and the public, (2) validate the assessment methodology, and (3) identify the monitoring, research, and modeling needs for future assessments. This section is devoted to a discussion of the last two goals.

In accordance with its congressional mandate, NAPAP will conduct another integrated assessment of the costs, benefits, and effectiveness of Title IV in 2000 and will document the results in its 2000 Report to Congress. Given the scope of the assessment and the advice and comments of participants and stakeholders in the assessment process, NAPAP will modify the scope of the assessment in the upcoming years, based on the availability of resources and relevant scientific and economic information.

The 2000 assessment will include more case studies and will improve the depth of regional assessments. The middle and southern Appalachian mountains, northern New England, and the high-elevation West are currently being considered as case studies. An issue expected to receive more attention in 2000 is characterizing and quantifying (both air concentrations and dry deposition) sulfate and nitrate fine particles, and quantifying their causal relationships to human health and materials. Improvements in predictive modeling of air chemistry and ecosystem responses and in valuation methodologies for health, cultural resources, and visibility will enhance our ability to assess the "lifetime" benefits of emission reductions in most of the effects areas.

Many of these needs are crosscutting; they serve to meet the goals and objectives of individual agency missions and improve the knowledge base for other national issues. Acid rain is a crosscutting issue itself, with linkages to several national and international environmental issues, such as fine particles, radiative forcing, and NAFTA, the North American Free Trade Agreement (these issues are discussed under the Linkages section toward the end of this chapter).

\section{Fundamental Program Needs}

Despite the concerted research effort on the effects of acid deposition during 1980-1995, many important scientific and socioeconomic areas require further investigation before a more quantitative and comprehensive assessment can be made. Fundamental monitoring and scientific inquiry must be continued and rein- 


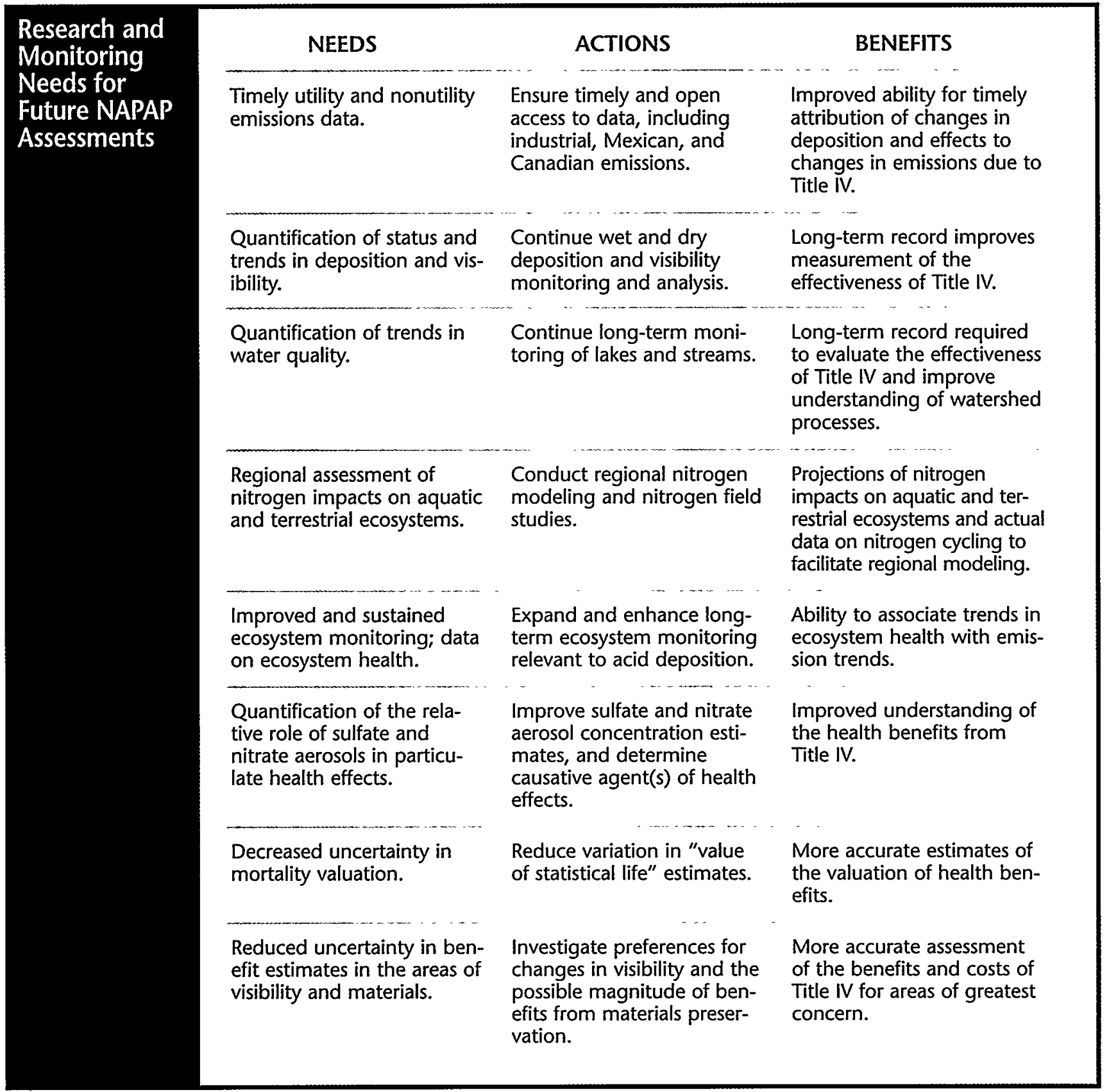

forced to provide a foundation upon which we can build better assessments. Near-term research, monitoring, and development needs must be addressed to improve the knowledge base for the 2000 NAPAP assessment, and long-term needs must be addressed for subsequent NAPAP assessments. The research, monitoring, modeling, and data needs listed below are intended to be general descriptions of the types of activities that will improve the knowledge base for future assessments. For a general overview of research and monitoring needs, see Table 9 . Specific projects will be conducted, depending on their individual merit and level of impact. The needs were identified by the contributors to this report, including reviewers and other stakeholders.

The fundamental needs are presented below, followed by the near-term and long-term needs, organized according to subject area. Each section is broken down by the four elements of a successful assessment: monitoring, research, modeling, and data availability. 
An assessment of the effectiveness of acid rain controls cannot be undertaken without the most basic scientific and technical information. This assessment depended on a set of elements that are essential, but not sufficient, for future NAPAP assessments. Primary examples are long-term environmental monitoring data and analysis, research and process studies leading to evolutionary model improvements, and data access. In most cases, the information sources are longstanding monitoring, research, and modeling programs within the NAPAP agencies. The following fundamental programs and activities require annual resources, attention, and evaluation. Although they are often under the programmatic control of one of the NAPAP agencies, they contribute to the mission of other agencies and are essential to interagency programs like NAPAP. For that reason, relevant agencies are also identified, where appropriate.

\section{Monitoring}

Monitoring forms the basis of assessment. It provides the status and trends of the state of the environment, and the data are often used in ex post facto statistical inquiry into the form and magnitude of causal relationships (e.g., epidemiological studies). Existing longterm environmental records show considerable year-to-year variability due to meteorology, changes in source emissions, and other factors. A longer period of data is required before environmental trends can be established with confidence and reasonable inferences can be made into the causal relationships between emissions and deposition and deposition and effects. Monitoring consists of regular data collection, quality control and assurance, routine analysis, and presentation of peer-reviewed findings. The following monitoring efforts need to be continued to ensure a credible and comprehensive assessment of atmospheric deposition and its effects in 2000 .

Emission Inventories. A comparison and benchmarking of continuous emission monitoring data versus historical emission estimates will ensure a continuous, longterm data record. Such a record is the essential first step in linking changes in emissions to changes in deposition.

Air Concentration and Deposition. Air chemistry and composition data represent the most direct indication of whether emission reductions produce the desired results. Long-term monitoring and assessment of ambient air concentrations and total deposition are needed to determine whether the air quality benefits that appear to be accruing in terms of emission reductions will translate into reductions in the rate of atmospheric deposition, or of the loadings to sensitive ecosystems that the legislation is attempting to protect. A commitment to continuing monitoring of the kind reported here at key sites is needed. The current monitoring networks-EPA's CASTNet, the multiagency IMPROVE, and NOAA'S AIRMON-have had benefits. These networks are quite different in their design purposes, and each has proved successful in meeting its original expectations.

Continued monitoring and interpretation of atmospheric deposition are needed. Such information provides the only physically based, nationwide evidence to determine the extent to which emission reductions affect atmospheric deposition and its associated adverse environmental impacts. Continued acquisition and analysis of the deposition data from the federal-, state-, and private-sector-sponsored National Atmospheric Deposition Program/National Trends Network (NADP/NTN) will provide the information necessary to evaluate the effectiveness of Title IV in protecting the environment. Continued monitoring from all these networks will also provide information to evaluate other air quality issues, such as utility restructuring and expected changes in $\mathrm{NO}_{\mathrm{X}}$ emissions from mobile and stationary sources of air pollution.

Soil and Surface Water Chemistry. Continued monitoring of lakes and streams in EPA's Long-Term Monitoring program, Temporally Integrated Monitoring Ecosystems program, and other state and federal programs is necessary for quantifying the responses of surface waters to changing levels of sulfur and nitrogen deposition. For the most part, the Long-Term Monitoring program represents the longest continuous record of surface water chemistry in the United States and is often used to study watershed (soil) chemistry, an essential element in both terrestrial and aquatic ecosystems.

Forest Health. Continued monitoring of sites in sensitive ecosystems with prior strong databases on forest condition and soil chemistry is necessary to quantify the responses of terrestrial ecosystems to changing levels of sulfur and nitrogen deposition.

Visibility. Visibility is the most direct, well-understood indicator of changes in emissions. Aerosol composition and visibility monitoring, such as that provided by the multiagency IMPROVE network, should be continued consistently at sites with a record of such monitoring. Although the relationship between emissions and air 
concentrations is highly variable because of the weather and other factors, the relationship between concentrations and visibility is well understood.

\section{Research and Analysis}

Comparison of Actual to Predicted Visibility Trends. Extensive periodic assessments (at least every five years) of the fine-particle sulfate and visibility trends, and their relationships to $\mathrm{SO}_{2}$ emission trends and variations in meteorology, need to be conducted to determine whether expected benefits of $\mathrm{SO}_{2}$ emission reductions are being realized and to test the credibility of modeled predictions.

\section{Modeling}

Integrated Assessment Tool. NAPAP has developed a prototype integrated assessment tool called the Tracking and Analysis Framework (see Appendix A). TAF has been peer reviewed and possesses unique capabilities to provide the kind of information that NAPAP needs for its assessments. Continued maintenance and development of TAF, especially of those components that would benefit all effects areas (e.g., emissions, air transport and diffusion, and economic assumptions), would provide an analytical tool specifically designed for an integrated assessment of Title IV.

Regional Acid Deposition Modeling. Regional atmospheric deposition models, such as the Regional Acid Deposition Model, are necessary to study the geographic origins of deposited pollutants and the anticipated effectiveness of future emission reductions. Continuous evolutionary improvements of model physics and chemistry, such as parameterizations of internal nitrogen cycling, are necessary to develop an improved analytical tool. Consistent with NAPAP's principles, formal model evaluation and peer review should be a part of the overall model development process.

Economic/emissions Predictive Models. Predictions of air quality and atmospheric deposition rely on reliable economic and emission prediction models. The improvement of current models and the development of new models are necessary if new insight are to be expressed in future assessments.

\section{Data Access and Database Development}

The free and open exchange of data ensures the broadest participation in scientific and economic inquiry. Basic to this are the availability and access to quality- assured data. In some cases, data exist but have not been analyzed and/or quality-assured, access is neither timely nor inexpensive, or the data need to be placed in a useable form. In other cases, needed data have not been collected or observed.

Emission Inventories. Monthly, up-to-date inventories of utility and nonutility $\mathrm{SO}_{2}$ and $\mathrm{NO}_{\mathrm{x}}$ emissions are required at the substate level.

Deposition Data. Quality-assured wet deposition data are already available for downloading via the World Wide Web. Dry deposition estimates from EPA and NOAA monitoring networks also need to be made available in a timely manner.

Geographic Information Systems. GIS are already used by NAPAP agencies to support their missions. These GIS should be screened and explored as acid rain analysis and display tools, and geographic measures of the effectiveness of emission reductions should be developed.

Model Assumptions. Much of an assessment relies on modeling. NAPAP aims to use only peer-reviewed, nonproprietary models and information in its assessments. To that end, models that are potential contributors to NAPAP assessments, including their assumptions and science, must be peer reviewed and accessible.

\section{Issue-Specific Needs}

In addition to the fundamental needs, near- and longterm needs must be addressed in the various topical areas. Strides must be made to meet these issuespecific needs and thereby enhance NAPAP's assessment capabilities for future reports.

Near-term needs are defined as new activities that must be completed and peer reviewed in time to be useful to the 2000 assessment-nominally, the second quarter of fiscal year 2000. These needs can be divided into two groups: large benefit areas (where even small uncertainties could have large valuation implications or acceptable valuation methodologies are not yet developed), and reductions in scientific and economic uncertainties (unknown or large uncertainties in scientific and economic understanding prevent any improved analysis of costs and benefits, either physical or economic). The degree to which the expectations for the 2000 assessment can be met depends on which near-term needs are addressed by 2000 . A summary of the near-term needs can be found in Table 9 . 
Long-term needs are defined as those that cannot be met in time for the 2000 assessment but that are needed to contribute to future assessments.

\section{Emissions and Compliance}

Most of the emissions and compliance data and information requirements for an assessment of Title IV are satisfied by EPA operational activities or will be satisfied if the relevant fundamental needs specified above are met. However, there is a need to address the issues of transboundary pollution, as well as the technological and state regulatory impacts on the effectiveness and costs of Title IV.

\section{Near-Term Needs}

Research. Investigations in the following areas must be completed in time to be useful to the 2000 assessment: (1) analysis of industrial $\mathrm{SO}_{2}$ and $\mathrm{NO}_{\mathrm{X}}$ emission inventories, (2) analysis of Canadian and Mexican emission inventories, (3) retrospective analysis of causes of emission changes in the late 1980s and early 1990s, (4) analysis of the impacts of state Public Utility Commission regulations and policies on the allowance market, (5) analysis of the relationship between Title IV requirements and technology innovations (dynamic efficiency), and (6) analysis of the dynamics of allowance trading and its effects on economics and the spatial and temporal distributions of emissions.

\section{Concentration and Deposition}

Acid deposition rates and ambient air concentrations of acid rain precursors will continue to be the most direct measures of the effectiveness of acid rain controls. The space and time variability of the data presents a challenge to documenting regional deposition trends. It is also a challenge to integrate the information from many different networks, each having its own (often mission-oriented) objectives and purpose of design. Projections of future deposition rates will be necessary in developing or modifying emission controls. This is only possible through the use of validated, peer-reviewed models.

\section{Near-Term Needs}

Monitoring. Additional monitoring and interpretation from the concentration and deposition monitoring networks will be necessary to determine what effect vari- ous changes in nitrogen emissions are having on nitrates and nitrogen deposition. The data can be used to assess if increases in nitrates from mobile sources in some areas are offsetting reductions achieved by the Clean Air Act Amendments.

Research. There is a continuing need to assess rates of dry deposition from the atmosphere, especially to areas where ecosystems are sensitive to sulfate, nitrate, and other chemicals that together make up acid deposition. Although dry deposition constitutes a significant fraction of total deposition, the scientific understanding of the processes is incomplete, and measurement technology is inadequate. The questions of deposition to landscapes and spatial heterogeneity remain largely unanswered. Research is modeled to develop methods for extrapolating from areas with dry deposition measurements to nearby areas with different terrain, vegetation, and chemistry.

Modeling. Learning how to link the site-specific deposition values made by monitoring programs with the spatial average deposition predictions yielded by regional atmospheric deposition models remains a challenge.

\section{Long-Term Needs}

Research. Increased attention to the processes that modify acid-generating compounds in the air are needed, in particular insofar as these processes include mixes of natural and anthropogenic chemicals.

\section{Aquatic Ecosystems}

Additional work is required to improve the scientific understanding of the effects of acid deposition on surface water chemistry. A variety of organizations and agencies have called for a coordinated, integrated assessment of the environmental effects of anthropogenic emissions. The occurrences of coastal eutrophication are concurrent with acid deposition. Continued model development and application will provide an adequate basis for preparing an assessment of aquatic effects in the year 2000 . The principal needs relate to monitoring and modeling activities.

\section{Near-Term Needs}

Monitoring. The monitoring of lakes and streams in EPA's Long-Term Monitoring program must be continued at least through 1999 to allow quantification of the 
responses of surface waters to changing levels of sulfur and nitrogen deposition due to continued implementation of Title IV. This information will be needed to provide an adequate basis for the 2000 assessment.

Modeling. Modeling needs fall into three general categories: further regional sulfur modeling; implementation of regional nitrogen modeling; and continued model testing and verification, especially of nitrogen models. The effect of seasonal variations in $\mathrm{NO}_{X}$ emissions and deposition on aquatic systems also needs to be studied. Testing and improvement of the MAGIC sulfur model since 1990 have substantially modified forecasts of the $\mathrm{pH}$ of Adirondack lakes as sulfur deposition declines in response to Title IV, as well as forecasts of ranges of watershed responses to simultaneous changes in sulfur and nitrogen deposition. Model revision and reapplication efforts should be pursued in the following priority order: mid-Appalachian Mountains, northern New England, and southern Appalachian Mountains.

It is now evident that nitrogen may be critical in chronic and episodic acidification. Models to simulate the terrestrial and aquatic effects of nitrogen deposition are now available. One or more such models should be implemented in areas of the United States thought to be highly sensitive to potential nitrogen effects. Candidate regions, in priority order, include the Adirondack Mountains, mid-Appalachian Mountains, southern Appalachian Mountains, portions of the West, and northern New England. This effort would require some field data collection to quantify nitrogen and carbon storage in important ecosystem compartments, mainly soils and foliage. Field work would have to be conducted at the latest during the summer and fall of 1998 to be useful for the 2000 assessment. Testing of the nitrogen models should continue in 1997 and 1998. Available data sets, with which to further test the models, include ecosystem manipulation data sets from Maine and Europe and long-term monitoring data sets from New York, New Hampshire, Norway, and Germany.

Model development efforts are necessary to improve the characterization of short-term events (episodic acidification) as they relate to surface water chemistry, adverse effects to aquatic biota, coastal eutrophication, and harmful algal blooms.

\section{Long-Term Needs}

Monitoring. Long-term monitoring is the only approach that can be used to determine the ultimate effectiveness of implementing any policy or management option.
Because model projections will always entail considerable uncertainty, it is critical that real monitoring data continue to be collected in the long term within all regions of interest.

Research. Research is needed on the effects of atmospheric nitrogen deposition on estuarine and nearcoastal marine ecosystems. Atmospheric nitrogen is known to contribute to the eutrophication of such systems (excessive productivity, which can deplete dissolved oxygen and harm aquatic biota). The quantitative importance of atmospheric inputs, in addition to other sources of nitrogen, such as agriculture, sewage, and industry, is not well known.

\section{Forest Ecosystems}

Forest ecosystems are exposed at varying rates to a multitude of stressors. Stresses can be delivered by atmospheric process or can be related to weather or soil condition. This multiple-stressor paradigm makes attribution of damages and the quantification of causal relationships difficult.

\section{Near-Term Needs}

Monitoring. An updated analysis of the health of forest ecosystems should be undertaken. The analysis would include a designation of ecosystems that are and are not sensitive to acid deposition.

Research. A focus on the degree to which sensitive ecosystems are affected by current and reduced deposition rates. In particular, studies on older trees in acid soils are needed to evaluate the long-term, interactive effects of acid deposition and ozone.

Modeling. Development and refinement of regionalscale, spatially explicit models need to be accelerated, and data for running and testing the models (PnET, MAGIC, NuCUM) need to be acquired. These models are required to predict responses of soil and soil water chemistry to increases or decreases in sulfur and nitrogen deposition and to assess potential responses to changes in management practices.

\section{Long-Term Needs}

Monitoring. Because of the often long lag time involved in ecosystem responses to changes in deposition, future monitoring is necessary to elucidate responses attributable to emission reductions already realized. 
Periodic monitoring of terrestrial resources, including forest and soil conditions, should be initiated for a suite of carefully selected forest research sites. The effects of changes from both sulfur and nitrogen deposition should be documented.

Research. Mechanistic studies are needed to evaluate the consequences of changes in soil chemistry (e.g., calcium depletion) on essential plant processes ranging from physiological processes to ecosystem function. These studies should include the synergistic relationship of soil chemistry with changes in sensitivity of vegetation to natural stresses, such as cold damage; decreased resistance to disease; and decreased structural resistance to physical stresses, such as wind and ice (i.e., multiple stressors). There are seven specific areas.

- Research on the effects of changes in soil chemistry on forest health in northern hardwoods, especially sugar maple.

- Long-term studies on the role of cation depletion and nitrogen addition on nutrient cycling and tree growth for southern pine forests.

- Studies on the relative importance of cation leaching from foliage and cation losses from soils on whole-plant function (short-term versus longer-term effects).

- Studies to explore the role of acid deposition in limiting cation availability in southern pine forests growing on poorly buffered soils.

- Studies on the role of cation depletion in soil profiles on the distribution and function of roots.

- Evaluation of the role of acid deposition in contributing to nitrogen saturation of forest soils through impaired root uptake of soil nitrogen.

- Development of reliable indicators of ecosystem condition and potential susceptibility to acid deposition. These indicators are needed to assess potential responses to altered nitrogen and sulfur deposition rates, and the spatial variability that is evident within a region. The indicators must be applicable at the site and watershed scales.

Data Access and Database Development. The distribution of soils that are susceptible to leaching of base cations and mobilization of aluminum needs to be determined. This information is critical to understanding doseeffect relationships and to projecting future impacts and improvements in response to changing deposition.

\section{Materials and Cultural Resources}

There are particularly significant benefits arising from materials and cultural resources.

\section{Near-Term Needs}

Research. Applied research is needed to develop and improve treatments to prevent or minimize injury of cultural resources. Effective preservation of cultural resources affects our ability to assess the economic impact of Title IV. Costs for long-term maintenance and corrective treatment of injury to cultural resources must be considered in the overall economic valuation. Innovative treatments built upon fundamental research and accurately tested through applied studies may lead to more cost-effective strategies that will ultimately influence economic assessments.

Continued emphasis is needed on determining ways to value cultural resources and estimate damage. One of the most promising approaches for economic evaluation of the effects of Title IV is the study of improving the "health" of a group of cultural resources by retarding the process of deterioration through treatments. This results in the extension of the average lifetime of cultural resources. In the proposed approach, historically documented changes in deterioration rates can be related to the prolonged life of the cultural asset.

\section{Long-Term Needs}

Research. A better understanding of the factors and variables influencing pollution-induced stone deterioration is needed to improve diagnoses of damage to cultural resources caused by individual pollutants. In particular, it is important to further resolve effects associated with anthropogenic activities from the natural background weathering effects. A systematic approach to identifying and studying the individual dominant interactions contributing to the overall weathering of stone is needed to elucidate the deterioration processes.

Data Access and Database Development. The main obstacle to valuing the benefits of both materials and cultural resources is the lack of a complete inventory 
of affected assets. Combined with the above, the potentially large database could be used to quantify the particularly significant benefits to materials and cultural resources.

\section{Visibility}

\section{Near-Term Needs}

Data Access and Database Development. Sulfur dioxide emissions data must be developed with at least monthly averaged temporal resolution and at least county spatial resolution to be able to assess relationships between fine-particle sulfate and sulfur dioxide emission trends.

\section{Long-Term Needs}

Monitoring. Visibility is a local phenomenon. However, its impairment is a national issue involving both urban and rural settings. Additional collocated visibility and ambient air concentration monitoring sites should be initiated to provide a more complete spatial coverage.

\section{Human Health}

\section{Near-Term Needs}

Monitoring. Adequate monitoring data are needed for epidemiological research efforts and the characterization of exposure risks. Separate monitoring of fine and coarse particulate matter is essential. Further characterization of particulate matter is necessary to determine the quantitative relationship of the different atmospheric components, including transition metals, ultrafine fraction, particle number, hydrogen ion, gases associated with particulate matter (e.g., ozone and carbon monoxide), and sulfur and nitrogen oxides. The ambient conditions that potentially confound epidemiological studies-weather and other pollutants (e.g., biological particles, organic compounds)-must also be monitored. The monitoring must be consistent across time and space, and must be frequent enough to determine temporal and spatial variability, especially of an episodic and seasonal nature; annual levels are not adequate.

Research. Further epidemiological research is necessary to improve our understanding of the individual health parameters affected by particulate matter and co-pollutants (e.g., lung function parameters, causes of death) and the relationships between co-pollutants and health effects. Improved characterization of longterm health effects is needed and, in particular, the extent of life shortening that can be attributed to particulate matter in general and sulfates and nitrates in particular. Studies need to follow large healthy populations living in areas with elevated particulate matter, sulfate, nitrate, or ozone for an extended number of years, as well as during episodic pollution events. In addition, more studies should be focused on populations at risk and on the issue of confounders; for example, meteorological factors, the coarse fraction of PM10 (2.5-10.0 microns), and the ages of those adversely affected. Further characterization of individual exposure is needed to adequately account for the large portion of time most individuals spend indoors. Improved personal exposure assessments for particulate matter, especially for the most vulnerable members of the population, are necessary for better risk assessments.

Studies need to continue to identify the underlying biological causes of the relationship observed in epidemiological studies between particulate matter and human health to better understand the aspects of particulate matter pollution that need to be reduced or controlled and how certain members of sensitive populations can be better protected. It is important to understand how particulate matter could lead to death immediately associated with exposure and how particulate matter could contribute to shortening the lives of the sick and healthy, old and young. Further evaluation is needed for specific components of particulate matter (especially different forms in which acids can exist), as well as their fates and their effects on the environment and on human health.

Modeling. Development, refinement, and more experience are needed with models that associate pollution and health, including air quality models, as well as models that associate health effects with changes in air quality, and models that value those changes in health effects. Also, the models used in clinical and toxicological studies need to be improved, for example, in the pollutants used to model ambient pollution and in the subjects exposed to air pollutants in the lab.

\section{Benefits Valuation}

\section{Near-Term Needs}

The greatest value of incremental, near-term information to reducing uncertainty in benefit estimates is in 
the areas of health, visibility, and materials. These priorities are illustrated under Question 5 in Table 7.

Research. Near-term research efforts (by 2000) would make a substantial contribution to reducing uncertainty in estimates of economic benefits. The areas most deserving of additional research are not necessarily the same as those where expected benefits are largest (see Table 7). For instance, though ecosystem health has potentially large benefits and there is tremendous uncertainty surrounding those benefits, the cost of reducing this uncertainty through additional research is great, and the time frame for such a research project is long. On the other hand, the costs of reducing uncertainty around human health mortality are probably much less. Research should be conducted to improve our basis for valuing life years lost or for adjusting the value of a statistical life for the age of individuals and various risks and health status. Also, the empirical basis for valuing morbidity effects is weak.

Modeling. Economic models are incomplete in almost every benefit area, but they are adequate to provide some illustrative estimates and to reveal the relative magnitudes of potential benefits in many cases. Development of economic models requires both theoretical underpinnings and readiness for implementation. In aquatics recreation, agriculture, and human health, economics has the capability of providing reliable, replicable estimation of benefits. In the areas of visibility and materials, economics provides at least a sufficient foundation for investigating the relative magnitudes of potential benefits and the likely direction of potential bias resulting from factors left out of the model or flaws in the data.

Data Access and Database Development. Limitations on environmental and/or economic data are the weakest link in estimating benefits, especially in areas that are suspected to have the largest potential benefits. Typically, the cost of research in economics and the collection of economic and environmental data are less than the cost of scientific research. This is reflected in the priorities for research aimed at improving benefit estimates. In the areas of health, visibility, and materials, the greatest gaps are in economics and data collection rather than science. Hence, the biggest "bang for the buck" in the near term can be bought through investments in these areas.

In some cases, weaknesses in the scientific understanding - as in the case of forest recreation or ecosystem health-preclude collection of data linking changes in primary pollutants with economic end points. In other cases, such as visibility, monitoring has been inadequate to calibrate links with economics. Where benefit end points are not well established, data will be inadequate.

\section{Linkages to Other Issues}

In the early years of NAPAP, it became clear that acid deposition could not be easily isolated from other air pollution issues. Acid rain is but one of many related environmental issues and is a focus for several international activities. Research has established linkages between acid deposition and other environmental issues that are not within the scope of this report and are adequately addressed by other programs. However, from a policy perspective, it is important to understand the science linkages so that the public policy linkages can be made. The long-range transport of air pollution has made acid deposition an international concern and it is being addressed in several fora.

\section{Related Science Issues}

The environmental science issues related to acid deposition include radiative forcing, tropospheric ozone, fine particles, atmospheric deposition, and coastal ecosystem health.

\section{Radiative Forcing}

In addition to reducing visibility, interference with light transmission can lead to changes in climate on local, regional, and global scales. Climatic variables influenced by aerosols include temperature, relative humidity, amount of clouds or fog, volume and type of precipitation, and albedo (reflectivity) of both clouds and clear air.

Aerosol particles affect climate by (1) scattering and absorbing solar radiation, (2) absorbing infrared radiation, and (3) acting as nuclei for the formation of cloud droplets and ice particles, thereby increasing cloud albedo. The first two effects are referred to collectively as direct effects, whereas the third is referred to as an indirect effect. The term indirect is not an indication that cloud effects are less important than direct effects. Indeed, the highest sensitivity of regional and global heat balance to aerosols may involve interaction with clouds.

The average total anthropogenic decrease in solar radiation at the ground due to reflection and absorp- 
tion is about 10 watts per square meter (about $7 \%$ ) over an area of approximately $10,000,000 \mathrm{~km}^{2}$ in eastern North America (and evidently over similarly sized areas in Europe and eastern Asia). This effect acts in a manner opposite to the mechanism for greenhouse warming. Direct heat can occur through absorption of infrared radiation from the earth by coarse dust particles (as is done by greenhouse gases), although it is not well characterized. Indirect effects are also highly uncertain and not well understood.

Sulfates are assumed to contribute about half of the total direct solar reflection in the East (a $7 \%$ reduction in solar radiation, compared with natural background levels). The role of sulfur and nitrogen oxides with respect to indirect cloud effects is not well understood. ${ }^{3}$

\section{Tropospheric Ozone}

Nitrogen oxides and volatile organic compounds are the primary precursors of tropospheric ozone. As a result of oxidation reactions in the atmosphere, these compounds form ozone. These same oxidation reactions convert sulfur oxides and nitrogen dioxides to their sulfate and nitrate forms, leading to acid deposition. Research contributing to the understanding of ozone chemistry, transport, and fate (now being conducted as part of the North American Research Strategy for Tropospheric Ozone-NARSTO) will be critical in interpreting the results of sulfur dioxide and nitrogen oxide controls to reduce acid deposition. It will be important to know how controls of these compounds have interacted to produce beneficial results in environmentally sensitive regions, and to be able to sort out their respective contributions.

Both issues have nitrogen oxides in common. Understanding their sources and sinks will be important in resolving the acid deposition and ozone issues. Nitrogen oxide control is emerging as an essential feature of the eastern ozone control strategy and is also a significant part of the national acid deposition reduction program. An important question to address in the future will be the degree to which ozone-related nitrogen oxide controls (which are predominately summertime controls) also mitigate acid deposition and coastal eutrophication problems.

\section{Fine Particles}

The fine particulate matter (PM) and acid deposition issues are closely linked in the eastern United States. Both share the same dominance of a large sulfate frac- tion in the chemical composition of collected samples. Sulfates are a significant (30-40\%) component of fine particles in the East. However, where sulfates have been linked directly to ecosystem damage, they have yet to be identified as a principal causal agent in human health effects correlated to elevated concentrations of particulate matter. The characteristics of particulate matter, including sulfates responsible for morbidity and mortality effects, are the subject of ongoing research.

Both direct emissions of particulate matter and secondary particle formation caused by oxidation of sulfur dioxide, nitrogen dioxide, and aerosol organic carbon species contribute to overall levels of airborne particles. With sulfates being the focus of the nation's acid deposition control strategy, and an expectation of a $40 \%$ reduction in sulfur oxide emissions from 1980 levels by 2010 , a dramatic decrease in eastern fine particles is expected, particularly in the sulfate fraction. This should also have a beneficial impact on health effects related to particulate matter. Ongoing health and exposure research and future environmental monitoring will provide the answers and bear watching closely for this synergy.

\section{Atmospheric Deposition}

The deposition of sulfates and nitrates originating from utilities is but one facet of a larger science and policy issue, atmospheric deposition. Many other pollutants find their way to the Earth's surface by wet and dry deposition processes, including trace metals, hazardous air pollutants, and organic compounds. Prominent examples are pesticides and mercury. The atmosphere is now recognized as a major pathway by which these pollutants can be transported and deposited in areas sometimes far removed from their sources. Recent research suggests that mercury is more mobile than previously thought because of volatilization and atmospheric transport. Although actual ambient air concentrations of these pollutants are generally small and below air quality levels, it is the long-term accumulation in the ecosystem via deposition that is most harmful.

The overabundance of certain nutrients, primarily nitrogen (nitrate and ammonia) and phosphorus, can cause adverse ecological effects. More than 3.2 million tons of nitrogen are deposited from the atmosphere each year in the United States. This nitrogen falls upon both land and water, contributing to serious problems, such as eutrophication. 
Commonalties often arise in studying the causes and effects of acid deposition. There are several significant sources of nitrogen deposition besides utilitiesnamely, other combustion sources (primarily automobiles) and ammonia (often a result of agricultural practices). Combustion sources (including utilities) also emit, albeit in much smaller amounts, trace metals and carbonaceous aerosols. Many of these pollutants $\left(\mathrm{SO}_{2}, \mathrm{NO}_{\mathrm{x}}\right.$, ozone, fine particles, etc.) are subject to the same (or similar) atmospheric transport and diffusion processes.

\section{Coastal Ecosystem Health}

It is now obvious that ammonium and nitrate deposition are central concerns to the health of coastal ecosystems. Although these species are major contributors to acid deposition, their main environmental consequence is eutrophication of coastal waters. The problem is not just the deposition to the water bodies themselves, but the transport of airborne nitrogen species through surrounding watersheds, streams and ground water into the water bodies that become overenriched with nutrients. Depending on the water body in question, atmospheric deposition is likely to account for as much as $30-40 \%$ of the total nutrient loading received. Reducing deposition is not simply a case of each state or region controlling its own emissions. The chemicals of concern come from sources that are sometimes quite distant and outside the regulatory reach of any such local authority.

Along the eastern seaboard of the United States, the importance of long-range transport and atmospheric deposition in the regulatory process has been evidenced by the success of a series of "Shared Resources" workshops. Conducted by the Chesapeake Bay Program (EPA and NOAA), these workshops are focusing on the need to recognize that the emission decreases imposed by the Clean Air Act Amendments will benefit all eastern estuaries, but to an extent that is not yet well determined.

\section{Related International Activities}

\section{United States/Canada Air Quality Agreement}

The benefits of the $\mathrm{SO}_{2}$ emission-reduction program under the 1990 Clean Air Act Amendments are extensive and are not limited to the United States. Improvements in Canadian air quality that can be attributed to Title IV's reduction of U.S. emissions-and the associ- ated benefits-should be expected. The United States and Canada continue to address transboundary air pollution issues under the bilateral Air Quality Agreement signed in March 1991. The third biennial report, published in 1996, focuses on the substantial progress the United States and Canada have made in achieving emission-reduction goals and in carrying out longterm programs to reduce the effects of acid rain in both countries. The report also discusses new areas of concern, such as ground-level ozone (smog), inhalable particles, and air toxics. Developments in scientific and technical cooperation are reported, including emission inventories and data trends from 1980 to 2020 for $\mathrm{SO}_{2}$, $\mathrm{NO}_{\mathrm{x}}$, and volatile organic compounds, which along with $\mathrm{NO}_{\mathrm{x}}$ emissions contribute to the formation of ground-level ozone.

The progress report also contains the first five-year review and assessment of the Air Quality Agreement by the two governments. While the Agreement does not currently focus on transboundary air pollutants other than acid rain, both governments have begun to study regional ozone management and are evaluating the role the Air Quality Committee may play regarding air toxics. The review concludes that, overall, both governments have been successful in fulfilling their obligations under the Agreement, particularly the acid rain control programs in both countries.

\section{U.N. Convention on Long-Range Transboundary Air Pollution}

The 1979 United Nations Convention on Long-Range Transboundary Air Pollution develops various protocols for air pollution control commitments. U.S. participation in the Convention consists of providing expertise and advice on a number of issues, including compliance monitoring, enforcement, emission inventory development, and market-based mechanisms.

\section{NAFTA}

At the continental level, the issue of atmospheric transport and deposition is receiving considerable attention. The North American Agreement on Environmental Cooperation (a side agreement of the North American Free Trade Agreement) is engaging in a process to enlighten regulatory authorities in Mexico and Canada, as well as in the United States, on the need to consider local environmental problems related to atmospheric deposition (including acid rain and nutrient overenrichment) as problems that disregard political and geographic boundaries. The Council for Environmental 
Cooperation of the North American Agreement on Environmental Cooperation is currently finalizing documentation relating to "continental pollutant pathways" that will propose new multilateral steps toward protecting the continental environment from threats related to chemical deposition from the air.

\section{Global Atmospheric Watch}

At the global scale, the leadership of the United States science developed under the auspices of NAPAP is now well recognized. Three of the contributing agencies of
NAPAP (EPA, DOE, and NOAA) have joined forces to set up a Quality Assurance/Science Activity Center for the Global Atmosphere Watch under the auspices of the World Meteorological Organization. A major contribution of this Center is related to precipitation chemistry. The Center leads the global quality assurance program for precipitation chemistry, including a major focus on acid precipitation. This activity positions U.S. science in a leadership role globally, and ensures that future decisions regarding long-range transport of pollutants from one continent to another will have a sound data base to guide them. 
2l Cason, T.N. 1993. Seller incentive properties of EPA's emission trading auction. Journal of Environmental Economics and Management 25:177-1 95.

22 Cason, T.N. 1995. An experimental investigation of the seller incentives in the EPA's emission trading auction. American Economic Review 85(4):905-922.

23 Joskow, P.L., R.L. Schmalensee, and E. Bailey. 1996. Auction Design and the Market for Sulfur Dioxide Allowances. Center for Energy and Environmental Policy Research, Massachusetts Institute of Technology, Cambridge, MA.

${ }^{24}$ Dean, M., and J. Kruger. 1997. Using EPA's Allowance Tracking System to Assess the Allowance Market. Presented at Air \& Waste Management Association Acid Rain II Specialty Conference, Scottsdale, AZ.

${ }^{25}$ McLean, B.J. 1996. The Sulfur Dioxide $\left(\mathrm{SO}_{2}\right)$ Allowance Trading Program: The First Five Years. U.S. Environmental Protection Agency, Washington, DC.

${ }^{26}$ U.S. EPA. 1997. Acid Rain Program Emissions Scorecard 1995. U.S. Environmental Protection Agency, Washington, DC. EPA-430/R-97-009.

${ }^{27}$ Ellerman, A.D., and I.P. Montero. 1996. Why are Allowance Prices So Low? Working Paper 96-00I, Center for Energy and Environmental Policy Research, Massachusetts Institute of Technology, Cambridge, MA.

28 Placet, M., R.E. Battye, F.C. Fehsenfeld, and G.W. Bassett. 1991. Emissions involved in acidic deposition. In: Acidic Deposition: State of the Science and Technology. Report 1. U.S. National Acid Precipitation Assessment Program, Washington, DC.

29 U.S. EPA. 1995. National Air Quality and Emissions Trends Report, 1995. U.S. Environmental Protection Agency, Washington, DC. EPA-454/R-95-01 4.

${ }^{30}$ Sickles, J.E. II, D. Holland, P. Principe, R. Baumgardner, G. Evans, P. Finkelstein, I. Suggs, B. Eder, S. LeDuc, E. Cooter, J. Pleim, J. Clarke, D. Schwede, R. McMillen, L.A. Byrd, T. Elestad, D. Filmore, L. Truppi, 1. Shreffler, B. Bloomer, K. Endres, and R. Dennis. 1997. Examination of CASTNet: Data, results, costs, and implications. (Preliminary Results). U.S. Environmental Protection Agency, Research Triangle Park, NC.
${ }^{31}$ Malm, W.C., J. F. Sisler, D. Huffman, R.A. Eldred, and T.A. Cahill. 1994. Spatial and seasonal trends in particle concentration and optical extinction in the United States. Journal of Geophysical Research 99(D I):1347-1370.

32 Cahill, T.A., R.A. Eldred, and P.H. Wakabayashi. 1996. Trends in fine particle concentrations at Great Smoky Mountains National Park. Presented at the 89th Annual Meeting of the Air and Waste Management Association, Nashville, TN. Paper No. 96MP1A.05.

${ }^{33}$ Lynch, J.A., V.C. Bowersox, and J.W. Grimm. 1996. Trends in Precipitation Chemistry in the United States, 1983-94-An Analysis of the Effects in 1995 of Phase I of the Clean Air Act Amendments of 1990, Title IV. U.S. Geological Survey, Washington, DC. Open-File Report 96-0346.

${ }^{34}$ NADP. 1996. NADP/NTN Wet Deposition in the United States 1995. National Atmospheric Deposition Program/National Trends Network, Natural Resources Ecology Laboratory, Colorado State University, Fort Collins, $\mathrm{CO}$.

${ }^{35}$ Meyers, T.P., P. Finkelstein, J. Clarke, T.G. Ellestad, and P.F. Williams. 1997. Description and evaluation of a multi-layer model for inferring dry deposition using standard meteorological measurement. National Oceanic and Atmospheric Administration/ARL/ATDD, Oak Ridge, TN. Report Number 97/2.

${ }^{36}$ Sisterson, D.L., V.C. Bowersox, T.P. Meyers, A.R. Olsen, and R.J. Vong. 1991. Deposition monitoring: Methods and results. In: Acidic Deposition: State of Science and Technology. Report 6. U.S. National Acid Precipitation Assessment Program, Washington, DC. pp. 6-104, 6-105, 6-145-174, 6-220.

${ }^{37}$ Hicks, B.B., R.P. Hosker, Jr., T.P. Meyers, and J.D. Womack. 1991. Dry deposition inferential techniques-l. Design and tests of a prototype meteorological and air chemical system for determining dry deposition. Atmospheric Environment 25A:23452370.

${ }^{38}$ Stoddard, J.L., C.T. Driscoll, S. Kahl, and J. Kellogg. 1997 (in press). Can site-specific trends be extrapolated to the regional level? A lake acidification example for the northeastern U.S. Ecological Applications. 
${ }^{39}$ Herlihy, A.T., P.R. Kaufmann, J.L. Stoddard, K.N. Eshleman, and A.J. Bulger. 1996. Effects of acidic deposition on aquatic resources in the southern Appalachians with a special focus on Class I wilderness areas. Southern Appalachian Mountain Initiative, Asheville, NC.

to Driscoll, C.T., K.M. Postek, W. Kretser, and D.J. Raynal. 1995. Long-term trends in the chemistry of precipitation and lake water in the Adirondack region of New York, U.S.A. Water, Air, and Soil Pollution 85:583-588.

${ }^{4}$ Mitchell, M.J., C.T. Driscoll, J.S. Kahl, G.E. Likens, P.S. Murdoch, and L.H. Pardo. 1996. Climatic control of nitrate loss from forested watersheds in the Northeast United States. Environmental Science and Technology 30:2609-2612.

42 Wigington, P.J. Jr., T.D. Davies, M. Tranter, and K.N. Eshleman. 1991. Episodic Acidification of Surface Waters Due to Acidic Deposition. In: Acidic Deposition: State of Science and Technology. Report 12. U.S. National Acid Precipitation Program, Washington, DC.

43 Wigington, P.J. Jr., J.P. Baker, D.R. DeWalle, W.A. Kretser, P.S. Murdoch, H.A. Simonin, J. Van Sickle, M.K. McDowell, D.V. Peck, and W.R. Barchet. 1993. Episodic Acidification of Streams in the Northeastern United States: Chemical and Biological Results of the Episodic Response Project. U. S. Environmental Protection Agency, Corvallis, OR. EPA/600/R-93/190.

${ }^{4}$ Wigington, P.J. Ir., D.R. DeWalle, P.S. Murdoch, W.A. Kretser, H.A. Simonin, J. Van Sickle, and J.P. Baker. 1996. Episodic acidification of small streams in the northeastern United States: Ionic controls of episodes. Ecological Applications 6(2):389-407.

45 Webb, J.R., F.A. Deviney, J.N. Galloway, C.A. Rinehart, P.A. Thompson, and S. Wilson. 1994. The acidbase status of native brook trout streams in the mountains of Virginia. A regional assessment based on the Virginia trout stream sensitivity study. Virginia Game and Inland Fisheries, Richmond, VA.

46 Driscoll, C.T., M.D. Lehtinen, and T.J. Sullivan. 1994. Modeling the acid-base chemistry of organic solutes in Adirondack New York lakes. Water Resources Research 30:297-306.

${ }^{47}$ Sullivan, T.J., B.J. Cosby, C.T. Driscoll, D.F. Charles, and H.F. Hemond. 1996. Influence of organic acids on model projections of lake acidification. Water, Air, and Soil Pollution $91: 271-282$.
${ }^{48}$ Hedin, L.O., L. Granat, G.E. Likens, T.A. Bulshand, J.N. Galloway, T.J. Butler, and H. Rodhe. 1994. Steep declines in atmospheric base cations in regions of Europe and North America. Nature $367: 351-354$.

${ }^{49}$ Kirchner, J.W., and E. Lyderson. 1995. Base cation depletion and potential long-term acidification of Norwegian catchments. Environmental Science and Technology 29:1953-1960.

50 Likens, G.E., C.T. Driscoll, and D.C. Buso. 1995. Long-term effects of acid rain: Response and recovery of a forest ecosystem. Science 272:244-246.

51 Kauppi, P.E., K. Mielikäinen, and K. Kuusela. 1992. Biomass and carbon budget of European forests, 197I to 1990 . Science 256:70-74.

52 Aber, J.D., K.J. Nadelhoffer, P. Steudler, and J.M. Melillo. 1989. Nitrogen saturation in northern forest ecosystems: Excess nitrogen from fossil fuel combustion may stress the biosphere. BioScience 39(6):378386.

${ }^{53}$ Stoddard, J.L. 1994. Long-term changes in watershed retention of nitrogen: Its causes and aquatic consequences. In: Environmental Chemistry of Lakes and Reservoirs. L.A. Baker, ed. Advances in Chemistry. Series, No. 237. American Chemical Society, Washington, DC. pp. 223-284.

${ }^{54}$ Fenn, M.E., M.A. Poth, and D.W. Johnson. 1996. Evidence for nitrogen saturation in the San Bernardino Mountains in southern California. Forest Ecology Management 82:211-230.

55 Baron, J.S., D.S. Ojima, E.A. Holland, and W.J. Parton. 1994. Analysis of nitrogen saturation potential in Rocky Mountain tundra and forest: Implications for aquatic systems. Biogeochemistry 27:61-82.

56 Williams, M.W., J.S. Baron, N. Caine, R. Sommerfeld, and R. Sanford, Jr. 1996. Nitrogen saturation in the Rocky Mountains. Environmental Science and Technology 30(2):640-646.

57 Gilliam, F.S., M.B. Adams, and B.M. Yrish. 1996. Ecosystem nutrient responses to chronic nitrogen inputs at Fernow Experimental Forest, West Virginia. Canadian Journal of Forest Research 26:196205 
${ }^{58}$ Murdoch, P.S., and I.L. Stoddard. 1992. The role of nitrate in the acidification of streams in the Catskill Mountains of New York. Water Resources Research 28:2707-2720.

${ }^{59}$ Cook, R.B., J.W. Elwood, R.R. Turner, M.A. Bogle, P.J. Mulholland, and A.V. Palumbo. 1994. Acid-base chemistry of high-elevation streams in the Great Smoky Mountains. Water, Air, and Soil Pollution 72:331-356.

${ }^{60}$ Peterjohn, W.T., M.B. Adams, and F.S. Gilliam. 1996. Symptoms of nitrogen saturation in two central Appalachian hardwood forest ecosystems. Biogeochemistry 35:507-522.

${ }^{61}$ Kahl, J.S., S.A. Norton, I.J. Fernandez, K.J. Nadelhoffer, C.T. Driscoll, and J.D. Aber. 1993. Experimental inducement of nitrogen saturation at the watershed scale. Environmental Science and Technology 27:565-568.

${ }^{62}$ Sullivan, T.J., B. MCMartin, and D.F. Charles. 1996. Re-examination of the role of landscape change in the acidification of lakes in the Adirondack Mountains, New York. The Science of the Total Environment I 83(3):23I-248.

${ }^{63}$ Cosby, B.J., A. Jenkins, J.D. Miller, R.C. Ferrier, and T.A.B. Walker. 1990. Modeling stream acidification in aforested catchments: Long-term reconstructions at two sites in central Scotland. Journal of Hydrology 120:143-162.

${ }^{64}$ Nilsson, S.I. 1993. Acidification of Swedish oligotrophic lakes-interactions between deposition, forest growth, and effects on lake water quality. Ambio 22:272-276.

${ }^{65}$ Gunn, J.M., ed. 1995. Restoration and Recovery of an Industrial Region. Springer-Verlag, New York, NY.

${ }^{66}$ Havas, M., D.G. Woodfine, P. Lutz, K. Yung, H.J. Maclsaac, and T.C. Hutchinson. 1995. Biological recovery of two previously acidified, metal-contaminated lakes near Sudbury Ontario, Canada. Water, Air, and Soil Pollution 85:791-796.

${ }^{67}$ Jackson, D.A., and H.H. Harvey. 1995. Gradual reduction and extinction of fish populations in acid lakes. Water, Air, and Soil Pollution 85:389-394.

${ }^{68} \mathrm{McNicol}$, D.K., B.E. Bendell, and M.L. Mallory. 1995. Evaluating macroinvertebrate responses to recovery from acidification in small lakes in Ontario, Canada. Water, Air, and Soil Pollution 85:451-456.
${ }^{69}$ Yan, N.D., W. Keller, K.M. Somers, T.W. Pawson, and R.E. Girard. 1996. Recovery of crustacean zooplankton communities from acid and metal contamination: Comparing manipulated and reference lakes. Canadian Journal of Fish and Aquatic Science 53:13011327.

70 Yan, N.D., P.G. Welsh, H. Lin, D.J. Taylor, and J.M. Filion. 1996. Demographic and genetic evidence of the long-term recovery of Daphnia galeata mendotae (Crustacea: Daphniidae) in Sudbury lakes following additions of base: The role of metal toxicity. Canadian Journal of Fish and Aquatic Science 53:1328-1344.

${ }^{71}$ Schofield, C.L., and C. Keleher. 1996. Comparison of brook trout reproductive success and recruitment in an acidic Adirondack lake following whole lake liming and watershed liming. Biogeochemistry 32:323-337.

72 Bulger, A.J., C.A. Dolloff, B.J. Cosby, K.N. Eshleman, I.R. Webb, and J.N. Galloway. 1995. The "Shenandoah National Park: Fish in Sensitive Habitats" (SNP:FISH) Project. An integrated assessment of fish community responses to stream acidification. Water, Air, and Soil Pollution 85:309-314.

73 Dennis, T.E., S.E. MacAvoy, M.B. Steg, and A.J. Bulger. 1995. The association of water chemistry variables and fish condition in streams of Shenandoah National Park (USA). Water, Air, and Soil Pollution 85:365-370.

${ }^{74}$ MacAvoy, S.E., and A.J. Bulger. 1995. Survival of brook trout (Salvelinus fontinalis) embryos and fry in streams of different acid sensitivity in Shenandoah National Park, USA. Water, Air, and Soil Pollution 85:445-450.

${ }^{75}$ Baker, J.P., D.P. Bernard, S.W. Christensen, M.J. Sale, J. Freda, K. Heltcher, D. Marmorek, L. Rose, P. Scanlon, G. Suter, W. Warren-Hicks, and P. Welbourn. 1991. Biological effects of changes in surface water acid-base chemistry. In: Acidic Deposition: State of Science and Technology. Report 13. U.S. National Acid Precipitation Assessment Program, Washington, DC.

${ }^{76}$ Baker, J.P., J. Van Sickle, C.J. Gagen, D.R. DeWalle, W.E. Sharpe, R.F. Carline, B.P. Baldigo, P.S. Murdoch, D.W. Bath, W.A. Kretser, H.A. Simonin, and P.J. Wigington, Jr. 1996. Episodic acidification of small streams in the northeastern United States: Effects on fish populations. Ecological Applications 6:422-437. 
${ }^{77}$ Gerritsen, J., J.M. Dietz, and H.T. Wilson, Jr. 1996. Episodic acidification of coastal plain streams: An estimation of risk to fish. Ecological Applications 6:438-448.

78 Marcus, M.D., and D.R. Mount, eds. 1991. Physiological, toxicological, and population responses of rainbow trout to acidification. Interim Report of the Lake Acidification and Fisheries Project. Electric Power Research Institute, Palo Alto, CA. EPRI EN-71I 4.

$7^{\circ}$ McNicol, D.K., M.L. Mallory, and H.S. Vogel. 1995. Using volunteers to monitor the effects of acid precipitation on common loon (Gavia immer) reproduction in Canada: The Canadian Lakes Loon Survey. Water, Air, and Soil Pollution 85:463-468.

${ }^{80}$ Sullivan, T.J., and J.M. Eilers. 1994. Assessment of Deposition Levels of Sulfur and Nitrogen Required to Protect Aquatic Resources in Selected Sensitive Regions of North America. Final report prepared for Technical Resources, Inc., Rockville, MD, under Contract to U.S. Environmental Protection Agency, Environmental Research Laboratory-Corvallis, Corvallis, OR.

81 Tietema, A., and C. Beier. 1995. A correlative evaluation of nitrogen cycling in the forest ecosystems of the EC projects NITREX and EXMAN. Forest Ecology and Management 71:143-151.

82 Jenkins, A., R.F. Wright, N. Van Breemen, E.D. Schulze, F. Berendse, F.I. Woodward, and L. Brussard. 1992. The CLIMEX Project-Climate change experiment. International Symposium on Experimental Manipulations of Biota and Biogeochemical Cycling in Ecosystems-Approach, Methodologies, Findings. Copenhagen, Denmark.

${ }^{83}$ Cronan, C.S., and D.F. Grigal. 1995. Use of calcium/aluminum ratios as indicators of stress in forest ecosystems. Journal of Environmental Quality 24:209-226.

${ }^{84}$ Joslin, J.D., C.M. McDuffie, and P.F. Brewer. 1988. Acidic cloud water and cation loss from red spruce foliage. Water, Air, and Soil Pollution 39:355-363.

${ }^{85}$ McLaughlin, S.B., M.G. Tjoelker, and W.K. Roy. 1993. Acid deposition alters red spruce physiology: Laboratory studies support field observations. Canadian Journal of Forest Research 23:380-386.

86 Robarge, W.P. and D.W. Johnson. 1992. The effects of acidic deposition on forested soils. Advances in Agronomy 47:1-81.
87 Johnson, D.W., W.T. Swank, and J.M. Vose. I 993. Simulated effects of atmospheric sulfur deposition on nutrient cycling in a mixed deciduous forest. Biogeochemistry 23:169-196.

88 Richter, D.D., and D. Markewitz. 1996. Atmospheric deposition and forest resources of the Southern Pine Forest. In: Impact of Air Pollutants on Southern Pine Forests. S.A. Fox and R.A. Mickler, eds. SpringerVerlag, New York, NY. pp 315-336

89 Vann, D.R., G.R. Strimbeck, and A.H. Johnson. 1992. Effects of ambient levels of airborne chemicals on freezing resistance of red spruce foliage. Forest Ecology and Management 51:69-79.

${ }^{90}$ Sheppard, L.J., J.N. Cape, and I.D. Leith. 1993. Influence of acidic mist on frost hardiness and nutrient concentrations in red spruce seedlings, Part I: Exposure of the foliage and rooting environment. New Phytology 124:595-605.

9I Sheppard, L.J., J.N. Cape, and I.D. Leith. 1993. Influence of acidic mist on frost hardiness and nutrient concerntations in red spruce seedlings, Part II: Frequency and dose. New Phytology 124:607-617.

${ }^{92}$ Craig, B.W., and A.J. Friedland. 1991. Spatial patterns in forest composition and standing dead red spruce in montane forests of the Adirondacks and northern Appalachians. Environmental Monitoring and Assessment 18:129-143.

93 Eagar, C., and M.B. Adams, eds. 1992. Ecology and Decline of Red Spruce in the Eastern United States. Springer-Verlag, New York, N.Y.

${ }^{94}$ Mclaughlin, S.B., and R. Kohut. 1992. The effects of atmospheric deposition on carbon allocation and associated physiological processes in red spruce. In: Ecology and Decline of Red Spruce in the Eastern United States. C. Eagar and B. Adams, eds. Springer-Verlag, New York, NY. pp.338-384.

95 Peart, D.R., N.S. Nicholas, S.M. Zedaker, M.M. Miller-Weeks, and T.G. Siccama. 1992. Condition and recent trends in high-elevation red spruce populations. In: Ecology and Decline of Red Spruce in the Eastern United States. C. Eagar and M.B. Adams, eds. Springer-Verlag, New York, NY. pp. 125-191.

96 Nicholas, N.S., and S.M. Zedaker. 1989. Ice damage in spruce-fir forests of the Black Mountains, North Carolina. Canadian Journal of Forest Research 19:1487-1491. 
${ }^{97}$ Johnson, A.H., S.B. McLaughlin, M.B. Adams, E.R. Cook, D.H. DeHayes, C. Eagar, I.J. Fernandez, D.W. Johnson, R.l. Kohut, V.A. Mohnen, N.S. Nicholas, D.R. Peart, G.A. Schier, and P.S. White. 1992. Synthesis and conclusions from epidemiological and mechanistic studies of red spruce decline. In: Ecology and Decline of Red Spruce in the Eastern United States. C. Eagar and M.B. Adams, eds. SpringerVerlag, New York, NY.

98 Joslin, J.D., I.M. Kelly, and H. Van Miegroet. 1992. Soil chemistry and nutrition of North American spruce-fir stands: Evidence for recent change. Journal of Environmental Quality 21:12-30.

99 Lawrence, G.B., M.B. David, S.W. Bailey, and W.C. Shortle. 1997. Assessment of calcium status in soils of red spruce forests in the northeastern United States. Biogeochemistry 38:19-39.

100 Shortle, W.C., K.T. Smith, R. Minocha, G.B. Lawrence, and M.B. David. 1997. Acidic deposition, cation mobilization, and biochemical indicators of stress in healthy red spruce. Journal of Environmental Quality 26(3):871-876.

101 Joslin, J.D., and M.H. Wolfe. 1994. Foliar deficiencies of mature southern Appalachian red spruce determined from fertilization trials. Soil Science Society of America Journal 58:1572-1579.

102 Minocha, R., W.C. Shortle, D.J. Coughlin, Jr., and S.C. Minocha. 1996. Effects of aluminum on growth, polyamine metabolism, and inorganic ions in suspension cultures of red spruce (Picea rubens). Canadian Journal for Forest Research 26:550-559.

${ }^{103}$ Mclaughlin, S.B., C.P. Andersen, P.). Hanson, M.G. Tjoelker, and W.K. Roy, 1991. Increased dark respiration and calcium deficiency of red spruce in relation to acidic deposition at high-elevation southern Appalachian Mountain sites. Canadian Journal of Forest Research 21:1234-1244.

${ }^{104}$ Amundson, R.G., J.L. Hadley, J.F. Fincher, S. Fellows, and R.G. Alscher. 1992. Comparisons of seasonal changes in photosynthetic capacity, pigments, and carbohydrates of healthy sapling and mature red spruce and/or declining and healthy red spruce. Canadian lournal of Forest Research 22:1605-1616.
105 Van Miegroet, H., D.W. Cole, and N.W. Foster. 1992. Nitrogen distribution and cycling. In: Atmospheric Deposition and Forest Nutrient Cycling. D.W. lohnson and S.E. Lindberg, eds. Springer-Verlag, New York, NY. pp. 178-196.

${ }^{106}$ Fox, S.A., and R.A. Mickler. 1996. Impact of Air Pollutants on Southern Pine Forests. Springer-Verlag, New York, NY.

107 Teskey, R.O. 1996. Synthesis and conclusions from studies of southern pines. In: Impact of Air Pollutants on Southern Pine Forests. S.A. Fox and R.A. Mickler, eds. Springer-Verlag, New York, NY. pp. 467-490.

108 Turner, R.S., R.J. Olson, and C.C. Brandt. 1986. Areas having soil characteristics that may indicate sensitivity to acidic deposition under alternate forest damage. U.S. Department of Energy, Oak Ridge National Laboratory, Oak Ridge, TN. TM 9917.

${ }^{109}$ Binkley, D., C.T. Driscoll, H.L. Allen, P. Schoeneberger, and D. McAvoy. 1989. Acidic Deposition and Forest Soils. Ecological Studies 72. SpringerVerlag, New York, NY.

110 Allen, H.L. 1987. Forest fertilizers, nutrient amendment, stand productivity and environmental impact. Journal of Forestry 85:37-46.

III Dougherty, P.M. 1996. Response of loblolly pine to moisture and nutrient stress. In: Impact of Air Pollutants on Southern Pine Forests. S.A. Fox and R.A. Mickler, eds. Springer-Verlag, New York, NY. pp. I 73-195.

112 Likens, G.E., C.T. Driscoll, and D.C. Buso. 1996. Long-term effects of acid rain: Response and recovery of a forest ecosystem. Science 272:244-246.

113 Mitchell, M.J., D.J. Raynal, and C.T. Driscoll. 1996. Biogeochemistry of a forested watershed in the central Adirondack Mountains: Temporal changes and mass balances. Water, Air, and Soil Pollution 88:355369.

114 Mitchell, M.J., C.T. Driscoll, I.H. Porter, D.J. Raynal, D. Schaefer, and E.H. White. 1994. The Adirondack manipulation and modeling project (AMMP): Design and preliminary results. Forest Ecology and Management 68:87-100. 
115 Norton, S.A., J.S. Kahl, I.J. Fernandez, L.E. Rustad, I.P. Scofield, and T.A. Haines. 1994. Response of the West Bear Brook Watershed, Maine, USA, to the addition of (NH4)2SO4: 3-year results. Forest Ecology and Management 68:61-73.

116 Rustad, L.E., I.J. Fernandez, M.B. David, M.J. Mitchell, K.J. Nadelhoffer, and R.B. Fuller. 1996. Experimental soil acidification and recovery at the Bear Brook Watershed in Maine. Soil Science Society of America Journal 60:1933-1943.

117 MacDonald, N.W., A.J. Burton, H.O. Liechty, J.A. Witter, K.S. Pregitzer, G.D. Mroz, and D.D. Richter. 1992. Ion leaching in forest ecosystems along a Great Lakes air pollution gradient. Journal of Environmental Quality 21:614-623.

118 Mitchell, M.J., C.T. Driscoll, J.S. Kahl, G.E. Likens, P.S. Murdoch, and L.H. Pardo. 1996. Climate control on nitrate loss from forested watersheds in the Northeast United States. Environmental Science and Technology 30: 2609-2612.

$"$ "Adams, M.B., T.R. Angradi, and J.N. Kochenderfer. 1997. Stream water and soil solution responses to five years of nitrogen and sulfur additions at the Fernow experimental forest, West Virginia. Forest Ecology and Management 95(1):79-91.

120 Desanker, P.V., D.D. Reed, and E.A. Jones. 1994. Evaluating forest stress factors using various forest growth modeling approaches. Forest Ecology and Management 69:269-282.

121 Kiefer, I.W., and M.E. Fenn. 1997. Using vector analysis to assess nitrogen status of ponderosa and Jeffrey pine along deposition gradients in forests of southern California. Forest Ecology and Management 94(1-3):47-59.

122 Williams, M.W., M. Losleben, N. Caine, and D. Greenland. 1996. Changes in climate and hydrochemical responses in a high-elevation catchment in the Rocky Mountains, USA. Limnology and Oceanography 45:939-946.

123 Fenn, M.E., and A. Bytnerowicz. 1993. Dry deposition of nitrogen and sulfur to ponderosa pine and Jeffrey pine in the San Bernardino National Forest in southern California. Environmental Pollution 81:277-285.
124 Bytnerowicz, A., and M.E. Fenn. 1996. Nitrogen deposition in California forests: A review. Environmental Pollution 92:127-146.

125 Miller, P.R. 1992. Mixed conifer forests of the San Bernardino Mountains, California. In: The Response of Western Forests to Air Pollution. R.K. Olson, D. Binkley, and M. Bohm, eds. Springer-Verlag, New York, NY.

126 Fenn, M. 1991. Increased site fertility and litter decomposition rate in high-pollution sites in the San Bernardino Mountains. Forest Science 37:1163-1181.

${ }^{127}$ Sievering, H., D. Rusch, and L. Marquez. 1996. Nitric acid, particulate nitrate and ammonium in the continental free troposphere: Nitrogen deposition to an alpine tundra ecosystem. Atmospheric Environment 30:2527-2537.

128 Neff, J.C., W.D. Bowman, E.A. Holland, M.C. Fisk, and S.K. Schmidt. 1994. Fluxes of nitrous oxide and methane from nitrogen-amended soils in a Colorado alpine ecosystem. Biogeochemistry 27:23-33.

129 Van Miegroet, H.V., D.W. Johnson, and D.E. Todd. 1993. Foliar response of red spruce saplings to fertilization with $\mathrm{Ca}$ and $\mathrm{Mg}$ in the Great Smoky Mountains National Park. Canadian Journal of Forest Research 23:89-95.

130 Fowler, D., J.N. Cape, J.D. Deans, I.D. Leath, et al. 1989. Effects of acid mist on frost hardiness of red spruce seedlings. New Phytology 113:321-335.

131 Cape, J.N., I.D. Leith, D. Fowler, M.B. Murray, L.J. Sheppard, D. Eamus, and R.H.F. Wilson. 1991. Sulphate and ammonium in mist impair the frost hardiness of red spruce seedlings. New Phytology 118:119-126.

132 Sheppard, L.]. 1994. Causal mechanisms by which sulphate, nitrate and acidity influence frost hardiness in red spruce: Review and hypothesis. New Phytology 127:69-82.

133 DeHayes, D.H., F.C. Thornton, C.E. Waite, and M.A. Ingle. 1991. Ambient cloud deposition reduces cold tolerance of red spruce seedlings. Canadian Journal of Forest Research 21:1292-1295. 
${ }^{134}$ DeHayes, D.H. 1992. Winter injury and developmental cold tolerance of red spruce. In: Ecology and Decline of Red Spruce in the Eastern United States. C. Eagar and M.B. Adams, eds. Springer-Verlag, New York, NY. pp. 295-337.

135 Thornton, F.C., J.D. Joslin, P.A. Pier, H. Neufeld, I.R. Seiler, and J.D. Hutcherson. 1994. Cloud water and ozone effects upon high-elevation red spruce: A summary of study results from Whitetop Mountain, Virginia. Journal of Environmental Quality 23:1158-1167.

${ }^{136}$ Anderson, C.P., McLaughlin, S.B., and Roy, W.K. 1991. Foliar injury symptoms and pigment concentrations in red spruce saplings in the southern Appalachians. Canadian Journal of Forest Research $21: 1119-1123$.

${ }^{137}$ Johnson, D.W., R.B. Susfalk, and P.F. Brewer. 1996. Simulated responses of red spruce forest soils to reduced sulfur and nitrogen deposition. Journal of Environmental Quality 25:1300-1309.

${ }^{138}$ Lawrence, G.B., M.B. David, and W.C. Shortle. 1995. A new mechanism for calcium loss in forestfloor soils. Nature 378:162-165.

139 McLaughlin, S.B., D.J. Downing, T.J. Blasing, E.R. Cook, and H.S. Adams. 1987. An analysis of climate and competition as contributors to decline of red spruce in high-elevation Appalachian forests of the eastern United States. Oecologia 72:487-501.

140 McLaughlin, S.B., J.D. Joslin, A. Stone, R. Wimmer, and S. Wullschleger. 1997 (in press). The impact of global change on high-elevation spruce/fir forests. In: The Productivity and Sustainability of Southern Forest Ecosystems in a Changing Environment. R.A. Mickler and S. Fox, eds. Springer-Verlag, New York, NY.

141 Fernandez, I.J. 1992. Characterization of eastern U.S. spruce-fir soils. In: Ecology and Decline of Red Spruce in the Eastern United States. C. Eagar and M.B. Adams, eds. Springer-Verlag, New York. pp. 40-63.

142 Johnson, D.W., H. Van Miegroet, S.E. Lindberg, R.B. Harrison, and D.E. Todd. 1991. Nutrient cycling in red spruce forests of the Great Smoky Mountains. Canadian Journal of Forest Research 21:767-787.

${ }^{143}$ Sasser, C.L. and D. Binkley. 1989. Nitrogen mineralization in high elevation of the Appalachians. II. Patterns with stand development in fir waves. Biogeochemistry 7:147-156.
144 Joslin, I.D., and M.H. Wolfe. 1993. Temperature increase accelerates nitrate release from high-elevation red spruce soils. Canadian Journal of Forest Research 23:756-759.

145 Flagler, R.B., and A.H. Chappelka. 1996. Growth responses of southern pines to acidic deposition and ozone. In: Impact of Air Pollutants on Southern Pine Forests. S.A. Fox and R.A. Mickler, eds. Springer-Verlag, New York, NY. pp 388-424.

${ }^{146}$ McLaughlin, S.B., and D.J. Downing. 1995. Interactive effects of ambient ozone and climate measured on growth of mature trees. Nature 374:252-254.

${ }^{147}$ McLaughlin, S.B., and D.J. Downing. 1996. Interactive effects of ambient ozone and climate measured on growth of mature loblolly pine trees. Canadian Journal of Forest Research 26:670-681.

148 McLaughlin, S.B., P.A. Layton, M.B. Adams, N.T. Edwards, P.J. Hanson, E.G. O'Neill, and W.K. Roy. 1994. Growth responses of 53 open pollinated loblolly pine families to ozone and acid rain. Journal of Environmental Quality 23:247-257.

149 Williams, M.W., P.D. Brooks, A. Mosier, and K.A. Tonnessen. 1996. Mineral nitrogen transformations in and under seasonal snow in a high-elevation catchment in the Rocky Mountains, United States. Water Resources Research 32:3161-3171.

150 Reuss, J.O. 1983. Implicatiuons of the calcium-aluminum exchange system for the effect of acid precipitation on soils. Journal of Environmental Quality 12:591-595.

151 Cronan, C.S., and C.L. Schofield. 1990. Relationships between aqueous aluminum and acidic deposition in forested watersheds of North America and northern Europe. Environmental Science and Technology 24:1100-1105.

${ }^{152}$ Shriner, D.S., W.W. Heck, S.B. McLaughlin, D.W. Johnson, P.M. Irving, J.D. Joslin, and C.E. Peterson. 1991. Response of vegetation to atmospheric deposition and air pollution. In: Acidic Deposition: State of Science and Technology, Report 18. U.S. National Acid Precipitation Assessment Program, Washington, DC.

153 Haynie, F.H., and T.J. Lemmons. 1990. Particulate matter soiling of exterior paints at a rural site. Aerosol Science and Technology 13:356-367. 
${ }^{154}$ Meierding, T.C. 1993. Marble tombstone weathering and air pollution in North America. Annals of the Association of American Geographers 83(4):568-588.

155 McGee, E.S. 1996. Development of Gypsum Alteration on Marble and Limestone. American Society for Testing and Materials, West Conshohocken, PA. Standard Technical Publication 1258.

156 Mossotti, V.G., A.R. Eldeeb, T.L. Fries, V.N.Naudé, L.Soderberg, and G.S.Wheeler. 1997 (in preparation). Effect of cleaning techniques on Berkshire Lee marble. Case study: Philadelphia City Hall, East Center Pavilion Facade. U.S. Geological Survey, Washington DC. Digital Data Series DDS-xx-87 (CD-ROM).

${ }^{157}$ Spence, J.W., F.H. Haynie, F.W. Lipfert, S.D. Cramer, and L.G. McDonald. 1992. Atmospheric corrosion model for galvanized steel structures. Corrosion 48: 1009-1019.

158 Spence, I.W., and J.N. McHenry. 1994. Development of regional corrosion maps for galvanized steel by linking the RADM Engineering Model with an atmospheric corrosion model. Atmospheric Environment 28 (18):3033-3046.

159 Reimann, K.J. 1994. Color measurements on marble and limestone briquettes exposed to outdoor environment in the eastern United States. Volume I: Results of exposure 1984-1990. Argonne National Laboratory, Argonne, IL. Open-File Report ANL-94/27.

160 Reimann, K.J. 1995. Weight losses of marble and limestone briquettes exposed to outdoor environment in the eastern United States: Results of exposure 1988-1992. Argonne National Laboratory, Argonne, IL. Open-File Report ANL-95/22.

161 Reimann, K.J. 1996. Chemical alteration of limestone and marble samples exposed to acid rain and weathering in the eastern United States, 1988-1992. Argonne National Laboratory, Argonne, IL. Open-File Report ANL-96/7.

${ }^{162}$ Spiker, E., R.P. Hosker Jr., V.J. Comer, J.R. White, R.W. Werre Jr., F.L. Harmon, G.D. Dandy, and S.I. Sherwood. 1992. Environmental chamber for study of the deposition flux of gaseous pollutants to material surfaces. Atmospheric Environment 26a(16):2885-2892.
${ }^{163}$ Spiker, E., R.P. Hosker Jr., V.C. Weintraub, and S.I. Sherwood. 1995. Laboratory study of sulfur dioxide dry deposition on limestone and marble: Effects of humidity and surface variables. Water, Air, and Soil Pollution 85:2679-2685.

${ }^{164}$ Sisler, J.F., W.C. Malm, K.A, Gebhart, and M.L. Pitchford. 1996. Spatial and seasonal patterns and long-term variability of the composition of the haze in the United States: An analysis of data from the IMPROVE Network. Report by the Cooperative Institute for Research in the Atmosphere, Colorado State University, Fort Collins, CO.

165 Pitchford, M.L. and W.C. Malm. 1994. Development and application of a standard visual index. Atmospheric Environment 28(5):1049-1054.

166 Eldred, R.A., and T.A. Cahill. 1994. Trends in elemental concentration of fine particles at remote sites in the United States. Atmospheric Environment 28(5): 1009- 1019.

167 Trijonis, J.C., W.C. Malm, M. Pitchford, W.H. White, R. Charlson, and R. Husar. 1991. Visibility: Existing and historical conditions-causes and effects. In: Acidic Deposition: State of Science and Technology, Report 24. U.S. National Acid Precipitation Assessment Program, Washington, DC.

168 U.S. EPA. 1996. Air quality criteria for particulate matter. U.S. Environmental Protection Agency, Office of Research and Development, Washington, DC. EPA/600/P-95/001 aF-CF.

169 U.S. EPA. 1995. Human health benefits from sulfate reductions under Title IV of the 1990 Clean Air Act Amendments. U.S. Environmental Protection Agency, Office of Air and Radiation, Washington, DC.

${ }^{170}$ Samet, J.M., S.L. Zeger, J.E. Kelsall, J. Xu, and L.S. Kalkstein. 1997. Particulate air pollution and daily mortality. Analyses of the effects of weather and multiple pollutants. In: The Phase IB Report of the Particle Epidemiology Evaluation Project. Health Effects Institute, Cambridge, MA.

171 Vedal, S. 1997. Ambient particles and health: Lines that divide. Journal of the Air and Waste Management Association 47:551-581. 
172 U.S. EPA. 1996. Review of the national ambient air quality standards for particulate matter: OAQPS staff paper. U.S. Environmental Protection Agency, Office of Air Quality Planning and Standards, Research Triangle Park, NC. EPA-452/R-96-013.

173 CASAC. 1996. A closure letter to EPA's Administrator Carol Browner from the Clean Air Scientific Advisory Committee (CASAC) regarding the Staff Paper for Particulate Matter. Letter EPA-SAB-CASAC-LTR-96008, June 13, 1996.

174 Burnett, R.T., R. Dales, D. Krewski, R. Vincent, T. Dann, and J.R. Brook. 1995. Associations between ambient particulate sulfate and admission to Ontario hospitals for cardiac and respiratory diseases. American Journal of Epidemiology 142:15-22.

175 Bates, 1995. Observations on asthma. Environmental Health Perspective 103(suppl 6):243-247.

176 U.S. EPA. 1996. Air quality criteria for ozone and related photochemical oxidants. Environmental Protection Agency, Office of Research and Development, Research Triangle Park, NC. EPA-600/P-93/004F.

177 Freudenthal P.C., H.D. Roth, T. Hammerstrom, C. Lichtenstein, and R.E. Wyzga. 1989. Health risks of short-term $\mathrm{SO}_{2}$ exposure to exercising asthmatics. Journal of the Air Pollution Control Association 39:831835.

178 Pope, C.A. III, M.J. Thun, M.M. Namboodiri, D.W. Dockery, J.S. Evans, F.E. Speizer, and C.W. Heath, Jr. 1995. Particulate air pollution as a predictor of mortality in a prospective study of U.S. adults. American Journal of Respiratory and Critical Care Medicine 151:669-674.

${ }^{179}$ Godleski, J.J., C. Sioutas, M. Katler, P. Catalano, and P. Koutrakis. 1997. Death from inhalation of concentrated ambient particles in animal models of pulmonary disease. Applied Occupational and Environmental Hygiene.

180 Walsh, R.G., et al. 1990. Nonmarket values from two decades of research on recreation demand. Advances in Applied Micro-Economics 5:167-193.

181 Englin, J.E., et al. 1991. Valuation of Damages to Recreational Trout Fishing in the Upper Northeast Due to Acidic Deposition. Pacific Northwest Laboratory, Seattle, WA.
182 Mitchell, R.C. and R.T. Carson. 1986. Valuing Drinking Water Risk Reductions Using the Contingent Valuation Method: A Methodological Study of Risks from THM and Giardia. U.S. Environmental Protection Agency, Washington, DC.

${ }^{183}$ McClelland, G., W. Schulze, D. Waldman, J. Irwin, and D. Schenk. 1991. Valuing eastern visibility: A field test of the contingent valuation. Report prepared for the U.S. Environmental Protection Agency, Washington, DC.

184 Tolley, G.A., et al. 1986. Establishing and Valuing the Effects of Improved Visibility in the Eastern United States. U.S. Environmental Protection Agency, Washington, DC.

185 Brookshire, D., et al. 1979. Methods Development for Assessing Air Pollution Control Benefits. Volume 2: Experiments in Valuing Nonmarket Goods. A Case Study of Alternative Benefit Measures of Air Pollution in the South Coast Air Basin of Southern California. U.S. Environmental Protection Agency, Washington, DC. EPA600/6-79-0016.

186 Brown, G.M. Ir., J.M. Callaway, R.M Adams, F. Kalser, D. Rosenthal, L.G. Chestnut, M.J. Kealy, R.D. Rowe, J.E. Englin, M.L. Plummer, J.D. Scheraga, and R. Hayes. 1991. Methods for Valuing Acidic Deposition and Air Pollution Effects. In: Acidic Deposition: State of Science and Technology. Report 27. U.S. National Acid Precipitation Assessment Program, Washington, DC.

187 Chestnut, L.G., and R.D. Rowe. 1990. Preservation Values for Visibility Protection at the National Parks. U.S. Environmental Protection Agency, Research Triangle Park, NC.

188 Electric Power Research Institute and Decision Focus, Inc. 1991. Analysis of Alternative $\mathrm{SO}_{2}$ Reduction Strategies. Electric Power Research Institute, Palo Alto, CA. EN/GS-7132.

189 Chestnut, L.G., and R.L. Dennis. 1997. Economic benefits of improvements in visibility: Acid rain provisions of the 1990 Clean Air Act Amendments. Journal of Air and Waste Management Association 47:395-402.

${ }^{190}$ Morrey, E., K. Rossman, L. Chestnut, and S. Ragland. 1997. Valuing Acid Deposition Injuries to Cultural Resources. U.S. National Acid Precipitation Assessment Program, Washington DC. 
191 Johannesson, M., and P. Johansson. 1996. To be or not to be, that is the question: An empirical study of the willingness-to-pay for an increased life expectancy at an advanced age. Journal of Risk and Uncertainty 13(2):163-174.

192 Resources for the Future. 1997. The costs and benefits of Title IV: An integrated assessment using TAF. Resources for the Future, Washington, DC. Discussion Paper 97-31.

193 Jones-Lee, M.W., M. Hammerton, and P.R. Philips. 1985. The value of safety: Results of a national sample survey. The Economic Journal 95(March):49-72.

194 U.S. EPA. 1997. The Benefits and Costs of the Clean Air Act 1970 to 1990: Report to Congress (Draft - July). U.S. Environmental Protection Agency, Washington, DC.

195 U.S. EPA. 1997. Regulatory Impact Analysis for Proposed Particulate Matter National Ambient Air Quality Standard (Final Draft-July). Prepared by Innovative Strategies and Economics Group, Office of Air Quality Planning and Standards, U.S. Environmental Protection Agency, Research Triangle Park, NC.
196 U.S. EPA. 1996. Regulatory Impact Analysis for Proposed Particulate Matter National Ambient Air Quality Standard (Draft). Prepared by Innovative Strategies and Economics Group, Office of Air Quality Planning and Standards, U.S. Environmental Protection Agency, Research Triangle Park, NC.

197 Van Sickle, J., and M.R. Church. 1995. Methods for Estimating the Relative Effects of Sulfur and Nitrogen Deposition on Surface Water Chemistry. U.S. Environmental Protection Agency, Washington, D.C. EPA/600/R-95/172.

198 McLean, B.J. 1997. Evolution of marketable permits: The U.S. experience with sulfur dioxide trading. In: Proceedings from Controlling Carbon and Sulphur, International Trading Initiatives. Royal Institute of International Affairs, London, England. 


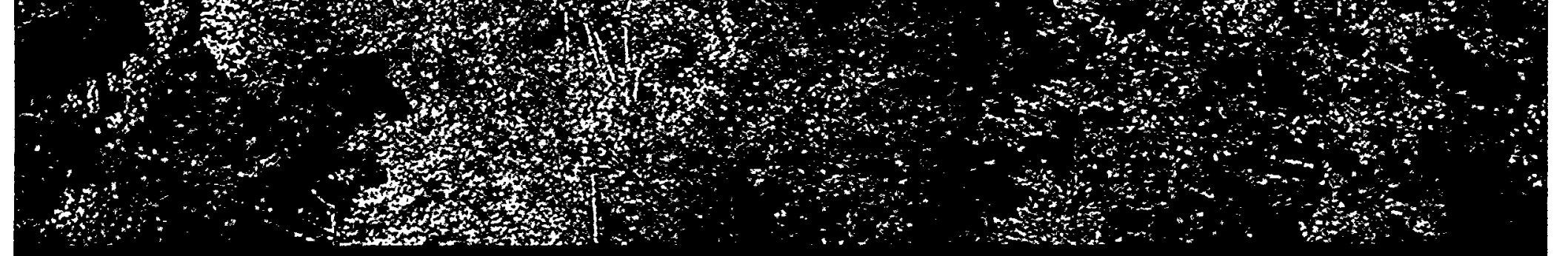




\title{
Advances in Integrated and Issue-Specific Modeling
}

\begin{abstract}
A successful assessment relies on modeling. Issue-specific models are used to understand such processes as pollution transport and diffusion or visibility impairment and, in some cases, to make predictions. In performing an integrated assessment of a science-policy issue that involves many disciplines, analysts must be able to understand and assess the relationships and dependencies between the disciplines. Integrated models that link issue-specific models are tools that scientists and economists can use to provide the understanding necessary for an integrated assessment. This appendix provides descriptions of a few issue-specific and integrated models that are relevant to the acid deposition issue.
\end{abstract}

\section{Integrated Models}

Integrated models link issue-specific models to enhance understanding of a complex issue that is broad in scope. This section describes three integrated models of the acid deposition issue. They all include emissions, transport and diffusion, deposition, and economics in their frameworks but have different modeling approaches that match the needs of their users. The Tracking and Analysis Framework was developed in the United States, while RAINS and RAISON were developed by the European Community and Canada, respectively.

\section{Tracking and Analysis Framework}

With the passage of the 1990 Clean Air Act Amendments, the United States embarked on an acid deposition control policy that has been estimated to cost billions of dollars. The Amendments created a major innovation in environmental regulation by introducing market-based incentives-specifically, trading among electric utility companies in allowances to emit sulfur dioxide. NAPAP is charged with (1) evaluating the status of the implementation, effectiveness, and costs and benefits of the acid deposition control program created by Title IV of this Act, and (2) determining whether additional reductions in deposition rates are necessary to prevent adverse ecological effects.

To help NAPAP face this challenge, the U.S. Department of Energy, with support from other federal agencies, sponsored the development of an integrated assessment model, known as the Tracking and Analysis Framework (TAF). TAF was developed in less than two years with relatively modest resources for such a comprehensive model. This rate of progress was made possible by an innovative combination of methods for integrated assessment. An overview of TAF follows with an outline of these methods, including references to companion documents that provide more details on selected methods and modules.

\section{General Objectives}

Following are the general objectives of TAF.

A framework for integrated assessment: TAF is designed to provide a comprehensive framework to address the major issues of concern, from end to end-that is, from 
the effects of the Clean Air Act Amendments on reducing emissions of pollutants, atmospheric transport, deposition, and environmental degradation, all the way to economic valuation of the environmental benefits of emission reductions. A variety of modules can be slotted into this framework. At present, the areas of environmental effects addressed by TAF include visibility, aquatic ecosystems, soils, and human health. Modules for forests and terrestrial ecosystems, crops, and materials remain to be added.

Complete integration: TAF is designed to include all components within a unified computing environment so that they can be examined and evaluated together, including exploration of the interactions among components.

Agility and flexibility: TAF is designed to be run on a personal computer in a few minutes, and to allow easy modification of input assumptions and reconfiguration to assess alternative policy scenarios, as new policy issues arise and new data and science become available. It is designed to allow analysts to address new questions in hours or days, rather than the weeks or months many models need.

Transparency: TAF is designed to provide the models in a form whose structure, relationships, and assumptions can easily be inspected and reviewed. It is designed as a "glass box," rather than a "black box," model.

Scientific credibility: TAF is based on the best available peer-reviewed science and data.

Explicit treatment of uncertainty: TAF provides explicit representation of the uncertainties due to limitations in scientific understanding, lack of data, and model precision.

\section{Modeling Methods}

The following set of methods was adopted to achieve these general objectives:

Influence diagrams: Influence diagrams provide a graphical representation for display of the qualitative structure of models.

Modular structure: The model is organized throughout in a hierarchy of modules so that each module is simple enough to be easily understood.

Integrated documentation: Documentation is integrated, explaining the variables and their role in the computer representation.
Reduced-form models: Most modules are "reducedform" models - that is, simplified models fitted to more detailed, scientific full-form models. They derive their scientific credibility from the quality of their fit to the detailed models. Both the full-form and the reducedform models used in TAF are peer reviewed.

Probabilistic analysis of uncertainty: Probability distributions are used to represent variability, uncertainty due to lack of scientific knowledge or data, and imprecision due to model approximations. Monte Carlo and related methods are used to propagate and combine these distributions to assess the implied uncertainty in the results, and to compare the importance of the various sources of uncertainty.

Progressive refinement: The team has developed TAF as a series of prototypes of increasing sophistication and refinement, progressively reviewing and refining each to create the next version. Several of these methods have been used in the development of other integrated assessment models. In adopting and refining the entire set of methods, the team found significant synergies among them, leading to what is believed to comprise some important innovations in integrated assessment methodology. The use of many of these methods has been facilitated by the use of Lumina's Analytica, which is software for quantitative modeling and integrated assessment. Analytica (Henrion et al., 1996) provides a variety of features used in TAF, including influence diagrams, hierarchies of modules, integrated documentation, and Monte Carlo simulation.

\section{Overview of TAF Modules}

A comprehensive assessment of the costs, benefits, and effectiveness of Title IV of the Clean Air Act Amendments requires consideration of many issues. Figure A-1 shows the top level of TAF as an influence diagram. Each of the nodes on the diagram represents a module currently in TAF.

The scenario selector on the top left allows the model user to select one or more scenarios for projecting future emissions and to assess and compare the effects of those emissions. Users can specify their own scenarios, making assumptions about future growth rates in emissions, by pollutant type $\left(\mathrm{SO}_{\mathrm{x}}\right.$ and $\left.\mathrm{NO}_{\mathrm{x}}\right)$, and source region. Alternatively, users can select a predefined scenario from recent U.S. Environmental Protection Agency (EPA) projections, or estimated projections from one of 16 scenarios defined by TAF's emissions module. These 16 scenarios are based on 
Figure A-1. A computer screen image shows a top-level influence diagram from the TAF prototype.

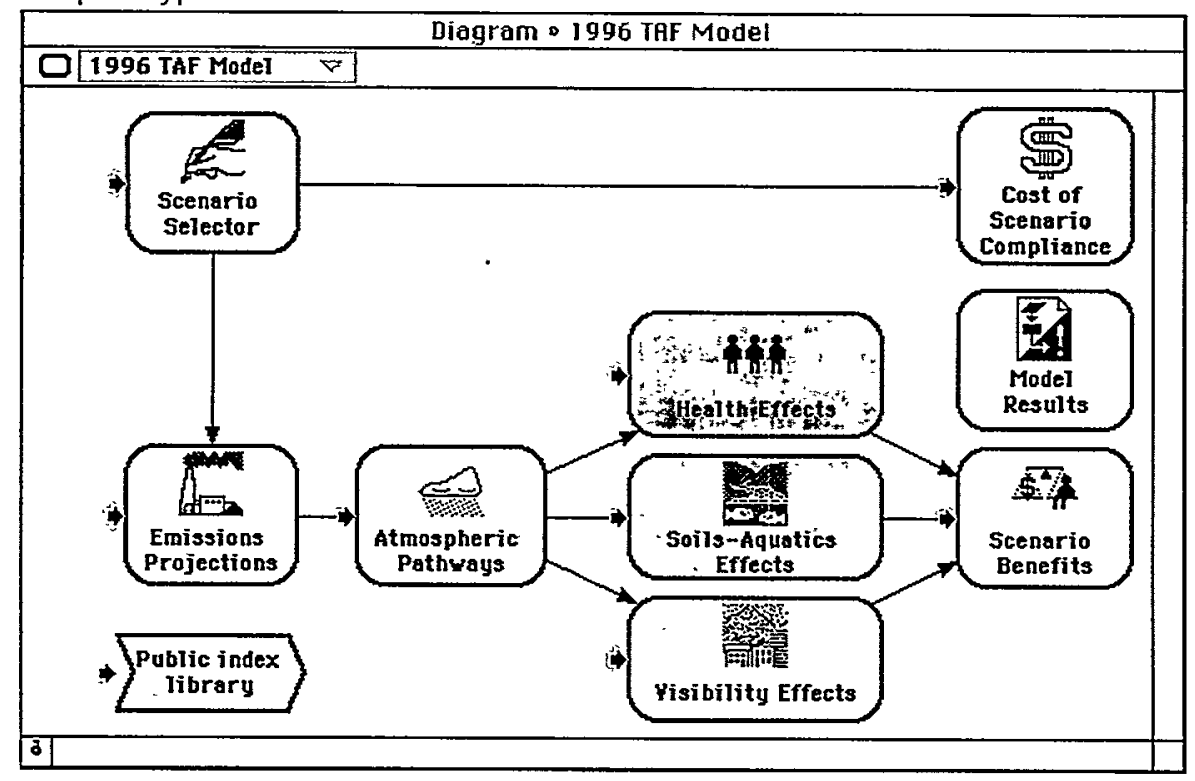

model documentation in the same computer representation used for computation. Figure A-1 shows the top-level influence diagram, including the key modules and arrows indicating the dependencies among these modules.

Each module consists of a diagram, showing the key inputs and outputs, and submodules containing the details of the model. These submodules are themselves arranged hierarchically, as illustrated in Figure A-2. Clicking the mouse on one of these nodes in the diagram opens up the diagram for the model it contains. This model hierarchy in TAF extends down to six levels in parts of TAF. combinations of Phase I caps only and Phase II caps, with and without trading in emission allowances, and with alternative assumptions about future electricity demand growth rates and power plant retirement ages.

TAF currently contains 10 modules developed by over 30 people at 10 different sites, including four consulting firms, three national laboratories, two universities, and a nonprofit foundation.

\section{Model Transparency and Organization}

A common complaint about computer models-be they scientific or policy models-is that they are too complicated and too poorly documented to be understood, verified, or trusted. Typically, model documentation is created and updated separately from the computer model, with the result being inconsistent with the model it is supposed to document. In some cases, models are proprietary, and their developer wishes to keep their internal structure secret. Since a major objective of TAF is to support communication and coordination among scientists and policy analysts, an essential requirement for TAF is that the models be documented clearly and consistently.

\section{The Module Hierarchy}

TAF employs features of Analytica to display the model as a hierarchy of influence diagrams and to integrate
Each variable in a model is represented in a diagram by a node with a thin outline. Variables that are defined as uncertain, using a probability distribution are represented by oval nodes. Other variables are represented as rounded rectangles. Index variables are represented by parallelogram nodes.

\section{Integrated Documentation}

Each variable in TAF is documented by a card (object window), containing a set of attributes describing the variable, as illustrated in Figure $\mathrm{A}-3$. The card shows the variable class, name, units of measurement, description, definition (mathematical relationship for calculation), list of inputs and outputs, and, optionally, a reference to the publication or authority on which the definition is based. When the definition of a variable is specified or modified, Analytica automatically updates the lists of inputs and outputs and the arrows in the parent diagram to reflect any changes in the dependency relationships.

\section{Scientific Credibility and Reduced-Form Models}

Previous attempts to develop integrated assessment models have sometimes been criticized as lacking sound scientific foundations due to the degree of simplification (Balson and North, 1982; Alcamo et al., 1987). The challenge is to reconcile the need for integrated assessment models to be based on the best 
Figure A-2. This example of the module hierarchy in TAF shows that double clicking the mouse on a module node (thick outline) opens up the diagram for that module.

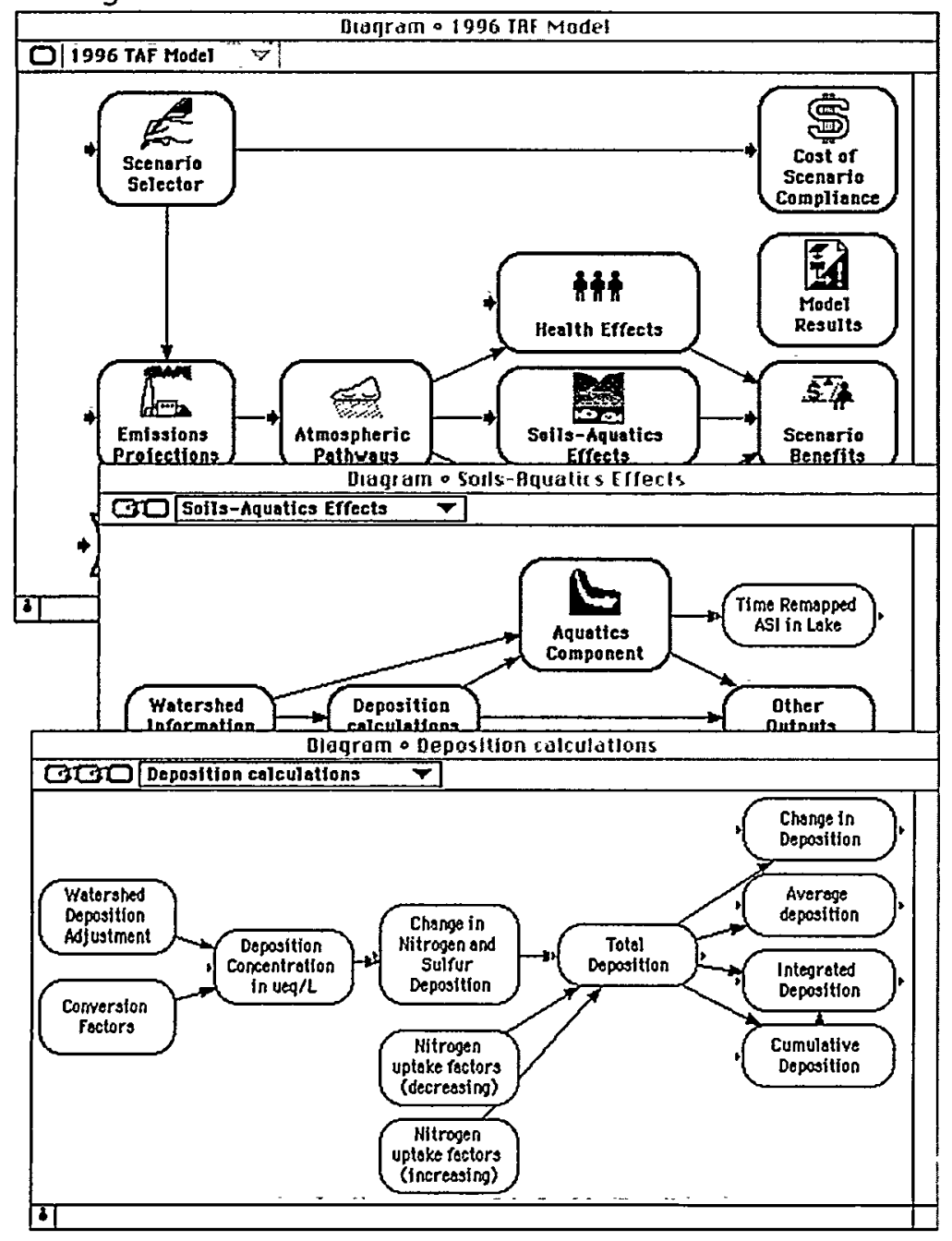

Figure A-3. Each variable is documented internally with an object window, or card, which shows key information about the variable.

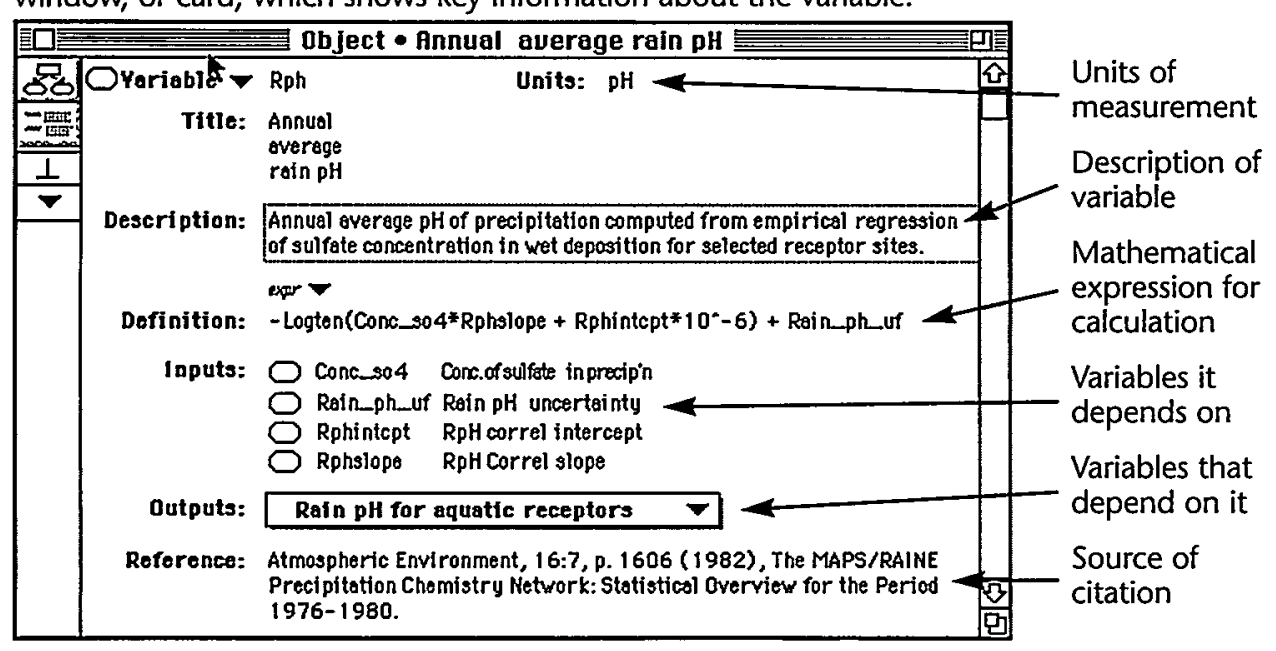

available scientific data and models yet be small, agile, flexible, and comprehensible. TAF meets this challenge by building most modules as reduced-form models based directly on the best available detailed scientific model or data.

Reduced-form models are simplified models, intended to approximate the behavior of larger, more complicated full-form models or data sets. Reduced-form models contain fewer variables, less causal detail, or higher levels of aggregation. Their performance is calibrated against or fitted to the performance of the full-form, detailed models. In practice, the approximation uncertainty introduced by the simplification for the reduced-form models in TAF is usually dwarfed by the inherent uncertainty in the full-form model. In these cases, the loss in precision from the reduced-form model is negligible.

In integrated assessments, it is generally necessary to link several models togetherthe outputs of one are matched to the inputs of the next. Typically, problems arise because the detailed models are at different levels of aggregation. For example, emission projections may be by season for each power plant, but the atmospheric transport model may need emissions on a daily basis aggregated by a 20 -kilometer grid square. Also, the file formats and platforms are often incompatible. Moreover, the models are so large that it is too expensive and time consuming to run them for many different scenarios, especially to handle uncertainty using Monte Carlo or other techniques. It is often impractical to reconfigure and rerun them every time a new policy problem arises. Reduced-form models can obviate these problems, provided they are designed explicitly to use compatible levels of aggregation and file formats. 
Figure A-4. The lower window shows part of the normalized transport matrix by source plant and receptor region, as a detail of the diagram in the upper window. The two-dimensional transport matrix displayed is for winter and ambient $\mathrm{SO}_{2}$, and is a slice from a four-dimensional array, indexed by four seasons and ambient species.

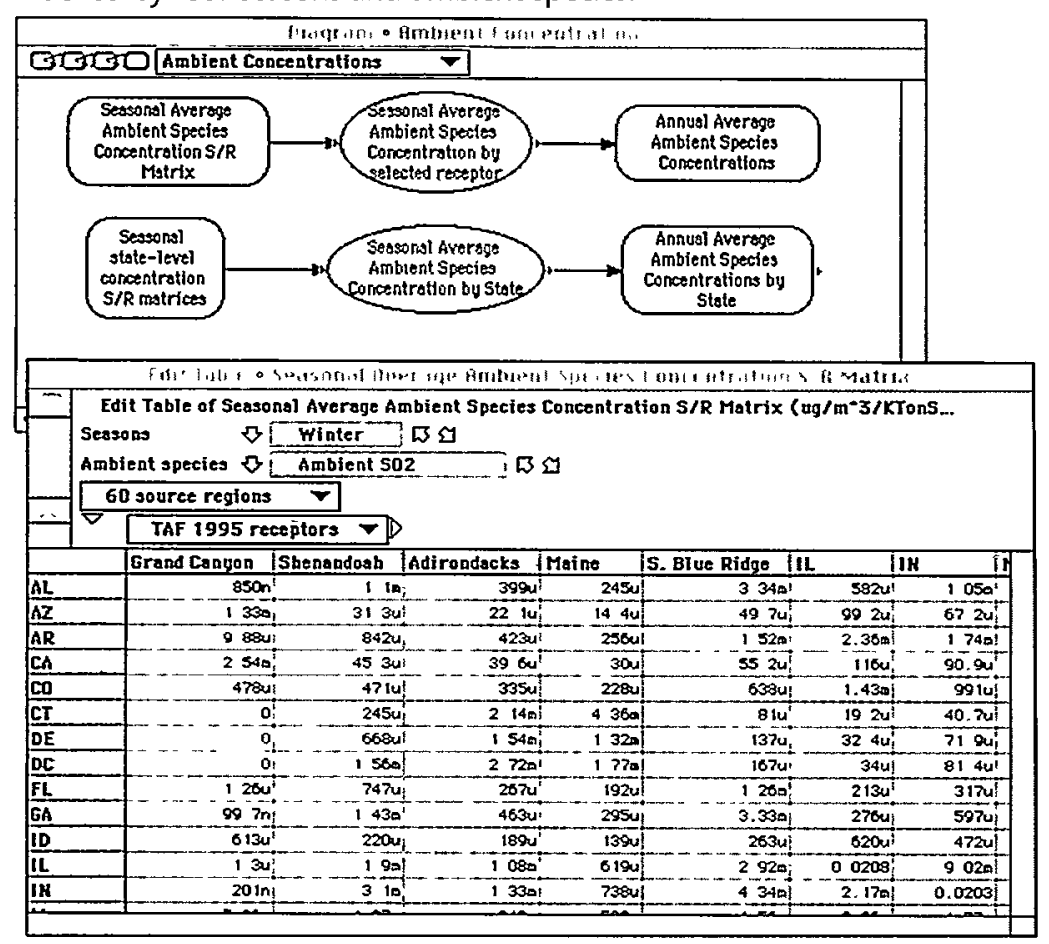

Specific receptors have been selected for the visibility, aquatics, crops, and human health effects. Figure A-4 shows the top left corner of a source-receptor matrix for ambient $\mathrm{SO}_{2}$ in winter.

Shannon et al. (1997) have compared the performance of ASTRAP with a nonlinear transport model called RADM (Regional Acid Deposition Model), and actual observations for annual average atmospheric concentrations at selected receptor sites in the eastern United States. Figure A-5 shows an example comparison with regression lines fitting the observations to predictions for each model. Both models appear to underestimate the observations on average. Both models show a similar quality of fit to the data. Since ASTRAP is a linear model, it generates ambient concentrations and deposition at each receptor that are proportional to the emissions at the sources. Therefore, representing it by normalized transport matrices, as in TAF, introduces no additional approximation imprecision for a given time period (seasons). In other words, there is no approximation uncertainty introduced by the reduced-form model beyond Reduced-form models may be developed or formulated in a wide variety of ways. Following is a description of the approach employed for the atmospheric transport module.

\section{Reduced-Form Models for the Atmospheric Transport Module}

The atmospheric pathways module of TAF is a reduced-form model based on results from the Advanced Statistical Trajectory Regional Air Pollution (ASTRAP) model, a detailed long-range atmospheric transport model developed at Argonne National Laboratory (Shannon, 1981). The reduced-form models consist of source-receptor matrices, normalized to unit emissions at each source. The normalization allows the model to be applied to any emission scenario. Since ASTRAP generates ambient concentrations and deposition rates that are linear in emission rates, this normalization involves no additional approximation.

The 60 sources are centroids of the United States, Canadian provinces, and northern Mexico. Temporal aggregation is by season and year. Transport matrices are provided for dry and wet deposition for $\mathrm{SO}_{\mathrm{X}}$ and $\mathrm{NO}_{\mathrm{X}}$. the uncertainty inherent in the detailed model on which it is based. Moreover, the uncertainty of the latter appears to be no more at the selected levels of aggrega-

Figure A-5. A comparison of predictions by ASTRAP (the TAF module) and RADM (another more detailed transport model) with actual observations of annual average concentrations of atmospheric sulfate $\left(\mu \mathrm{g} / \mathrm{m}^{3}\right)$ in the eastern United States in 1990.

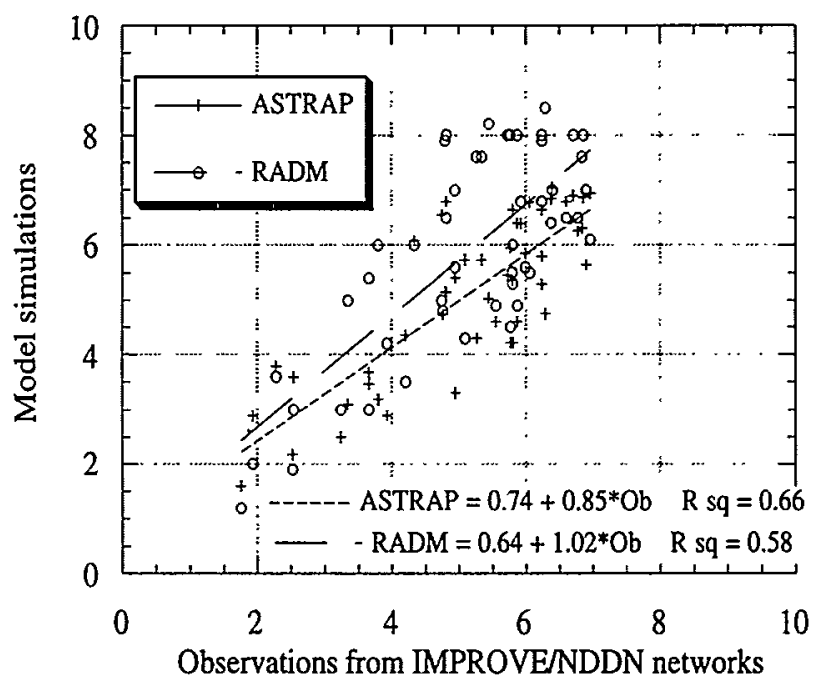


tion over space and time than RADM, which is significantly more complex than ASTRAP.

\section{Progressive Refinement}

Model development is-or should be-a learning process. It requires many decisions about the level of detail and aggregation of each variable, making compromises between accuracy and practicality, between detail and computer time and memory, between the policy questions of concern and the pragmatic limitations on what questions the model can address. Finding the best trade-offs is a major challenge, even for the most experienced modelers. The most satisfactory results are obtained when the modelers can revisit decisions in the light of experience with early versions of the model-expanding, simplifying, and refocusing models as the process continues. This process is called progressive refinement.

Progressive refinement was adopted as the approach to TAF from the start, beginning with an earlier model named ADAM, developed for NAPAP in the mid-1980s at Carnegie Mellon University. In 1993, NAPAP commissioned a revised prototype integrated assessment model, based on ADAM, which came to be known as TAF. And so began the multiple cycles of progressive refinement, which were essential in obtaining a fully integrated model.

\section{TAF Peer Review}

An intensive peer review of TAF by 12 scientists in December 1995 concluded that TAF was generally successful in meeting its objectives (Report on the Peer Review, 1996). The development team provided considerable refinement in the following year to address remaining concerns and to improve the analysis.

Hierarchical influence diagrams have proved valuable as a visual tool to support transparency for organizing and communicating complex models. Analytica's tools for integrated documentation and array abstraction have also proved helpful. Members of the TAF team and reviewers have been able to scrutinize model structure and assumptions using the built-in model diagrams and documentation.

TAF is small enough to run in a few minutes, allowing multiple Monte Carlo runs for comprehensive uncer- tainty analysis. It is also flexible enough to be rapidly reconfigured to address new policy issues. Yet it is derived from credible, detailed scientific models. The key to reconciling these apparently conflicting goals has been the development of reduced-form models for key modules. Thus, the relatively small size and simplicity of TAF impose no important loss of precision in the results that it generates.

The general approach has been one of progressive refinement, in which each module and the integrated model are developed as a series of versions, starting with module specifications, being progressively refined in response to review and critique by other members of the team. The current version of TAF is the result of four major cycles of refinement, each comprised of a number of minor cycles.

The methods and tools that have been developed and the experience gained in developing TAF could be of value to other teams involved in the collaborative development of models for integrated assessment. Other domains of application might include integrated assessments for regional or local air pollution policy, and for international environmental problems, especially for global climate change.

\section{Exercises with Historical \\ Data and the Aquatics Module}

In this section, the transport and aquatics modules in TAF are exercised using historical emissions data from the period 1980 through 1995. Some of the intermediate ambient concentration and deposition results are presented, and the aquatics module is used to estimate the changes in alkalinity for a series of lakes in the Adirondack Mountain region of New York. The acid stress index for three fish species within these lakes is also estimated. Finally, some of the sensitivity and uncertainty analyses made possible using the TAF framework are presented.

\section{Historical Emission Trajectories}

The utility $\mathrm{SO}_{\mathrm{x}}$ and $\mathrm{NO}_{\mathrm{x}}$ emission trajectories used in this exercise are derived from the EPA's emission databases (see footnote 1). Additional nonutility emissions (from commercial, industrial, and transportation sources) are from the emission databases at Argonne National Laboratory (see footnote 2). Mexican and

\footnotetext{
1 Acld Rain Division, Environmental Protection Agency, Washington, DC.

2 Environmental Research Division, Argonne National Laboratory, Argonne, IL.
} 
Figure A-6. National $\mathrm{SO}_{\mathrm{x}}$ and $\mathrm{NO}_{\mathrm{x}}$ emissions.

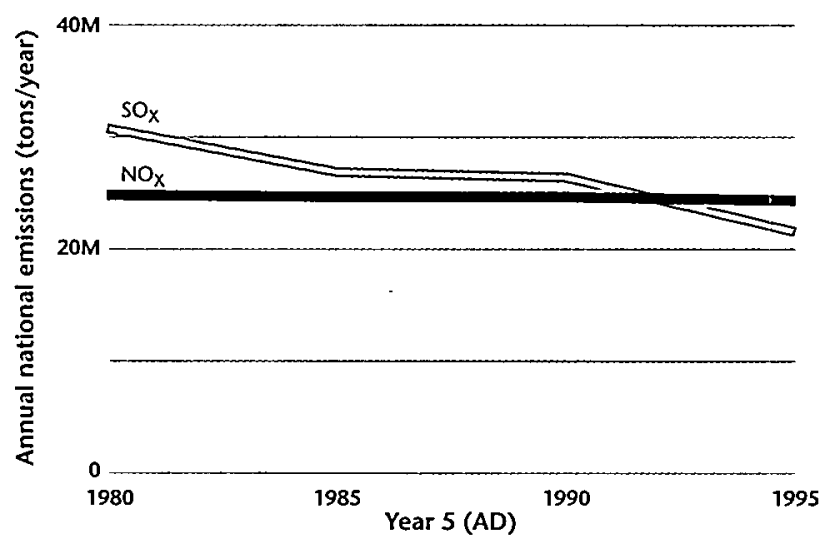

Canadian emission trajectories are also included because of their contributions to ambient pollutant concentrations within U.S. borders.

The emissions are aggregated to the state level in TAF. Figure A-6 includes utility and nonutility sources of U.S. emissions during 1980-1995.

TAF also contains emission projections based on models run by ICF for EPA and models run by Argonne National Laboratory for the Department of Energy. Other emission projections can be input by TAF users, and propagated through the entire model.

\section{Estimating Ambient Concentrations and Deposition in the Pathways Module}

The pathways module uses linear source-receptor matrices to calculate seasonal ambient pollutant concentrations and deposition estimates integrated over states and at a few selected point receptors, based on state-level data from the emissions module. Because the TAF module is primarily concerned with annual averages of deposition and ambient pollutant concentration levels (a few exceptions are handled downstream in the assessment), a linear approximation of transport processes is appropriate.

The source-receptor matrices are from the ASTRAP model. Using historical emissions data, the ASTRAP matrices have been validated against ambient concentration/deposition data. Eleven years of wind and precipitation data have been used in the model to estimate the variability of model results based on climatological variability. The resulting variability in ambient concentration and deposition estimates was then incorporated into the module to represent clima-
Figure A-7. Annual average species concentration of $\mathrm{SO}_{2}$ in the Grand Canyon area.

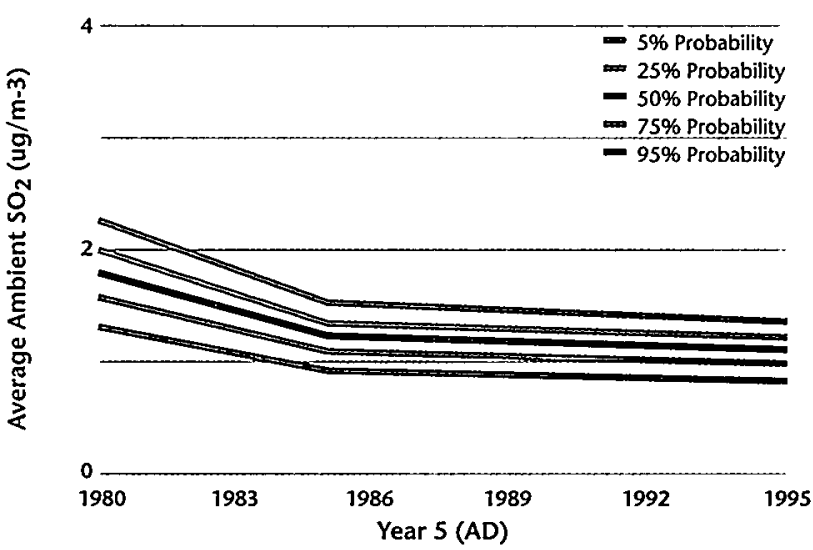

tological variability. Normal distributions representing the annual variability of the source-receptor relationship are multiplied by the concentrations and depositions estimated at each receptor site.

The variability in ambient concentrations based on climatic fluctuations is illustrated in Figure A-7, for micrograms per cubic meter of $\mathrm{SO}_{2}$ in the Grand Canyon area. Probabilities of occurrence of $5 \%, 25 \%$, $50 \%$ (median), $75 \%$, and $95 \%$ are used to represent the annual variability of average ambient pollutant concentration.

This variability is significant when examining the baseline or Title IV pollutant concentrations alone, but when the Title IV concentrations are subtracted from the baseline concentrations to obtain an estimate of concentration reductions under Title IV, much of the year-to-year variability due to climatological differences is canceled out, resulting in estimates of reduced ambient concentrations. The climatological variability factored into the transport of pollutants has a measurable effect on reductions in pollutant concentrations, as demonstrated by the confidence interval surrounding the mean estimate of ambient pollutant concentrations. The next section compares this variability to other sources of variability and uncertainty that contribute to the aquatic effects of acid deposition.

\section{Aquatics Effects: Using TAF to Rank Effects}

The aquatics module is a reduced-form version of the Model of Acidification of Groundwater in Catchments (MAGIC). Using deposition data from the pathways module and Adirondack lake background data, the aquatics module calculates lake $\mathrm{pH}$, acid-neutralizing capacity, base saturation, fish species richness, and 
fish acid stress indices for 33 Adirondack lakes. The module has been calibrated to data and results from the full-form version of MAGIC, and performs comparably, despite its much more modest computational requirements.

This discussion is limited to the acid stress index, also known as the conditional mortality rate. The acid stress index is a common estimate of the increased likelihood that a fish of a given life stage will die when exposed to the specified water quality conditions, over and above the mortality expected in a circumneutral reference water. Higher numbers indicate higher stress and increased likelihood of death. The benefits module in TAF uses the acid stress index computed at the Adirondack lake sites, for three fish species, to estimate the catch per unit of effort expended by recreational fishermen. Figure A-8 contains the median $(50 \%)$ brook trout acid stress index results for a single Adirondack lake. Figure A-8 also shows $25 \%$ and $75 \%$ probability estimates. The confidence intervals are not symmetric, indicating that the distribution of possible acid stress index values is itself asymmetric, with a right-hand tail.

\section{Aquatics Effects: Using TAF to Rank Sensitivities and Uncertainties}

The uncertainty around the acid stress index includes a fraction above zero. This indicates that, when the uncertainty in the aquatics modeling and natural climatological variability is taken into account, a reduction in the acid stress index cannot be guaranteed. That said, the chance of a nonzero, favorable change in acid stress index (i.e., a reduction) is quite large. An importance analysis can be used to compare the relative contributions of the uncertainties in the model to the acid stress index results. The uncertainties affecting the acid stress index include:

Uncertainty in deposition from the pathways module. This is similar to the climatological variability in the visibility module, except it is expressed as cumulative acid deposition instead of annual ambient concentration.

Uncertainties in the fit between MAGIC and empirical data. There are four components to this uncertainty: uncertainty in the estimation of lake calcium concentrations, uncertainty in the estimation of acid-neutralizing capacity, uncertainty in the estimation of lake $\mathrm{pH}$ from acid-neutralizing capacity, and uncertainty in the estimation of acid stress index from lake pH (described with four parameters).
Figure A-8. Acid Stress Index and confidence intervals for an Adirondack lake.

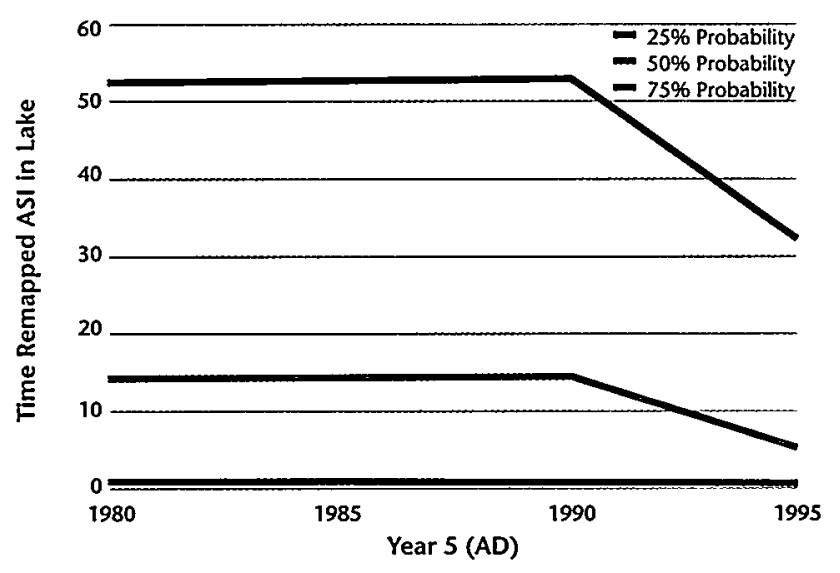

Uncertainties in the fit between the reduced-form model version in TAF and the full-form MAGIC. There are two components to this uncertainty: (1) uncertainty in the estimation of lake calcium concentrations and (2) uncertainty in the estimation of lake acid-neutralizing capacity.

The reduced-form model and MAGIC uncertainties were quantified from the results of linear and nonlinear regressions. Climatic variability was quantified by measuring variability in ASTRAP deposition results using historical wind trajectory data from 11 separate years. These sources of uncertainty are ranked using an importance analysis. The results of the analysis are shown in Figure A-9.

The uncertainty in the relationship that translates $\mathrm{pH}$ to acid stress index (ASI parameters 1, 2, and 4) dominates the result. The conversion from acid-neutralizing capacity (ANC) to $\mathrm{pH}$ also provides a significant amount of uncertainty in the result. These uncertainties swamp the other sources of uncertainty in the model, including the imprecision in the reduced-form

Figure A-9. Importance of uncertain inputs on uncertainty in ASI output for brook trout.

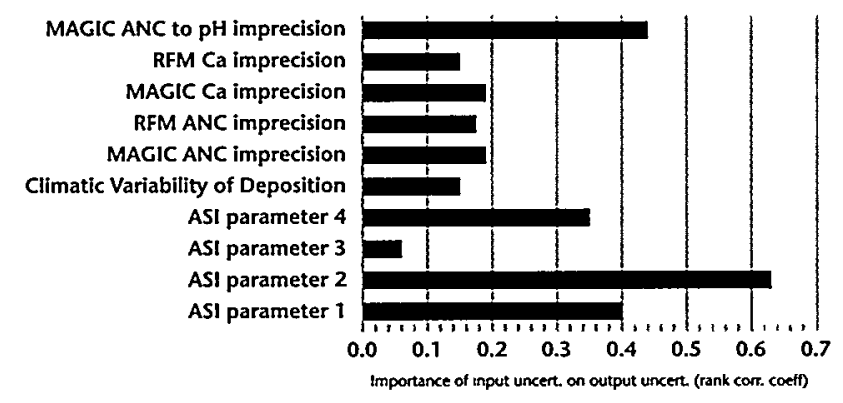


model (RFM) and the variability caused by year-toyear changes in deposition. Because the overarching uncertainties in MAGIC dominate the uncertainty in the result, we conclude that the reduced-form version of MAGIC within TAF performs comparably to MAGIC.

Note also that the climatological variability is not large compared to some of the other uncertainties. This is true in part because much of the climatological uncertainty is canceled out when the difference of the baseline and comparison scenario results is taken. The climatological uncertainty is the same across the two scenarios, so it is reduced when the difference of the two scenarios is taken.

This analysis identifies the conversion of $\mathrm{pH}$ to acid stress index and of acid-neutralizing capacity to $\mathrm{pH}$ as critical sources of uncertainty in the aquatics module. Acid-neutralizing capacity is converted to $\mathrm{pH}$ by using a four-parameter nonlinear equation based on work by Small and Sutton (1986), calibrated to data for the 33 Adirondack lakes considered in TAF. Whether this source of uncertainty should be refined and reduced in future versions of the aquatics module depends on the effect of this uncertainty in calculation of aquatics benefits.

\section{Future TAF Analyses}

The analyses described here are just a small sample of the potential of an integrated assessment. Future analyses in TAF can compare results not only across effect modules, but also across unmodeled effects using back-of-the envelope scoping analyses. These analyses will permit prioritization of additional modules to be added to TAF.

As additional information on the costs of Title IV regulations on utilities is integrated, utility costs can be compared to the benefits calculated in TAF to determine whether the subset of benefits calculated is sufficient to suggest that Title IV is cost-effective. Also, the capability exists to compare the geographic distribution of costs with the distribution of benefits, because TAF calculates both costs and benefits on a state level.

The model is able to compare both uncertainties that propagate through several modules, and uncertainties across different effects and benefits. It enables comprehensive identification of those inputs and model forms sensitive to change and most influential in their effects on output uncertainty. These abilities allow TAF to provide important information on future research priorities and the confidence in current estimates of acid deposition damages and Title IV benefits.

In a further effort to share TAF-related research, information on the TAF project, including draft models and the Analytica modeling software, is being made available over the World Wide Web via the Internet (http://www.lumina.com/taflist). In addition, examples of TAF used as an analytical tool appear in Palmer and Burtraw as well as in Shannon et al.

\section{TAF References}

Alcamo, J., M. Amann, J.P. Hettelingh, N. Holmber, L. Hordjik. 1987. Acidification in Europe: A simulation model for evaluating control strategies. Ambio 16(5):232-245.

Balson, W.E., and D.W. North. 1982. Acid Deposition: Decision Framework. Prepared by Decision Focus, Inc., for the Electric Power Research Institute, Palo Alto, CA. EA-2540.

Henrion, M., et al. 1996. Analytica User Guide, Lumina Decision Systems, Los Altos, CA.

Palmer, K.L., and D. Burtraw. 1997. Electricity restructuring and regional air pollution. Resource and Energy Economics 19:139-174.

Report on the Peer Review of the Tracking and Analysis Framework (TAF) for Use in the 1996 NAPAP Integrated Assessment, December 18-20, 1995, Bethesda, Maryland. 1.996. Organized by Oak Ridge National Laboratory for the National Acid Precipitation Assessment Program. ORNL/M-4994.

Shannon, J.D. 1981. A model of long-term average sulfur atmospheric pollution, surface removal, and net horizontal flux. Atmospheric Environment 15(5):689-701.

Shannon, J.D., E.C. Trexler, Jr., and R.S. Sonnenblick. 1997. Modeling visibility for assessment. Atmospheric Environment $31(22): 3719-3727$.

Small, M.J., and M.C. Sutton. 1986. A regional pH-alkalinity relationship. Water Resources 20:335-343.

\section{RAISON}

The National Water Research Institute of Environment Canada has developed a model to support environmental decision makers. The Regional Analysis by Intelligent Systems on Computer (RAISON) system is designed for a teamwork approach to developing decision-support systems for various environmental prob- 
lems. The teamwork approach considers not just the software but also the scientists and end users who must be involved in the development from an early stage. The RAISON prototype is sufficiently robust to interact with scientists and policy advisors, first to overcome any communication problems among themselves and with the computer, and then to iteratively improve the system toward creating a useful final product. While RAISON has some similarities to geographic information systems (GIS), it differs significantly insofar as it emphasizes decision support and analysis that are difficult or impossible in a typical GIS.

RAISON offers a generic framework to integrate data, text, maps, satellite images, pictures, video, and other knowledge input. The system provides the user with a library of software functions and tools-including algorithms, models, optimization procedures, expert systems, neural network, and other information technologies-to produce customized interfaces and output, including interpretation, advice, scenario tests, strategic analysis, and policy recommendations. For example, data can be entered into RAISON through conversion interfaces available for many off-the-shelf databases. GIS maps can be entered in vector and raster formats. Models can be incorporated into the system by: (1) using the codes as given if compatible with the programming languages used in RAISON (Visual Basic, Visual C, C ++ ), (2) building an interface that intercepts the input and output to connect to the database in RAISON, or (3) executing the model off-line but writing and reading the input and output. By using the various modules in RAISON (since all components are linked via graphical interfaces), scientists and policy advisors can adapt different applications with customized interfaces using optimization procedures or expert system techniques to direct control of the information and knowledge.

The RAISON system is property of the Government of Canada. It is distributed under license by NWRI Software. For further details, please consult the references, or contact:

\author{
Dr. David Lam \\ Phone: (905) 336-4916 \\ Fax: (905) 336-4582 \\ Email: david.lam@cciw.ca
}

\section{RAISON References}

Lam, D.C.L., C.I. Mayfield, C.I. Swayne, and K. Hopkins. 1994. A prototype information system for watershed management and planning. Journal of Biological Systems 2(4):499-517.
Lam, D.C.L., D.A. Swayne, G.S. Bowen, and D. Kay. 1995. A teamwork approach to decision support system development for watershed management problems. Proceedings of the International Conference on Computing and Information, Conference on Computer Modeling and Application, Peterborough, Ontario, June 1995.

\section{RAINS-Asia}

Expanded energy use in Asia, combined with use of indigenous coal, will result in an increase in emissions of acidifying compounds and greenhouse gases. By the year 2010, $\mathrm{SO}_{2}$ emissions from Asia will most likely exceed the emissions of North America and Europe combined.

In recent years, integrated assessment models have been used for international negotiations on acid deposition in Europe and North America. These models provide negotiators and regulators with a full regional picture of the problems associated with the entire causal process, from energy systems and emissions to the ultimate impact on the natural and man-made environment. The model user can analyze the regional and national implications of various scenarios, which include options for energy use, control strategies, and mitigation policies.

The Regional Air Pollution Information and Simulation (RAINS)-Asia model is a tool for integrated analysis of air pollution. It consists of three modules: (1) Resource and Energy Scenario Generator, (2) Energy Emissions, and (3) Deposition and Critical Loads Assessment. Each module describes various aspects of acidifying emissions and dry and wet deposition. A set of menus and options guides users through the modules.

The three modules together permit users to operate the PC-based RAINS-Asia policy model in a scenarioanalysis mode. They can estimate current costs and impacts of alternative emission control strategies on a country or regional basis. Emissions can be tracked through the deposition process to assess their potential impacts on critical ecosystems. Control strategies can be specified for specific fuel types, economic sectors, emission-generating power plants, emission control technologies, and regions or countries under study, and they can be applied individually or in any combination. The model can also be used to identify potential maximum impact locations for establishing monitoring sites, which in turn could assist in model validation.

RAINS-Asia covers East, South, and Southeast Asia, with particular emphasis on Japan, India, China, 
Indonesia, Thailand, and South Korea. It contains databases on energy consumption for 23 countries, 94 subregions, and 250 large point sources of deposition, and estimates the acid deposition carrying capacity of 3I types of ecosystems. Values for sulfur depositions are based on a yearly average and are calculated at a $1 \times 1$ degree of resolution. Aggregate results of source-receptor information on acid deposition patterns for each subregion or country can be obtained, and local impacts can be estimated as well. The temporal range of the model is 1990-2020.

\section{Resource and Energy Scenario Generator (RESGEN)}

Based on best-estimate assumptions of economic development and population growth, RESGEN makes possible the generation of scenarios of energy consumption pathways. Energy consumption is disaggregated into industrial, transportation, residential, commercial, and other sectors. The supply side of the module identifies different technologies for energy generation and sources of emissions, such as electricity generation, oil refining, and other energy-sector operations with combustion of fossil fuels. This framework makes it possible to generate rough estimates of future energy demand and supply trends under a variety of socioeconomic and technical assumptions.

\section{Energy Emissions (ENEM)}

The ENEM module takes the energy consumption scenarios at the sectoral and regional levels, as given by the RESGEN module, and estimates the corresponding $\mathrm{SO}_{2}$ emissions and costs of various emission control options. Sulfur emissions from combustion of fossil fuels are calculated based on fuel characteristics, combustion technology, and emission control assumptions. Emissions are characterized as low-level area sources and high-level large point sources. The module considers a number of options to reduce sulfur emissions, including fuel desulfurization and fluegas desulfurization. To explore integrated abatement strategies, the users can apply specific control policies to selected countries or regions within countries. The results of energy-conservation measures and fuel substitution can be explored by analyzing alternative energy pathways, either by selecting one of the several preset energy-use scenarios or by creating a new scenario based on expectations of fuel use.
Emission control and associated costs are based on the most commonly used emission control technologies. Cost evaluation is based on international operating experiences of pollution control equipment, and extrapolating them to country context. It is assumed that a relatively free and competitive market exists for control technology. This module also computes national cost curves that rank abatement measures by their cost-effectiveness.

\section{Deposition and Critical Loads Assessment (DEP)}

This module estimates ambient levels of acid deposition precursors and acid deposition throughout the region and compares them with data on environmental sensitivities that are presented in the form of critical-load maps. This module consists of two submodules: Atmospheric Transportation and Deposition and Ecosystems Impact.

\section{Atmospheric Transportation and Deposition (ATMOS)}

The ATMOS submodule is based on the National Oceanic and Atmospheric Administration's Branching Atmospheric Trajectory (BAT) model, which calculates wet and dry deposition of $\mathrm{SO}_{2}$ and sulfates from a particular source as the pollutant is transported by meteorological fields. If these trajectories are run for an entire year, then the submodule estimates the amount of annual deposition on the entire region from a particular source. If the calculations are repeated for all sources, then the total annual deposition in the region can be estimated. Inputs for this submodule include $\mathrm{SO}_{2}$ emission rates, winds and temperature, precipitation rates, and estimates of dispersion coefficients, dry deposition velocities, and wet-scavenging coefficients. The module is run for each large point source and area source estimated by ENEM, and sulfur deposition is calculated on a $1 \times 1$ grid. The results are aggregated to provide source-receptor information on acid deposition patterns for each of the subregions in the study region, and further aggregated to provide country-bycountry source-receptor information.

\section{Ecosystems Impact (IMPACT)}

The IMPACT submodule estimates critical loads (the maximum long-term deposition levels that could be tolerated without damage) for 14 different ecosystems (see footnote). The critical loads are compared with

Desert/semi-desert, mangrove woods, irrigated land/paddy, semi-arid and thorn woods, dry tropical/subtropical/savanna, agriculture, cool scrub/grassland, temperate broadleaf wood, tropical montane forest, other conifer trees, bog/mire/moor, wet tropical forest, Tibetan cold grass, northern/main/southern taiga/tundra. 
the estimates of sulfur deposition from the ATMOS submodule to determine which ecosystems may be at risk for different emission scenarios. This assessment is based on complex dynamics of processes in key ecosystems, such as soils, surface waters, and vegetation systems. These models include the computation of the depletion of acid buffer capacity of ecosystems under the influence of precipitation, evaporation, water flows, and budgets of chemical ecosystem constituents.

The critical-load calculation involves a two-step process. The first step applies a qualitative relativesensitivity approach to distinguish an ecosystem's sensitivity to acidification. In this method, weights are assigned to four indicators of ecosystem sensitivitybedrock lithology, soil type, land use, and annual rainfall. In the second step, based on the Steady-State Mass Balance Method, computations are performed to assign critical loads to all areas distinguished on the map of relative sensitivities. This method assumes steady-state equilibrium between soil solid phase and soil solution, and computes the maximum acid input to the system that will not cause an excess of the critical alkalinity value, which is computed from average thresholds for chemical values, such as $\mathrm{pH}$, aluminum, and aluminum-calcium ratios.

Weathering rate, which is a key input to the process, is determined by estimates of soil mineralogy, which are then modified by climate and soil attributes. The resulting map of weathering rates and ratios of land use and precipitation to potential evapotranspiration are used in the critical-load calculations.

\section{Issue-Specific Models}

A need has arisen to test the veracity of model projections, especially in cases where policy and/or economic interests are at stake. As Oreskes et al. (1994) pointed out, however, verification and validation of mathematical models of natural systems are impossible, because natural systems are never closed, and model results are not unique. Model confirmation is possible and entails demonstration of agreement between prediction and observation. Because such confirmation is inherently partial, it is critical that policy-relevant models be tested in a variety of settings and under a variety of conditions.

\section{MAGIC}

Since 1990, the Model of Acidification of Groundwater in Catchments (MAGIC) (Cosby et al., 1985) has been widely used throughout North America and Europe. It has been the principal model used by NAPAP to project the response of surface waters to changing levels of sulfur deposition. MAGIC projections of the effects on surface water chemistry of various sulfur emission scenarios formed the technical foundation for a large part of NAPAP's 1990 Integrated Assessment Report (NAPAP, 1991). Subsequently, a research effort was conducted from 1990 to 1996 to improve the performance of MAGIC and to test the model and confirm its results at multiple sites. Model evaluations have included hindcast comparisons with diatom reconstructions (see footnote) of preindustrial lake water chemistry in the Adirondack Mountains of New York, and tests of the veracity of model forecasts using the results of whole-catchment acidification experiments in Maine (Norton et al., 1992) and Norway (Gjessing, 1992) and whole-catchment acid-exclusion experiments in Norway (Wright et al., 1993).

Based on the results of this testing, it appears that MAGIC provides reasonably accurate forecasts of changes in surface water acid-base chemistry in response to changing levels of acid deposition. Although some uncertainties remain, particularly with respect to watershed nitrogen dynamics, MAGIC provides a generally accurate and well-tested tool for integrated assessment modeling.

The testing of MAGIC over the last six years has elucidated several potentially important deficiencies in structure and method of application, and has resulted in changes to the model and its calibration procedures. The work has included in-depth evaluation of issues related to regional aggregation of soils data, background sulfur deposition, natural organic acidity, nitrogen, and aluminum mobilization. The result has been an improved and more thoroughly tested version of MAGIC, which yields forecasts different from the version that served as the technical foundation for NAPAP's 1990 Integrated Assessment Report.

\section{Changes to the Model}

\section{Background Sulfate and Subregional Calibration}

Subsequent to the regional MAGIC modeling that was conducted for NAPAP (1991), there was concern that

Diatoms are microscopic algae, whose remains are incorporated into lake sediments that accumulate over time. The species composition and relative abundance of diatoms at different levels in the sediment can be used to estimate the pH of lake water using sophisticated mathematical relationships. 
(subregional) Adirondack soils might differ in their chemical properties from related (regional) soils in other areas of the Northeast, and that MAGIC projections for Adirondack watersheds might be biased because they were based on soil attributes that actually reflected conditions in the Northeast other than those in the Adirondacks. Therefore, the model input data were reaggregated to use only soil collected from Adirondack sites.

Modeling for the 1990 Integrated Assessment Report also assumed that the deposition of sulfur in preindustrial times was limited to sea salt contributions. Based on analyses presented by Husar et al. (1991), this assumption was modified so that preindustrial deposition of sulfate was assumed to be equal to $13 \%$ of current values (Sullivan et al., 1991).

Recalibration of MAGIC to the Adirondack lakes database using the regionally corrected soil and background sulfate data resulted in approximately $10 \mu \mathrm{eq} \mathrm{\textrm {L } ^ { - 1 }}$ lower model estimates of current acid-neutralizing capacity. A substantial downward shift was also observed in predicted preindustrial and current lake water $\mathrm{pH}(\sim 0.25$ $\mathrm{pH}$ units) for lakes having current $\mathrm{pH}$ greater than about 5.5. These differences were attributed to lower calibrated values for lake water sulfate concentrations and higher values for the partial pressure of carbon dioxide estimated for Adirondack lakes, compared with the Northeast as a whole (Sullivan et al., 1991).

\section{Organic Acids}

Concern was raised subsequent to the 1990 integrated Assessment Report regarding potential bias from the failure to include organic acids in the MAGIC formulations used by NAPAP (1991). MAGIC hindcasts of preindustrial lake water $\mathrm{pH}$ showed poor agreement with diatom-inferences of preindustrial $\mathrm{pH}$, and preliminary analyses suggested that these differences could be partly due to the presence of naturally occurring organic acids in Adirondack lake waters.

An organic acid model was developed by Driscoll et al. (1994) using data collected by the Adirondack Lakes Survey Corporation (Kretser et al., 1989) for 1,400 lakes located in the Adirondack region. This model was coupled with MAGIC. Model hindcasts using the unmodified MAGIC yielded preindustrial $\mathrm{pH}$ values that were substantially higher than diatom-based estimates, and the discrepancy was greatest for those lakes in the most biologically sensitive portion of the $\mathrm{pH}$ range ( $\mathrm{pH}$ of 5.0 to 6.0 ). Furthermore, MAGIC hind- cast $\mathrm{pH}$ estimates were greater than 6.0 for all lakes investigated, whereas diatom estimates of preindustrial $\mathrm{pH}$ ranged from as low as 5.2 to above 7.0. When the organic acid model was incorporated into MAGIC and simulated preindustrial $\mathrm{pH}$ values from the new model were compared with diatom-inferred $\mathrm{pH}$, the comparison yielded considerably closer agreement between model estimates of preindustrial $\mathrm{pH}$ than did the simulations that did not consider the effects of organic acids (Sullivan, Cosby et al., 1996).

When organic acids were omitted from the analysis, the lakes of greatest relevance with respect to potential biological effects of acidification, especially those having a $\mathrm{pH}$ of less than 5.5, exhibited increasingly larger discrepancies with decreasing $\mathrm{pH}$ between diatom and MAGIC model estimates of preindustrial $\mathrm{pH}$. Including an organic acid representation in the MAGIC simulations greatly improved the agreement between these two modeling approaches.

The results of these analyses of Adirondack lakes demonstrated that: (1) organic acids must be considered in modeling the response of lake waters in the Adirondack Mountains (and possibly other regions) to acid deposition; and (2) once organic acids are included in the modeling approach, reasonable agreement is obtained in hindcast comparisons with diatominferred $\mathrm{pH}$. It should be emphasized, however, that this test included only two points in time and involved only $\mathrm{pH}$. Even though the model adjustment with organic acids improved agreement for $\mathrm{pH}$, other variables in the model may have been poorly represented. MAGIC and other process models require further testing and confirmation. Many potentially important geochemical processes are not well represented in the model or the input data, and it was not clear how inclusion of such processes might affect model results.

\section{Aluminum}

Aluminum mobilization is now widely believed to be one of the most important ecological effects of surface water acidification. Potential effects of aluminum mobilization from soils to surface and soil waters include alterations in nutrient cycling, $\mathrm{pH}$ buffering effects, and toxicity to aquatic biota and terrestrial vegetation.

MAGIC simulates aluminum solubility based on an assumed equilibrium with the mineral gibbsite. The model first calculates the total concentration of acidic cations (e.g., hydrogen plus aluminum) on the basis of simulated concentrations of base cations and mineral 
acid anions (e.g., sulfate, nitrate, chloride) using mass balance and electroneutrality constraints. The acidic cations are then partitioned between hydrogen and aluminum, using the gibbsite mineral equilibrium, thermodynamic equations, the partial pressure of carbon dioxide, and the organic acid formulation. This partitioning is important because inorganic aluminum in solution can be highly toxic to aquatic biota, even at low concentrations (Baker and Schofield, 1982).

Model simulations often overpredict the change in aluminum concentration. The aluminum formulation in the MAGIC model has recently been modified to better reflect empirical relationships between aluminum and hydrogen ion. The revised formulation was used to predict aluminum concentrations in runoff at experimental ecosystem manipulation sites in Maine and Norway. In both cases, it yielded closer agreement with measured values than the original MAGIC predictions (Sullivan and Cosby, in press).

\section{Nitrogen}

MAGIC contains an extremely simplified representation of nitrogen dynamics within catchment soils. There are no processes controlling the details of nitrogen cycling in the model. The version of MAGIC used for NAPAP's 1990 Integrated Assessment Report was not appropriate for simulation of changes in atmospheric deposition of nitrogen. In light of the increasing concern about nitrogen saturation in forested ecosystems, this was a serious shortcoming in the model.

A new, coupled sulfur and nitrogen model, MAGICWAND, was developed by extending MAGIC to incorporate the major ecosystem nitrogen fluxes and their changes through time (Ferrier et al., 1995). MAGICWAND is perhaps the most generalized model, but several more detailed nitrogen models are also available, including MERLIN, NuCM, and PNET-CN. MAGIC-WAND has been applied regionally to simulate the response of lakes in the Galloway region of southwestern Scotland to changing deposition of sulfur and nitrogen from 1988 to 1993 . The model is currently being further evaluated for watersheds in the southern Appalachian, Cascade, and Rocky Mountain regions of the United States.

\section{Cumulative Impacts to Changes to MAGIC}

The improved MAGIC predicts that sensitive lakes and watersheds in the Adirondack Mountains are less responsive (in terms of change in acid-neutralizing capacity, $\mathrm{pH}$, and inorganic aluminum) than was predicted by the earlier version of MAGIC used for NAPAP's 1990 Integrated Assessment Report.

To evaluate the incremental and cumulative impacts of the modifications to MAGIC, Sullivan and Cosby (1995) conducted a suite of model simulations for the Adirondack Direct/Delayed Response Project (DDRP) lakes. They used the baseline model structure from the DDRP and the 1990 Integrated Assessment Report. The changes to the model they examined included modifying the assumption regarding background sulfur deposition, reaggregating the soils data, recalibrating the model specifically for the Adirondack subregion, adding the organic acid model to the surface water compartment, and changing the aluminum/hydrogen ion relationship from cubic to quadratic. However, these analyses did not examine the effects on model output of including nitrogen dynamics in the model simulations.

A suite of simulations was conducted based on the application of an assumed deposition scenario to derive a 50-year forecast using each model structure. The deposition scenario assumed constant sulfur deposition from 1984 (the calibration year) to 1994, followed by a $30 \%$ decrease in sulfur deposition from I 995 to 2009, with constant deposition thereafter until 2034. The modeled responses of 33 Adirondack lakes to this scenario were also considered. The impacts of the changes were illustrated by tabulating the percentage of lakes predicted to have $\mathrm{pH}$, acid-neutralizing capacity, or aluminum values in excess of commonly accepted thresholds of potential biological effects.

The overall effect of the various changes to the model structure and application procedures was an increase in the percentage of lakes exceeding various biological thresholds with respect to $\mathrm{pH}$, aluminum, and acidneutralizing capacity subsequent to an hypothesized $30 \%$ decrease in sulfur deposition (Table A-1). The largest changes were observed for $\mathrm{pH}$ and aluminum; acid-neutralizing capacity projections were less affected. The modifications to the model that caused the greatest changes in projected output were the recalibration of the model to the Adirondack subregion, modification of the assumption regarding background sulfate, and the incorporation of the organic acid model into MAGIC. The modification of the aluminum caused fewer lakes to be projected to exceed aluminum threshold values in response to the reduced deposition scenario; this change was quantitatively less important than the previous changes. 
Table A-1

Cumulative Effects of Post-1990 Changes to MAGIC

\begin{tabular}{|c|c|c|c|c|c|c|c|c|c|}
\hline \multirow{3}{*}{$\begin{array}{l}\text { Data Type } \\
\text { Measured } 1984 \text { Values }\end{array}$} & \multicolumn{3}{|c|}{$\begin{array}{c}\% \text { of Lakes with } \\
\text { pH Below: }\end{array}$} & \multicolumn{3}{|c|}{$\begin{array}{l}\% \text { of Lakes with } \\
\text { ANC Below: }\end{array}$} & \multicolumn{3}{|c|}{$\begin{array}{l}\% \text { of Lakes with } \\
\text { Al Above: }\end{array}$} \\
\hline & 5 & $\begin{array}{c}5.5 \\
\text { (acidity) }\end{array}$ & 6 & 0 & $\begin{array}{c}25 \\
\left(\mu e q L^{-1}\right)\end{array}$ & 50 & 50 & $\begin{array}{c}100 \\
\left(\mu \mathrm{eqL} L^{-1}\right)\end{array}$ & 200 \\
\hline & $12 \%$ & $32 \%$ & $38 \%$ & $18 \%$ & $48 \%$ & $59 \%$ & $30 \%$ & $18 \%$ & $10 \%$ \\
\hline \multicolumn{10}{|l|}{ MAGIC Projections of $2034:$} \\
\hline $\begin{array}{l}1990 \text { Version of MAGIC } \\
\text { Used for NAPAP }\end{array}$ & $0 \%$ & $8 \%$ & $20 \%$ & $6 \%$ & $34 \%$ & $44 \%$ & $4 \%$ & $0 \%$ & $0 \%$ \\
\hline Current Version of MAGIC* & $8 \%$ & $32 \%$ & $44 \%$ & $14 \%$ & $40 \%$ & $44 \%$ & $30 \%$ & $10 \%$ & $4 \%$ \\
\hline
\end{tabular}

*Does not include nitrogen dynamics, which are included in MAGIC-WAND.

Source: Sullivan and Cosby, 1995

The magnitude of effect of the cumulative modifications to the model was considerable. For example, $32 \%$ of the lakes had measured pH less than 5.5 in 1984, whereas only $8 \%$ were projected to still have $\mathrm{pH}$ less than 5.5 after the reduction in sulfur deposition, using the earlier version of MAGIC used for the 1990 Integrated Assessment Report. In contrast, the improved version of MAGIC projected that $32 \%$ of lakes would still have $\mathrm{pH}$ less than 5.5 in the year 2034. Similarly, of the $30 \%$ with measured inorganic aluminum concentrations greater than $50 \mathrm{\mu g} \mathrm{L}^{-1}$ in 1986, the original model structure projected only $4 \%$ would still have concentrations greater than $50 \mathrm{Hg} \mathrm{L}^{-1}$ in 2034 , compared to $30 \%$ projected to continue to have high inorganic aluminum by the improved version of MAGIC. Based on model projections using the improved version of MAGIC, little recovery of Adirondack lakes would be expected subsequent to a $30 \%$ reduction in sulfur deposition. The number of lakes having $\mathrm{pH}$ lower than 6.0 was actually projected to increase, and the number of lakes projected to have acid-neutralizing capacity lower than zero only decreased slightly in response to lower deposition. These estimates were independent of any possible increases in nitrate leaching that might occur. The lack of recovery suggested by these revised model projections is attributable partly to a decrease in the modeled base saturation of watershed soils. These results may affect expectations of recovery in response to sulfur emission controls mandated by Title IV.

The future response of lakes and streams to acid deposition is also highly dependent on the extent to which watersheds in acid-sensitive regions become nitrogen- saturated. EPA scientists conducted MAGIC simulations for 50 years into the future that effectively bounded the range of possible water chemistry responses-ranging from no watersheds reaching nitrogen saturation to all simulated watersheds reaching nitrogen saturation during the simulation period. The model projections for Adirondack lakes, for example, suggested that the percent of chronically acidic lakes in the target population in 50 years could range from $11 \%$ to $43 \%$, depending on the number of watersheds that become nitrogen saturated (U.S. EPA, 1995). Similarly, for mid-Appalachian streams, the modeled percent of streams acidic in 50 years ranged from $0 \%$ to $9 \%$, depending on the extent of nitrogen saturation (U.S. EPA, 1995).

\section{Magic Model Confirmation}

MAGIC has been tested after inclusion of many of the model modifications discussed in the preceding sections. The revised model with Driscoll et al.'s (1994) organic acid model yielded reasonable agreement between model hindcast $\mathrm{pH}$ and diatom-inferred $\mathrm{pH}$ for the data set of 33 Adirondack lakes. Differences between diatom and MAGIC estimates of preindustrial $\mathrm{pH}$ of Adirondack lakes, based on the version of MAGIC that includes an organic acid representation, were well within the range of expected differences due to annual and seasonal variability and uncertainties in the model algorithms.

However, "successful" comparison of MAGIC with diatom hindcasts in one region does not constitute a sufficient verification to impart complete confidence in using MAGIC, or any process model, for predicting 
the response of surface water chemistry to changes in acidic inputs. Additional model confirmation in the form of comparison of model output with measured data is required. This has been the focus of modeling efforts at the experimental manipulation site at Bear Brook Lake in Maine and at two sites in Norway.

Initial modeling efforts at Bear Brook (Norton et al., 1992; Sullivan et al., 1994; Cosby et al., 1996) predicted a much larger increase in stream water sulfate concentration than was observed in the treated stream. Although there is considerable uncertainty regarding the lag in sulfate release/adsorption in soils, it appears that MAGIC overpredicted the increase in stream water sulfate concentrations at Bear Brook by nearly a factor of two. This overprediction was due to the high value assumed for the half saturation of sulfur adsorption, which was based on laboratory measurements. As a consequence, other key variables (especially acid-neutralizing capacity and aluminum) were also predicted to increase to a greater degree in response to the experimental acidification than was actually observed.

The original calibration of MAGIC for the Bear Brook forecast was based on four years of data from the reference stream, East Bear Brook. To assess the degree to which discrepancies between predicted and observed stream water chemistry at Bear Brook could be improved by correcting the error in predicting sulfur dynamics and a priori differences between treatment and control catchments, a revised calibration was conducted. The revised calibration corrected for the obvious large bias in effective sulfur adsorption in watershed soils and also corrected for a priori differences between the treatment and reference catchments. In essence, in the latter case, expert judgment was substituted for strictly laboratory-derived information. The resulting simulations matched measured values in West Bear Brook to a substantially greater degree than the earlier forecasts.

Projected stream water sulfate concentrations closely agreed with measured values in West Bear Brook for the first three years of manipulation in the revised model simulation (Cosby et al., 1996). The model simulation also showed much better agreement with measured values for the sum of base cations and acid-neutralizing capacity, than the initial MAGIC simulation. Although the effects of a drought year (1992) on base cation concentrations and acid-neutralizing capacity were still not captured by the simulation, the overall agreement between predicted and observed base cation concentrations and acid-neutralizing capacity was much improved. Slight underestimation of $\mathrm{pH}$ decrease and overestimation of aluminum increase were still evident in the revised projections, although the magnitudes of these biases were reduced dramatically because of the improvement in predicted sulfate concentration and acid-neutralizing capacity.

Results of modeling efforts at Bear Brook, as well as measured chemical changes at Bear Brook, illustrate that a remaining major weakness of MAGIC (and other process models) relative to the needs of NAPAP is the failure to include algorithms to simulate nitrogen cycling and nitrogen retention in watershed soils and vegetation. The success of the nitrogen component of the modeling effort at Bear Brook was totally dependent on adjusting the nitrogen inputs to the model to match measured outputs in stream water. Nitrogen dynamics were extremely important at this site (Kahl et al., 1993), although this had not been anticipated at the inception of the Watershed Manipulation Project at Bear Brook.

The process of evaluating and improving MAGIC is iterative. It has now been shown that the inclusion of organic acids in the model is important and that MAGIC often yields acceptable model simulations of past and future change. It has also been shown that further improvements are needed, particularly with respect to nitrogen, which is the focus of the extended version of the model MAGIC-WAND. The model simulations at Bear Brook also revealed important weaknesses and uncertainties in several aspects of the model structure and/or the manner in which the model is applied to a given catchment. Results at Bear Brook verified that key remaining uncertainties relate to the modeling of aluminum dissolution, sulfur retention in soils, and the dependence of runoff chemistry on hydrological variations that are difficult to simulate.

\section{MAGIC References}

Baker, I.P., and C.L. Schofield. 1982. Aluminum toxicity to fish in acidic waters. Water, Air, and Soil Pollution 18:289-309.

Cosby, B.]., R.F. Wright, G.M. Hornberger, and I.N. Galloway. 1985. Modeling the effects of acid deposition: Assessment of a lumped-parameter model of soil water and streamwater chemistry. Water Resources Research 21:51-63.

Cosby, B.J., S.A. Norton, and J.S. Kahl. 1996. Using a pairedwatershed manipulation experiment to evaluate a catch- 
ment-scale biogeochemical model. The Science of Total Environment 183:49-66.

Driscoll, C.T., M.D. Lehtinen, and T.J. Sullivan. 1994. Modeling the acid-base chemistry of organic solutes in Adirondack New York lakes. Water Resources Research 30:297-306.

Ferrier, R.C., A. Jenkins, B.J. Cosby, R.C. Helliwell, R.F. Wright, and A.J. Bulget. 1995. Effects of future nitrogen deposition scenarios on the Galloway region of Scotland using a coupled sulfur \& nitrogen model (MAGIC-WAND). Water, Air, and Soil Pollution 85:707-712.

Gjessing, E. 1992. The HUMEX Project: Experimental acidification of a catchment and its humic lake. Environment international 18:535-543.

Husar, R.B., T.J. Sullivan, and D.F. Charles. 1991. Historical trends in atmospheric sulfur deposition and methods for assessing long-term trends in surface water chemistry. In: Acidic deposition and Aquatic Ecosystems. Regional Case Studies. D.F. Charles, ed. Springer-Verlag, New York, NY. pp. 65-82.

Kahl, J.S., S.A. Norton, I.J. Fernandez, K.J. Nadelhoffer, C.T. Driscoll, and J.D. Aber. 1993. Experimental inducement of nitrogen saturation at the watershed scale. Environmental Science and Technology 27:565-568.

Kretser, W., J. Gallagher, and J. Nicolette. 1989. An Evaluation of Fish Communicies and Water Chemistry. Adirondack Lakes Survey Corporation, Ray Brook, NY.

NAPAP. 1991. 1990 Integrated Assessment Report. U.S. National Acid Precipitation Assessment Program, Washington, DC.

Norton, S.A., R.F. Wright, J.S. Kahl, and J.P. Schofield. 1992. The MAGIC simulation of surface water at, and first-year results from, the Bear Brook Watershed Manipulation, Maine, USA. Environmental Pollution 77:279-286.
Oreskes, N., K. Shrader-Frechette, and K Belitz. 1994. Verification, validation, and confirmation of numerical models in the earth sciences. Science 263:641-646.

Sullivan, T.J., J.A. Bernert, E.A. Jenne, J.M. Eilers, B.J. Cosby, D.F. Charles, and A.R. Selle. 1991. Comparison of MAGIC and Diatom Paleolimnological Model Hindcasts of Lakewater Acidification in the Adirondack Region of New York. U.S. Department of Energy, Pacific Northwest Laboratory, Richland, WA.

Sullivan, T.J., and B.J. Cosby. 1995. Testing, improvement, and confirmation of a watershed model of acid-base chemistry. Water, Air, and Soil Pollution 85:2607-2612.

Sullivan, T.J., B.J. Cosby, C.T. Driscoll, H.F. Hemond, D.F. Charles, S.A. Norton, H.M. Seip, and G. Taugbl. 1994. Confirmation of the MAGIC Model Using Independent Data: Influence of Organic Acids on Model Estimates of Lakewater Acidification. U.S. Department of Energy, Washington, DC. DOE/ER/30I 96-4.

Sullivan, T.J., B.J. Cosby, C.T. Driscoll, D.F. Charles, and H.F. Hemond. 1996. Influence of organic acids on model projections of lake acidification. Water, Air, and Soil Pollution $91: 271-282$.

Sullivan, T.J., and B.I. Cosby. In press. Modeling the concentration of aluminum in surface waters. Water, Air, and Soil Pollution.

U.S. EPA. 1995. Acid Deposition Standard Feasibility Study. A Report to Congress. U.S. Environmental Protection Agency, Washington, DC. EPA 430-R-95-001A.

Wright, R.F., E. Lotse, and A. Semb. 1993. RAIN Project: Results after 8 years of experimentally reduced acid deposition to a whole catchment. Canadian Journal of Fish and Aquatic Science 50:258-268. 


\section{Design and Performance of Pollution Trading Programs}

\footnotetext{
Oontrol of $\mathrm{SO}_{2}$ emissions under the 1990 Clean Air Act Amendments instituted two important innovations in U.S. environmental policy. The more widely acknowledged of these is the $\mathrm{SO}_{2}$ emission trading program. Less acknowledged is the average annual cap on aggregate emissions by electric utilities, which guarantees that nationwide emissions will not increase as economic growth occurs in the future.
}

The two innovations are designed to work together. Firms are allocated annual $\mathrm{SO}_{2}$ emission "allowances" in proportion to their historic emissions, which they may transfer among facilities or "bank" for future use. Under this approach, the environmental goal emissions cap is established in the statute, but the means for accomplishing that goal is left to the ingenuity of the interested parties. In addition, each affected plant must continue to meet all other applicable state and federal emission standards.

The main attraction of a permit trading program or, more generally, of what is known as an incentive-based approach to environmental regulation, is the promise that it can achieve an environmental goal at a lower cost than regulatory approaches that dictate specific actions for individual facilities or groups of facilities. Because the cost of reducing emissions often varies tremendously among facilities, trading programs can help ensure that the least expensive means are pursued before undertaking more costly efforts. The savings can be a boon for consumers and industry by reducing the cost of regulation, and a boon for the environment by allowing society to purchase greater environmental protection at the same cost. The evidence to date for the $\mathrm{SO}_{2}$ emission trading program indicates that the cost savings have been substantial.

A second type of cost savings from incentive-based regulation are those that are expected to be achieved over time as firms find ways to lower the cost of reducing their emissions. Emission trading provides incentives for firms to innovate because firms can expect to keep the cost savings. At this juncture it is premature to say whether significant innovation has resulted from the $\mathrm{SO}_{2}$ program, but there are many anecdotes of process changes and efficiency improvements that have contributed to the low cost of emission reductions to date. It can be said at this point that competition between different methods of compliance has lowered the cost of compliance.

With the apparent success of the $\mathrm{SO}_{2}$ trading program, the question arises whether this approach should be used to guide other environmental protection efforts. To be sure, there are other environmental problems that would seem to lend themselves to the use of one or another incentive-based approaches, such as tradable permits, emission fees, or deposit-refund systems. However, there are also a variety of problems that are less well suited. This appendix considers the characteristics of environmental problems in general that may or may not be amenable to this approach, especially in the context of controlling air pollution. It evaluates why the $\mathrm{SO}_{2}$ problem appears well suited to the use of tradable permits, and describes new applications of incentive-based approaches for controlling $\mathrm{CO}_{2}$ and $\mathrm{NO}_{\mathrm{x}}$. 


\section{Characteristics That Contribute to the Success of Permit Trading Programs}

Emission permits are similar in many ways to other goods traded in markets. The success of the market for emission permits depends on the breadth of supply and demand. The larger the number of firms that can trade pollution permits the more successful a trading program will be in reducing control costs.

Paradoxically, while the participation of many firms makes it easier for buyers and sellers to find each other, it also makes it easier for them to remain anonymous. Firms may want to remain anonymous when it comes to trading permits because they do not want to signal to competitors their plans for the future. In a small permit market, the actions of one firm are easily recognized by its competitors. In a large permit market, it is less likely that any one firm can dominate the market. Most important, the greater the number and diversity of firms, the greater is the likelihood that there will be differences among firms in the cost of reducing emissions and, hence, greater potential gains from trading.

While a greater number of participants may offer greater potential cost savings, it also makes monitoring and enforcement more difficult. In cases where regulators cannot measure emissions accuratelyeither because of technological limitations or because there are a very large number of emitters (e.g., small sources and automobiles) - they are likely to prefer specific technology controls to incentivebased approaches. Technology standards ensure that the concentrations of pollution from a facility will meet the design value of the controls in place. The drawback, however, is that since the use of the facility or vehicle may vary, this approach will not allow regulators to achieve a cap on the total volume of emissions.

The environmental consequences of pollution may depend on where and when emissions occur. For some pollutants, a ton of emissions will have basically the same effect on the environment, regardless of its location or source. These types of pollutants are called "uniformly mixing," and their homogeneity broadens the potential market by expanding the realm for trades among greater numbers of emitters. Ozone-depleting substances and greenhouse gases are good examples of uniformly mixing air pollutants, because their effects on the environment do not depend on the individual sources of emissions.

On the other hand, many pollution problems have important local attributes. For example, $\mathrm{NO}_{x}$ emissions contribute to ground-level ozone, which is a local and, sometimes, a regional problem. The role of $\mathrm{NO}_{\mathrm{X}}$ in ozone creation depends not only on where emissions occur, but also on the presence of other pollutants and on the season and the time of day when emissions occur. At the same time, $\mathrm{NO}_{\mathrm{X}}$ emissions contribute to other environmental problems-such as particulate pollution and nitrogen deposition-that have distinct spatial characteristics.

Incentive-based approaches, such as tradable permits, can be designed to overcome local concerns in a variety of ways. A trading program may restrict trading between geographic zones, or may allow trading among zones at ratios that reflect the relative environmental damage that results from a unit of emissions at each location. Similarly, concerns about the timing of emissions can be addressed through trading rules that restrict increases in emissions during certain time periods. In some cases, these approaches have been applied successfully. However, experience has shown that restrictions on trading programs detract from their likely success because they limit the breadth or scope of the market and raise transaction costs.

In considering the applicability of trading programs to various pollution problems, there appears to be a simple trade-off. The more localized over space or time the environmental effect of concern is, the smaller the potential market will be, and the less likely trading programs will offer significant potential cost savings.

On the other hand, experience suggests that it is not always necessary to allow local concerns about the spatial and temporal effects of emissions to narrowly determine the ultimate design of a trading program. In some cases, the cost savings from a broader-scale, less encumbered trading program outweigh local environmental concerns and ultimately lead to net gains for environmental protection. Moreover, in some cases very simple safeguards are sufficient to protect against most adverse local effects, while not significantly restricting the scope for trading. For example, although the local effects of some pollutants vary greatly, the lion's share of this variation may be controlled by a simple system of trading zones that generally limits the pattern of trading. 


\section{Elements That Led to the Success of the $\mathrm{SO}_{2}$ Program}

Several features of the $\mathrm{SO}_{2}$ problem make it a good candidate for a permit trading program. Among these is the large number of electricity-generation facilities that are responsible for a significant majority of all $\mathrm{SO}_{2}$ emissions and that provide ample potential buyers and sellers of pollution permits. The physical differences among these facilities and their fuels correspond to the great variation in the cost-and cost-saving opportunities-of reducing emissions.

An interesting feature of the $\mathrm{SO}_{2}$ program is that it is a national trading program, absent restrictions on trading between or among facilities in different locations. However, the environmental problems caused by $\mathrm{SO}_{2}$ are regional and relate to the geographic source of emissions. For instance, due to wind patterns, emissions from a coal-fired power plant in the Ohio Valley make a greater contribution to acidification of the Adirondacks than do emissions from a plant in Mississippi.

By treating all emissions equally, the program has extended the breadth of the market and has opened up greater opportunities for trading. The presumption is that opportunities to reduce costs and to apply those savings to achieve greater emission reductions outweigh the possibility that pollution control will be greater or less in some locations than in others. Any differentiation in the benefits in local areas should be measured against this substantial reduction overall.

The program also affords significant potential cost savings by allowing sources of $\mathrm{SO}_{2}$ emissions to bank their emission reductions in one period to offset necessary future reductions. Environmental problems associated with $\mathrm{SO}_{2}$ emissions are not particularly sensitive to the timing of emissions. For example, the ecological impacts of acidification are primarily the result of accumulated deposition of sulfur. The secondary particulates that cause health effects are evident in the atmosphere for time periods that extend over several days, which also helps to mitigate the effects of changes in emissions at a particular time.

One further important ingredient in the successful formula for $\mathrm{SO}_{2}$ trading is the availability of continuous emissions monitoring systems, which provide a means to ensure compliance when regulators are not sure what actions should be taken by individual firms. Indeed, compliance has been achieved by $100 \%$ of facilities affected under the first two years of the Title IV program.

\section{Closely Related Experiments}

Several closely related experiments on a somewhat smaller scale also provide lessons about the potential viability of permit trading programs in different settings. One of the earliest and most successful was the program to phase out lead in gasoline.

In the 1980s, EPA set a schedule to virtually eliminate lead in gasoline. To achieve this schedule, it allowed trading among refineries in order to obtain an average lead content in gasoline specified in their 1983-1987 phase-out time schedule. The program also allowed refineries to bank their lead rights, so that a refiner could lower the average lead content of its fuels ahead of schedule in order to fall behind schedule at a later point in time.

The primary success in the case of the lead phase-out, as in the case of any environmental program, rests in achieving its environmental goal. However, the trading aspect of the phase-out program contributed to this success because it helped to reduce the cost of achieving the environmental goal and, in so doing, helped build consensus among industry and consumers for the viability of that goal. Environmental concerns were not significantly affected by the program, and monitoring lead content and measuring performance were straightforward. Further, although some variation in the timing and geography of emissions inevitably resulted under the program, there is no evidence that it was significant.

Another closely related experiment is the phase-down of chlorofluorocarbons and halons-collectively described as ozone-depleting chemicals-under international agreements to which the United States has been a signatory. The ultimate goal is to phase out or severely limit the use of these chemicals. To achieve this goal, EPA issued regulations to control both the production and the consumption of ozone-depleting chemicals through a quota system that allocated tradable quotas to producers and consumers in proportion to their historic levels of use. Producers need to use both types of allowances, while importers only need to use consumption allowances. Allowances may be traded domestically or internationally among signatory countries.

An interesting aspect of this phase out was concern that the decreasing availability of ozone-depleting chemicals would raise their profitability. In response, Congress imposed a tax on these chemicals in part to 
capture some of the windfalls that would result from their increased scarcity, and also to promote development of substitutes.

The ozone-depleting chemical program is widely viewed as a success. The cost of the phase-out has not been exorbitant, due in part to the large number of substitutes that have been brought to the market, allowing the phase-out schedule to be moved forward in some cases. One class of ozone-depleting chemicals was eliminated in 1996, except for very limited uses. A second class of chemicals is to be phased out in the early decades of the next century.

A third experiment that has been repeated in a number of local settings is the use of emission-reduction credits for criteria air pollutants. These experiments have taken a number of forms. "Offset" programs allow a new source of emissions locating in an urban area in violation of the National Ambient Air Quality Standards to obtain "offsets" for new emissions by reducing emissions at older sources. The "bubble" program allows new or modified emission sources to avoid stricter new source performance standards as long as total emissions from an entire industrial facility do not increase as a result of the changes. In some cases, emission reduction credits may be "banked" for subsequent use.

Most analyses of the numerous efforts to promote local emission reduction credit programs have concluded that the programs have fallen short of their expectations. One reason is the programs have had to accommodate the geographic and time-sensitive nature of emissions of criteria air pollutants in urban nonattainment areas. Also, there has been concern that offsets may be generated from reduced activity at facilities that were about to shut down anyway, and that trading a credit to a new facility effectively increased emissions in an urban area. The result of these concerns has been a variety of controls on the nature of trading that limit the scope of the market, effectively raising transaction costs and reducing the volume of trading.

Programs other than emission-reduction credit programs are geared toward controlling the total quality of emissions. For instance, both the $\mathrm{SO}_{2}$ and ozonedepleting chemicals programs cap overall emissions. The lead phase-out program comes close to doing the same thing because there was expected to be relatively little variation in refinery production over the brief period when the phase-out was achieved. However, the emission-reduction credit programs are calibrated with emission rates (tons of pollutant per volume of output), rather than emission quantities (tons of pollutant per year). This provides no guarantee that emissions will not increase with intensified economic activity.

Such a possibility meant the program had to impose additional constraints to make sure emissions remain stable or decrease. These constraints undermined the performance of the emission-reduction credit programs to some extent. This approach was taken in many cases, since it was not possible for environmental agencies to consider the alternative approach of capping emission quantities. For many types of emission sources, monitoring of emissions has not been established, and an historic emissions profile is not known with which a baseline can be established, making an overall cap unattainable.

In general, as noted previously, one finds the greater the number and type of sources emitting a pollutant, the more difficult it is to monitor emissions. This makes it difficult to design an incentive-based approach to regulate emissions, and more likely that a traditional command-and-control approach will be necessary. Given the inability to monitor total emissions, regulators have relied on the use of specific technologies to ensure that emission rates are controlled, even though total emissions are not known or controlled with certainty.

\section{New Applications of Emission Trading Programs}

Two air pollution problems have recently attracted growing attention as potential new applications of emission trading programs. These two problems $-\mathrm{CO}_{2}$ and $\mathrm{NO}_{\mathrm{x}}$ emissions-are aligned at opposite ends of the spectrum with respect to the breadth of their environmental impacts. $\mathrm{CO}_{2}$ emissions contribute to global climate change, regardless of their location. However, the contribution of $\mathrm{NO}_{\mathrm{X}}$ emissions to pollution problems depends strategically on the timing and location of those emissions. Also, $\mathrm{CO}_{2}$ emissions cannot readily be controlled through post-combustion abatement technologies, so emission reductions must be achieved through efficiency improvements and fuel switching. However, $\mathrm{NO}_{\mathrm{X}}$ emissions can be controlled through abatement technologies, although significant opportunities also exist for efficiency improvements and fuel switching. 
In other ways the two pollutants are similar. A significant portion of national emissions of both pollutants comes from large electricity-generating facilities and industrial facilities, which are easily monitored. However, a significant portion of both pollutants also comes from smaller sources, including vehicles, which are not easily monitored. Furthermore, in both cases there is tremendous variation in the costs of reducing emissions among the various sources, which provides considerable motivation to find ways to design trading programs that can overcome these obstacles.

The prospects for a $\mathrm{CO}_{2}$ trading program were significantly bolstered by the Draft Protocol Framework for an international agreement proposed by the United States in January 1997. The protocol promotes the use of permit trading for $\mathrm{CO}_{2}$ reductions among so-called Annex A and Annex B countries, which roughly correspond to the more developed economies. Furthermore, the draft protocol calls for expanded use of "joint implementation" between Annex A/B and other countries, allowing more-developed countries to invest in projects in less-developed countries to generate requisite $\mathrm{CO}_{2}$ emission reductions. The prospect for the proposed $\mathrm{CO}_{2}$ trading program is very uncertain at the time of this report's publication, as well as is the potential design for such a program. However, the differences in the cost of emission reductions among potentially affected sources and different countries is enormous. These differences argue strongly for designing a program that will allow the international community to reduce emissions more cost-effectively than uniform national approaches would allow.

At the other end of the spectrum are local experiments to reduce $\mathrm{NO}_{x}$ emissions. Previously established emission reduction credit programs for $\mathrm{NO}_{\mathrm{x}}$ and other pollutants are delivering important cost savings. However, some of their conditions have prevented them from achieving widespread success. Also, as with the use of traditional technology standards, they cannot necessarily contain the level of emissions that result.

Increasingly, regulators are considering the use of cap and trading programs to explicitly limit the total quantity of emissions and to allow flexibility in attaining this goal. However, these trading programs must consider the local nature of the $\mathrm{NO}_{\mathrm{x}}$ pollution-hence, calling for local or regional markets, sometimes with restrictions on the direction or timing of trading. Consequently, an emission trading program will produce less savings than a market covering a larger geographic area with more potential traders. Although, there are such a large number of potential sources of $\mathrm{NO}_{\mathrm{x}}$ emission reductions (e.g., potential traders), that cost savings could still be great. Regulators are striving to design programs that maintain environmental safeguards while providing incentives to capture these potential savings.

Table B-I provides a status report on a number of efforts to establish markets for $\mathrm{NO}_{\mathrm{X}}$ trading. In some of these cases, regional markets have been established that are significantly large enough to overcome this geographic limitation. For instance, the RECLAIM program in Los Angeles has over 500 participants. Others, such as the Texas market, have been so small as to all but prevent trading between firms, though some trading among facilities within the same firm has occurred.

The regional nature of the environmental impacts of $\mathrm{NO}_{\mathrm{x}}$ emissions also has restricted $\mathrm{NO}_{\mathrm{x}}$ trading in other ways. The southern California RECLAIM and emerging Ontario, Canada markets can only trade in directions that reflect regional wind patterns. The Texas market has regional boundaries trades may not cross, and the proposed northeastern market may have similar barriers. These restrictions limit the amount of, and the corresponding potential gains from, trading.

As mentioned, $\mathrm{NO}_{x}$ emissions come from a wide variety of sources that include mobile and stationary emitters, small and large sources, and facilities that may be on the geographic fringe of the emission trading market. When many small and mobile sources exist in this market, it is difficult to include all of them because of problems in monitoring and administering the program. Nonetheless, in some cases, the small sources can contribute significant emissions to the local airshed. Therefore, regulators tend to rely on conventional approaches to control emissions from numerous, small sources, which typically control emission rates but not the overall level of emissions from these sources. Their exclusion from the trading program misses not only significant opportunities for cost savings, but also significant opportunities for emission reductions and, hence, is an issue attracting increasing attention.

Episodic constraints are also an important issue in $\mathrm{NO}_{\mathrm{x}}$ trading markets. In contrast to the $\mathrm{SO}_{2}$ emission trading market, some experts believe that the potential of emission "spikes" from $\mathrm{NO}_{\mathrm{X}}$ are a key issue. Some markets have restrictions on the amount of trading or banking between seasons of the year. Additional episodic restrictions placed on $\mathrm{NO}_{\mathrm{x}}$ trades include limitations on when banked credits may be used. 
Table B-1

\section{Status Report \\ on Efforts \\ to Establish \\ NOX Trading \\ Markets \\ Chicago-_Potential rules submitted in October 1996. \\ The market originally included $\mathrm{NO}_{\mathrm{X}}$ and VOCs. $\mathrm{NO}_{\mathrm{X}}$ emissions were later dropped. The market runs from May 1 to September 30, covers the Chicago area (Cook, DuPage, Kane, Lake, McHenry, and Will counties) and only includes stationary sources. Facili- ties that emit more than 50 tons of $\mathrm{NO}_{x}$ per year must submit emission abatement plans by 1998; firms with 10 tons of $\mathrm{NO}_{X}$ emissions per year must submit plans by 1999 .}

\section{ALLOTMENTS/ \\ BASELINE EMISSIONS}

\section{Michigan-Market started in 1996.}

Established in 1996, this voluntary program for mobile and stationary sources includes VOCs, $\mathrm{NO}_{\mathrm{x}}$, and criteria pollutants. The market covers the entire state and includes all sources.
Firms are given emission allotments measured against baseline emissions from the two highest ozone seasons from 1990 to 1997 . This amount is reduced by $12 \%$ in 1999 and then reduced according to the State Implementation Plan.
The baseline is determined as the average of two ozone seasons prior to the creation of the emission reduction credit.

\section{Ontario, Canada-Trades have occurred, but the market is not yet official.}

The market includes $\mathrm{NO}_{x}$ and VOCs. It runs from April 1 to September 30 and is focused around the Windsor-Quebec corridor. There is a strong desire to have the market be similar to the Michigan market to promote cross-country trades.
Baselines are calculated relative to each company's specific process operations.

\section{Northeast Ozone Transport Region (OTR)-Market is still in the planning stage.}

The market includes $\mathrm{NO}_{X}$ and VOCs and runs from May 1 to September 30. It includes CT, DC, DE, MA, $\mathrm{MD}, \mathrm{NH}, \mathrm{NJ}, \mathrm{NY}, \mathrm{PA}, \mathrm{VA}$, and VT. There is a possibility of expanding the market to include mobile sources.
Two possible scenarios: ( 1 ) A credit model that calculates an emission responsibility and a uniform emission rate for each facility. (2) A method where allocations are auctioned off or given away based on historical emissions. This historical allotment then becomes the baseline. Once the nature of the emission allotment is determined, the allotment is given to each state to decide how to allocate it within the state.

\section{Southern California (RECLAIM)—Market started on January 1, 1994.}

The market currently includes all stationary sources that emit more that 4 tons of $\mathrm{NO}_{\mathrm{x}}$ or $\mathrm{SO}_{\mathrm{x}}$ per year. An extension of the market to include VOCs is planned. The market, which covers the Los Angeles basin, contains 535 sources of $\mathrm{NO}_{\mathrm{X}}$ and $\mathrm{SO}_{\mathrm{x}}$.
Each facility is given an emission factor based on the type of facility. The initial allotment is calculated by multiplying the maximum throughput for each $\mathrm{NO}_{\mathrm{X}}$ source from 1989 to 1992 by the applicable starting emission factor for that source. Once this is calculated, any additional reductions made from 1992 to 1994 are then added to the baseline level.

\section{Texas-Stationary market started in 1992; mobile sources joined in 1995.}

The year-round market is currently open, but is in the process of designing cap and trade systems. It includes $\mathrm{NO}_{X}$ and VOCs mobile, area, and stationary sources. The market originally included the Houston-Galveston area, and has since expanded to include Beaumont and Dallas-Ft. Worth. As of March 3,1997 , only six intra-firm trades had occurred.
The initial allotment is based on a two-year average plus a standard deviation. 


\section{BANKING AND EPISODIC CONSTRAINTS}

\section{Chicago (continued)}

Allotments are available for use during the season they are given out and during the following ozone season.

\section{SPATIAL CONSTRAINTS}

No spatial restrictions exist within market boundaries.

\section{NEW SOURCES}

\section{Michigan (continued)}

Banking is allowed for up to five years with no discounts for use during this period. Credits generated during the ozone season may be used at any time; credits generated outside of the ozone season may only be used outside of that season.

\section{Ontario, Canada (continued)}

No external measure is placed on banked credits-no shelf life or discounts for future use. Same-season trades are not favored over inter-seasonal trades.

\section{Northeast OTR (continued)}

Unlimited banking of credits is allowed, with a price-based, progressive-flow control. The flow control is based on the number of credits banked. A certain number of credits may be used at a 1-to- 1 ratio. After this level has been reached, the remaining credits may be extracted at a 2-to:-1 ratio.
No spatial restrictions exist within market boundaries.

Trades involving more than 2,000 tons in a single ozone season may only follow the prevailing seasonal downwind pattern.

If the market is large enough and there is a sufficient amount of trading, then there should be no limits to the direction of trade. This issue will be revisited in three years.
New sources will have to acquire allotments through the market. Small emitters must purchase allotments at a 1-to-1 ratio. Large emitters must purchase them at a 1.3-to-1 ratio.
New sources must purchase allotments for 2.5 years.
Two options: (1) government could hold additional allotments for new entrants, or (2) new entrants could be required to purchase allotments.

\section{Southern California (RECLAIM) (continued)}

Banking is not allowed due to the possibility of emission spikes. However, permits are allocated for overlapping time periods, providing one mechanism for short-run banking.

\section{Texas (continued)}

Emission reduction credits may be banked for up to $\mathbf{1 0}$ years. The shelf life of mobile emission reduction credits is a function of the vehicle mileage. All credits are discounted at $3 \%$ per year.
The Los Angeles basin is divided into two zones-coastal and inland. Trade is allowed within each zone and from the coastal zone to the inland zone. Trade is prohibited from the inner zone to the outer zone.
New sources must follow all CAAA rules and purchase allotments either (1) from sources in the same nonattainment area or (2) from a source that is in a nonattainment area that has an equal or worse classification, or where the emissions from that area contribute to the National Ambient Air Quality Standard violations in the area where the facility will be located.

New firms must comply with best achievable control technology standards and must purchase offsets at a 1-to-1 ratio.
The unit that created the emission reduction credit must be in the same zone (Dallas-Ft. Worth, Beaumont, Houston-Galveston) as the unit that consumes the credit.
For the three areas, new facilities must comply with best achievable control technology standards. They currently do not need to purchase any additional offsets. However, this may change, depending on additional evidence regarding the effect of $\mathrm{NO}_{X}$ emissions on the production of ozone. 


\section{Interpretation of "Adverse" Effects for NAPAP Biennial Reports to Congress}

\section{Background}

The 1990 Clean Air Act Amendments require that the National Acid Precipitation Assessment Program (NAPAP) prepare biennial reports to Congress, and that "every four years ... the report ... shall include the reduction in deposition rates that must be achieved in order to prevent adverse ecological effects" (Public Law 10I-549, Title IX, Section $903(\mathrm{j})(3)(\mathrm{F})(\mathrm{i})$, codified as amended at 42 USC $\S 7403(j)(3)(F)(I))$. This report is the first to address this requirement.

Although the term adverse ecological effects is not specifically defined in the Clean Air Act Amendments, a working definition can be derived from relevant statements at various locations in the statute. Congress expresses its concern with ecological components (the scope is broad and inclusive, since ecology encompasses the interrelationships of organisms and their environment) in the preceding subsection (E) of the statute. It requires reporting on "the status of ecosystems (including forest and surface waters) ... affected by acid deposition ... including changes in surface water quality and forest and soil conditions ... [and] high elevation watersheds" (42 USC $§ 7403(j)(3)(E)(i i i-v)$ ). The adverse effects of concern to Congress, as evidenced in its findings and declaration of purpose, are the "dangers to the public health and welfare ... including injury ... damage ... and ... deterioration" (42 USC $\S 7401(a)$ ).

\section{Working Definition}

Based on the intent of Congress, as expressed above and elsewhere in the Clean Air Act Amendments, and shaped by indications of intent expressed in other relevant environmental statutes and regulations, the following working definition of adverse ecological effects has been derived and is used in the preparation of this report:

any injury (i.e., loss of chemical or physical quality or viability) to any ecological or ecosystem component, up to and including at the regional level, over both long and short terms. Similarly, adverse effects for other areas of concern addressed in this report-i.e., visibility, materials, and human health-consist of loss of quality up to and including at the regional level, over both long and short terms.

\section{Bases for Working Definition}

Ecological components of concern to Congress are addressed in the Clean Air Act Amendments section titled "Research, investigation, training, and other activities" (42 USC $\S 7403$ ). In the subsection that includes the provision for the continuation of NAPAP, the ecological components mentioned include ecosystems, forests, surface waters, soil, and high-elevation watersheds; ecological effects that could be adverse include changes in surface-water quality, changes in forest and soil conditions, and occurrence of episodic acidification (especially in high-elevation 
watersheds) 42 USC $\$ 7403(j)(3)($ E)(iii-v). Additional ecological components and attributes of interest to Congress with respect to adverse effects are named in a preceding Clean Air Act Amendment subsection titled "Ecosystem research" (42 USC $\$ 7403(\mathrm{e})$ ), and include "regionally representative and critical ecosystems ... crops, biological diversity, wetlands, estuaries, groundwater, other terrestrial systems, and other aquatic systems"; effects named that could be adverse include those that are "short-term and long-term ... [show] trends of ecosystem damage .... [are due to] chronic and episodic exposures ... [and] multiple environmental stresses." Also, "sensitive and critically sensitive aquatic and terrestrial resources" are the subject of specific congressional protection to be achieved through the adoption of an acid deposition standard(s) (Appendix B of $\S 404$ (42 USC $\S 7651$ c) of Title IV of the 1990 Clean Air Act Amendments).

Nowhere in the Clean Air Act Amendments, or associated case law, is the specific type of damage or injury that would constitute an adverse ecological effect specified. Other environmental statutes, however, deal with similar concepts. The Comprehensive Environmental Response, Compensation, and Liability Act (CERCLA) assigns liability for damage to natural resources from releases of hazardous substances-a broad concept encompassing adverse ecological effects. The term damages is defined as "injury or loss of natural resources." Natural resources are "land, fish, wildlife, biota, air, water, groundwater, drinking water supplies, and other such resources" 42 USC $\$ 9601(6,16)$. The regulations delineating how natural resource damage assessments may be carried out for CERCLA (and also the Clean Water Act (CWA)), are at $43 \mathrm{CFR} \S 11.10$ et seq., and define injury as:

a measurable adverse change, either long or short term, in the chemical or physical quality or the viability of a natural resource resulting either directly or indirectly from exposure to ... a hazardous substance, or ... to a product of reactions resulting from ... a hazardous substance (43 CFR $§ 11.14(\mathrm{v})$ ).

There are, in turn, detailed injury definitions applicable to specific resources. Portions of these definitions potentially relevant to ecological effects of acid deposition are at 43 CFR $\S 11.62$ and include:

(e) Geologic resources. An injury ... has resulted $\ldots$ if one or more of the following changes ... is measured:
(4) Concentrations of substances sufficient to decrease the water holding capacity such that plant, microbial, or invertebrate populations are affected;

(5) Concentrations of substances sufficient to impede soil microbial respiration to an extent that plant and microbial growth have been inhibited;

(6) Concentrations in the soil of substances sufficient to inhibit mineralization resulting from a reduction in soil microbial populations;

(7) Concentrations of substances sufficient to restrict the ability to access, develop, or use mineral resources within or beneath the geologic resources

(9) Concentrations in the soil of substances sufficient to cause a toxic response to soil invertebrates;

(10) Concentrations in the soil of substances sufficient to cause a phytotoxic response, such as retardation of plant growth.

(f) Biological resources. (1) An injury ... has resulted ... if concentration of the substance is sufficient to:

(i) Cause the biological resource Ifish and wildlife and other biotal or its offspring to have undergone at least one of the following adverse changes in viability: death, disease, behavioral abnormalities, cancer, genetic mutations, physiological malfunctions (including malfunctions in reproduction), or physical deformations.

Since natural resources are ecological components, and the injuries are adverse effects, these definitions give a further indication of adverse ecological effects that lie within the intent of Congress within the environmental statutes of CERCLA and the CWA.

Incorporating the content and concepts above, the adverse ecological effects of acid deposition that could lie within the scope of this NAPAP report are those effects that cause- 


\section{C-4 Appendix C}

injury, damage, or deterioration

consisting of

a measurable adverse change, either long or short term, in the chemical or physical quality or the viability of

ecosystems (sometimes causing trends), regionally representative ecosystems, critical ecosystems, other terrestrial systems, other aquatic systems, sensitive and critically sensitive aquatic and terrestrial resources, forests, surface waters, wetlands, estuaries, groundwater, high elevation watersheds, soil, crops, biological diversity, land, fish, wildlife, biota, air, water, drinking water supplies, and other such resources;

due to

occurrence of episodic and chronic exposures, short- and long-term exposure, multiple environmental stresses; and resulting either directly or indirectly from exposure to acid deposition, or exposure to a product of reactions resulting from acid deposition; and including for geological resources

decreases in the water holding capacity such that plant, microbial, or invertebrate populations are affected; impedance of soil microbial respiration to an extent that plant and microbial growth have been inhibited; inhibition of mineralization resulting from a reduction in soil microbial populations; restrictions in the ability to access, develop, or use mineral resources within or beneath the geologic resources; toxic responses to soil invertebrates; and phytotoxic responses, such as retardation of plant growth;

and including for biological resources

changes sufficient to cause the biological resource or its offspring to have undergone at least one of the following adverse changes in viability: death, disease, behavioral abnormalities, cancer, genetic mutations, physiological malfunctions (including malfunctions in reproduction), or physical deformations.

From this detailed, descriptive, lengthy, and sometimes redundant definition, the working definition of adverse ecological effects in the text was derived. 
In Title IV of the 1990 Clean Air Act Amendments, Congress set out to decrease the adverse effects of acid rain through reductions in annual emissions of sulfur dioxide $\left(\mathrm{SO}_{2}\right)$ and nitrogen oxides $\left(\mathrm{NO}_{X}\right)$ from utilities burning fossil fuels. The legislation called for placing a cap on utility emissions to achieve a total reduction of 10 million tons of $\mathrm{SO}_{2}$ emissions below 1980 levels by 2010. In combination with reductions under Title I (compliance with National Ambient Air Quality Standards) and Title II (mobile sources), Title IV will contribute to the overall 2-million-ton reduction of $\mathrm{NO}_{X}$ emissions from 1980 levels. In contrast to the typical commandand-control approach to regulation, Congress adopted a market-based control strategy for $\mathrm{SO}_{2}$, including an innovative $\mathrm{SO}_{2}$ emission allowance trading and banking program. The Act mandated the interagency National Acid Precipitation Assessment Program (NAPAP) to evaluate the costs, benefits, and effectiveness of Title IV and to assess what further reductions in deposition rates are needed to prevent adverse ecological effects. In compliance, NAPAP conducted its first in a series of quadrennial integrated assessments of Title IV. In this report NAPAP takes a look at the first year of implementation of Title IV by assessing the full causal chain of events, including emission reductions; compliance costs; changes in pollutant concentrations and deposition; effects on aquatic and terrestrial ecosystems; effects on visibility, materials and cultural resources, and human health; and the economic valuation of benefits achieved from reducing emissions.

Proper citation of this document is as follows:

NAPAP. 1998. NAPAP Biennial Report to Congress: An Integrated Assessment. U.S. National Acid Precipitation Assessment Program, Silver Spring, MD.

\section{For additional copies or information, please contact:}

National Acid Precipitation Assessment Program

NOAA, Mail Code R/PDC

1315 East West Highway

Silver Spring, MD 20910

telephone: 30I-713-2465 (ext. 205)

fax: 301-713-0158

email: napap@noaa.gov

National Science and Technology Council Executive Secretariate

telephone: $202-456-6102$

fax: 202-456-6026

This report is also available via the World Wide Web on the NSTC Home Page via link from the OSTP Home Page at: http://www.whitehouse.gov/WH/EOP/OSTP/html/OSTP_Home.html 